\title{
MHD Integrated Topping Cycle Project
}

\section{Thirteenth Quarterly Technical Progress Report}

\section{Report No. MHD-ITC-92-001}

Date Submitted: Jarmary 1992

Period Covered: $\quad$ August 1990 through October 1990

Reporting Organization: Applied Technology Division TRW Space and Technology Group One Space Park.

Redondo Beach, Califomia 90278

Sponsoring Organization: U.S. Department of Energy

Pitusburgh Energy Technology Center

Contract Number:

DE-ACC22-87PC90274

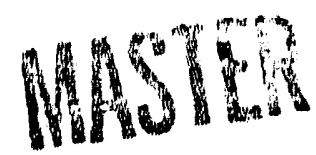




\section{Table of Contents}

Executive Summary

Page

1. INTRODUCTION

ix

2. PROJECT DESCRIFTION

3. SYSTEMS ENGINEERING (TASK 1)

3.1 SYSTEMS ENGINEERING ANALYSIS 3-1

3.1.1 HPCS Electrical Isolation 3-1

3.1.2 Power Train Alignment 3-1

3.1.3 Rationale for Proposed 1A4 Operating Conditions 3-3

$\begin{array}{ll}3.1 .3 .1 & \text { Surnmary } \\ 3.1 .3 .2 & 3-3\end{array}$

3.1.3.2 Introduction $3-3$

3.1.3.3 Definition of "Prototypical" Conditions 3-5

3.1.3.4 Comparison of 1A4 to Retrofit and Baseload Studies 3-6

3.1.3.5 Conclusions 3-6

3.1.4 Reintroduction of Coal Fines into the Coal System at the CDIF 3-9

$\begin{array}{ll}3.2 & \text { SYSTEM/SUBSYSTEM DOCUMENTATION }\end{array}$

$\begin{array}{ll}3.2 .1 \text { Subsystem Requirements } & 3-10\end{array}$

$\begin{array}{ll}3.2 .2 & \text { Interface Documentation 3-10 }\end{array}$

$\begin{array}{lll}3.2 .3 & \text { Test Plan } & 3-10\end{array}$

$\begin{array}{ll}3.3 \text { CDR FOLLLOW-UP } & 3-10\end{array}$

4. COMBUSTION SUBSYSTEM DESIGN AND FABRICATION (TASK 2) 4-1

4.1 COMBUSTION SUBSYSTEM DESIGN ACTIVITIES (SUBTASK 2.1.3)

4.1.1 Critical Design Review and Action Items $4-1$

4.1.2 Power Train Alignment Procedure 4-2

4.1.3 Manufacturing Development Activities $\quad 4-4$

4.1.4 Manufacturing Planning 4.5

4.2 HIGH PRESSURE COOL.ING SUBSYSTEM DESIGN (SUBTASK 2.1.3)

$\begin{array}{lll}4.2 .1 & \text { HPCS Procurement } & 4-10\end{array}$

$\begin{array}{lll}4.2 .2 \text { Electrical Isolator Testing } & 4-10\end{array}$

4.3 PROTOTYPICAL PANEL CONFTRMATION TESTING (SUBTASK 2.1.3)

$\begin{array}{lll}\text { 4.3.1 Test Preparations } & \text { 4-12 }\end{array}$

4.2.3 LMF-4-U Test Operations 4-16

4.3.3 Post Test Observations 4-18

5. PROTOTYPICAL CHANNEL. DESIGN (TASK 3)

5.1 MARK VII SLAGGNG ANODE EVALUATION TESTS 5.1

5.2 WATER CORROSION TEST RESULTS 
5.2.1 Background $5-9$

5.2.2 Materials 5-11

$\begin{array}{ll}5.2 .3 & \text { Water Chemistry } \\ 5.2 .4-12\end{array}$

5.2.4 Electrochemistry $5-13$

5.2 .5 Tests $\quad 5-1.5$

$\begin{array}{ll}\text { 5.2.6 Molybdenum Cormosion } & \text { 5-17 }\end{array}$

5.2.7 Analysis of Test Specimens from Tests 1 Through $3 \quad 5-18$

5.2.7.1 Observations by Betz $\quad 5-18$

5.2.7.2 Conclusion by Betz $\quad 5-20$

5.2.7.3 Comments on Betz Analysis $\quad 5-20$

5.2.8 Results of Test 5E 5-21

$\begin{array}{ll}5.2 .9 \text { Conclusions } & 5-21\end{array}$

5.3 1A4 HARDWARE FABRICATION STATUS $\quad 5-22$

5.3.1 Introduction $5-22$

5.3.2 Fabrication Preparations $\quad 5-22$

5.3.3 Configuration Control 5-23

5.3.3.1 Organization $\quad 5-24$

5.3.2.2 Responsibilities $\quad 5-24$

5.3.3.3 Configuration Identification $\quad 5.24$

5.3.3.4 Configuration Control/Engineering Changes $\quad 5.24$

$\begin{array}{ll}\text { 5.3.3.5 Configuration Change Implementation } & 5-25\end{array}$

5.3.3.6 Configuration Status and Accounting $\quad 5-25$

5.3.4 Project Status $\$ .25$

$\begin{array}{llr}\text { 5.3.5 Summary } & 5-25\end{array}$

6. CURRENT CONSOLIDATION SUBSYSTEM DESIGN AND FABRICATTON (TASK 5) 6"-1

6.1 CONSOLIDATION CONVERTER TRANSFORMER

6.2 GTO AND SCR VOLTAGE RATINGS

6.3 GTO AND SCR CURRENT RATLNGS

6.4 CONVERTER OUTPUT FILTER

6.5 CDIF CONTROL SYSTEM

6.6 HIGH VOLTAGE CONSIDERATIONS

6.7 BACKUP RESISTTVE CONSOLIDATION

6.8 MECHANICAL PACKAGING/LAYOUT $6-8$

6.9 INVERTER IMPACT ON CURRENT CONSOLIDATION EQUIPMENT

7. CDIF TESTING $7-1$

7.1 BACKGROUND 7.1

7.1.1 Combustor 7-1

7.1 .2 Channel $7-1$ 
7.1.3 Currni Controls and Consolidation 7.2

7.2 WORKHORSE POWER TRAIN TESTING (SUBTASK 6.3)

$\begin{array}{ll}7.3 & \text { OTHER CDIF ACTIVITIES }\end{array}$

7.3.1 Combustor Hardware Activities $\quad 7.6$

$\begin{array}{ll}\text { 7.3.2 Channel Hardware Activities } & 7.7\end{array}$

7.3.2.1 Sidewall $7-8$

$\begin{array}{ll}7.3 .2 .2 \text { Anode } & 7-8\end{array}$

$\begin{array}{ll}7.3 .2 .3 \text { Cathode } & 7-8\end{array}$

$\begin{array}{ll}7.3 .2 .4 & \text { Inlet Frame } \\ 7.8\end{array}$

$\begin{array}{lll}7.3 .3 & \text { Current Controls } & 7.8\end{array}$

$\begin{array}{ll}\text { 7.3.4 Current Consolidation } & 7-12 \\ 7.3 .5 & 7-12\end{array}$

7.3.5 Slag Rejection System Activities $\quad$ 7-12

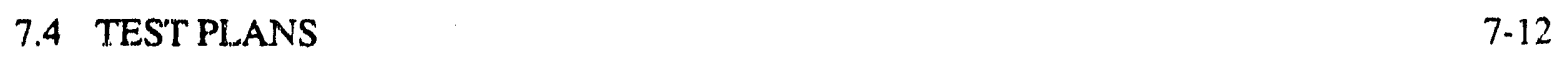

8. MODELING AND PERFORMANCE ANALYSIS ACTIVITIES (SUBTASK 1.3) 8-1

8.1 ANALYSIS OF PRECOMBUSTOR HEAT FLUX OSCILLATIONS $8-1$

8.2 INVESTIGATION OF CDIF INTERANODE VOLTAGE IRREGULARITIES

$\begin{array}{lll}8.2 .1 & \text { Summary } & 8-2\end{array}$

8.2 .2 Introduction $8-6$

8.2.3 Observations 8.6

8.2.4 Possible Causes and Discussion $\quad 8-8$

8.2.4.1 Comer Joint Deficiencies $8-8$

8.2.4.2 Anode Wall Deficiencies

8.2.4.3 Anode Wall Test Coupons 8-9

8.2.4.4 Moisture Condensation on the Anode Wall 8-10

8.2.4.5 Reflection of Intercathode Voltage Irregularities 8-10

8.2.4.6 Excess Iron Oxide Addition $\quad 8-10$

8.2.5 Conclusions 8-11

9. TTIRC AND POC INTEGRATION TASK FORCE ACTIVITIES (TASK 8)

10. PLANNED ACTTVITIES 10-1

11. SUMMARYY 11-1

12. QUARTERLY REPORT DISTRIBUTION LIST 12-1

APPENDIX A. NOMENCLATTURE A-1 


\section{List of Figures}

Figure

Page

3-1 1A4 Channel Performance Over the Range of Anticipated Operating Conditions with SOW Westem Coal

3-2 1A4 Channel Performance Over the Range of Anticipated Operating Conditions with SOW Eastem Coal

3-3 Distinction Between Jy(core) and Jy(ave)

34 1A4 Performance Characteristics at Reference Operating Condition \#1: Power

3-5 1A4 Performance Characteristics at Reference Operating Condition \#2: Stress

3.6 Ratio of Average Current Density to Core Current Density as a Function of Channel Size

4-1 Baffle Bore Slag Retention Grooves

4-2 Power Train Alignment

4-3 Baffle Fabrication Fixture

44 RTV Fixture Plexiglas Panels

4-5 Combustion Subsystem Manufacturing Schedule

4-6 HPCS Electrical Isolator

4-7 Test Electrical Isolator

4-8 Spool Section Assembly

4.9 Prototypical Spool Section Panel

4-10 Installation of Prototypical Panels into Spool Section

4-11 Spool Installation into CFFF Combustor Module

4-12 Combustor Operation During LMF4-U Startup

4-13 Spool Section Heat Flux During LMF4.U Startup

4-14 Prototypical Panel Heat Flux During LMF4-U Startup

4-15 Statistical Distribution of Prototypical Panel Heat Flux During LMF4-U Startup

4-16 Spool Section Heat Flux During 80-Hour Pericd at CFFF

4-17 Statistical Distribution of Prototypical Panel Heat Flux for 250-Hour Test

4-18 Panel Heat Flux Averages and Range During 80-Hour Period at CFFF

4-19 Prototypical Panel Grooves After 250-Hour Test

5-1 1 A4 Slagging Anode Designs

5-2. Mark VII Anode Wall with 1A4 Slagging Anodes $\quad 5-3$

5-3 Mark VII Slagging Anode Test Sequence $5-3$

5-4 Mark VII Average Current Density - Test Date 10/11/90

5-5 Mark VIl Average Currerit Density - Test Date 10/15/90 5-5

5-6 Mark VIl Anode Wall Slagging Performance - 10/11/90 5-5

5-7 Mark VII Slagging Performance of the 1A4 Test Anodes - 10/11/90 5-6 
5-8 Mark VIl Anode Wall Slagging Performance - 10/15/90 5-6

5-9 Mark VII Slagging Performance of Four 1A4 Test Anodes - 10/15/90 5-7

5-10 Post-Test Condition of 1A4 Slagging Anodes $\quad$ 5-7

5-11 Post-Test Condition of 1A4 Slagging Anodes $\quad 5-8$

5-12 Post-Test Condition of 1A4 Slagging Anodes $\quad 5-8$

5-13 Comparison of Grain Structure: Pt vs. Zirconia Grain Stabilized Pt

5-14 Schematic Temperature Distribution in High Heat Flux Mo Test Peg 5-18

5-15 SEM Photomicrographs of Inner Surface of Water Passage in Mo Specimen from Test 3 at $1000 x$ Magnification $\quad 5-19$

5-16 1A4 Channel and Diffuser Fabrication Schedule 5-23

$\begin{array}{ll}\text { 5-17 Configuration Control Flow Chart } & \text { 5-26 }\end{array}$

5-18 Configuration Control Change Distribution $\quad$ 5-27

$\begin{array}{ll}\text { 5-19 Cathode Wall Fabrication Schedule } & 5-28\end{array}$

6-1 Consolidation Converter Transformer Secondary Voltage Selection $\quad 6-2$

6-2 Consolidation Converter Components 6-3

6-3 Alternative Network Connections 6-6

6-4 High Voltage Considerations $\quad$ 6-7

6-5 Anode Side Resistive Network Connection

6-6 Candidate Floor Plan 6-9

6-7 Candidate Cabinet Layout $\quad$ 6-10

6-8 "Kirk" Key Interlock System 6-11

6-9 Electrical Relationship of an Individual Cathode Consolidation Converter

7-1 Typical Streamwise Current Distribution with Current Controls $7-5$

7-2 Schematic of 1A4 Style Z-bar Sidewall Test Coupons $\quad 7-9$

7-3 Schematic of 1 A4 Style Anode Wall Test Coupons $7-10$

$\begin{array}{lll}7-4 & \text { Schematic of } 1 \text { A4 Style Cathode Wall Test Coupons } & 7-10\end{array}$

7.5 Schematic of Second Stage Test Frame Which is Being Constructed Similar to the

7-6 Current Consolidation Test and Installation Logic $\quad 7-12$

8-1 Precombustor Transition Thermal Spiking - (90-MATL-5) 8-2

8-2 Effect of Test Duration on the Numbers of Thermal Spikes in the Transition Section $8-4$

8-3 Effect of Test Duration on Major Thermal Spike Amplitudes

8-4 Effect of Lower Transition Heat Effect of Loss Value on Spike Amplitudes

8-5 Effect of Test Duration on Precombustor Can Heat Loss 8-5

8-6 Interanode Voltage Distribution at the End of the 80-Hcur Build Test Series 8.7 
8-7 Interanode Voltage Distribution at the End of the 20-Hour Build Test Series 8-7

8-8 Interanode Voltage Distribution in the 16-Hour Build Test Series 8-8

8-9 Map of the 1A4 Type Test Coupon Location in the 1A1 Channel: Forward Region 8-9

8-10 Map of the 1A4 Type Test Coupon Location in the 1A1 Channel: Aft Region 8-10

8-11 1A1 Anode Wall Plumbing: Forward and Aft Cooling Passes 8-11 


\section{List of Tables}

Table

2-1 MHD ITC Task Objectives

Page

3-1 Summary of Systems Engineering Analyses

$2-2$

3-2 Typical 1A4 Power Conditions

3-2

3-3 Typical 1A4 Stress Conditions

$3 \cdot ?$

3-4 Comparison of 1A4 to Retrofit and Baseload Studies

$3-4$

4-1 Comparison of CFFF Conditions to CDIF Conditions

5-1 Relative Resistance of Metals to Arc Erosion

4-15

5-2 Materials of Construction

5-10

5-12

5-3 Cathode Wear Rates

5-12

5-4 Dissolved Oxygen and pH in Power Plant Practice

$5-13$

5-5 Methods of Dissolved Oxygen and $\mathrm{pH}$ Control

5-6 Corrosion Test Summary

5-16

6-1 Current Consolidation Subsystem Requirements

6-1

7-1 Long Duration Thermal/Electrical Operation

$7-3$

7-2 CDIF Current Control Diagnostic Testing

$7-4$

7-3 CDIF Long Duration Continuous Electrical Testing

$7-6$

7.4 ITC CDIF Test Schedule as of 10/10/90

7-14

8-1 Precombustor Can and Transition Heal Losses for CDIF PC Tests

$8-3$

9-1 Recommendations for POC Program Integration

9-2 


\section{EXECUTIVE SUMMARY}

This thirteenth quarterly technical progress report of the MHD Integrated Topping Cycle Project presents the accomplishments during the period August 1, 1990 to October 31, 1990. A summary of the work completed during this reporting period is presented in this Executive Summary.

\section{SYSTEMS ENGINEERING (SECTION 3)}

Testing of the High Pressure Cooling Subsystem electrical isolator continued this quarter. As of the end of this reporting period, testing to $1000 \mathrm{psi}$ and $4000 \mathrm{~F}$ was successfully completed. Duration testing is in progress.

The study on the alignment requirements for the prototypical power train, which will have different anchor points than the workhorse hardware, was completed. The results were reported at the CDR.

Critical Design Review's (CDR's) were held with DOE for the Combustion, High Pressure Cooling, and Channel Subsystems. The Preliminary Design Review (PDR) was held for the Current Consolidation Subsystem.

The integrater manufacturing schedule for the four subsystems was completed this quarter.

\section{COMBUSTION SUBSYSTEM DESIGN AND FABRICATION (SECTION 4)}

The Combustion Subsystem design was approved for fabrication at the CDR.

The 250-hour panel design confirmation test was successfully performed at UTSI without any signs of deterioration in performance.

Sign-off of the Combustion Subsystem drawings is in progress.

Work continued on the high temperature electrical isolator.

\section{CHANNEL SUBSYSTEM DESIGN (SECTION 5)}

Increased corrosion on CDIF anodes compared to Mark VII at similar operating conditions is postulated to be the result of thicker boundary layers on the $1 \mathrm{Al}$ (CDIF) which can produce larger Faraday arcs. To reduce arc size, a slagging anode design is now proposed for the $1 \mathrm{~A} 4$, and two configurations are currently being tested in the Mark VII channel. The first test has been completed with good slagging performance and no serious platinum attack at prototypical current density.

Water corrosion tests were performed to establish the optimum water conditions for the POC test and to quantify, where possible, the corrosion rates expected for the water-side materials used. Variations in flow' velocity, temperature, and $\mathrm{pH}$ were examined along with the use of a corrosion inhibitor.

The results of water corrosion tests determined that the use of an NRC-approved corrosion inhib: such as CopperTrol or Tolytriazole which is compatible with existing materials should cause no difficulty. None of the materials being contemplated for use in the 1A4 channel exhibited serious water-side corrosion.

The recommended $\mathrm{pH}$ range for the water is 6 to 7.5 if molybdenum is used on the sidewall, and 6.7 to 7.5 if tungsten copper is used on the sidewall.

No serious effects were noted using the existing CDIF dissolved oxygen (DO) level of 3.2 to $3.4 \mathrm{ppm}$. Although a low DO range of 50 to $200 \mathrm{ppb}$ is recommended as being the preferred level, acceptable operating performance is attainable with a range of dissolved oxygen up to $3.5 \mathrm{ppm}$.

The minimum acceptable resistivity for the deionized water is $500 \mathrm{kohm}-\mathrm{cm}$. There is no maximum acceptable water resistance.

Faci'ities for fabrication of the $1 \mathrm{~A} 4$ hardware are in place and are being used to build gas-side elements for the Mark VII and IA channels. Procedures necessary for the hardware fabrication have been written as 
have procedures for inspection and quality control. The channel and diffuser fabrication schedule shows delivery of the hardware to the CDIF in March 1992. The design of the diffuser is complete and assembly is in progress.

\section{CURRENT CONSOLIDATION SUBSYSTEM DESIGN (SECTION 6)}

The Preliminary Design Review (PDR) for the Current Consolidation Subsystem was conducted during this quarterly reporting period. The proposed prototypical design for the CDIF is a scaled version of the breadboard subsystem that was successfully tested on the Mark VII at Avco. The design review discussed the breadboard design and how this system will be scaled to meet the requirements for the CDIF.

An investigation of voltage transients appearing on the DC bus of the inverter at the CDIF was carried out. The cause of the transients was identified, and the installation of a simple RC filter from the positive bus to ground greatly reduced both the amplitude and frequency of the transient wave form. Also, it was shown that the spike does not affect any aspert of the proposed current consolidation subsystem design.

\section{CDIF TESTING (SECTION 7)}

Confirmation testing continued at the CDIF and consisted of three test series as follows: 1) facility checkout to confirm overall system readiness for a long duration test, 2) long duration thermal/electrical operation, and 3) current control design verification testing. There were a total of 46.6 thermal test hours which resulted in 15.7 power hours.

The results of a diagnostic test series established that the cause of the current control operational problems was a combination of voltage sag and line supply noise. Possible corrective actions being investigated include current control design modifications, filtering of the existing supply voltage, and/or separate supply power. MSE is providing a temporary "clean" supply voltage as an interim solution.

\section{MODELING AND PERFORMANCE ANALYSIS ACTIVITIES (SECTION 8)}

An evaluation of precombustor heat flux oscillations was performed in order to determine the origin and the general nature of the oscillations. An investigation of CDIF interanode voltage irregularities was performed to determine the cause of the irregularities on the $1 \mathrm{Al}$ workhorse channel.

\section{TTIRC (SECTION 9)}

The POC Integration Task Force recommendations were reviewed, approved, ranked in order of importance, and passed on to the DOE.

\section{SCHEDULE}

The overall schedule for the ITC project is shown on the following pages. 


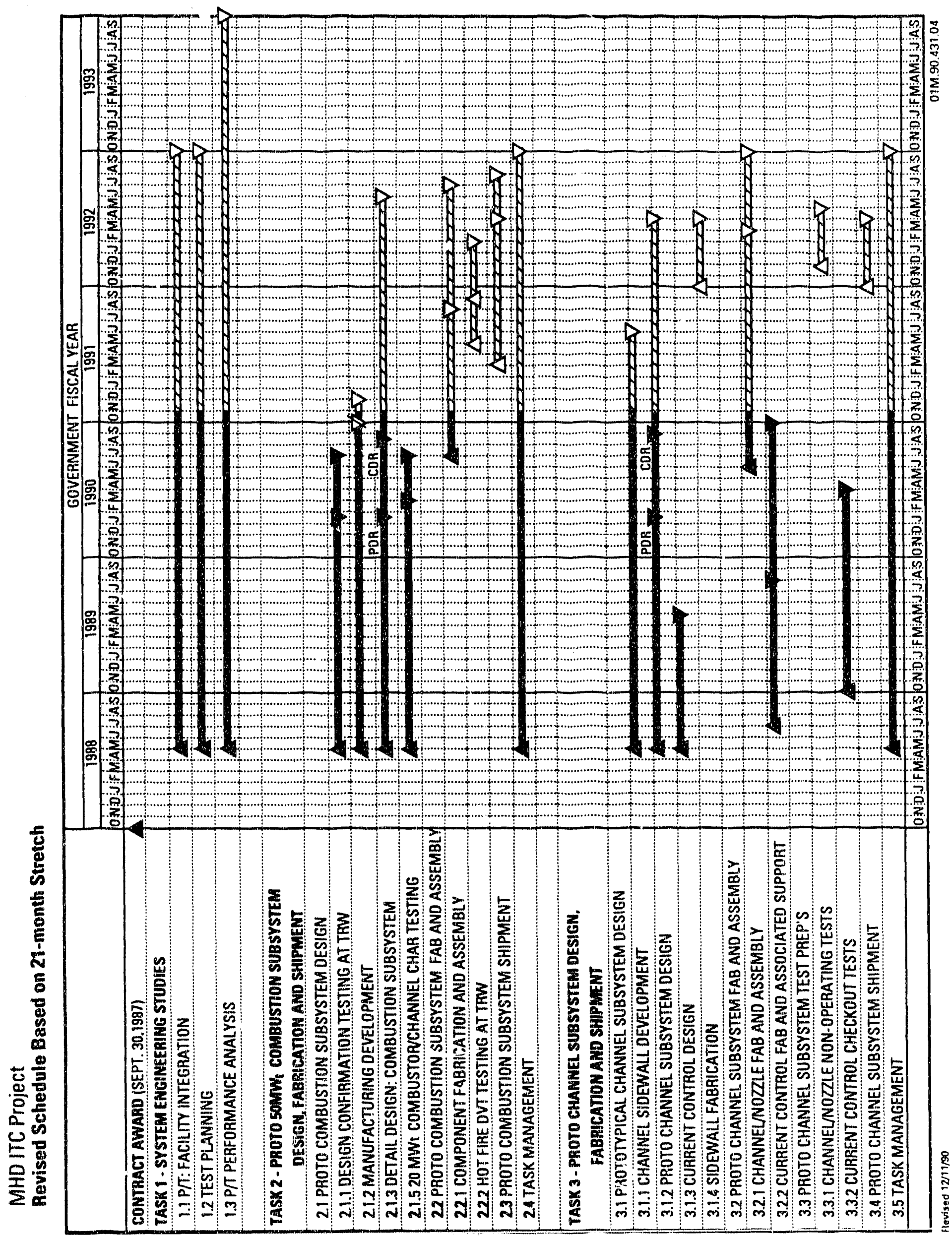




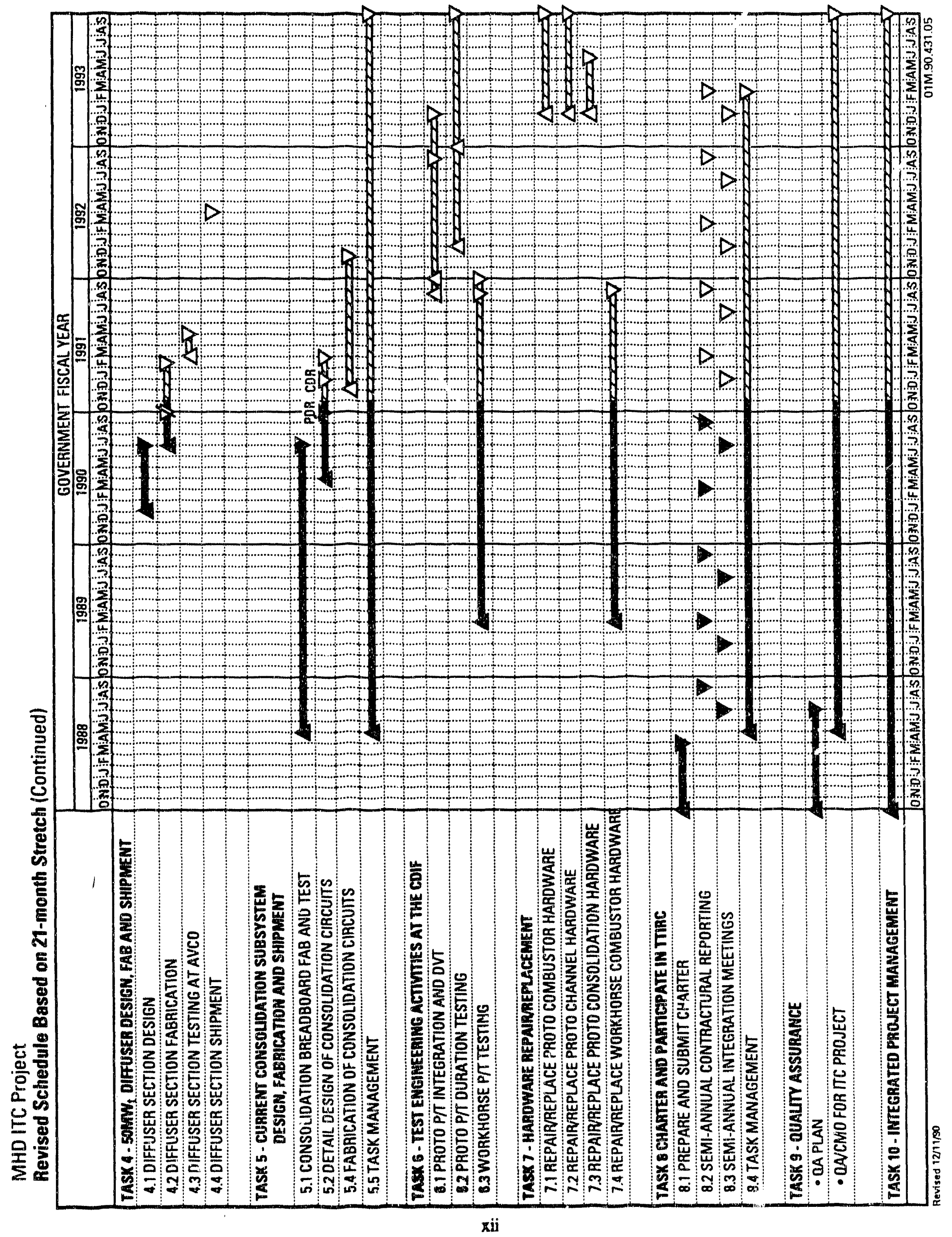




\section{INTRODUCTION}

The Magnetohydrodynamics (MHD) Integrated Topping Cycle (ITC) Project represents the culmination of the proof-of-concept (POC) development stage in the U.S. Department of Energy (DOE) program to advance MHD technology to early commercial development stage utility power applications. The project is a joint effor, cumbining the skills of three topping cycle component deveiopers: TRW, Avco, and Westinghouse. TRW, the prime contractor and system integrator, is responsible for the 50 thermal megawatt ( $50 \mathrm{MW}$ ) slagging coal combustion subsystem. Avco is responsible for the MHD channel subsystem (nozzle, channel, diffuser, and power conditioning circuits), and Westinghouse is responsible for the current consolidation subsystem.

The ITC Project will advance the state-of-the-an in MHD power systems with the design, construction, and integrated testing of $50 \mathrm{MW}$ power train components which are prototypical of the equipment that will be used in an eari: commercial scale MHD utility retrofit. Long duration testing of the integrated power train at the Component Development and Integration Fasitiiy (CDIF) in Butte, Montana will be performed, so that by the early 1990 's, an engineering data hase on the reliability, availability, maintainability and performance of the system will be available to allow scale up of the prototypical designs to the next development level.

Ten tasks comprise the ITC Project.

Task 1 - Systems Engineering Studies

Task 2 - $50 \mathrm{MW}_{1}$ Combustor Design, Fabrication, and Shipment

Task 3 - $50 \mathrm{MW}$ Channel Design, Fabrication, and Shipment

Task 4 - Diffuser Design, Fabrication, and Shipment

Task 5 - Power Conditioning Design, Fabrication, and Shipment

Task 6 - Test Engineering Activities at the CDIF

Task 7 - Hardware Repair/Replacement

Task 8 - MHD Technology Transfer/nntegration

Task 9 - Quality Assurance

Task 10 - Integraié Projeca Management

This Thirteenth Quanterly Technical Progress Report covers the period August 1, 1990 to October 31. 1990. The report is organized into sections which roughly follow the above task structure. The first section is this introduction. Section 2 contains a concise description of the contract tasks to be performed and their objectives. Section 3 summarizes the systems engineering activities in Subtask 1.1. Sections 4 through 7 summarize progress on the combustion subsystem (Task 2), channel subsystem (Tasks 3 and 4), and current consolidation subsystem (Task 5 ) for this reporting period, and discuss testing at the CDIF (Sublasks 1.2 and 6.3). Section 8 repons the results of ongoing power train performance analyses, uncluding cold flow modeling studies, which are pan of Subtask 1.3. Activities of the Technology Transfer, Integration and Review Committe (TTIRC) are reponted in Section 9. Planned activities during the next reporting period are summarized in Section 10. Section 11 is a brief summary of the work performed during the quarter, and Section 12 is the distribution list for this report. 


\section{PROJECT DESCRIPTION}

The overall objective of the project is to design and construct prototypical hardware for an integrated MHD topping cycle, and conduct long duration proof-of-concept tests of the integrated system at the U.S. DOE Component Development and integration Facility in Butte, Montana. The results of the long duration tests will augment the existing engineering design data base on MHD power train reliability, availability, maintainability, and performance, and will serve as a basis for scaling up the topping cycle design to the next level of development, an early commercial scale power plant retrofit.

The components of the MHD power train to be designed, fabricated, and tested include:

- A slagging coal combustor with a rated capacity of $50 \mathrm{MW}$ thermal input, capable of operation with an Eastern (Illinois \#6) or Westem (Montana Rosebud) coal,

- A segmented supersonic nozzle.

- A supersonic MHD channel capable of generating at least 1.5 MW of electrical power,

- A segmented supersonic diffuser section to interface the channel with existing facility quench and exhaust systems,

- A complete set of current control circuits for local diagonal current control along the channel, and

- A set of current consolidation circuits to inserface the channel with the existing facility inventer.

Specific objectives of the ten contract tasks are, shown in Table 2-1. The overall approach to meeting these objectives is to: 1) utilize the design and operational experience gained from workhorse hardware to design and construct prototypical hardware, 2) conduct design verification tests on the prototypical hardware, and 3 ) integrate and operate the components for 1000 hours as a complete power train at the CDIF. At the current stage of the project, the technical approach is focusing on item (1) above. Critical design reviews have been held for three of the four subsystems of the ITC systern and a preliminary design review has been held for the fourth ITC subsystem. Fabrication of prototypical hardware will begin this calendar year. Systems engineering disciplines are ensuring compatibility of each of the prototypical subs'stems with the overall topping cycle system as well as with the CDIF where they eventually will be integrated. Finally, the TTIRC is disseminating information on the POC program and airing the major integration issues involved in retrofitting an existing power plant so as to permit utilities, the potential future users of the technology, to assume an active role in the U.S. MHD program. 
TABLE 2-1. MHD ITC TASK OBJECTIVES

\begin{tabular}{|c|c|}
\hline $\begin{array}{l}\text { SYSTEMS ENGINEERING STUDIES } \\
\text { (TASK } 1)\end{array}$ & $\begin{array}{l}\text { Perform power train/farility integrafion activities to ensure } \\
\text { compatibility of toppin's cycle components with the existing } \\
\text { test bay at the CDIF } \\
\text { Define oystem lovel requirements and specifications for the } \\
\text { integrated topping cycle power train } \\
\text { Provide test planning and performance data analysis } \\
\text { support for CDIF power train testing }\end{array}$ \\
\hline $\begin{array}{l}\text { PROTOTYPICAL } 50 \text { MW, COMBUSTOR } \\
\text { DESIGN, FABRICATION, AND SHIPMENT } \\
\text { (TASK 2) }\end{array}$ & $\begin{array}{l}\text { Design, fabricate and deliver to the CDIF a prototypical } \\
\text { coal-fired combustor for the integrated topping cycle power } \\
\text { irain } \\
\text { Conduct testing in support of the prototypical design effort } \\
\text { or to evaluate the risks and benefits of proceeding to the } \\
\text { development of an early commercial scale retrofit MHD } \\
\text { power plant }\end{array}$ \\
\hline $\begin{array}{l}\text { PROTOTYPICAL } 50 \text { MW } \text { CHANNEL } \\
\text { (TASK 3) }\end{array}$ & $\begin{array}{l}\text { Design, fabricate and deliver to the CDIF a prototypical } \\
\text { MHD channel (including the inlet nozzle and diagonal } \\
\text { current controls) for the integrated topping cycle power } \\
\text { train } \\
\text { Conduct testing in support of the prototypical design effort } \\
\text { or to evaluate the risks and benefits of proceeding to the } \\
\text { development of an early commercial scale retrofit MHD } \\
\text { power plant }\end{array}$ \\
\hline DIFFUSER (TASK 4) & $\begin{array}{l}\text { Design, fabricate and deliver to the CDIF a diffuser section } \\
\text { for the initegrated topping cycle power train }\end{array}$ \\
\hline $\begin{array}{l}\text { POWER CONDITIONING AND INVERTER } \\
\text { (TASK 5) }\end{array}$ & $\begin{array}{l}\text { Design, faibricate and deliver to the CDIF current } \\
\text { consolidation circuits for the prototypical channel }\end{array}$ \\
\hline $\begin{array}{l}\text { TEST ENGINEERING ACTIVITIES AT } \\
\text { THE CDIF (TASK 6) }\end{array}$ & $\begin{array}{l}\text { Provide io CDIF personnel technical direction and guidance } \\
\text { for the ingtallation, checkout and testing of CDIF MHD } \\
\text { power train components and appropriate auxiliary } \\
\text { equipment }\end{array}$ \\
\hline $\begin{array}{l}\text { HAROWARE REPAIR/REPLACEMENT } \\
\text { (TASK } 7 \text { ) }\end{array}$ & $\begin{array}{l}\text { Provide for the repair or replacement of power train } \\
\text { components that show excessive wear, are damaged, or } \\
\text { fail as a result of operations and resting at the CDIF }\end{array}$ \\
\hline $\begin{array}{l}\text { CHARTER AND PARTICIPATE IN AN MHD } \\
\text { TECHNOLOGY TRANSFER, INTEGRATIOIN } \\
\text { AND REVIEW COMMITTEE (TASK (3) }\end{array}$ & $\begin{array}{l}\text { Organize, charter and co-chair a committee that will permit } \\
\text { potential users of MHD technology in the private sector to } \\
\text { assume an active role in the MHD Program } \\
\text { Review and integrate POC program schedules and } \\
\text { integration issues and provide for technology transfer to } \\
\text { potential future users }\end{array}$ \\
\hline QUALITY ASSURANCE (TASK 9) & $\begin{array}{l}\text { Prepare and implement plan to assure that prototypical } \\
\text { power train components are manufactured per the } \\
\text { approved design }\end{array}$ \\
\hline $\begin{array}{l}\text { INTEGRATED PROJECT MANAGEMENT } \\
\text { (TASK 10) }\end{array}$ & $\begin{array}{l}\text { Provide for overall technical, programmatic and } \\
\text { subcontract management for the project }\end{array}$ \\
\hline
\end{tabular}




\section{SYSTEMS ENGINEERING (TASK 1)}

Systems engineering activities related to the power train integration and testing at the CDIF arc discussed in this section. These activities comprise Subtask 1.1 of the ITC Project.

A principal objective of the systems engineering task is to focus the program's technical effort so that the subsystems designed and built for the topping cycle not only perform well by themselves, but also perform well when interconnected and integrated into the $50 \mathrm{MW}$ power train at the CDIF. The integrated topping cycle system must be prototypical, and it must be designed to operate at conditions which closely approximate the operating state of a $250 \mathrm{MW}$ retrofit power plant.

To attain these objectives, systems engineering studies are being performed on specific issues as they arise, and systems engineering documentation is being developed and maintained current to provide a consistent basis for the design, fabrication and testing of the prototypical power train. Brief summaries of the status and/or results of investigations into the CDIF integration issues are reported in Section 3.1. This section also addresses the proposed operating conditions for the diration testing of the prototypical power train. The status of the systems engineering documentation for the project is reported in Section 3.2. The follow-up activities to the Critical Design Review (CDR) with DOE are discussed in Section 3.3.

\subsection{SYSTEMS ENGINEERING ANALYSIS}

Table 3-1 lists the systems engineering analyses performed to date on the ITC project, summarizes the results of the analyses, and presents the current resolution of the issues in terms of how they impact the testing at the CDIF. The technical issues listed in the table were surfaced by the Technology Transfer, Integration and Review Committee (TTTRC) and during the investigation of iniegrating the prototypical power train into the CDIF. Issues on which studies continued during this reporting period included the following:

- High Pressure Cooling Subsystem (HPCS) Electrical Isolation

- Power Train Anchor Point/Alignment Requirements

- Prototypical Test Conditions

- Reintroduction of Coal Fines

\subsubsection{HPCS Electrical Isolation}

The initial tests on the polyamide insulator material (Vespel) proved encouraging until the $450^{\circ} \mathrm{F}$ temperatures were reached when the insulator could no longer hold the pressure (1000 psi). Inspection of the material showed evidence of hydrolysis of the Vespel which led to cracking.

An alternate material, a poly-ether-ether-ketone (PEEK), was then tested successfully up to the full operating temperature and pressure. At the end of the reporting period, duration testing was just starting to obtain 50 hours of operation at $400 \% \mathrm{~F}$ and $1000 \mathrm{psi}$. Pending successful completion of the duration testing, the electrical isolator material evaluation phase will be successfully completed.

Additional details on the electrical isolator testing are contained in Section 4.2.2 of this report.

\subsubsection{Power Train Alignment}

At the end of the last quarter, measurements were being taken to understand the allowable channel skew about the magnet centerline and the allowable misalignment in relation to axial displacement within the magnet bore. These measurements were completed and reported at the System wrap-up at the end of the Channel CDR.

Additionally, the problem of having to rotate the combustor each time the channel was installed in order to complete the channel alignment was addressed and recommendations made $t 0$ alleviate the problem. The recommendations were tried during subsequent channel installations and found to correct the problem. The combustor has since been secured to the stand as it will not require rotation now that the channel installation 
TABLE 3-1. SUMMARY OF SYSTEMS ENGINEERING ANALYSES

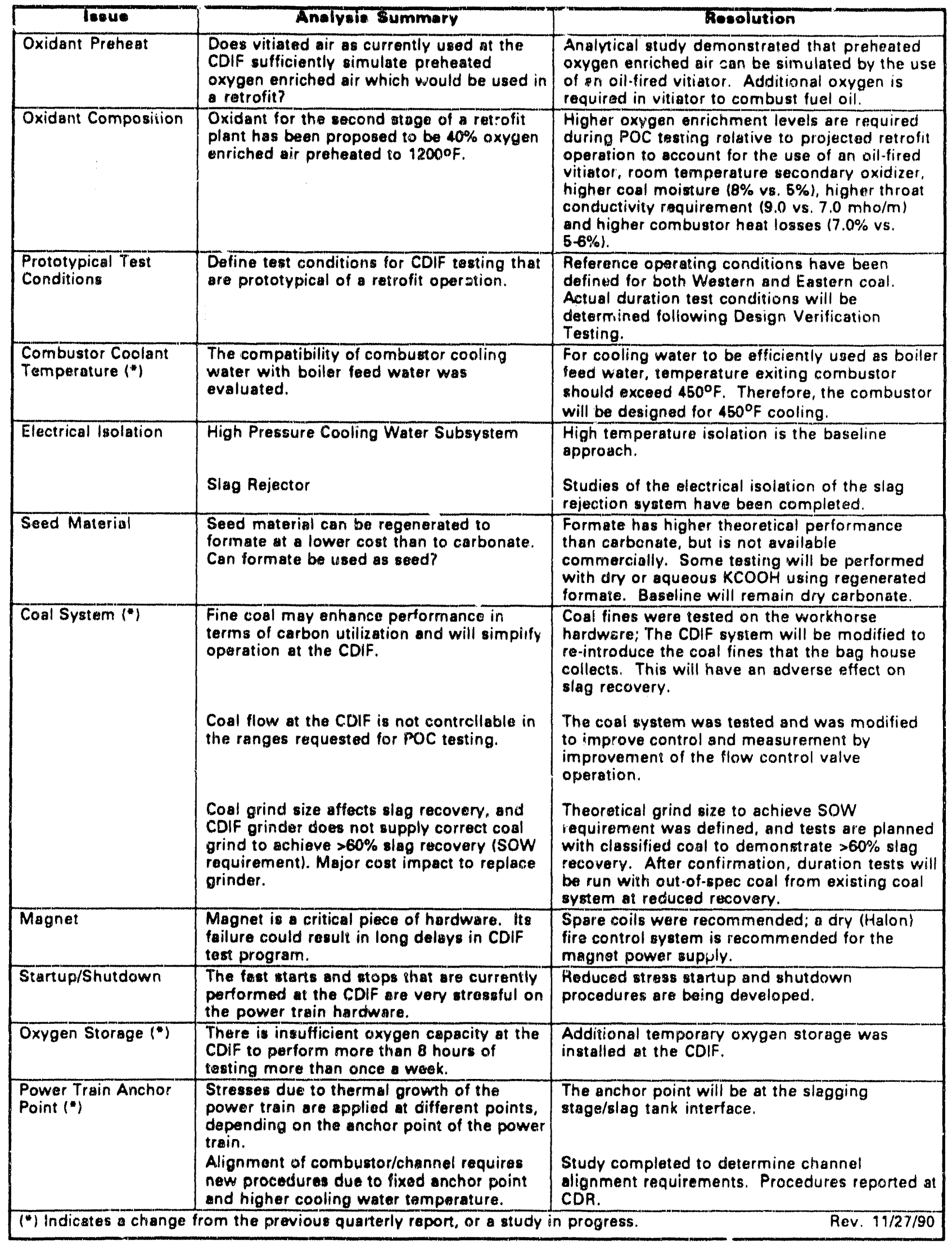


procedures have been implemented. Additional details on the power train alignment procedures are contained in Section 4.1.2 of this report.

\subsubsection{Rationale for Proposed 1A4 Operating Conditions}

\subsubsection{Summary}

A survey of previous retrofit and baseload MHD power plant studies was made to demonstratc the rationale for a "two-tier" Proof-of-Concept test plan. The required $1.5 \mathrm{MW}$ will be demonstrated at generator operating conditions typical of the 1A1 workhorse tests. Prototypical electrical stresses, however, must be demonstrated at a lower power than that of the $1 \mathrm{~A} 4$ "power" condition. The basis for prototypical "stress" conditions comes from comparisons with ECAS, ETF, APT, RRDB, Scholz and Corette retrofit plants, and Gilbert/Commonwealth studies.

\subsubsection{Introduction}

The efficiency of generators such as the $1 \mathrm{~A} 4$ and the $1 \mathrm{~A} 1$ are not as high as the baseload MHD generators due to the large surface loss effects at their small scales. The purpose of the Proof-of-Concept generator is to demonstrate lifetime and reliability. Table 3-2 summarizes the predicted performance of the 1 A4 under typical "power" operating conditions for both SOW Western and Eastern coals. A conscious decision was made at the beginning of the ITC program to use the existing 3 Tesla iron core magnet at the CDIF. This decision was based primarily on cost. As a result of the lower field of this magnet, one cannot simultaneously demonstrate $1.5 \mathrm{MWe}$ and stresses representative of baseload power plants at a single power train operating condition. Because of this, a "two-tier," i.e., stress/power proposal is suggested for the ITC Proof-of-Concept testing. The bulk of the testing would occur at "stress" conditions with intermittent excursions to "power" conditions to demonstrate the ability of the $1 \mathrm{~A} 4$ to produce $1.5 \mathrm{MW}$. Eight hundred of the required 1000 test hours would be conducted with SOW Rosebud coal; the balance would be achieved with SOW Illinois No. 6 coal. Table 3-3 summarizes the proposed test pararneters for the POC "prototypical stress" condition. Figure 3-1 shows the predicted "power" and "stress" conditions for the 1 A4 with SOW Rosebud coal. Similar characteristics, based on SOW Illinois No. 6 coal, are shown in Figure 3-2.

TABLE 3-2. TYPICAL 1A4 POWER CONDITIONS

\begin{tabular}{|l|l|c|c|}
\hline & & Western Cosl & Eastern Coal \\
\hline Combustor Pressure & $(\mathrm{atm})$ & 5.71 & 5.61 \\
Stoichiometry & $(-)$ & 0.90 & 0.88 \\
N/O & $(-)$ & 0.70 & 0.78 \\
Seed Fraction & $(\% \mathrm{~K})$ & 1.70 & 1.70 \\
Channel Performance & & & \\
$\quad$ Magnetic Field & $(\mathrm{T})$ & 2.94 & 2.94 \\
Hall Voltage & $(\mathrm{kV})$ & 6.13 & 6.08 \\
Load Current & $(\mathrm{A})$ & 275 & 300 \\
Output Power & $(\mathrm{MWe})$ & 1.69 & 1.82 \\
Channel Stresses & & & \\
$\quad$ Peak Hall Field & $(\mathrm{kV/m})$ & -2.06 & -2.02 \\
Peak Jy(core) & $\left(\mathrm{A} / \mathrm{cm}^{2}\right)$ & -1.02 & -1.08 \\
Peak Jy(ave) & $\left(\mathrm{A} / \mathrm{cm}^{2}\right)$ & -0.80 & -0.85 \\
\hline
\end{tabular}

* Note: Pressure changes are due to mass flow rate changes required to maintain a constant thermal input as the $\mathrm{N} / \mathrm{O}$ ratio is varied. 
TABLE 3-3. TYPICAL 1A4 STRESS CONDITIONS

\begin{tabular}{|l|l|c|c|}
\hline & & Western Coal & Eastern Coal \\
\hline Combustor Pressure & $($ atm) & 6.06 & 5.93 \\
Stoichiometry & $(-)$ & 0.90 & 0.88 \\
N/O & $(-)$ & 0.84 & 0.92 \\
Seed Fraction & $(\% \mathrm{~K})$ & 1.70 & 1.70 \\
Channel Performance & & & \\
Magnetic Field & $(\mathrm{T})$ & 2.94 & 2.94 \\
Hall Voltage & $(\mathrm{kV})$ & 6.23 & 5.97 \\
Load Current & $(\mathrm{A})$ & 160 & 168 \\
Output Power & $(\mathrm{MV} / \mathrm{e})$ & 1.00 & 1.00 \\
Channel Stresses & & & -1.98 \\
Peak Hall Field & $(\mathrm{kV} / \mathrm{m})$ & -2.06 & -0.81 \\
Peak Jy(core) & $\left(\mathrm{A} / \mathrm{cm}^{2}\right)$ & -0.79 & -0.62 \\
Peak Jy(ave) & $\left(\mathrm{A} / \mathrm{cm}^{2}\right)$ & -0.61 & \\
\hline
\end{tabular}

*Note: Pressure changes are due to mass flow rate changes required to maintain a constant thermal input as the $\mathrm{N} / \mathrm{O}$ ratio is varied.

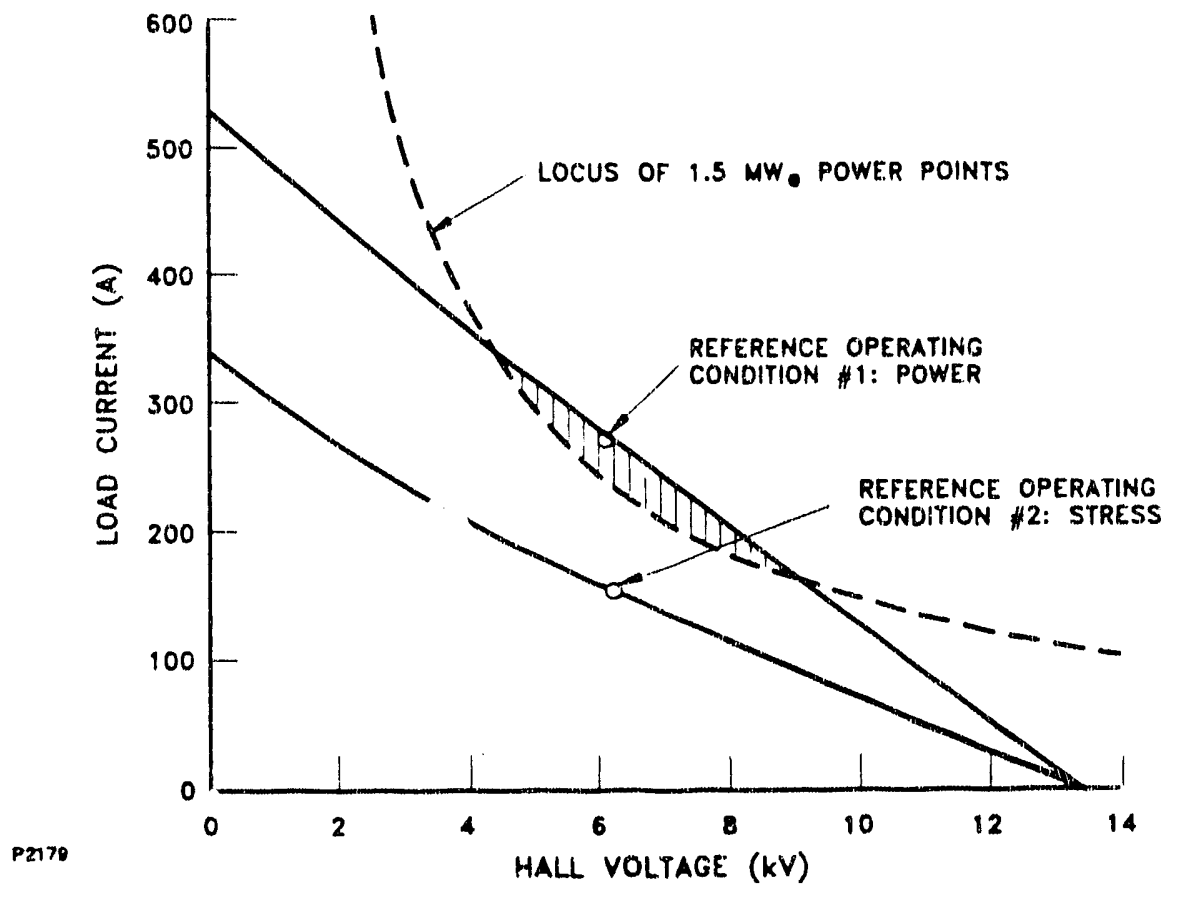

Figure 3-1. 1A4 Channel Performance Over the Range of Anticipated Operating Conditions with SOW Western Coal 


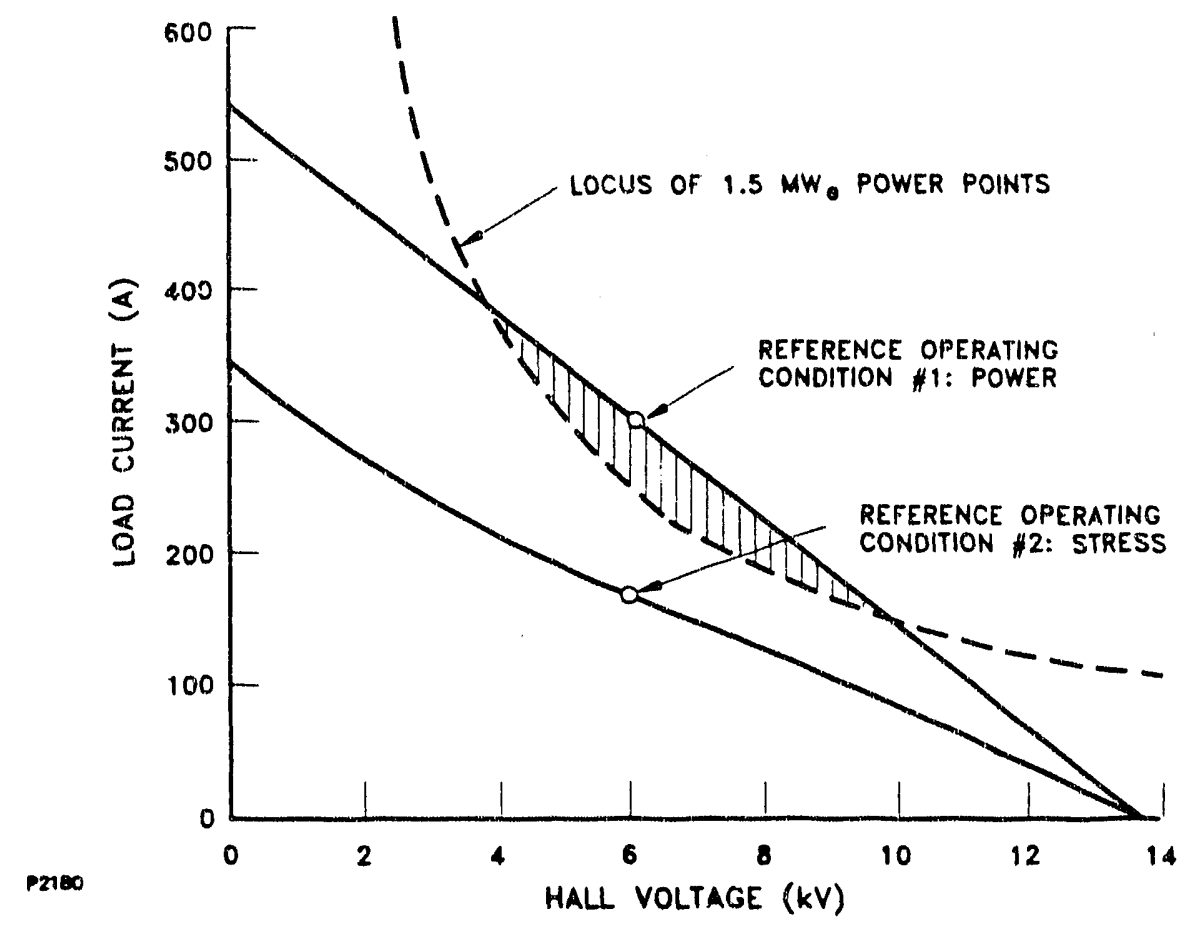

Figure 3-2. 1A4 Channel Performance Over the Range of Anticipated Operating Conditions with SOW Eastern Coal

\subsubsection{Definition of "Prototypical" Conditions}

A comparison of predicted $1 \mathrm{~A} 4$ performance and that predicted for conceptual designs of Retrofit plants and Baseload plants will be made. Before making this comparison, it is helpful to define "prototypical" stresses as used for this design.

$$
\begin{aligned}
& \mathrm{Ex}=2.0 \text { to } 2.5 \mathrm{kV} / \mathrm{m} \\
& \mathrm{Jy}(\text { core })=0.75 \text { to } 0.80 \mathrm{~A} / \mathrm{cm}^{2}
\end{aligned}
$$

Hall Parameter, Beta $=4.0$

$$
\text { Heat Flux }=200 \text { to } 300 \mathrm{~W} / \mathrm{cm}^{2}
$$

These were determined from a survey of the larger baseload and conceptual plant studies. It is also useful to differentiate between "average" and "core" transverse current density. The average current density is simply the total electrode current divided by the electrode surface area (electrode pitch $x$ width). On the other hand, the core current density is the current density in the core flow region of the channel. The distinction between the two current densities is shown in Figure 3-3. Boundary layers in large MHD channeis are small when compared to channel dimensions. For that reason, there is little difference between average and core current density in large MHD channels (it is all effectively cone). Therefore, to operate the $1 \mathrm{~A} 4$ at a current density equivalent to that of baseload plants requires that the core current density in the baseload channels, not the average transverse current density, be matched. This necessarily results in a lower average current density in a channel the size of the $1 \mathrm{~A} 4$ (with its relatively large boundary layers), than the average current density in a baseload generator. It dees not mean that the electrodes are operating at a lower current density, but that because of boundary layer effects at the sidewalls, only a fraction (roughly $80 \%$ ) of each electrode is active. 


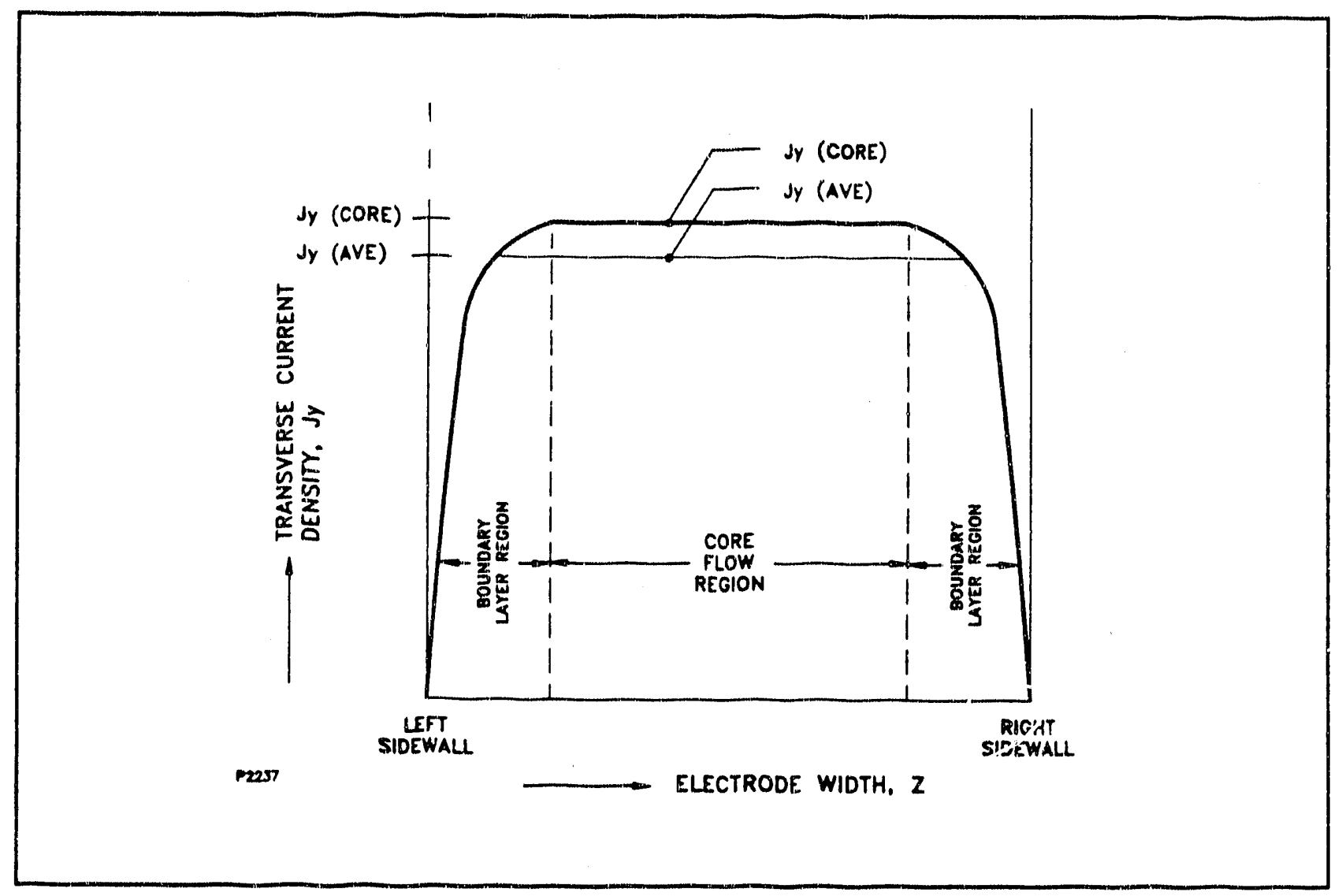

Figure 3-3. Distinction Between Jy(core) and Jy(ave)

\subsubsection{Comparison of 1 A4 to Retrofit and Baseload Studies}

Comparisons of the 1A4 channel with channel designs used in previous retrofit and baseload plant studies, including the Corette retrofit plant (PowerMHD $=28 \mathrm{MWe}$ ); the Avco $200 \mathrm{MWe}$ Advanced Power Train (PowerMHD $=85 \mathrm{MW}$ ) and the Avco $500 \mathrm{MWe}$ APT Baseload power plant (PowerMHD $=230$ $\mathrm{MW}$ ), are made in Table 3-4 (based on References 3-1 through 3-7). This table makes additional comparisons with ECAS, ETF, Retrofit Reference Design Basis (RRDB), Scholz and Gilbert/Commonwealth conceptual studies. Figures 3-4 and 3-5 show the comparison between parameters (for Westem coal) at power and stress conditions.

Over the "power" operating range shown in Figures 3-1 and 3-2, the transverse current density is higher for the 1A4 than for the majority of the baseload plants with which it is compared. At the "stress" operating range shown in the same figures, however, the transverse current density is comparable to the baseload power plants. At either power or stress conditions, the current density of the $1 \mathrm{~A} 4$ is comparable to that of the $1 \mathrm{~A} 1$. Figure 3-6 is a plot of the ratio of Jy(ave) to Jy(core) as a function of MHD channel size (output power). This figure was used to estimate the core or average transverse current densities when they were unavailable.

\subsubsection{Conclusions}

Several important conclusions supporting the "two-tier" Proof-of-Concept test plan are as follows:

1) A demonstration of $1.5 \mathrm{MW}$ in the $1 \mathrm{~A} 4$ requires a current density on the order of previous workhorse testing (i.e., Jy(ave) $=0.8 \mathrm{~A} / \mathrm{cm}^{2}$ )

2) The core, not the average, current density should be used as a basis of comparison between the $1 \mathrm{~A} 4$ and retrofit and baseload studies 


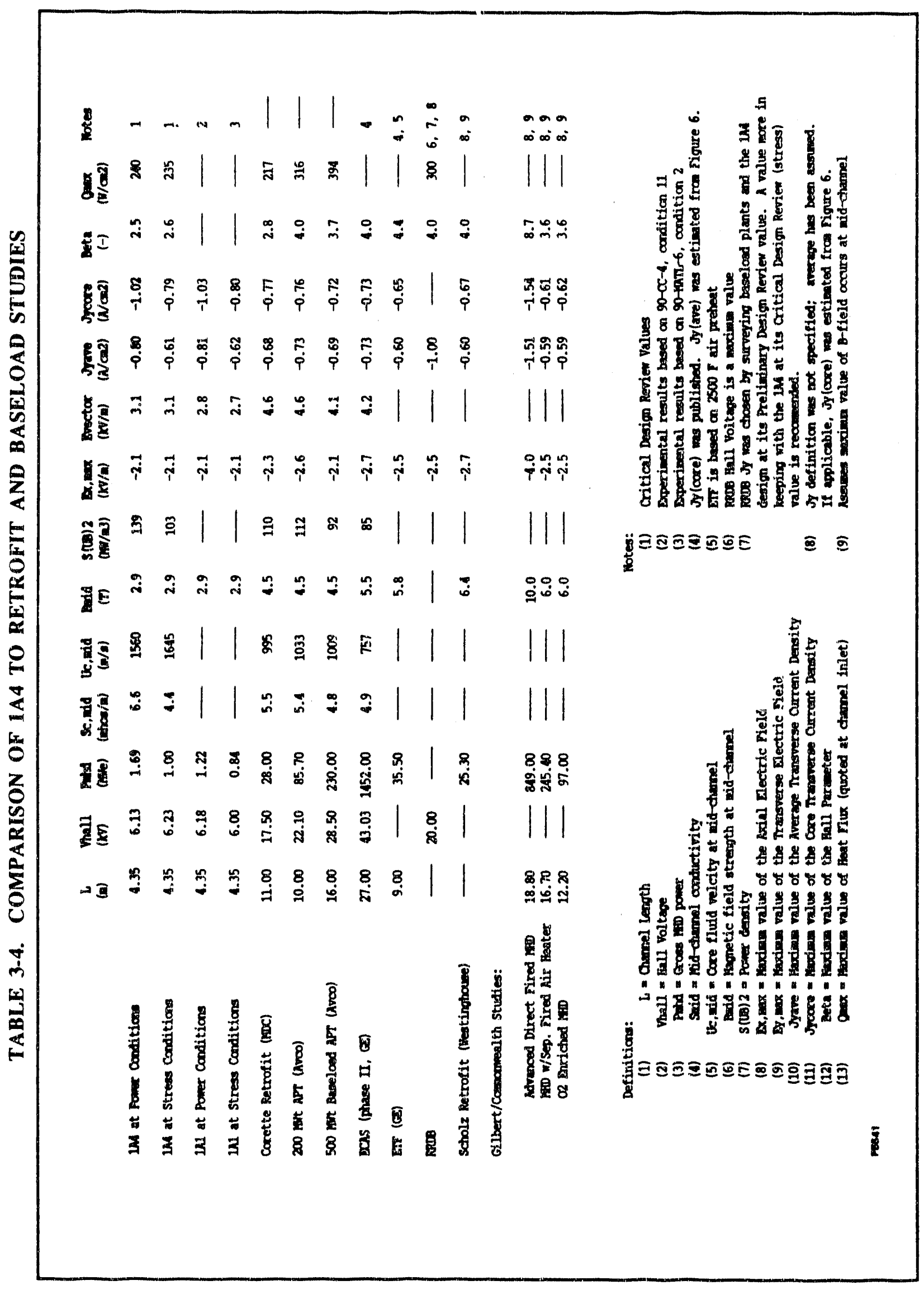




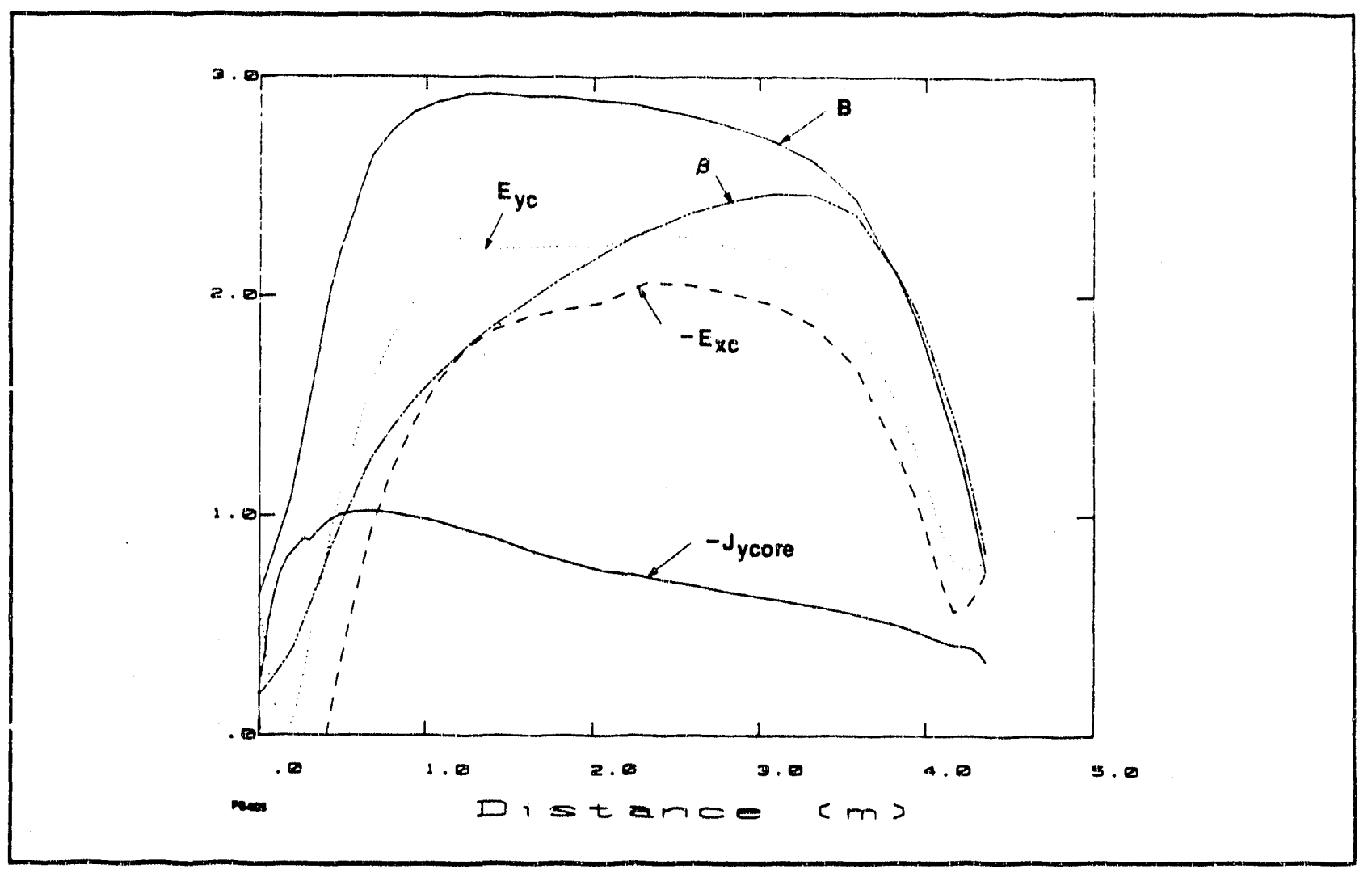

Figure 3-4. 1A4 Performance Characteristics at Reference Operating Condition \#1: Power

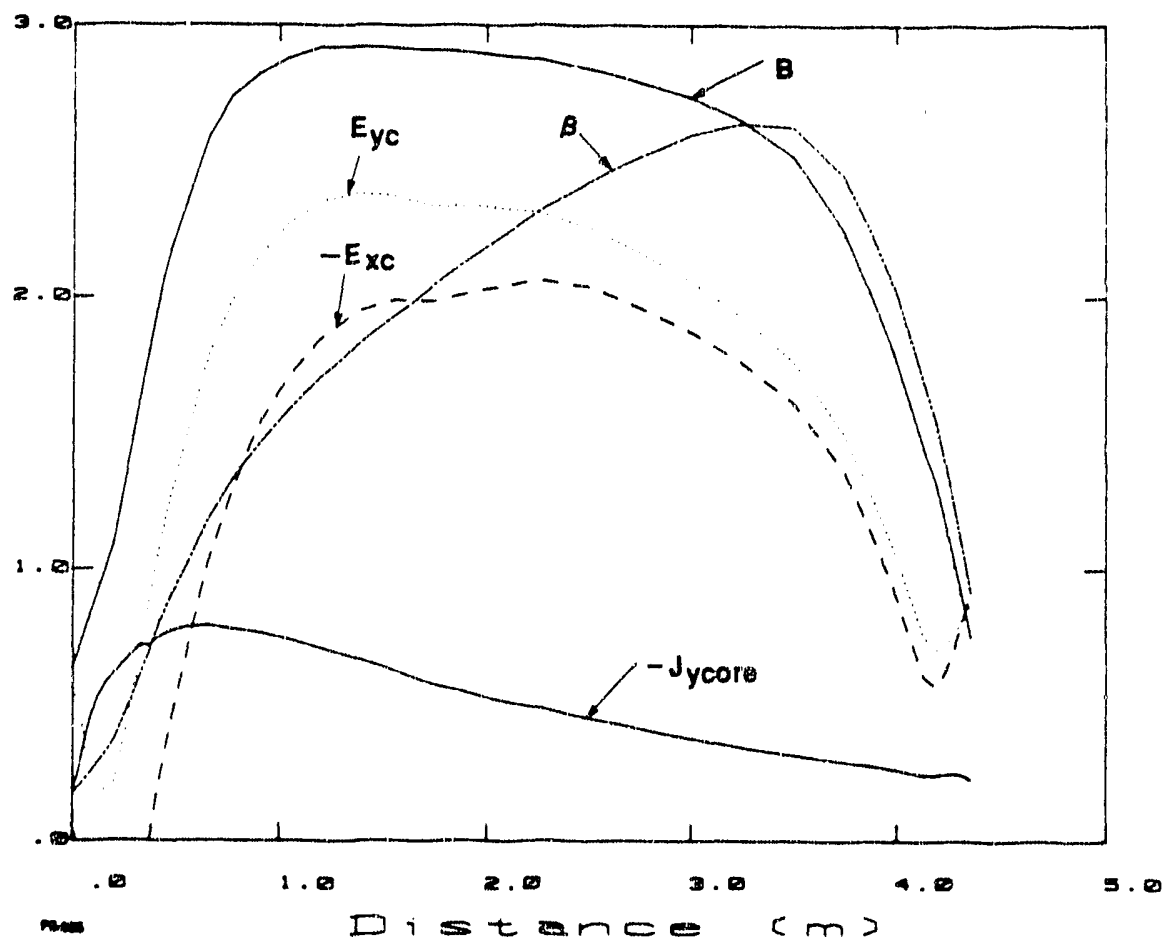

Figure 3-5. MA4 Performance Characteristics at Reference Operating Condition \#2: Stress 


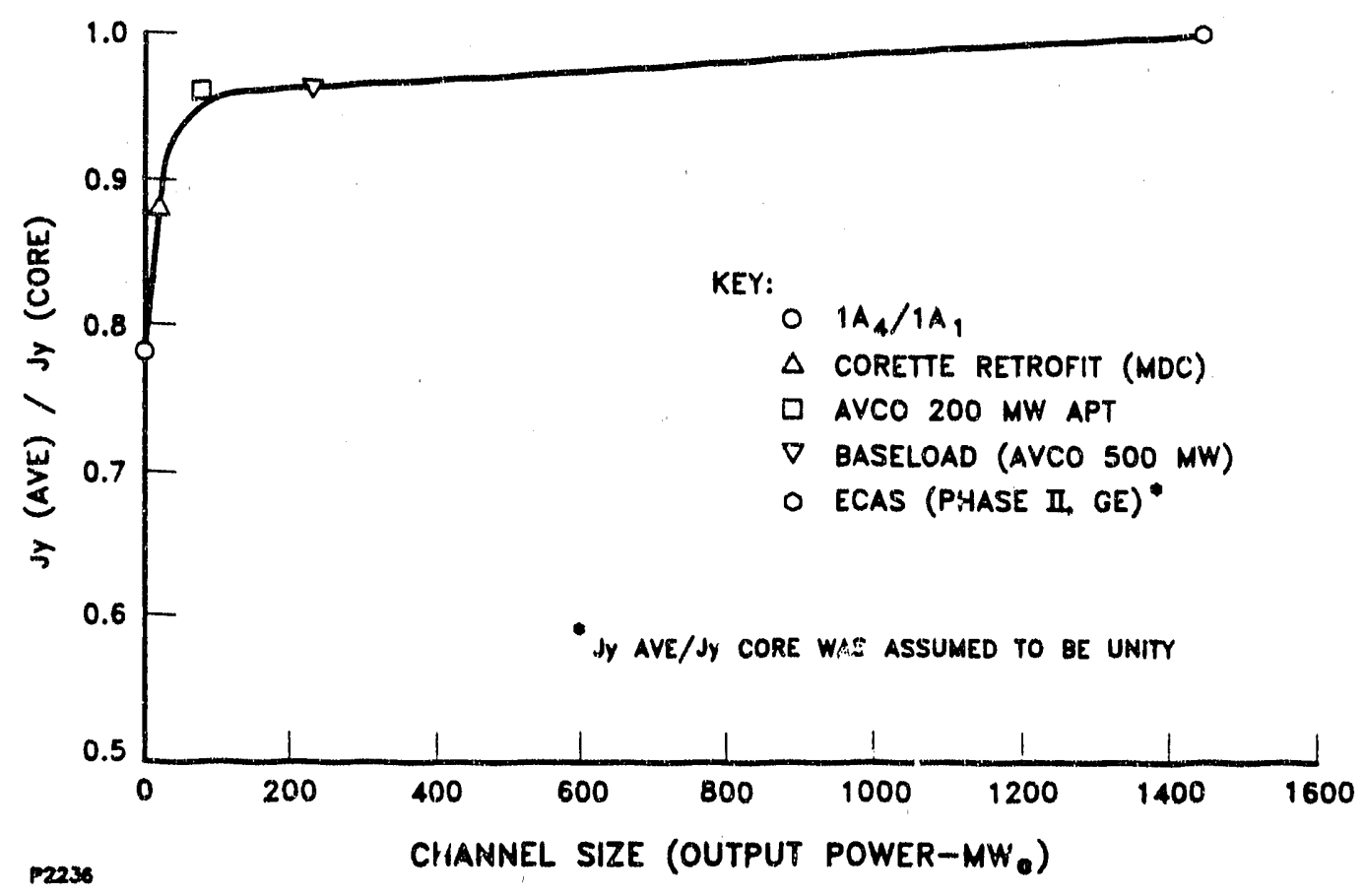

Figure 3-6. Ratio of Average Current Density to Core Current Density as a Function of Channel Size

3) Following are prototypical stress levels for the $1 \mathrm{~A} 4$ :

$$
\begin{aligned}
& \mathrm{Jy}(\text { ave })=0.6 \mathrm{~A} / \mathrm{cm}^{2} \\
& \mathrm{Jy}(\text { core })=0.8 \mathrm{~A} / \mathrm{cm}^{2} \\
& \mathrm{Ex}=2.1 \mathrm{kV} / \mathrm{m}
\end{aligned}
$$

The only way that both power and stress conditions can be demonstrated is with a two-tier test plan.

\subsubsection{Reintroduction of Coal Fines into the Coal System at the CDIF}

The existing coal pulverizing system at the CDIF rejects approximately $25 \%$ of the product to the baghouse. The rejected coal, referred to as coal fines, is generally of a very fine coal grind size ( $80 \%$ less than 500 mesh). Presently this coal is removed from the baghouse and disposed of in ponds which are periodically cleaned. A concern was raised that during the winter months the ponds would freeze, and it would be difficult, if not impossible, to clean them out. Therefore, the ponds holding capacity could limit test operations if they could not be cleaned during the winter months. One proposed solution was to reintroduce the coal fines back into the pulverized coal storage vessels and, hence, burn the coal in the combustor, A single test was performed utilizing a simulation of this approach during 1989 . The test results indicated that the combustion heat loss was siightly higher, the power output was slightly lower, and the slag recovery was significantly lower as a result of the overall finer coal grind size. Additional testing should be performed to confirm these results prior to incorporating the permanent equipment required in onder to reintroduce the coal fines into the coal feed systern. These tests are scheduled for April/May 1991. Pending the results of these tests, the current plan is to install a permanent system during FY 1991. 


\subsection{SYSTEM/SUBSYSTEM DOCUMENTATION}

Requirements, technical criteria, specifications and interfaces for the power train hardware are being documented to insure that Statement of Work requirements are met and that the subsystems designed and built for the power train are compatible with each other and with the test facility at the CDIF.

\subsubsection{Subsystem Requirements}

In support of the PDR, the Current Consolidation Subsystem Requirements were updated. The main changes from the previous version were the removal of the potential defining converter and the completion of the definition of the current per circuit and the output ripple current. These requirements were presented at the PDR and will be updated per the review comments for the CDR which is scheduled for the end of the year.

\subsubsection{Interface Documentation}

The interfaces for the Channel Subsystem were completed to support the CDR. The High Pressure Cooling Subsystem interfaces were updated to reflect the latest information. These interfaces can only be finalized after the design of the cooling assemblies is completed. This is presently scheduled for early in 1991.

The initial cut at the current consolidation interfaces was also completed and reviewed at the PDR. These interfaces will be completed and finalized prior to the CDR.

\subsubsection{Test Plan}

The test plan which covers all of the installation and checkout tests for the power train at the CDIF was reviewed at the CDR. An action item was assigned to update the test plan per the CDR comments. This was started late in this quarter and will be completed by the middle of November. A copy of the plan will then be sent to DOE as well as to all of the component developers and MSE for a detailed review. Although the $t$. ting is not scheduled to start until 1992, the test plan will be updated to be consistent with the latest master schedule and test logic.

\subsection{CDR FOLLOW-UP}

During this quarter, the CDR for the Combustion Subsystem, the High Pressure Cooling Subsystem, and the Channel Subsystem was held. Action items were assigned at the meetings and responses to the action items were initiated. A detailed schedule for responding to the action items was sent to DOE. Most of the items will be completed in November but the Facility Impact Report update will not be completed until mid-Januar; 


\section{REFERENCES FOR SECTION 3}

3-1. MHD ITC Channel Subsystem CDR Data Package, Avco Research Laboratory, Inc., August 16, 1990.

3-2. Preliminary Test Report, "90-CC-4, Condition 11," MSE Inc., August 30, 1990.

3-3. Preliminary Test Report, "90-MATL-6, Condition 2," MSE Inc., September 20, 1990.

3-4. Summary of Internal Avco ECAS, Phase Two Calculations, "Oxygen Enrichrnent Studies," Part I, 1978.

3-5. Avco Everett Rescarch Laboratory, inc., "Engineering Test Facility (ETF) Conceptual Design," Final Report, Part 1, June 1978.

3-6. Viewgraph of RRDB Prototypical Conditions Provided by TTIRC Committee Member Bruce Pote.

3-7. Correspondence from Richard Weinstein (Gilbert/Commonwealth) to Edwin Schmitt (Avco), dated October 16, 1990. 


\section{COMBUSTION SUBSYSTEM DESIGN AND FABRICATION (TASK 2)}

Task 2 combustion subsystem design support engineering and prototypical design activities are discussed in this section. Three subtasks comprise Task 2 of the ITC project: Subtask 2.1, prototypical combustor design; Subtask 2.2, prototypical combustor fabrication and assembly; and Subtask 2.3, prototypical combustor shipment.

During this quarteriy reporting period, the efforts were concentrated on Subtasks 2.1 and 2.2. The 2.1 subtask encompasses design suppor engineering and testing. as well as the actual design of prototypical combustor hardware, and procurement specification development for the high pressure cooling subsystem (HIPCS). The 2.2 subtask encompasses the combustor and HPCS fabrication and assembly, as well as the combustor hot fire design verification testing (DVT) at TRW.

Subtask 2.1 was originally comprised of five elements:

- Subtask 2.1.1, Design confirmation testing at TRW. This subtask has been completed and the results have been reported.

- Subtask 2.1.2. Wall construction evaluations. Also completed and the results reported.

- Subtask 2.1.3, Design of prototypical combustor.

- Subtask 2.1.4, Low pressure oxidant second stage testing and design. This subtask was deleted from the program.

- Subtask 2.1.5, 20 MWi combustor/channel characterization. Also completed and the results reponted.

Subrask 2.2 includes the following elements:

- Subtask 2.2.1. Component fabrication and assembly.

- Subtask 2.2.2, Hot fire DVT testing at TRW.

Section 4.1 titled Combustion Subsystem Design Activities, Section 4.2 titled High Pressure Cooling Subsystem Design, and Section 4.3 tilled Prototypical Panel Confirmation Testing include elements of Subtask 2.1.3.

\subsection{COMBUSTION SUBSYSTEM DESIGN ACTIVITIES (SUBTASK 2.1.3)}

As part of the combustion subsystem design development, the following activities occurred during this reporting period:

- Protorypical combustor detail drawings are in the signature approval cycle and will be released in November and Decernber.

- The Combustor Critical Design Review (CDR) with the Department of Energy was held September 8 and 9; the design was approved for fabrication.

- Responses to CDR action items were submitted as discussed in Section 4.1.1 below.

- A final CDR Data Package and Design Repor are being prepared.

- An IrC Puwer Train Alignment procedure was developed and is described in Section 4.1.2.

- Manufacturing developrnent artivities continued and are described in Section 4.1.3.

\subsubsection{Critical Design Review and Action Items}

The prototypical combustor design was reviewed by DOE and approved for fabrication. Several design inquiries were made in the form of action iterns. These responses have been submitued and no unresolved combustor design issues remain at this time. However, some manufacturing developmert continues and these effors are described in Section 4.1.3. The design issues which have been closed out include: 
Q-Ring Evaluation: The prototypical combustor flanges will be sealed with Viton o-rings as presented at the CDR. Information supporting this selection was contained in the Design Report. Viton o-rings have been tested in-house for 750 hours at $450^{\circ} \mathrm{F}$ without significant loss of properties.

Baffle Design: The baffle bore was redesigned as shown in Figure 4-1 to provide a better slag retention geometry. Due to questions at the CDR about the manufacturability of the baffle, a manufacturing sequence was also developed. The baffle manufacturing sequence is discussed in Section 4.1.3.

Inconel Cladding in Precombustor: The use of Inconel in the precombustor was confirmed and justified. While the slagging stage has a reducing atmosphere in general, the precombustor is an oxidizing region and Inconel 625 is well suited for this environment. The method of applying Inconel cladding to precombustor elements is the focus of the manufacturing efforts described in Section 4.1.3.

Power Train Alignment: Since the power train anchor point is the slagging stage, a procedure for aligning the MHD channel to the magnet using the slagging strge as an anchor was developed. The procedure is described in Section 4.1.2.

\subsubsection{Power Train Alignment Procedure}

The alignment procedure for the MHD Power Train was presented at the Channel CDR. In brief, the combustor will be the power train anchor point and will be bolted to the combustor stand. The initial combustor alignment will account for thermal growth during operation to optimize alignment. The fixed combustor hecomes an additional reference point for channel alignment. The initial channel alignment is described in Figure 4-2 (after which time the combustor is locked in place). Using this technique, the channel has been removed and reinstalled to its proper location without adjustment of the cornbustor location.

A: IS:

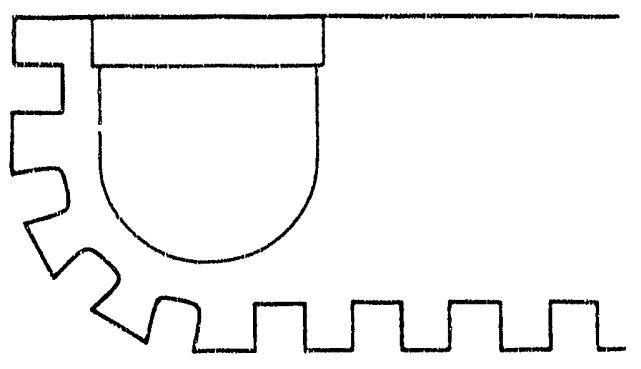

B: WAS:

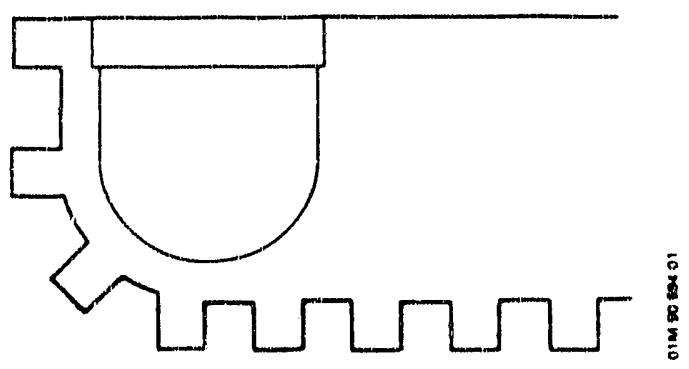

Figure 4-1. Baffe Bore Slag Retention Grooves 


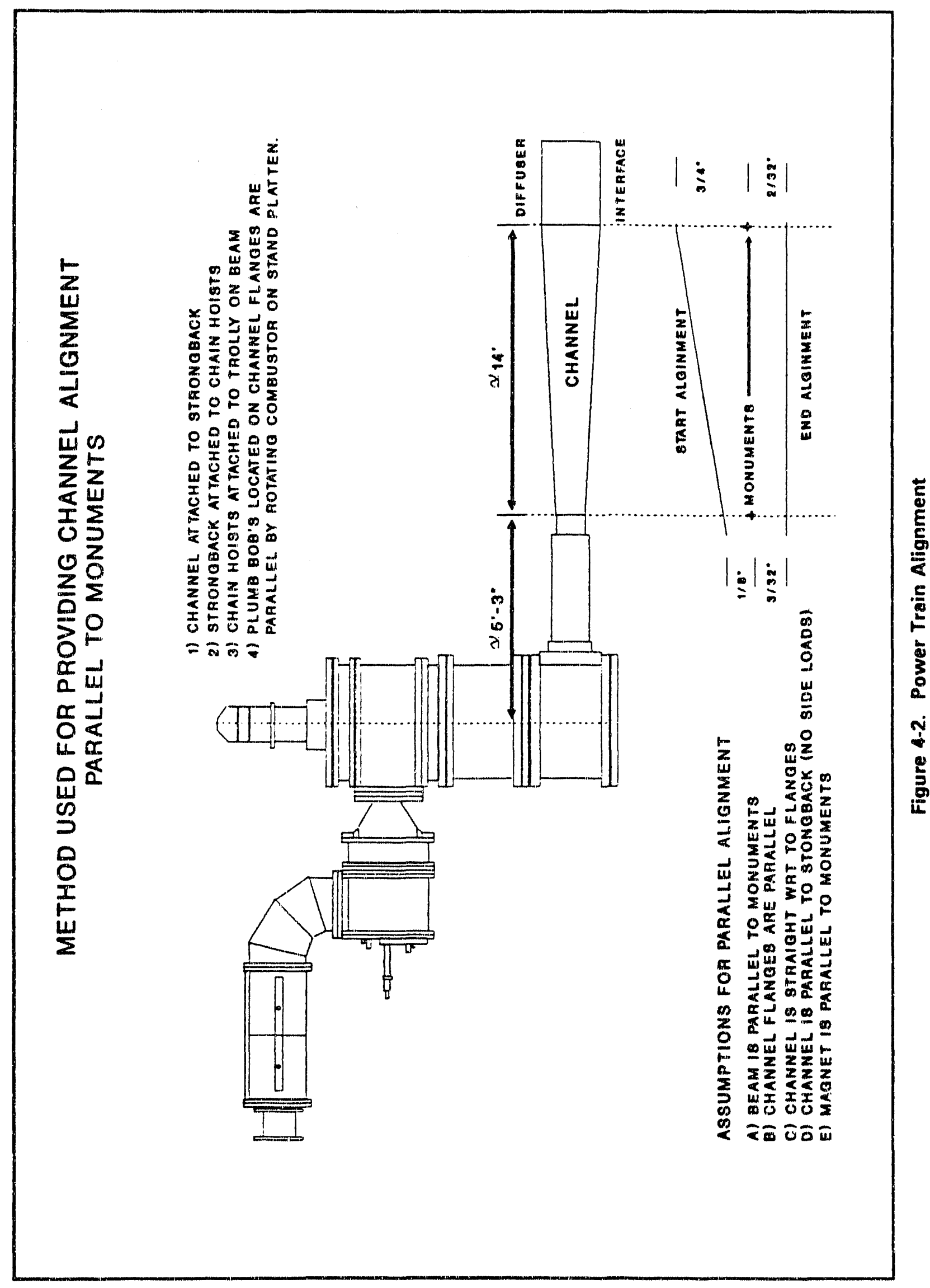




\subsubsection{Manufacturing Development Activities}

A manufacturing sequence lur the prototypical baffle was developed in response to a CDR action item. The key element is the use of a rigid fixture to which the baffle plate is attached during machining, welding, and heat treatment. The fixture, as shown in Figure 4-3, will control the flatness of the plate during manufacturing.

Two manufacturing options are being considered for the precombustor Inconel cladded gas-side surfaces. The first option, explosively bonded cladding, has been demonstrated and can be used if necessary. The second option is to use an Inconel 625 weld overlay. Samples of this commercial process are being prepared to determine if it will meet hardware requirements. These evaluations will be completed in December. Preliminary tests have also been performed on a chromium carbide coating, Sermatech GGCC-100. In these tests, this coating showed good adhesion strength. This material can be further tested if necessary.

Another area of manufacturing development is the brazed liners of the second stage copper frames. Braze alloys and braze cycle parameters are being optimized to reduce voids and porosity formation. This work will be completed in November.

Development of the technique for filling the gap between the cooling panels and the pressure shell with RTV is also in pmgress. A full-scale plexiglas model of the shell installation was constructed. The model simulates a region of three panels in the shell, covering a total area of $18 \times 36$ inches. The three panels, shown in Figure 4-4, are $18 \times 12$ inches (same as prototypical) and have tabs to set the proper installation gap. Initial tests have been performed. The gap has been successfully filled with RTV by pulling a vacuum in the instailation gap while pouring the RTV. Final tests and a written procedure will be completed in December.

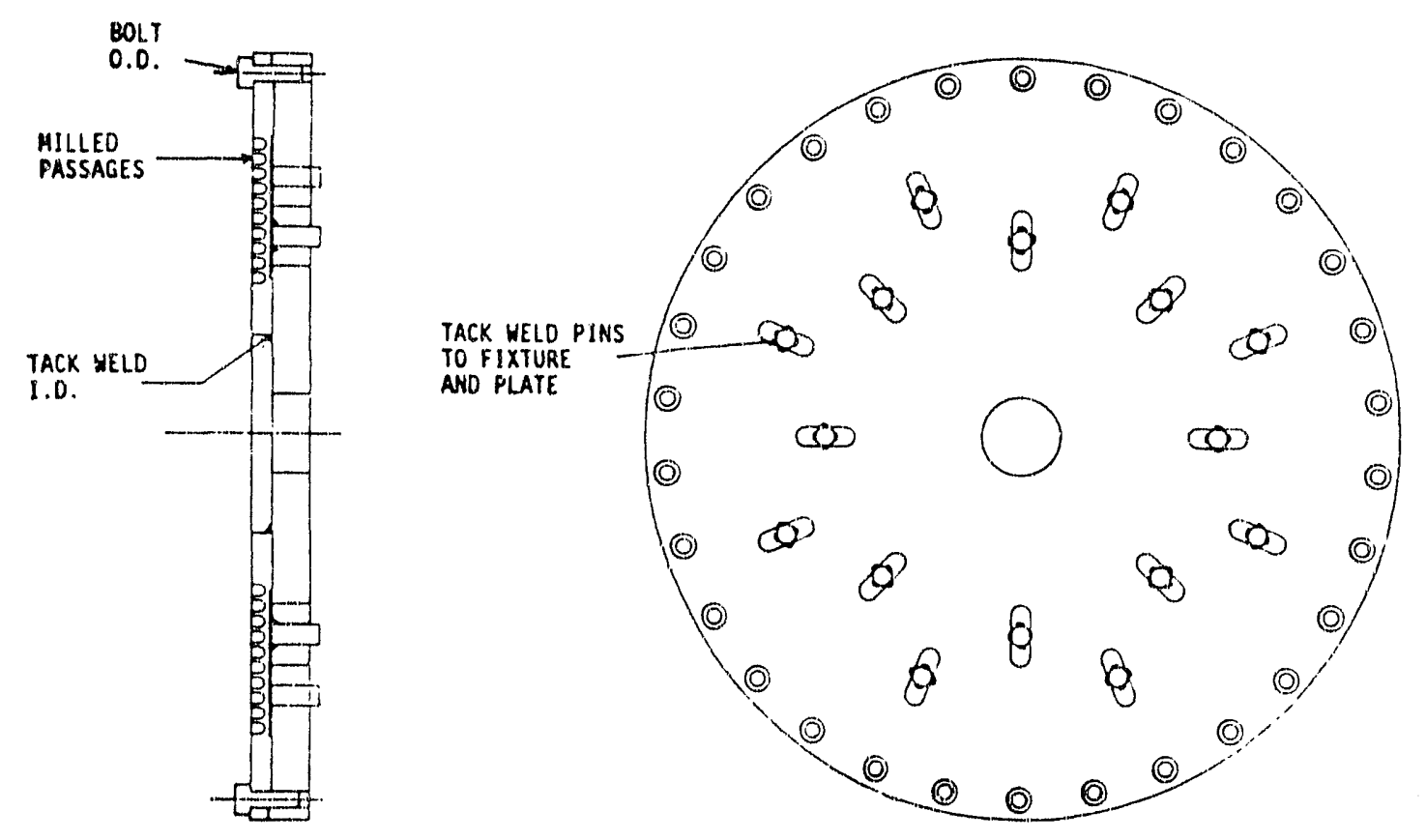

Figure 4-3. Baffe Fabrication Fixture 


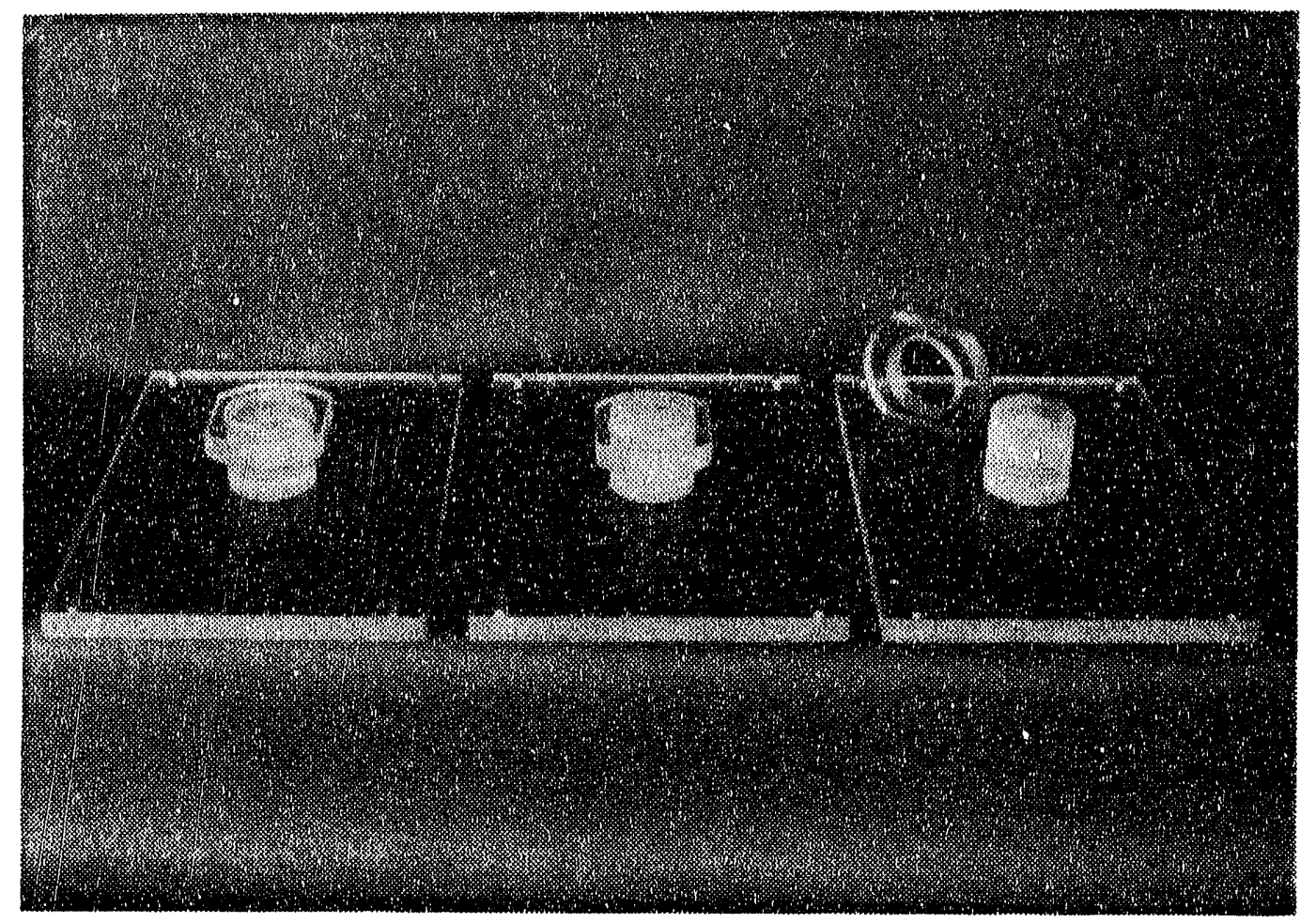

Figure 4-4. RTV Fixture Plexiglas Panels

\subsubsection{Manufacturing Planning}

Drawing releases for the Precombustor and Slagging Stage are scheduled for November. Pre-relcase detail drawings have been submitted to candidate vendors for review, comment, and budgetary estirnates. Procedures for welding and in-process testing are being finalized. Candidate vendors will be performing weld evaluation coupons to qualify for prototypical hardware. The formal RFQ for the prototypical components will be submitted in November with released procedures and drawings.

The manufacturing schedule for the Prototypical Combustion Subsystem hardware is presented in Figure 4-5. Procurement for the long lead raw stock for the second stage has been completed. Long lead material iterns for the slagging stage have been ordered (two necessary forgings were identified). Sources for the shell and panel materials have been identified.

\subsection{HIGH PRESSURE COOLING SUBSYSTEM DESIGN (SUBTASK 2.1.3)}

During this reporting period, the following tasks were performed as a part of the High Pressure Cooling Subsystem (HPCS) design effort:

- A Request for Proposals (RFP) was released to eight prospective vendors. Of the eight, three vendors indicated that they would bid on the HPCS.

- At the end of this reporting period, one vendor (Bethlehem Corp.) had submitted a proposal. The two other vendors (Foster Wheeler and Dyna-Therm Corp.) had requested proposal due date extensions to mid-November.

- Primarily due to budgetary concerns, a working group was established to assess the impact of using the existing CDIF PCW cooling system to cool the prototypical combustion subsystem hardware. 


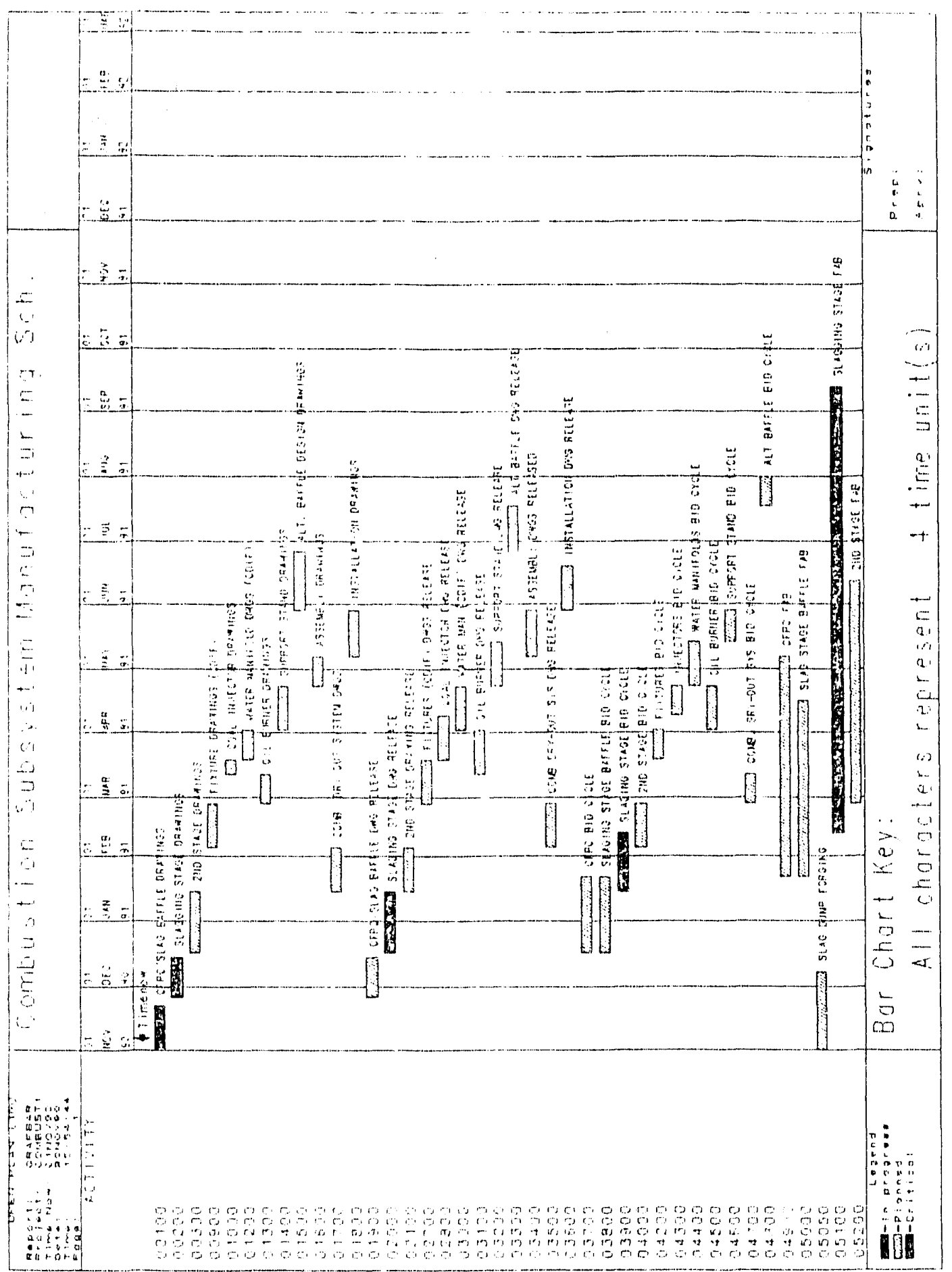




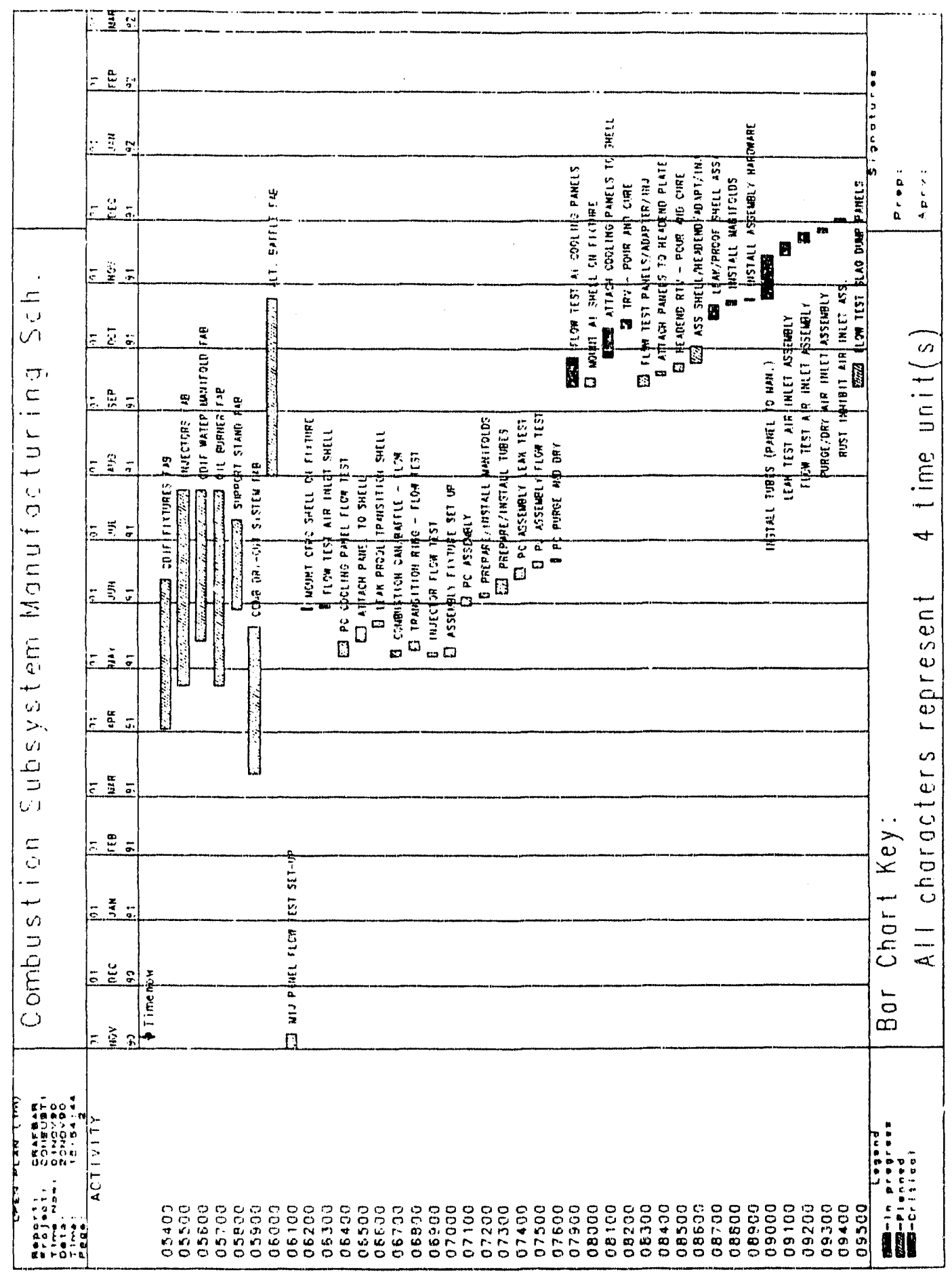




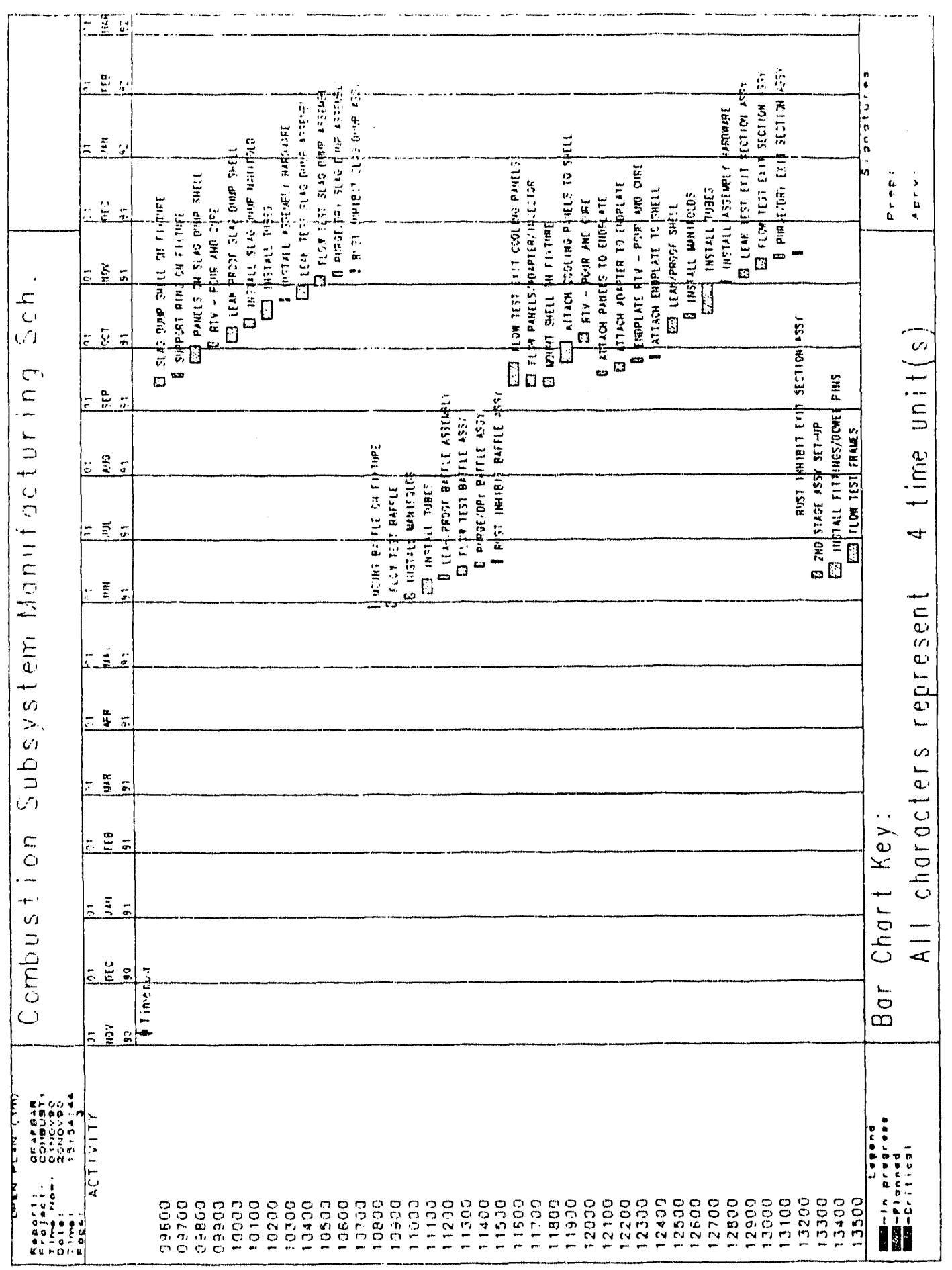




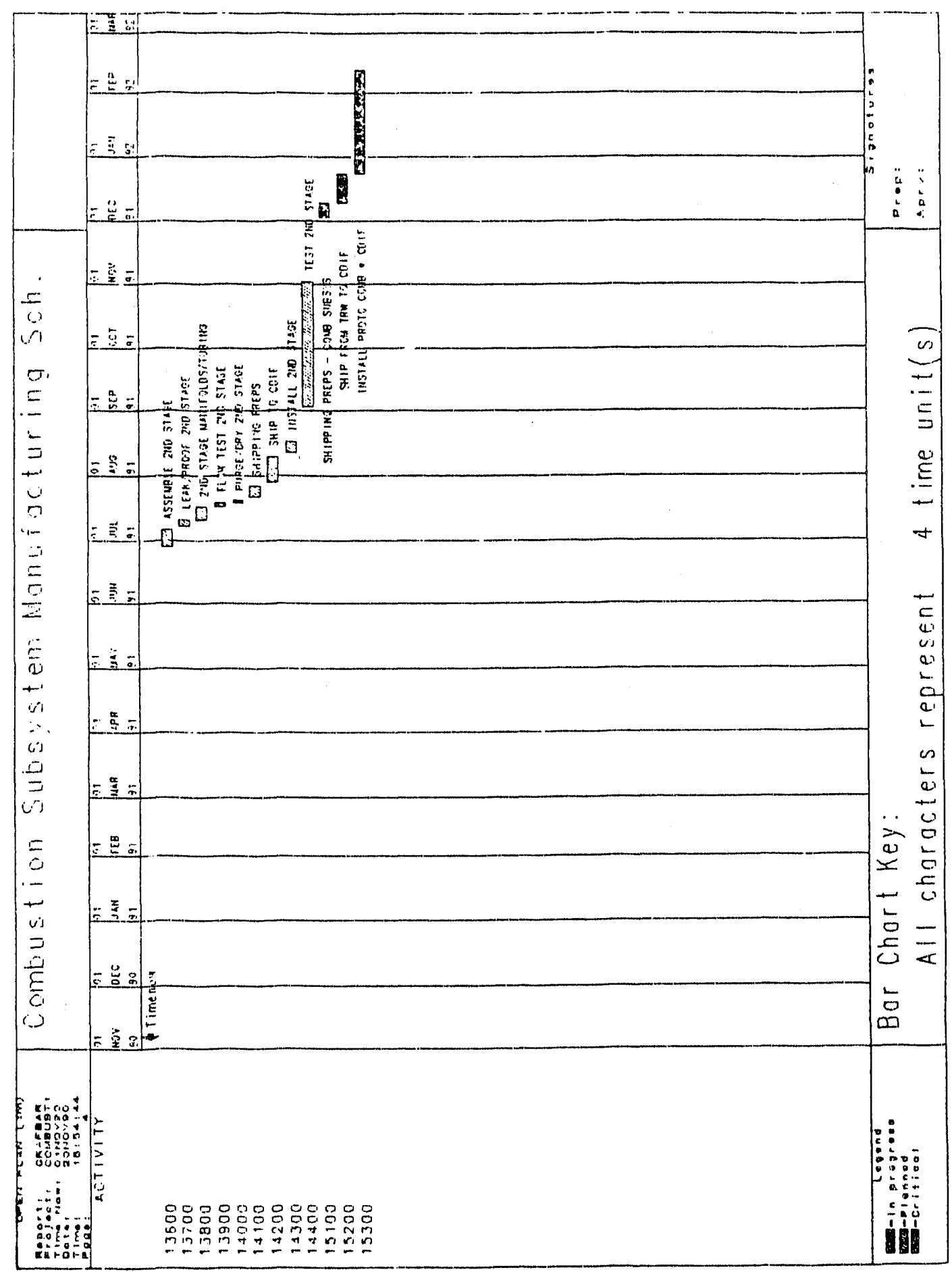


- Electrical isolator testing was continued. Tests were successfully conducted to $400^{\circ} \mathrm{F}$ with the "PEEK" candidate insulating material.

\subsubsection{HPCS Procurement}

At the CDR in September 1990, the DOE requested that TRW assess the impact of dropping the HPCS and cooling the prototypical combustion subsystem with the existing cooling water systems at the CDIF. As a result of this request, TRW established a working group with representatives from the CDIF and TRW, and participation from Avco, ANL and a water treatment industry representative. The goal of the group is to determine what modifications (if any) to the PCW system would be required, and to provide cost and schedule estimates for the modifications. In addition, the group will also consider the option of using a low pressure, stand-alone cooling skid to cool the Combustion Subsystem, rather than making changes to the existing PCW system.

One of the primary concerns of the working group is compatibility of water chemistry. The Combustion Subsystern will probably require control of both $\mathrm{pH}$ and dissolved oxygen to prevent corrosion of the low alloy steel cooling panels. Since the existing CDIF PCW system does not utilize water chemistry control, it may require some modifications to cool the POC hardware. In addition, it has yet to be determined if the Combustion Subsystem, Channel Subsystem, magnet, and other systems supplied by the PCW can all utilize a common water treatment approach. It may be necessary to consider modifying the existing PCW system to provide two separate closed loop systems, each with different water chemistry apr:oaches. Obviously, this type of modification will be very costly, with the expense perhaps pproaching that of the HPCS itself.

The working group is currently making progress in addressing these and other issues, and will prepare a draft report by 15 December 1990, with a final report delivered to the DOE by 21 December 1990 .

\subsubsection{Electrical Isolator Testing}

Tests on the high temperature, high pressure electrical isolator were continued during this reporting period. As previously reported, one of the primary goals of these tests is to identify an insulating material which maintains both mechanical and electrical integrity in the high temperature water environment. For reference, the prototype isolator design and the test isolator are shown in Figures 4-6 and 4-7, respectively. The isolator testing is scheduled for completion in mid-November, and a complete report on the test results will be presented in the next quarterly report. The test results to date are briefly summarized in the following paragraphs.

The first insulating material tested was the polyimide Vespel (produced by DuPont). The isolator mechanical integrity was verified by a hydrostatic proof test to 1800 psi with no leaks. At room temperature, up to $3000 \mathrm{~V}$ was applied to the isolator, with measured leakage current close to the theoretical predictions. Since the test isolator is one-third the length of the actual isolator, this test is equivalent to 9000 $\mathrm{V}$ on the actual isolator. The isolator was then tested to $250^{\circ} \mathrm{F}$ and $600 \mathrm{psi}$. No leaks were noted, however, the overall resistivity of the water was found to rapidly degrade with temperature. The isolator was then heated to $450^{\circ} \mathrm{F}$ and slowly pressurized to $1000 \mathrm{psi}$, at which point a leak was noted. Subsequent disassembly and inspection revealed cracks on the high stress I.D. region of the Vespel insulating plates. The suspected cause of the cracks is hydrolysis, and subsequent discussions with DuPont representatives supported this theory.

The second candidate material to be tested was a PEEK thermoplastic material, Vitrex 450GL20. The results with this material have been much more encouraging. At the end of this reporting period, a set of tests has been successfully completed at temperatures up to $400^{\circ} \mathrm{F}$ and $1000 \mathrm{psig}$. A total of 9 hours of operation at $400^{\circ} \mathrm{F}$ have been accumulated. Disassembly and inspection of the PEEK plates have not revealed any detrimental effects to the material. The water resistivity is still observed to decrease rapidly with temperature. Indications are that the effect is not driven by PEEK impurities introduced in the closed system, but is due to disassociation of the water itself $\left(\mathrm{H}_{2} \mathrm{O} \rightarrow>\mathrm{H}^{+}+\mathrm{OH}^{\prime \prime}\right)$. 


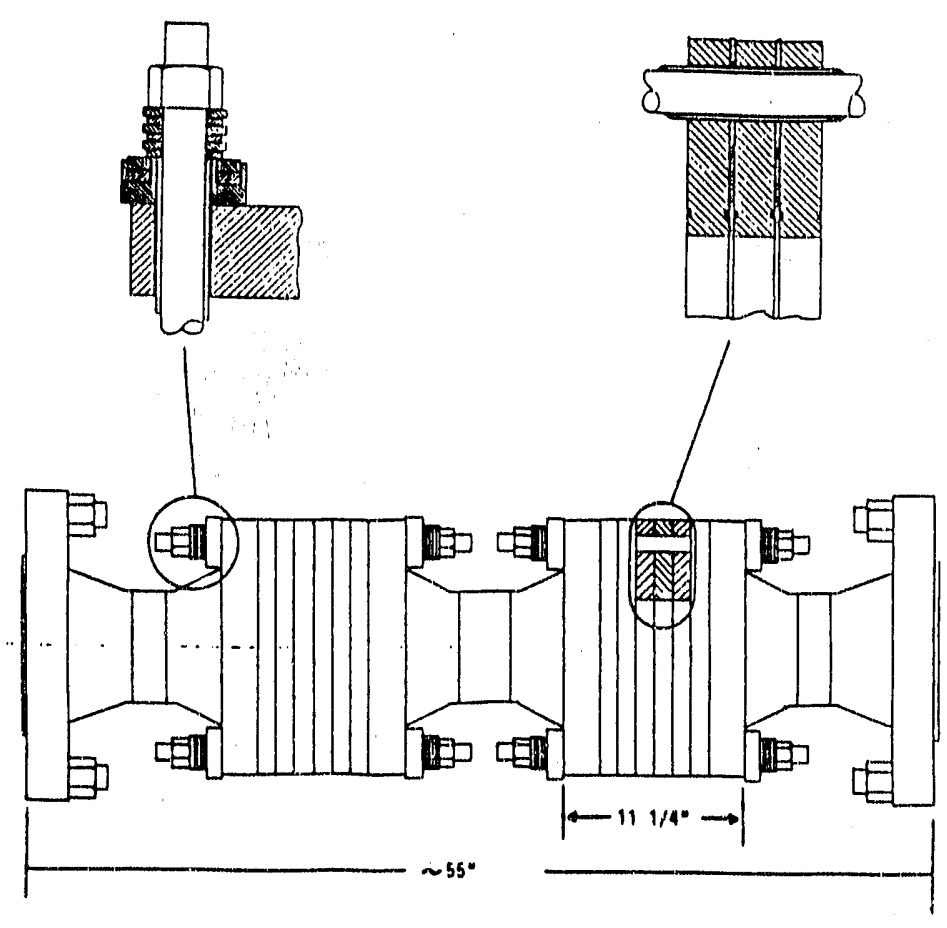

Figure 4-6. HPCS Electrical Isolator

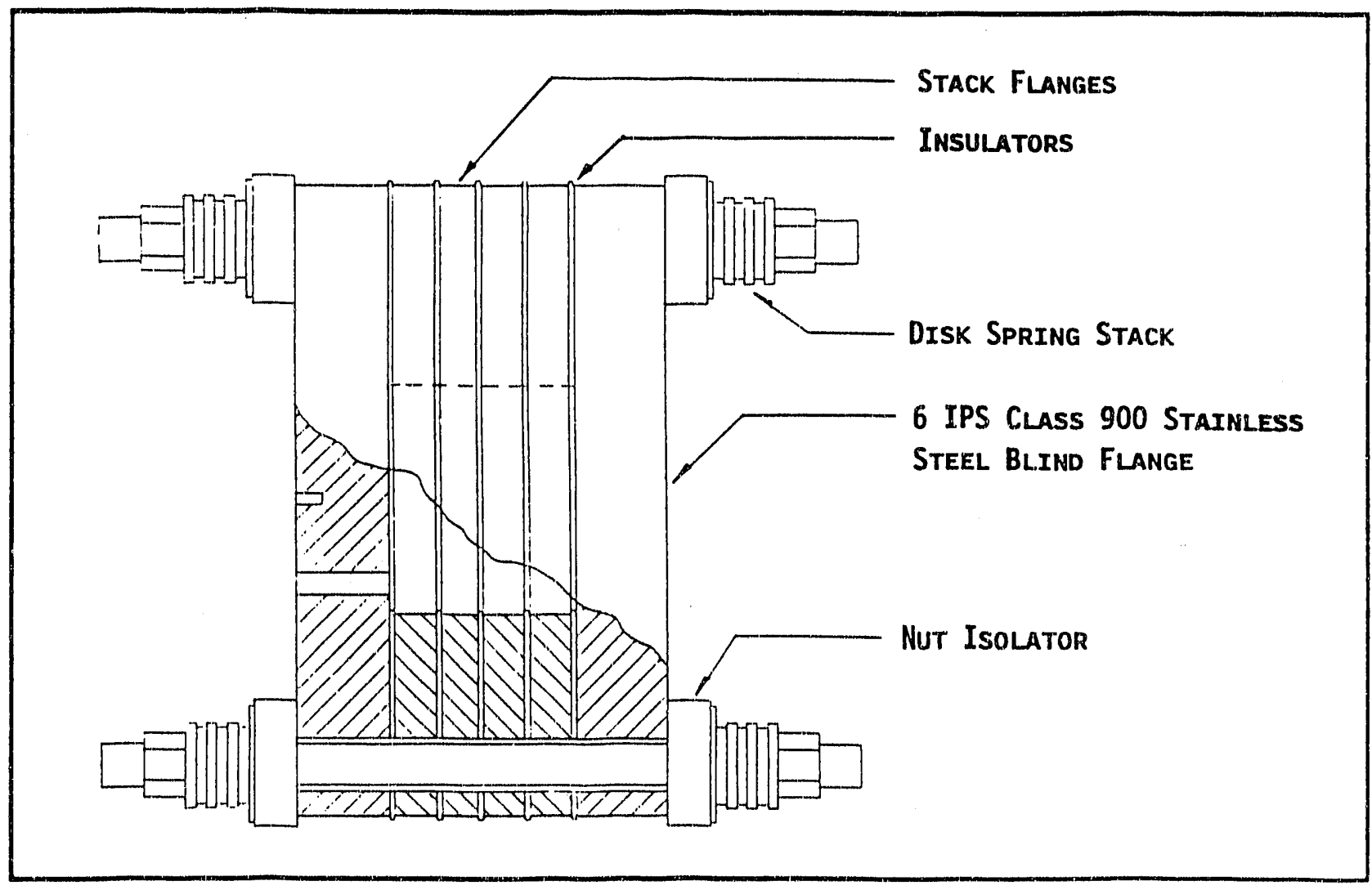

Figure 4-7. Test Electrical lsolator 
During the next reporting period, a set of tests will be conducted to accumulate 50 hours of operation at $400^{\circ} \mathrm{F}$ and 1000 psig on the test isolator, followed by limited testing at $450^{\circ} \mathrm{F}$ and 1000 psig. These tests should validate the PEEK as a material for the prototypical isolator. In addition, a literature search will be made to further investigate the effect of temperature on water resistivity.

\subsection{PROTOTYPICAL PANEL CONFIRMATION TESTING (SUBTASK 2.1.3)}

The panel confirmation test was performed in the University of Tennessee Space Institute's Coal Fired Flow Facility (CFFF). The test was accomplished with the TRW prototypical spool section installed in the CFFF upstream annular combustor section. The long duration, Proof-of-Concept (POC) tests being conducted at the CFFF facility provided an excellent opportunity to test thie prototypical panels and shell penetrations in the spool section under coal-fired conditions.

The spool section tested at CFFF consisted of 19 panels mounted to the inside of a stainless steel pressure shell as shown in Figure 4-8. Seventeen of these panels are steel or stainless steel test pariels which were used in previous testing at Avco. These panels are mounted to the pressure shell with four hanger screws, and the cooling water tubes penetrate the shell through Swagelok fittings. The two prototypical-type panels are 0.9 inches thick, 12 inches long, and approximately 10 inches wide, as shown in Figure 4-9. They are fabricated from low-alloy steel ASTM A-387, Grade 11. These two panels are curved to match the combustor diameter and replace seven original test panels in a reworked region of the spool shell. Each prototypical panel has one shell penetration; one panel has a welded penetration, the other has a bolted penetration. These two configurations are shown installed in the shell in Figure 4-10.

The filler material in the panel to shell gap is pourable silicone rubber (RTV31), except that a 1/16-inch layer of silicone rubber sponge sheet was attached inside the shell before pouring. This material is not necessary if room temperature cooling water is used for the spool piece, but if $450^{\circ} \mathrm{F}$ cooling water were used, the foam is necessary to relieve the stresses due to the expansion of the silicone rubber. Although testing high temperature water was not possible during this test, it is necessary to check out the behavior of the foam for long duration.

The CFFF upstream combustor operates on coal and oil, which is burned with oxygen-enriched air to produce typical MHD plasma temperatures of $4900^{\circ} \mathrm{F}$. The facility operates with $100 \%$ slag carry over, and the potassium seed $\left(\mathrm{K}_{2} \mathrm{CO}_{3}\right)$ is mixed with the coal prior to injection. The combustion gases are ducted to extensive seed capture and scrubbing equipment in the downstream section, which is the primary focus of the CFFF facility.

The nominal upstream operating conditions for the LMF4-U test were: $19 \mathrm{MW}_{\mathrm{t}}\left(11 \mathrm{MW}_{\mathrm{l}}\right.$ Illinois No. 6 coal and $8 \mathrm{MW}_{\mathrm{t}}$ oil), $\mathrm{Phi}=0.85, \mathrm{~N} / \mathrm{O}=1.00$ (by weight), and a $\mathrm{K}_{2} / \mathrm{S}$ ratio of 1.1 . The conditions at CFFF are compared to nominal CDIF operating conditions in Table 4-1.

Confirmation of the prototypical panel design was ultimately determined by the survivability of the prototypical-type panels in a representative combustion environment, but a further objective was to observe several other factors. Erosion and corrosion rates of panel surfaces, evidence of plastic deformation, and panel slag retention characteristics were observed. The performance of the panel gap filler materials was also observed for prevention of slag migration behind panels.

\subsubsection{Test Preparations}

The spool section was installed in the CFFF upstream annular combustor section as shown in Figure 4-11. Since the annular section had an inside diameter of 21.25 inches, the spool inside diameter of 23.16 inches had to be adapted with two transition rings. 


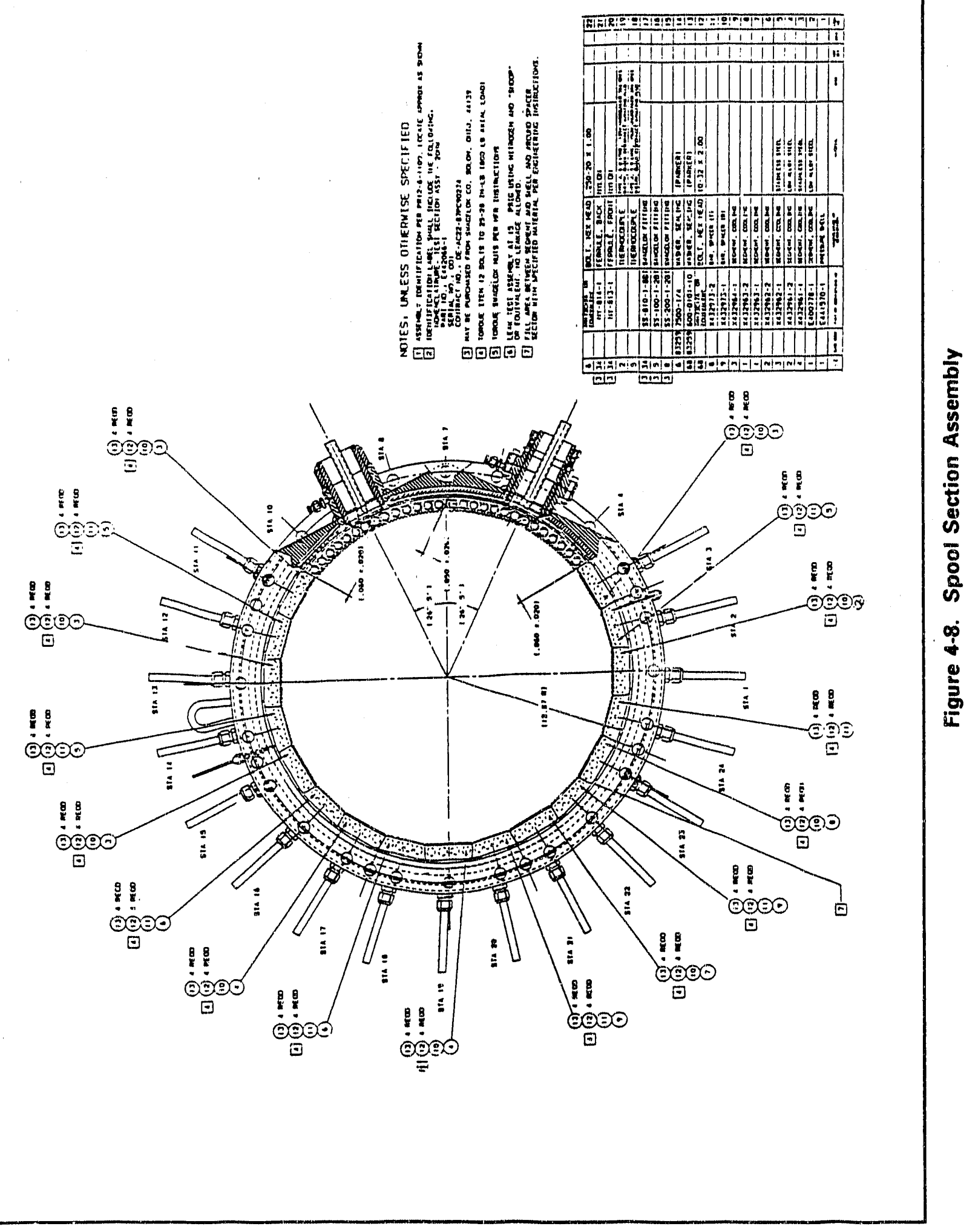



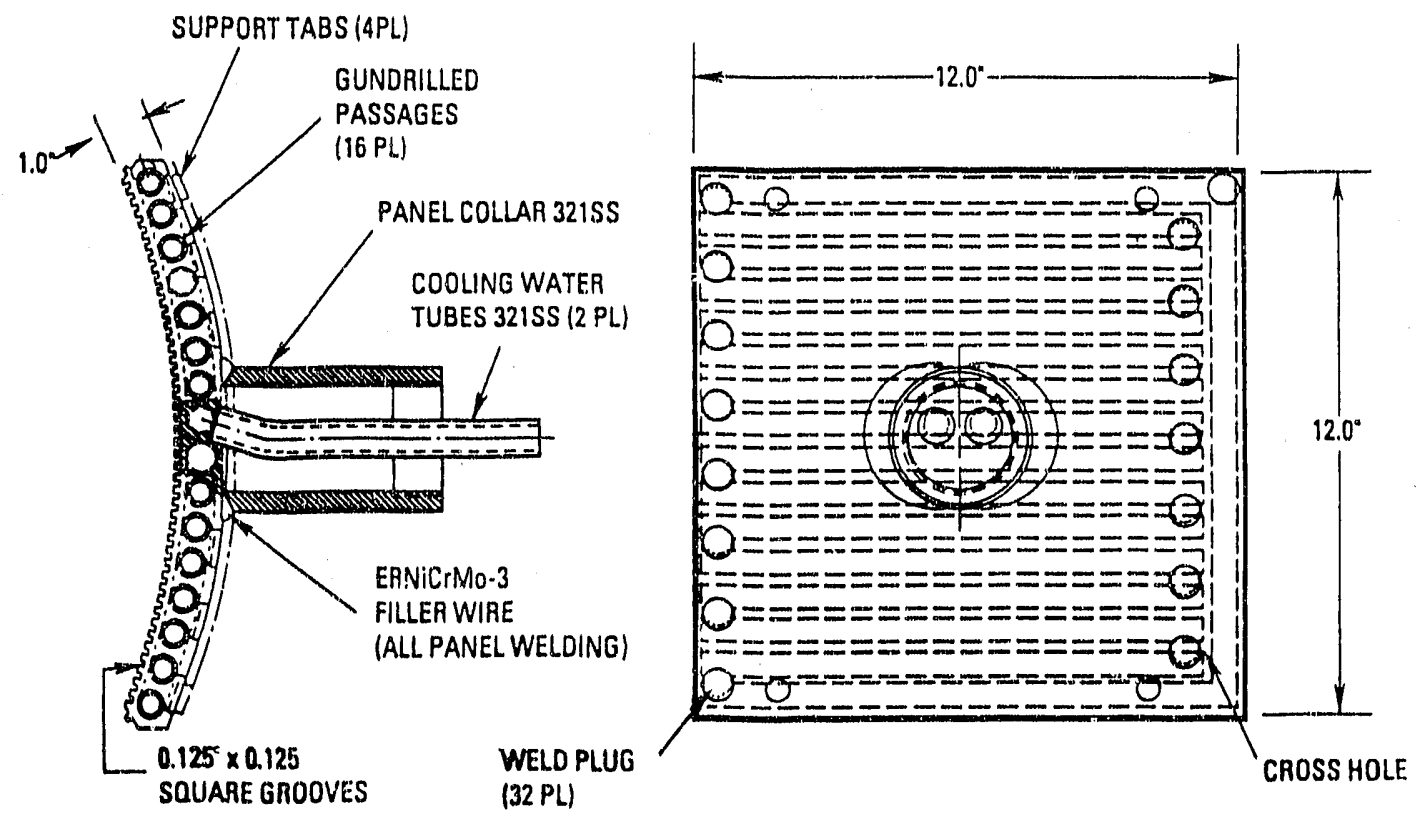

Figure 4-9. Prototypical Spool Section Panel

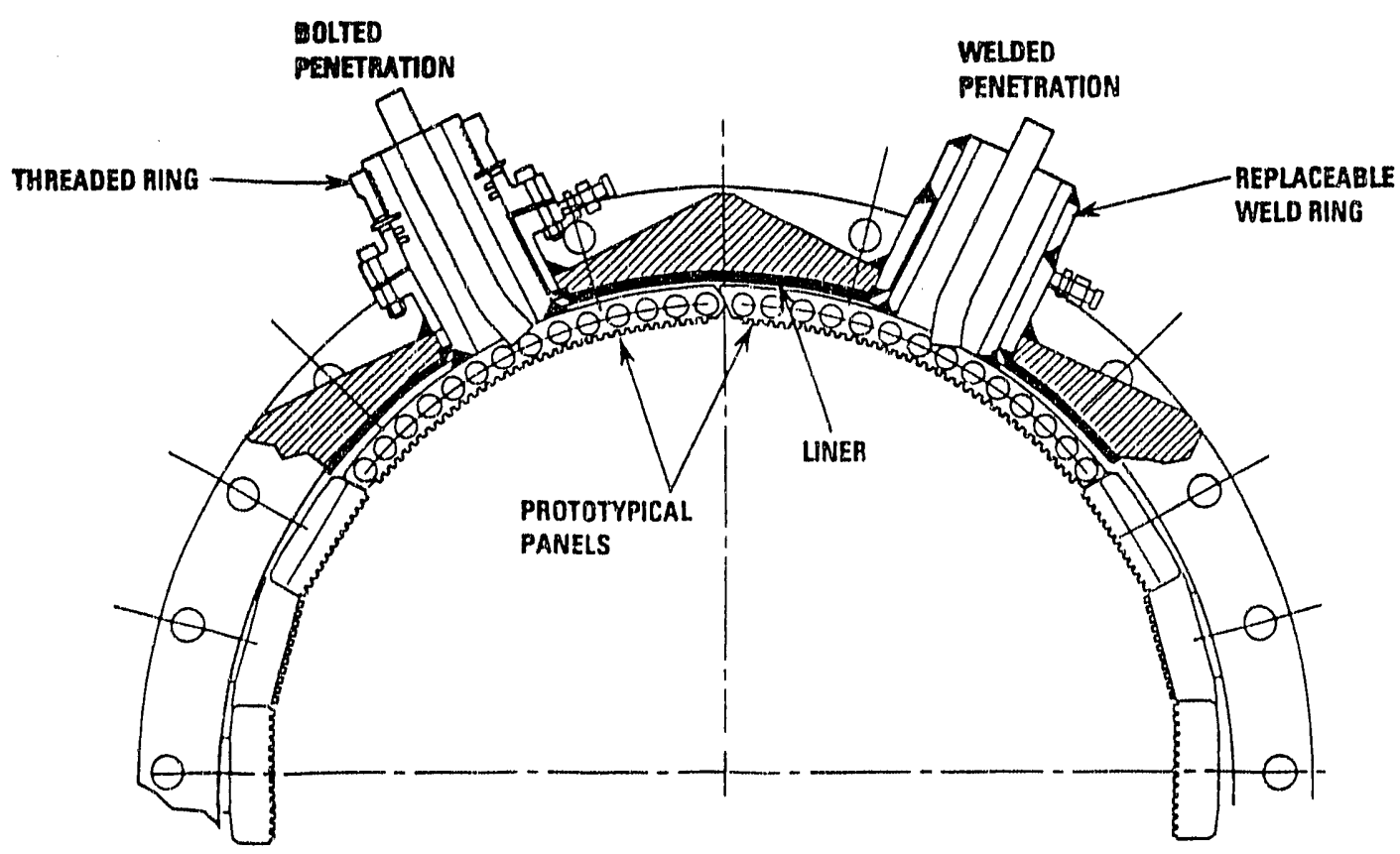

Figure 4-10. Installation of Prototypical Panels into Spool Section 


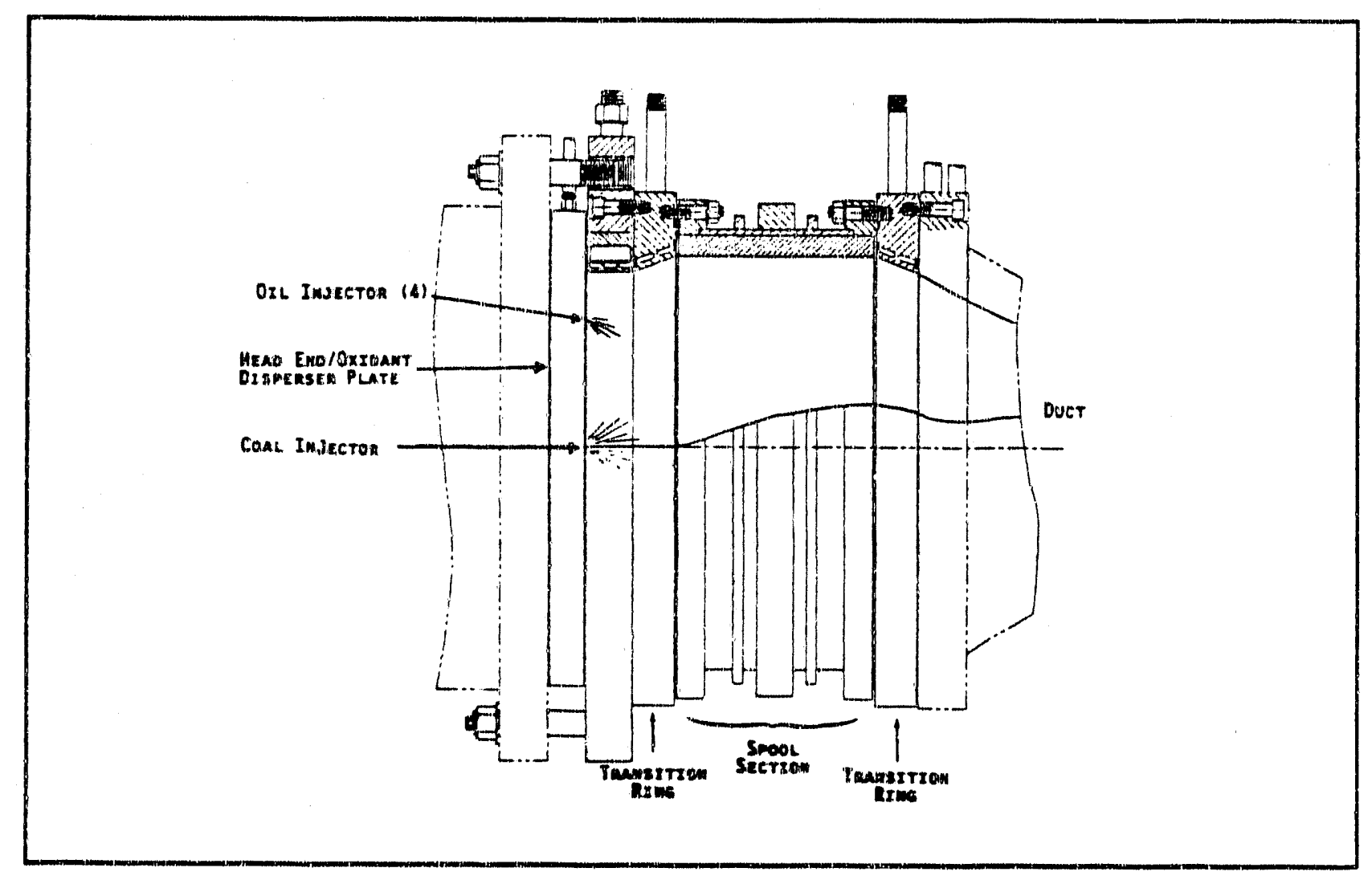

Figure 4-11. Spool Installation into CFFF Combustor Module

TABLE 4-1. COMPARISON OF CFFF CONDITIONS TO CDIF CONDITIONS

\begin{tabular}{|c|c|}
\hline CFFF Conditions & CDIF Conditions \\
\hline $20 \mathrm{MW}_{\mathrm{t}}$ Thermal Inpui & $50 \mathrm{MW}$ thermal Input \\
\hline Eastern Coal & Western Coal \\
\hline $3 \%$ Sulfur, $4 \% \mathrm{H}_{2} \mathrm{O}$ & $1 \%$ Silfur, $5 \% \mathrm{H}_{2} \mathrm{O}$ \\
\hline Phi $\pi=0.85$ & Phi $1=0.55$ \\
\hline $\mathrm{N} / \mathrm{O}$ Molar $=1.20$ & N/O Molar $=1.15$ \\
\hline $\begin{array}{l}T_{\text {gas }}=4800^{\circ} \mathrm{F} \\
\text { (in annular combustor) }\end{array}$ & $\begin{array}{l}\text { Tgas } 4000^{\circ} \mathrm{F} \\
\text { (air inlet region) }\end{array}$ \\
\hline Plug Velocity $=50 \mathrm{n} / \mathrm{sec}$ & Plug Velocity $=50 \mathrm{ft} / \mathrm{sec}$ \\
\hline Tangential Velocity Negligible & Tangential Velocity $=300 \mathrm{ft} / \mathrm{sec}$ \\
\hline Pressure $=65$ psia & Pressulte $=85$ psia \\
\hline
\end{tabular}

Water chemistry controls were installed in the cooling wower to control calcium levels and the pH of the facility water. The protorypical panels would nu with higher water-side metal temperatures than typical CFF hardware, and scaling could present a problem over a long duration test. The water pH level was controlled between 7.3 and 7.7 , and conductivity was held below $400 \mu \mathrm{mho} / \mathrm{cm}$.

Existing instrumentation on the CFFF manifolds was used, and instrumentation was added to meet spool requirements. The operational status of instrumertation and any applicable automatic calculations 
were checked out. The two prototypical panels were designated as panels 3 and 4 for the purpose of identification and data acquisition.

\subsubsection{LMF4-U Test Operations}

The LMF4-U test consisted of 262.7 hours of total operation (oil and coal-fired operation), 251.6 hours of coal-fired operation. A single sustained period of 80.5 hours of coal operation was achieved. Fourteen startups and shutdowns were recorded.

Figures 4-12 through 4-18 present a sampling of the experimental data from the LMF4-U test which summarize operation and performance of the TRW $20 \mathrm{MW}$ combustor spool section. Two periods of this test are reviewed. The first period illustrates the heat flux transients that the spool piece experienced during a typical startup. The second period is an 80-hour period of continuous coal-fired operation. Figure 4-12 shows the combustor operating point for a startup period of the LMF4-U test. The transient heat transfer response of the spool section to combustor startup can be seen as operation passes through a normal startup procedure, i.e., vitiation heater light off, an oil-fired combustion period which is held to complete preheat of the entire LMF test train, and finally ignition of the combustor with coal. The startup period encompasses about two hours of testing.

Figure 4-13 is a tirne history plot of the average heat flux of the spool during startup. Note that the global heat flux level responds to change in combustor operating conditions, but overall the average heat. flux during both oil and coal-fired operation is in the $50 \mathrm{~W} / \mathrm{cm}^{2}$ range.

Time history traces of the heat flux to the two prototypical panels during the startup period are shown in Figure 4-14. Distinct responses to the change in the combustor operating point are indicated by the spikes in the heat flux levels at initiation of heater light off, combustor oil firing and coal firing. Several inieresting characteristics can be seen in Figure 4-14. The first is the gerieral levels of the heat flux that these panels sustain during startup. Heat flux during the major portion of the startup period remained below the $80 \mathrm{~W} / \mathrm{crn}^{2}$ level. A $20 \mathrm{~W} / \mathrm{cm}^{2}$ increase in heat flux occurred between combustor oil-fired and coal-fired operation. The peak heat flux level that either of the prototypical panels experienced during the test was during this startup transient and was around $95 \mathrm{~W} / \mathrm{cm}^{2}$. This peak level was attained when operational changes to the vitiation heater air and oxygen were made in an attempt to reduce the heat flux reported on the vitiation heater bumer plate. The heat flux in the region of the prototypical panels was also affected by oil flow fluctuations on other occasions.

Figure 4-15 is a distribution plot which presents the statistical characteristics of the prototypical cooling panels heat flux during the startup period. The bar graphs were constructed by statistical evaluation of the heat flux data to determine the frequency with which specific heat flux ranges $\left(2.0 \mathrm{~W} / \mathrm{cm}^{2}\right.$ bands) were experienced during the total two-hour period. Two groupings or distinct distributions are evident for the oil-fired and coal-fired periods.

Throughout the LMF4-U test, there were several instances where heat flux changes occurned either gradually or abruptly. Even during an 80-hour continuous coal-fired period, heat flux fluctuations occurred. Figure 4-16 shows variations in total spool heat flux during this period. Although some anomalies in oil bumer flow were noted during this test, most fluctuations can be attributed to normal slag coverage perturtbations.

A second statistical distribution plot is given in Figure 4-17. This figure presents analysis of data for the entire 250 hours of LMF4-U. A broad heat flux distribution is apparent in these plots which indicates the range and duration of heat flux transients. The statistical mean for the two prototypical panels is still in the $70 \mathrm{~W} / \mathrm{cm}^{2}$ range. Since the existing heat flux levels in the $50 \mathrm{MW}$ combustor are on the order of 50 $W / \mathrm{cm}^{2}$, this was an extreme test for the prototypical panel design.

Figure 4-18 presents the experimental circumferential heat flux distribution as derived from LMF4-U data. This bar char gives the distribution of the heat flux for each cooling panel of the sponl piecc transformed onio a rectangular coortinate system, starting at the top $\left(0^{\circ}\right)$ and continuing around a complete 
TRANSIENT OPERATION - INITIAL STARTUP
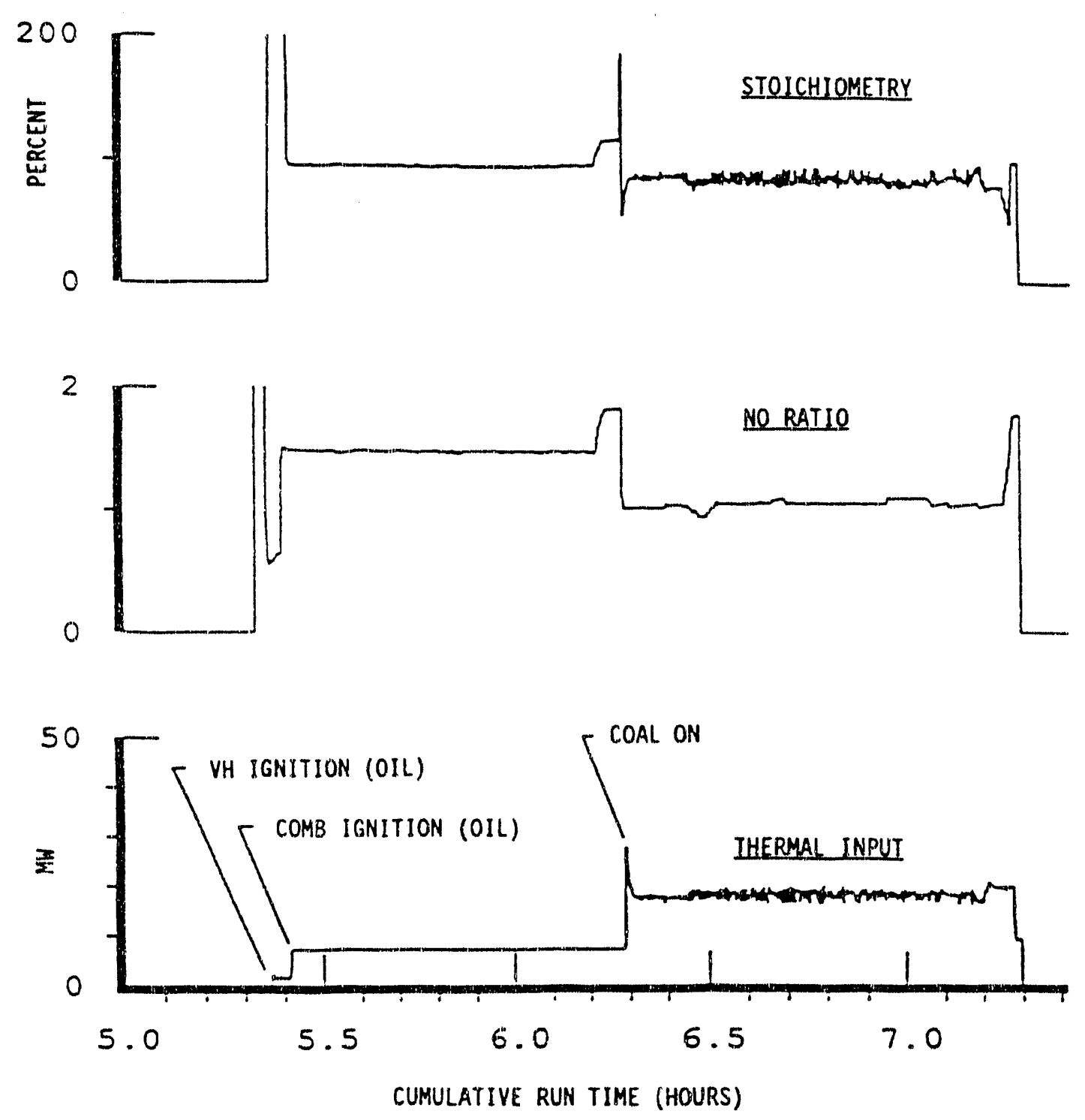

Figure 4-12. Combustor Operation During L.MF4-U Startup 


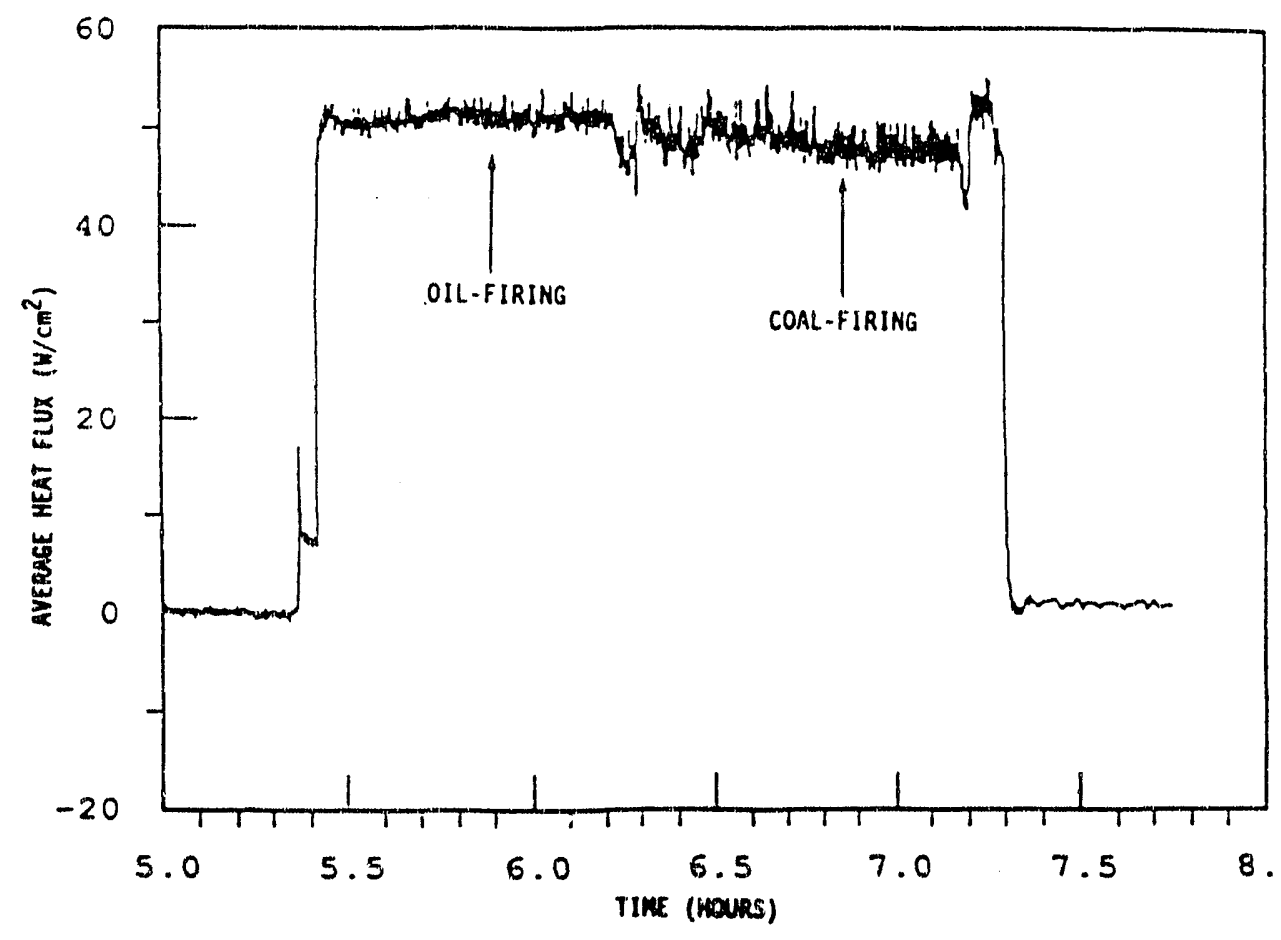

Figure 4-13. Spool Section Heat Flux During LMF4-U Startup

$360^{\circ}$ circuit. The level of each bar on this plot represents the mean value of heat flux while the plotted points indicate the maximum and minimum heat flux that was experienced during the 80-hour time period. The general trend of the circumferential distribution which is most striking is the extreme reduction in heat flux on the bottom of the combustion chamber. 'This characteristic is due to the thick pool of slag which forms in the bottom of the combustor due to gravity. For all practical purposes, the lower cooling panels were almost completely insulated from the flame by the slag pool. Aside from this obvious characteristic, the circumferential flux distribution is fairly uniform over the exposed portion of the internal perimeter. A slightly higher heat flux level is apparent in the region of the prototypical panels.

\subsubsection{Post Test Observations}

The spool section survived the test without incident. At the conclusion of 250 hours of testing, there were no signs of erosion or other damage on the prototypical panels. All panels in the spool had slag coverage, although the thickness of the slag layer varied considerably. On the prototypical panels, the layer was 1/16-inch thick, while the panels in the bottom of the combustor were covered by a 3-inch pool of slag. In Figure 4-19, the slag layer has been removed from a section of a prototypical panel; the grooves appear unaffected by testing. Post test installation gaps were consistent with pre-test measurements, indicating there had been no major panel shifts during the test.

Although combustor pressure had been detected behind the prototypical panels during the test, no slag or coal had migrated behind the panels. Gaps between panels and at the spool flanges also remained slagged. The RTV silicone rubber was not damaged. Gap measurements indicated the spool panels had not shifted or deformed during the test.

Further tests and analysis were performed on the prototypical panels. The panels were proof-tested to 1800 psi, and no leakage was found. A low-alloy steel test panel was sectioned to check for sulphur attack or early signs of fatigue cracking. Only a thin, stable oxide layer was found on the gas-side of the panel. 


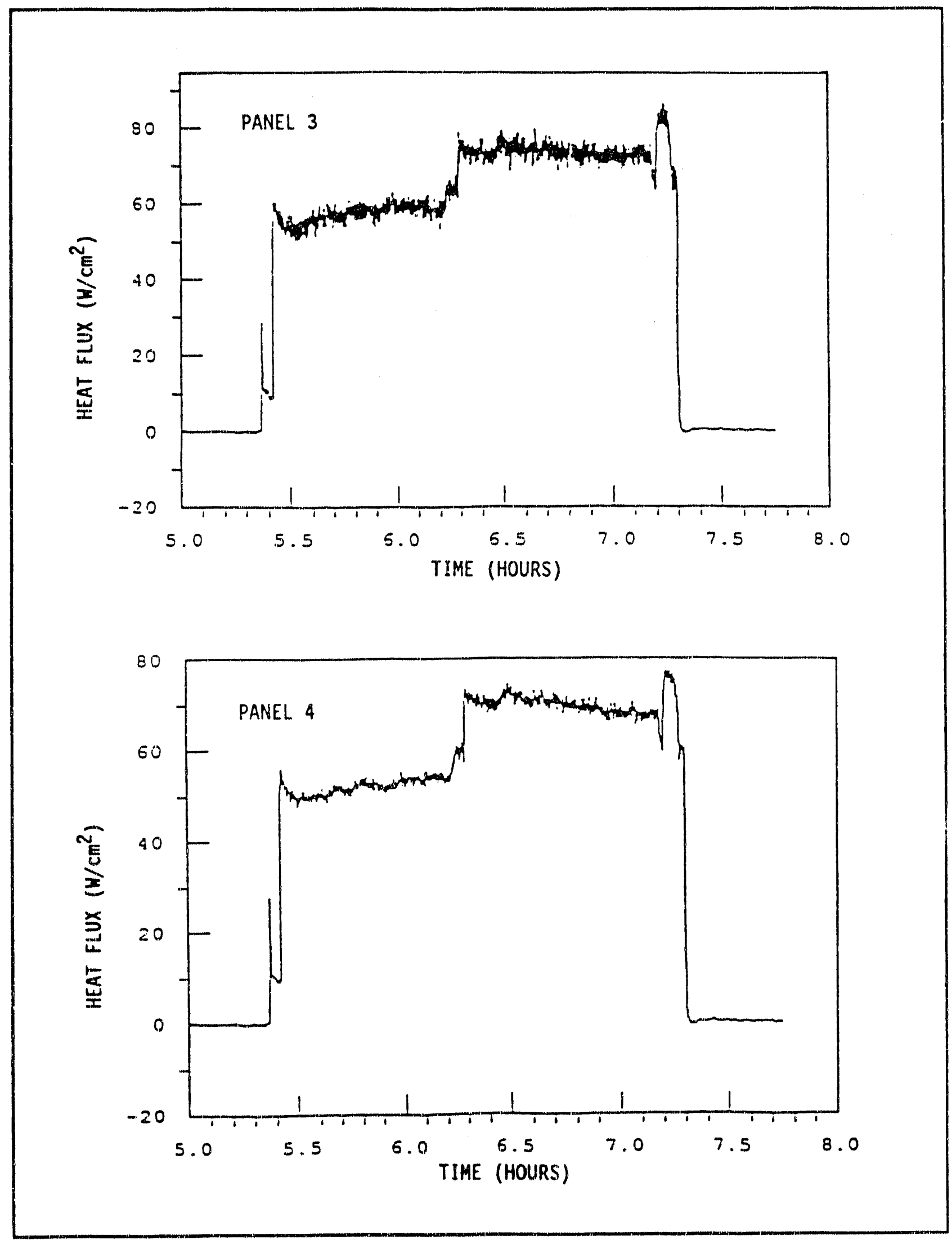

Figure 4-14. Prototypical Panot Heat Flux During L.MF4-U Startup 


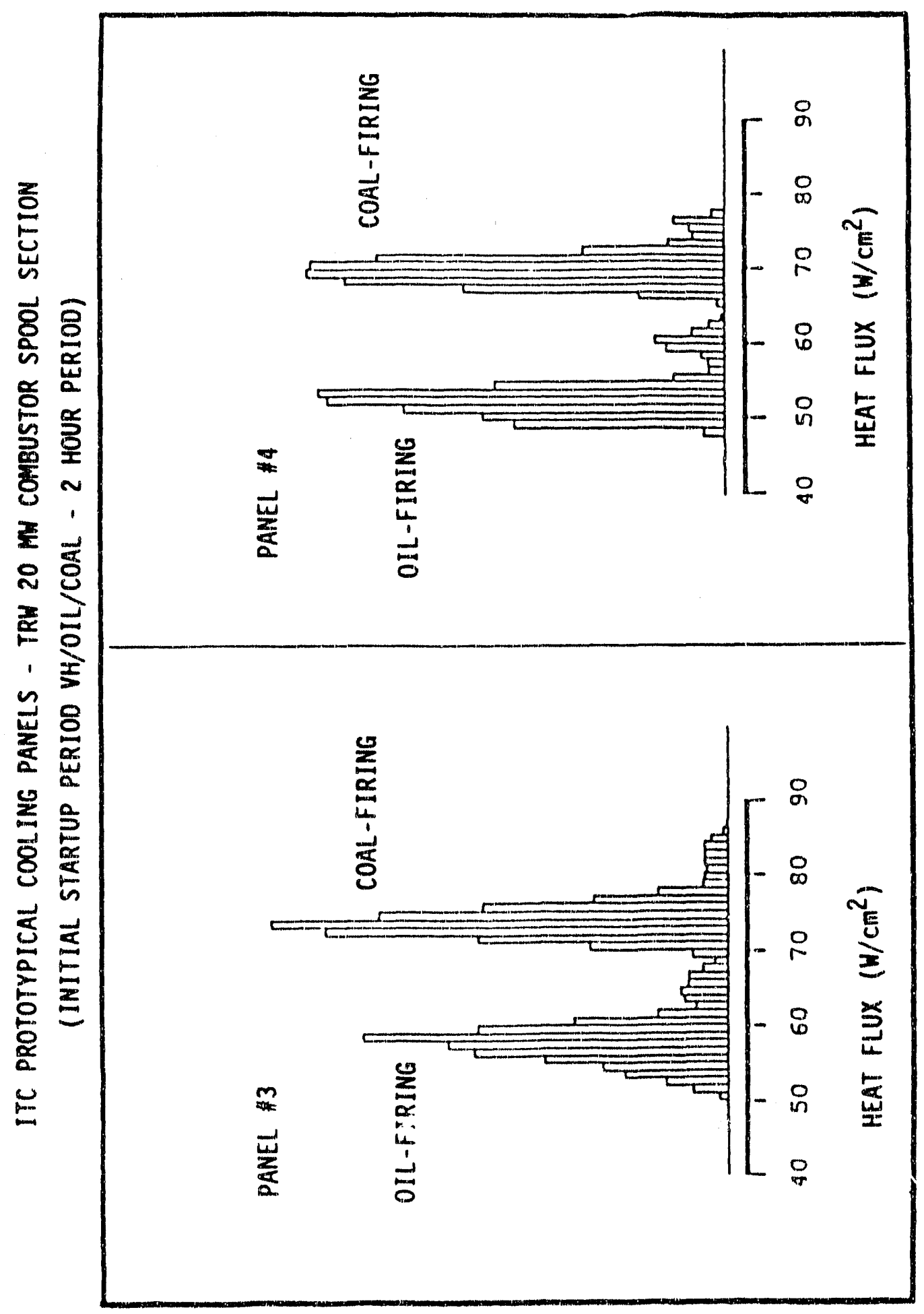

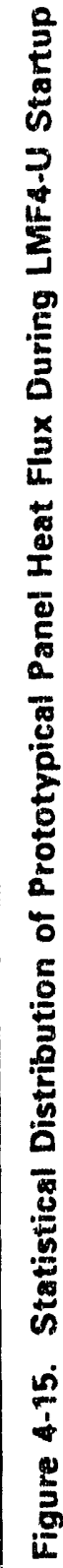




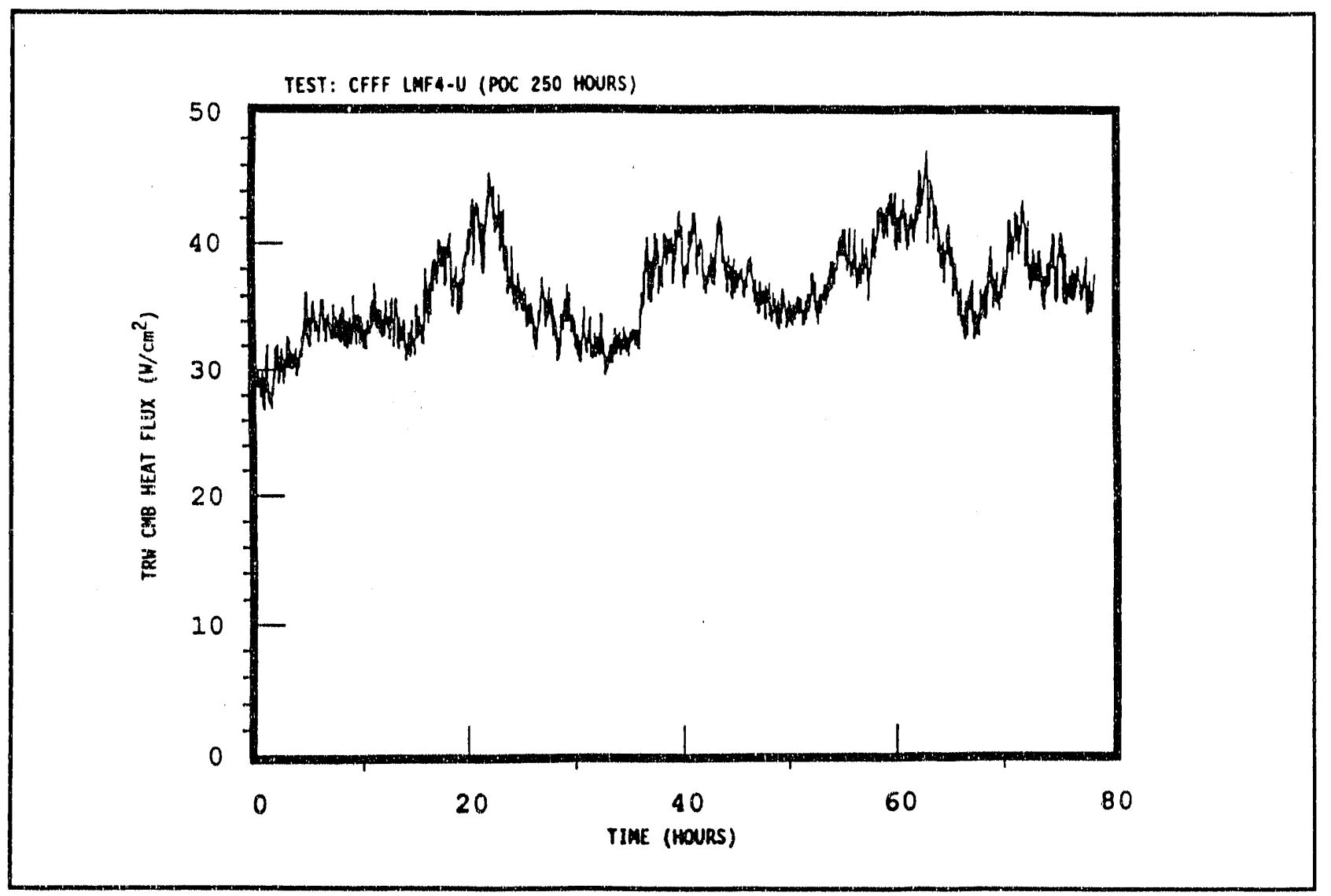

Figure 4-16. Spool Section Heat Flux During 80-Hour Period at CFFF

On the water-side, iron oxide deposits and some sulfur corrosion was found; this may have been due to the water chemistry controls used during the test. $\mathrm{H}_{2} \mathrm{SO}_{4}$ was used to control the water $\mathrm{pH}$, but other acids could be substituted.

Testing of the prototypical test panels at CFFF confirmed the operational reliability of the baseline prototypical cooling panel design and installation method. Although not all issues have been thomughly proven (i.e. high temperature cooling water compatibility), the issues of lifetime and scalability have been demonstrated with the prototypical panel design. 


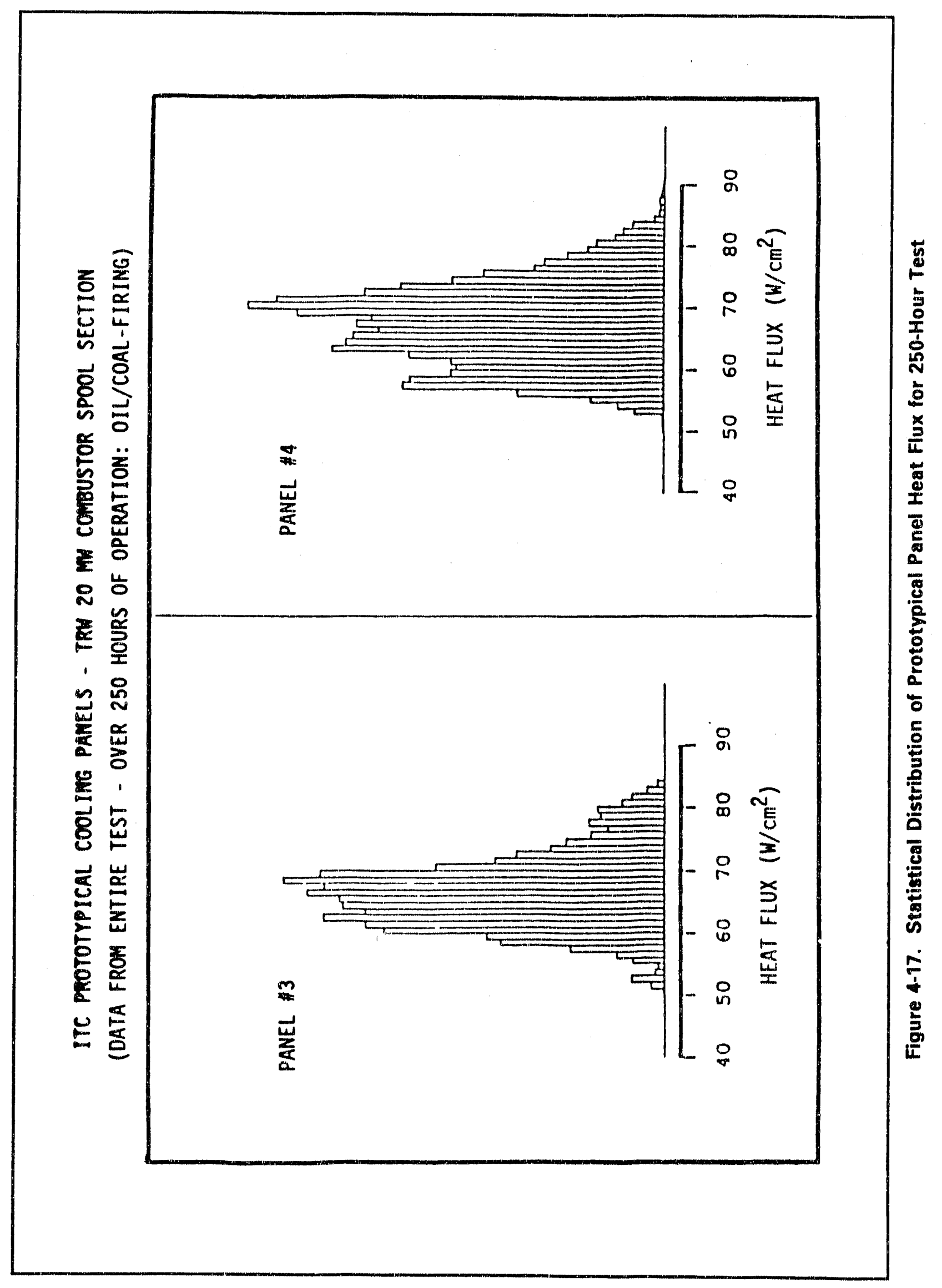




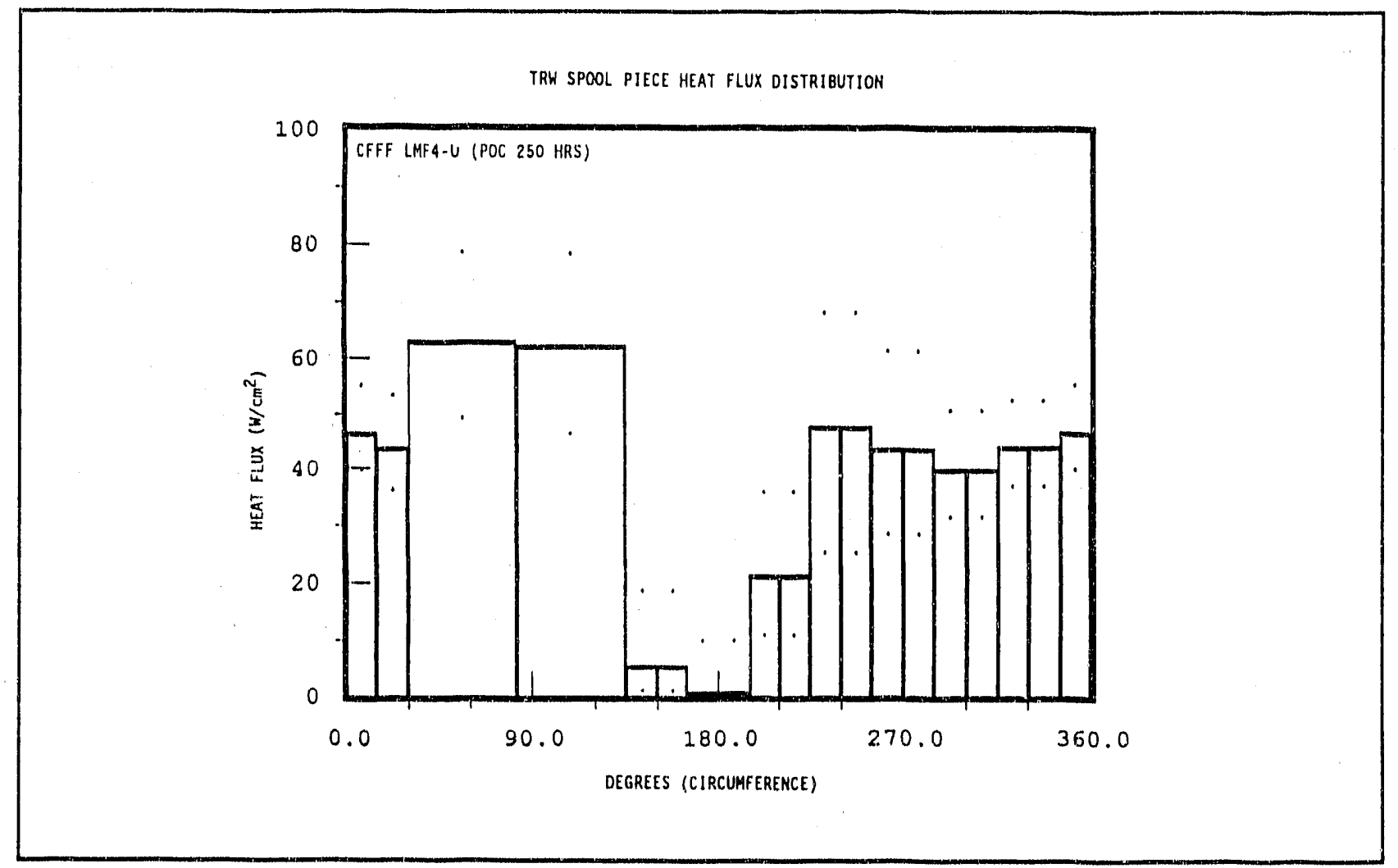

Figure 4-18. Panel Heat Flux Averages and Range During 80-Hour Period at CFFF

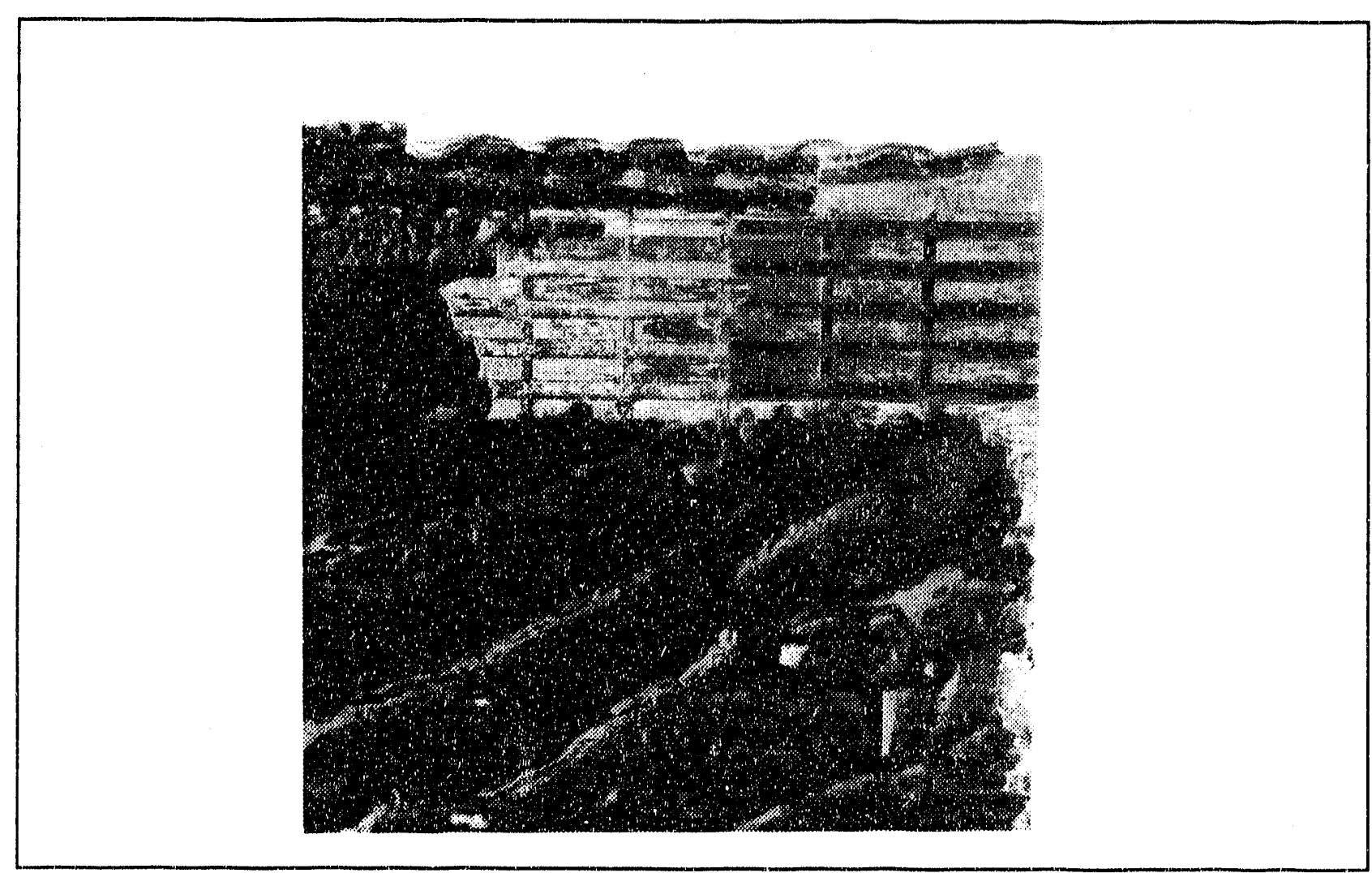

Figure 4-19. Prototypical Panel Grooves After 250-Hour Test 


\section{PROTOTYPICAL CHANNEL DESIGN (TASK 3)}

The Aven channel subsystem design activities during this quarter include prototypical channel design, slagging anode evaluation tests, water corrosion tests, and 1A4 hardware fabrication.

Increased corrosion on CDIF anodes compared to Mark VII at similar operating conditions may be due to the thicker boundary layers on the $1 \mathrm{~A} 1$ (CDIF) which can produce larger Faraday arcs. To reduce arc size, a slagging anode design is now proposed for the $1 \mathrm{~A} 4$ and two configurations are currently being tested in the Mark VII channel. The first test has been completed with good slagging performance and no serious platinum attack at prototypical current density.

Water corrosion tests were performed to establish the optimum water conditions for the POC test and to quantify, where possible, the corrosion rates expected for the water-side materials used. Variations in flow velocity, temperature, and $\mathrm{pH}$ were examined along with the use of a corrosion inhibitor.

The results of water corrosion tests determined that the use of an NRC-approved corrosion inhibitor such as CopperTrol or Tolytriazole which is compatible with existing materials should cause no difficulty. None of the materials being contemplated for use in the 1A4 channel exhibited serious water-side corrosion.

The recommended $\mathrm{pH}$ range for the water is 6 to 7.5 if molybdenum is used on the sidewall, and 6.7 to 7.5 if tungsten-copper is used on the sidewall.

No serious effects were noted using the existing CD'F dissolved oxygen (DO) level of 3.2 to $3.4 \mathrm{ppm}$. Although a low DO range of 50 to $200 \mathrm{ppb}$ is recommended as being the preferred level, acceptable operating performance is attainable with a range of dissolved oxygen up to $3.5 \mathrm{ppm}$.

The minimum acceptable resistivity for the deionized water is $500 \mathrm{kohm}-\mathrm{cm}$. There is no maximum acceptable water resistance.

Facilities for fabrication of the 1A4 hardware are in place and are being used to build gas-side elements for the Mark VII and 1A channels. Procedures necessary for the hardware fabrication have been written as have procedures for inspection and quality control. The channel and diffuser fabrication schedule shows delivery of the hardware to the CDIF in March 1992.

\subsection{MARK VII SLAGGING ANODE EVALUATION TESTS}

At the CDR for the "proof-of-concept" channel (1A4), an open issue regarding anode life was put forth and discussed. Accelerated corrosion of anode materials has been observed at the CDIF. Laboratory analysis of the anode wall slag samples from both the coal-fired CDIF channel and the ash-injected Mark VII channel resulted in virtually identical compositions. This would seem to eliminate any difference in slag chemistry as the cause. It is postulated that the thicker boundary layers of the CDIF channel result in stronger Faraday arcs on the anode wall. Higher arc currents produce higher local temperatures in the arc foot region. This has resulted in an order of magnitude increase over the Mark VII corrosion rate on stainless steel capped anodes. Very much smaller but still observable increases in attack of the platinum caps has occurred on the 1A4 test coupons. The nature and detail of the platinum corrosion are being investigated and will be reported in a later Quarterly Progress Report.

As a result of this increased corrosion observed with the CDIF 1A channel, changing the $1 \mathrm{~A} 4$ anode to a fully slagging design has been evaluated. This results in two very crucial differences in the operation of the anode wall:

1. Slagging raises the average wall temperature from something less than $1000^{\circ} \mathrm{K}$ to approximately $1800^{\circ} \mathrm{K}$. At given gas conditions and normal boundary layer development, this is the only way in reduce the size of the Faraday arcs while retaining a "cold" metal temperature.

2. Complete slag cover will eliminate temperature nonuniformities on the wall caused by local slag puddles and/or streamers. These "hot" spots accentuate current concentrations resulting in regions of high localized corrosion. 
Two slagging anode configurations have been fabricated for tests in the Mark VIl. Details of thesc designs are shown in Figure 5-1. The anode on the left has two slag grooves per pitch and two reinforced platinum comers in the regions where current concentrations oscur. The lower stressed areas of this anode employ tungsten as the gas-side material. The design on the right of Figure 5-1 is a simple modification of the original 1A4 anode in which the insulator has been widened and recessed to provide a single slag retention groove. Platinum over tungsten is the gas-side material.

Figure 5-2 is a photo of the Mark VII anode wall with the test electrodes installed. Anodes 22 through 29 are the double grooved configuration ( 31 through $45 \mathrm{~cm}$ on the scale), Anodes 30 through 50 have a recessed insulator as the only slag groove and a full platinum gas-side cap ( 46 through $82 \mathrm{~cm}$ on the scale). Anodes 39 and 41 ane special designs to assess temperature effects (No. 39 is platinum over 3/32 inch of stainless steel and No. 41 is platinum over copper). The remainder of the wall is assembled with recessed insulators between earlier $1 \mathrm{~A} 4$ candidate designs to provide maximum slag retention. Anodes 33 through 36 are separately cooled and instrumented for heat loss measurements to compare their slagging performance to the overall anode wall.

The test plan to evaluate the slagging anode design is outlined in Figure 5-3. If no platinum damage occurs at the normal POC current density of $J y(c o r e)=0.8 \mathrm{amps} / \mathrm{cm}^{2}$, the current density will be increased approximately $50 \%$ in an effort to produce damage at the Mark VII scale. If damage is produced at either level of current, then a test utilizing $\mathrm{FeO}$ additive to the anode wall will be conducted to see if reduction of the slag polarization voltage (very high with platinum) will mitigate the damage.

The first test has been completed with two 9-hour power runs (October 11 th and October 15th) at the POC (and base load) current density of Jy(core) $=0.8 \mathrm{amps} / \mathrm{cm}^{2}$. In the Mark VII channel a core current density of $0.8 \mathrm{amps} / \mathrm{cm}^{2}$ produces an average current density of approximately $0.65 \mathrm{amps} / \mathrm{cm}^{2}$ in the total cross-section of the plasma, i.e., core plus sidewall boundary layers. This value was set in the central
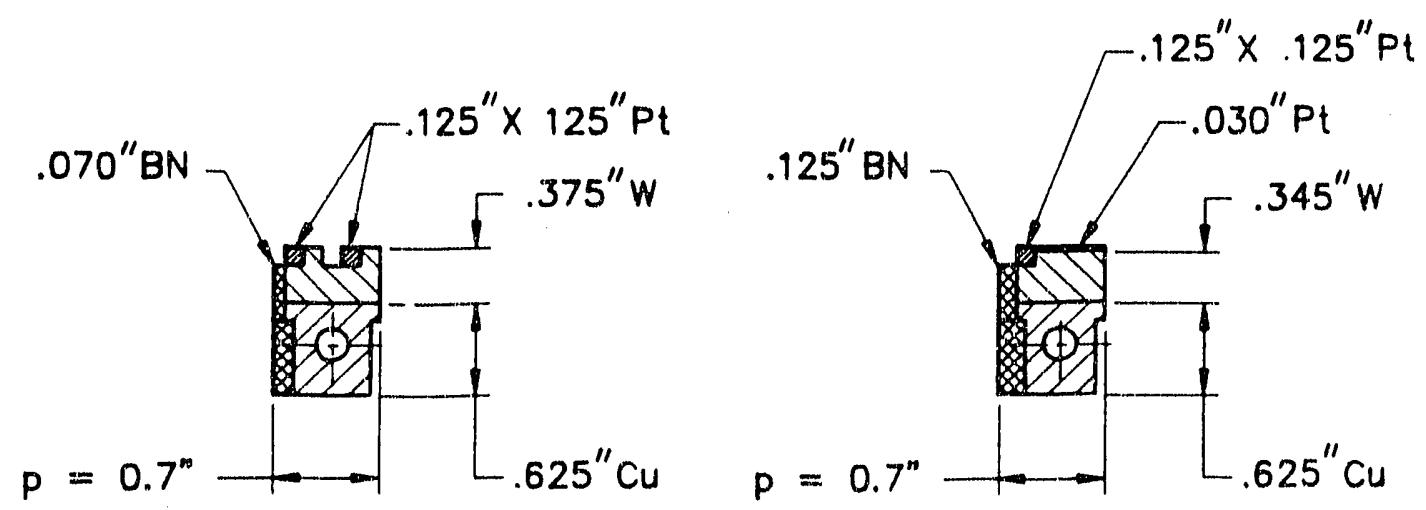

Figure 5-1. IA4 Slagging Anode Designs 


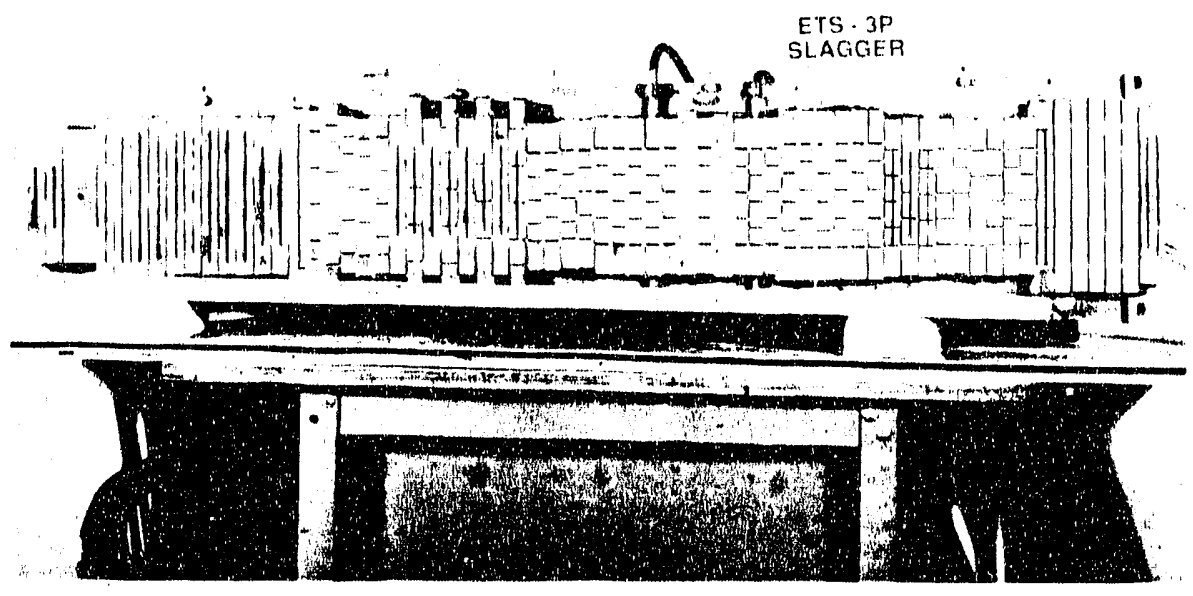

Figure 5-2. Mark VII Anode Wall with 1A4 Slagging Anodes

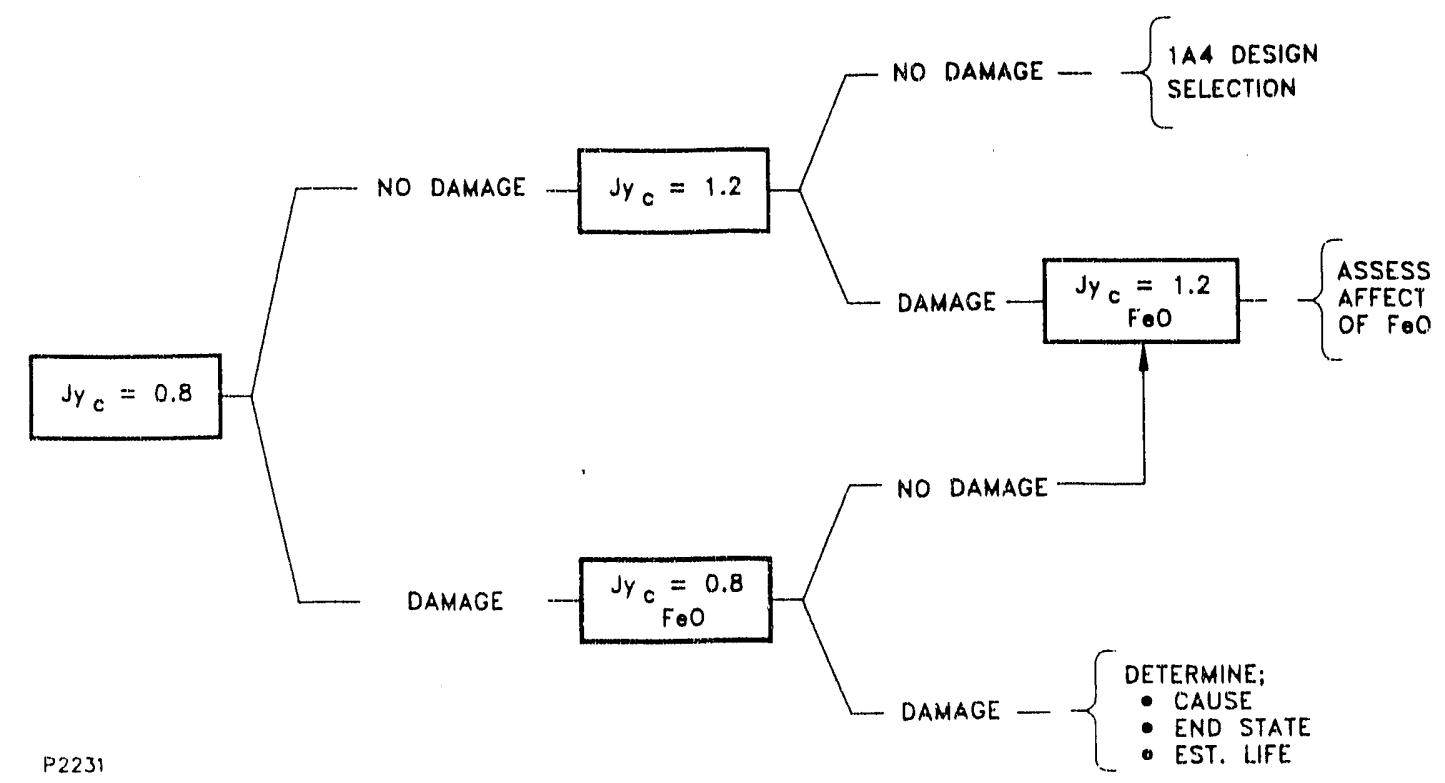

Figure 5-3. Mark VII Slagging Anode Test Sequence 
current control group of electrodes 35 to 49 in the diagonally loaded channel. Electrodes at either end had lower values of current due to the normal "end effect" distribution in the one meter long channel. Plots of "average" Jy (electrode current (electrode width $\mathrm{x}$ pitch) averaged over each 9-hour test are shown in Figures 5-4 and 5-5. Note, in these graphs electrodes 1 through 10 are unloaded bars in the supersonic nozzle (the first active anode is No. 11).

Slagging of the channel walls is accomplished at the combustor "light" condition, i.e., low flow, high $\mathrm{N} / \mathrm{O}$ producing a reduced heat flux. Once the wall temperatures have equilibrated (110rmally about 30 minutes) the mass flow, oxygen and fuel are brought to operating conditions. Figures 5-6 and 5-7 are plots of heat loss versus time for the entire anode wall and the separately instrumented group of four 1A4 slagging anode designs. Note that the heat loss reduction in both cases is just under $30 \%$ indicating that the test group slagged as well as the rest of the anode wall. Figures 5-8 and 5-9 are similar plots for the second 9-hour test four days later. Indications are that slag was almost completely retained as there was little, if any, heat loss reduction during the slagging period.

At the completion of 18 power hours, the channel was disassembled for detail inspection. Slag retention on both $1 \mathrm{~A} 4$ candidate groups was approximately $70 \%$. Close inspection of the interface between slagged and unslagged areas showed the majority had sharp edges indicating that slag had spalled off during shutdown or in removal and disassembly of the channel.

The anode slag was then removed for inspection of the metal surfaces, particularly the platinum. Figures 5-10, 5-11 and 5-12 are closeup photos of the gas-side metal from anode 25 to 50, all in the $1 \mathrm{~A} 4$ test group. Accelerated platinum damage, the so-called "marble" pattern (believed to be grain boundary attack) as distinct from the always present axial striations (arc melting), was observed only on anode No. 39. This is a special temperature effect anode that has a 3/32-inch thick cap of explosion bonded stainless steel between the platinum gas-side cap and a copper base. The stainless steel increases the

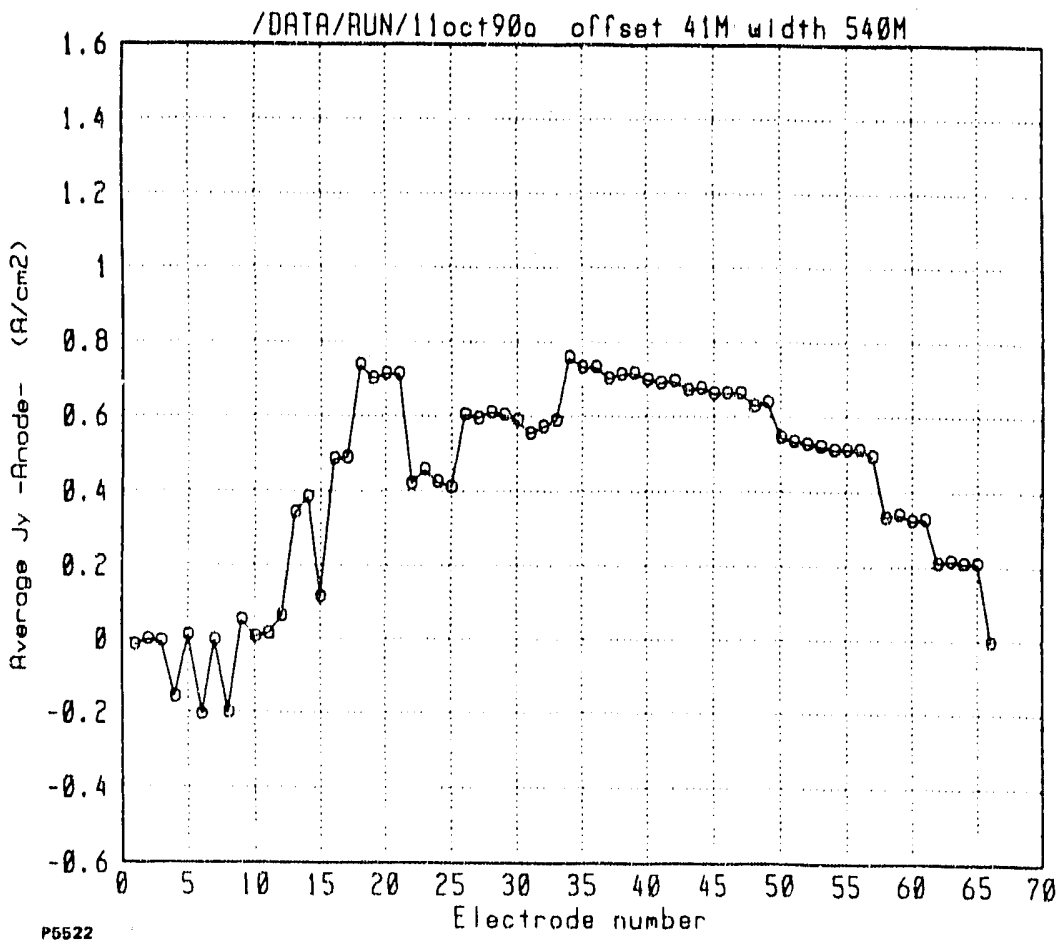

Figure 5-4. Mark VII Average Current Density - Test Date 10/11/90 


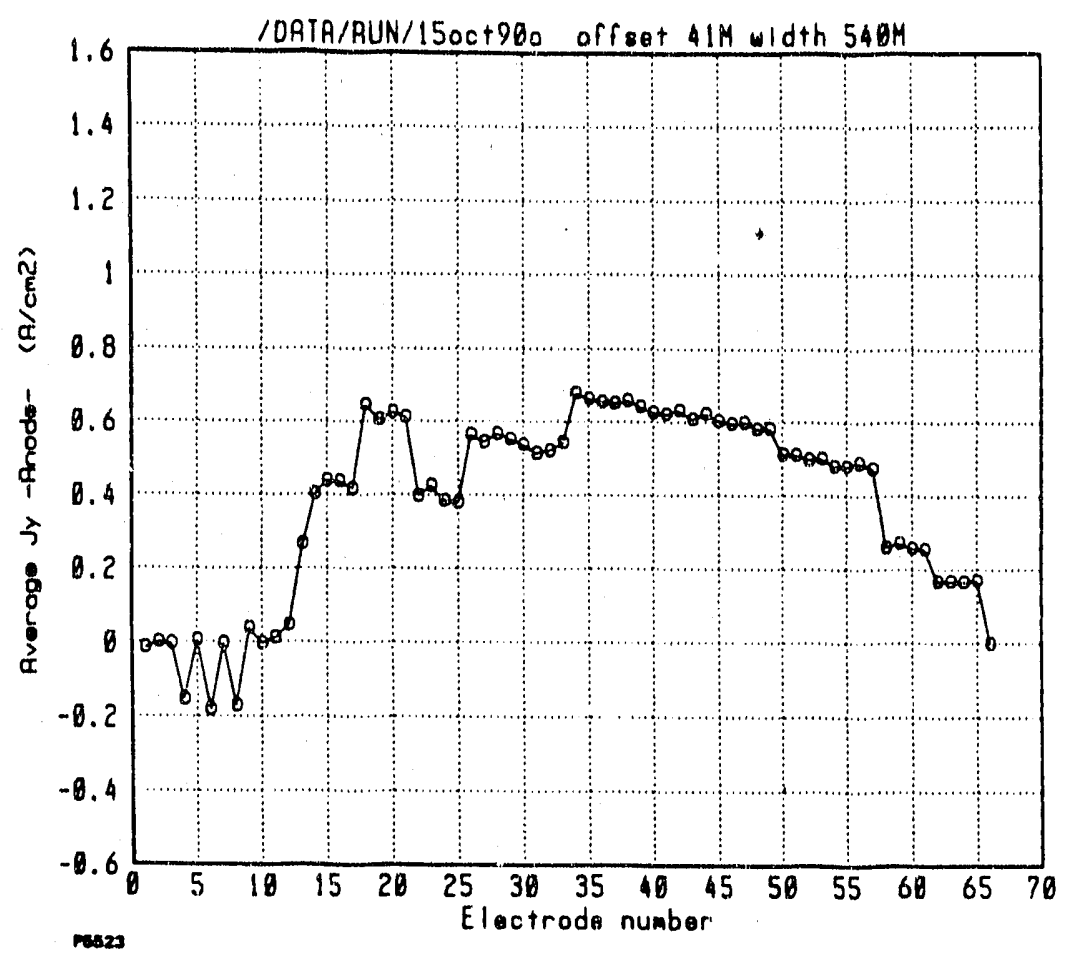

Figure 5-5. Mark VII Average Current Density - Test Date 10/15/90

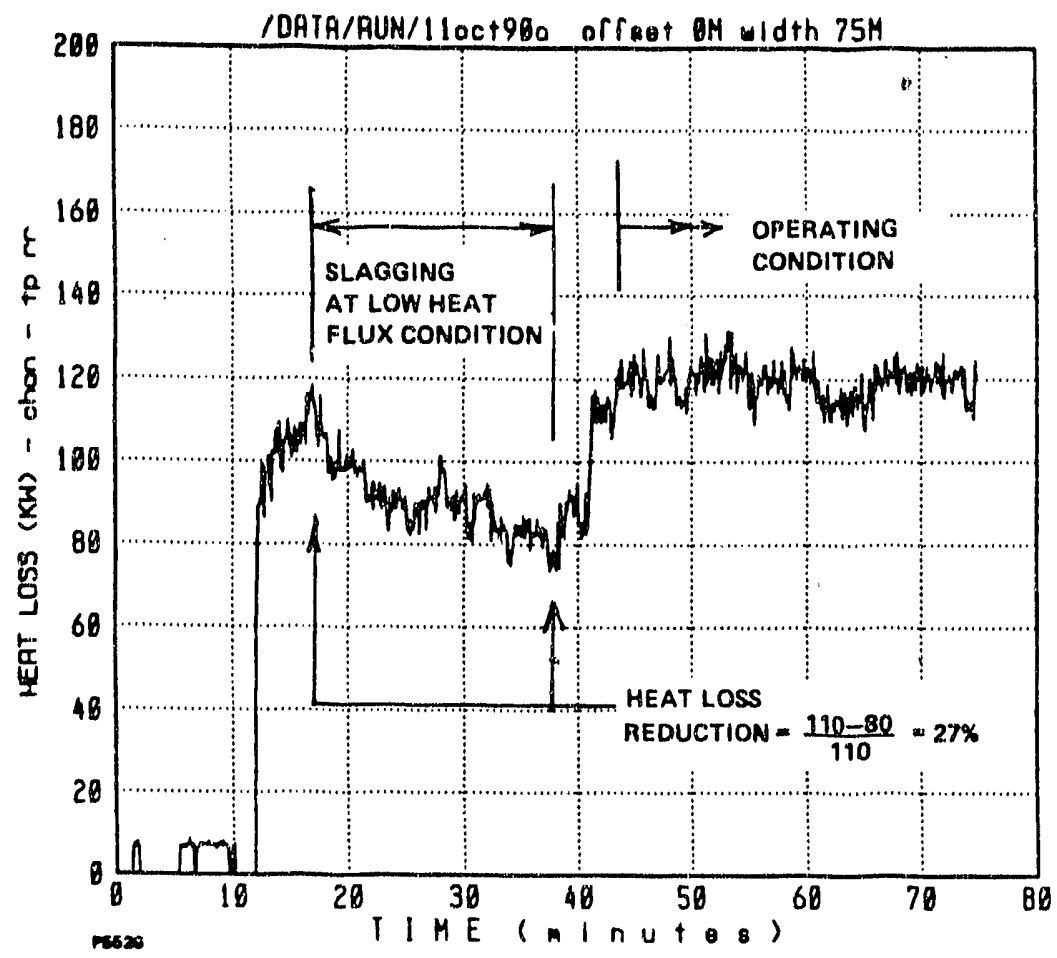

Figure 5-6. Mark VII Anode Wall Slagging Performance - 10/11/90 


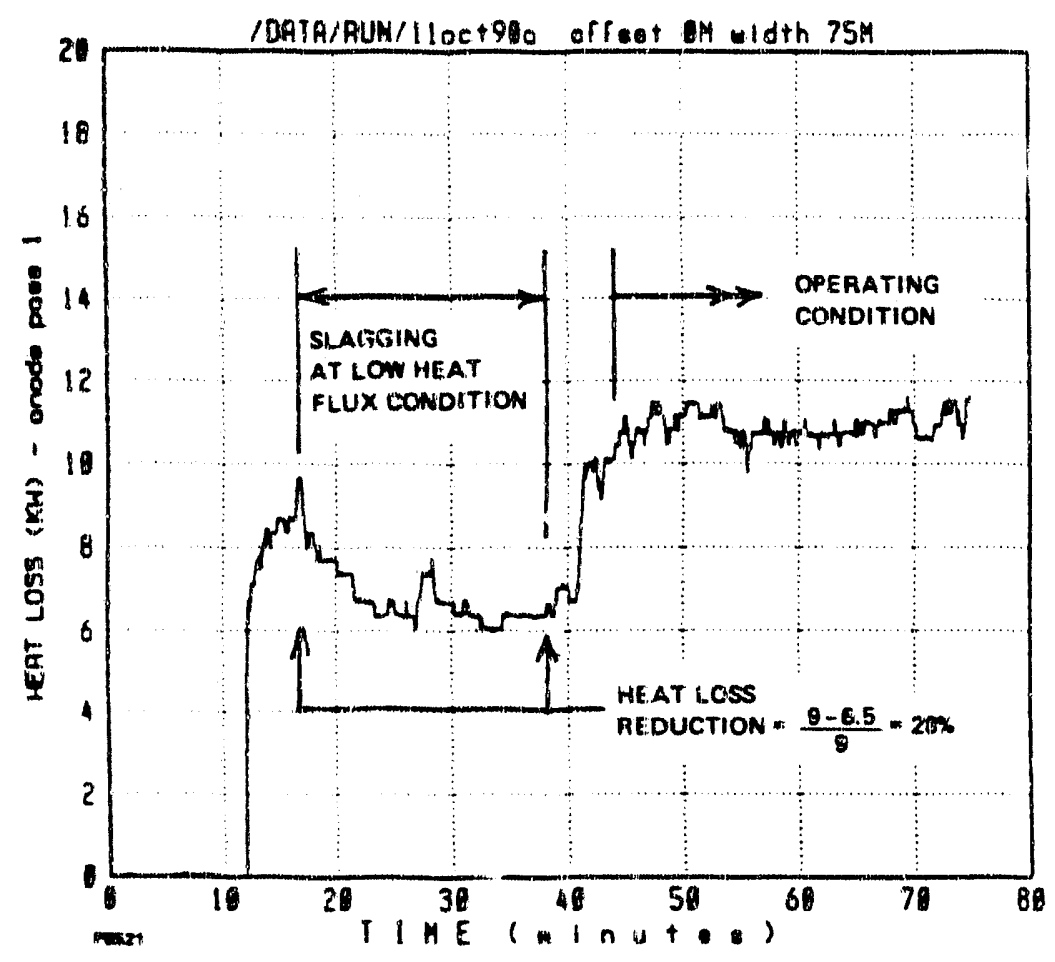

Figure 5-7. Mark VII Slagging Performance of the 1A4 Test Anodes - 10/11/90

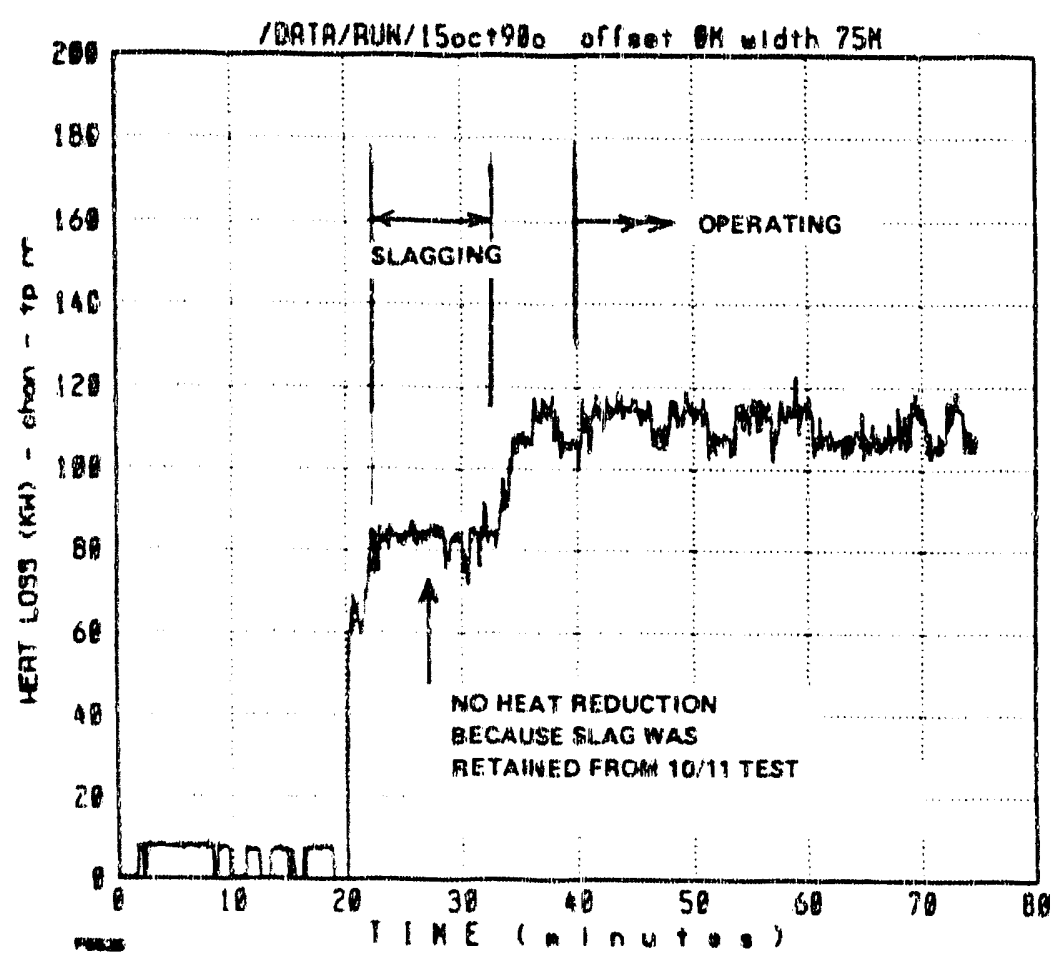

Figure 5-8. Mark VII Anode Wall slagging Porformance - 10/15/90 


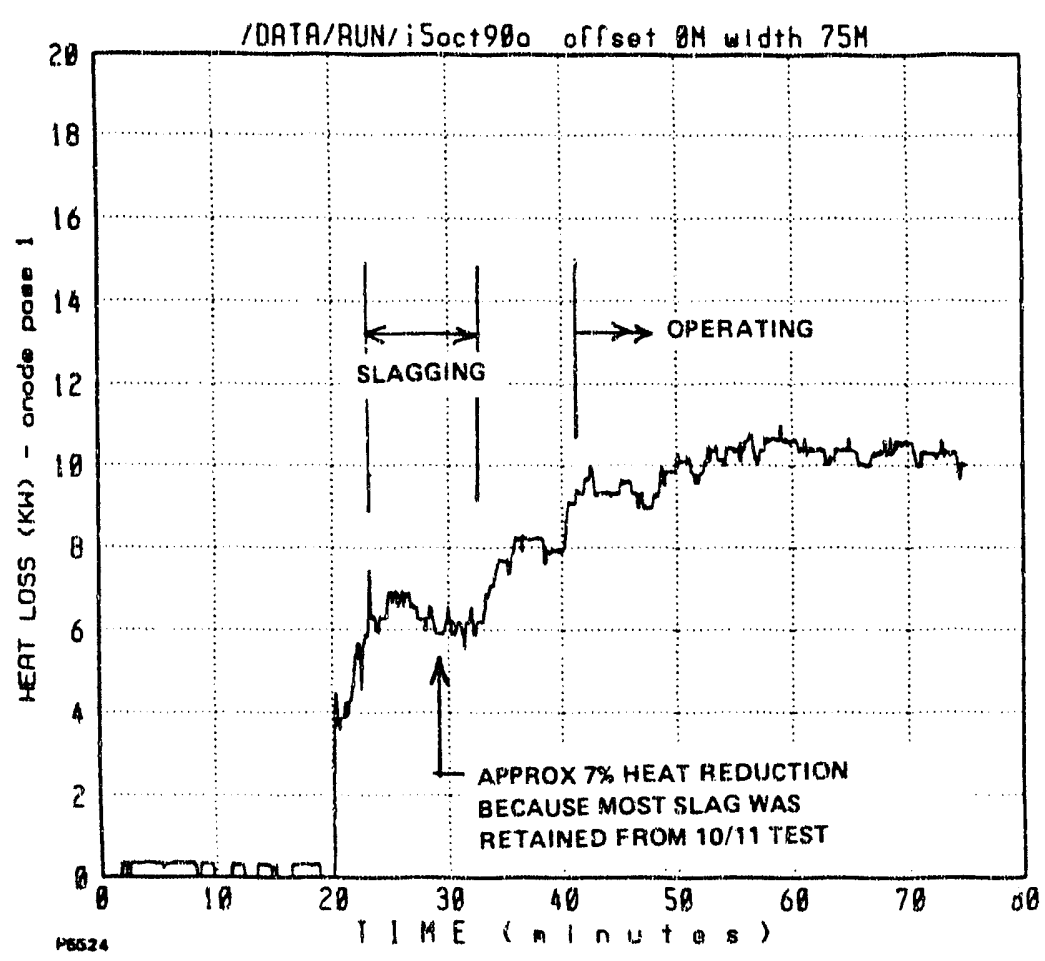

Figure 5-9. Mark VII Slagging Performance of Four IA4 Test Anodes - 10/15/90

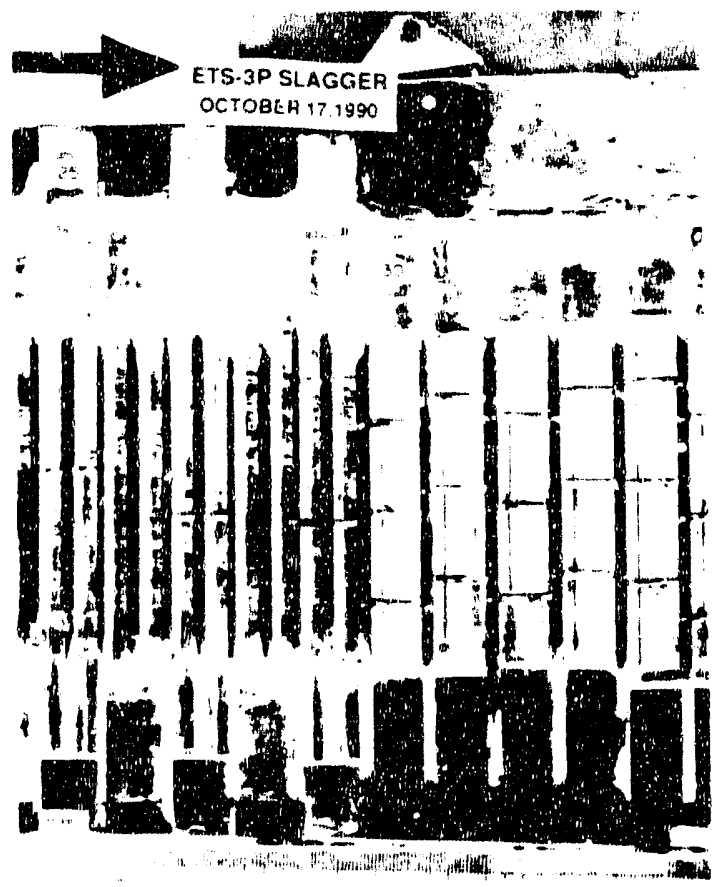

Figure 5-10. Past-Test Condition of MA4 Slagging Anodes 


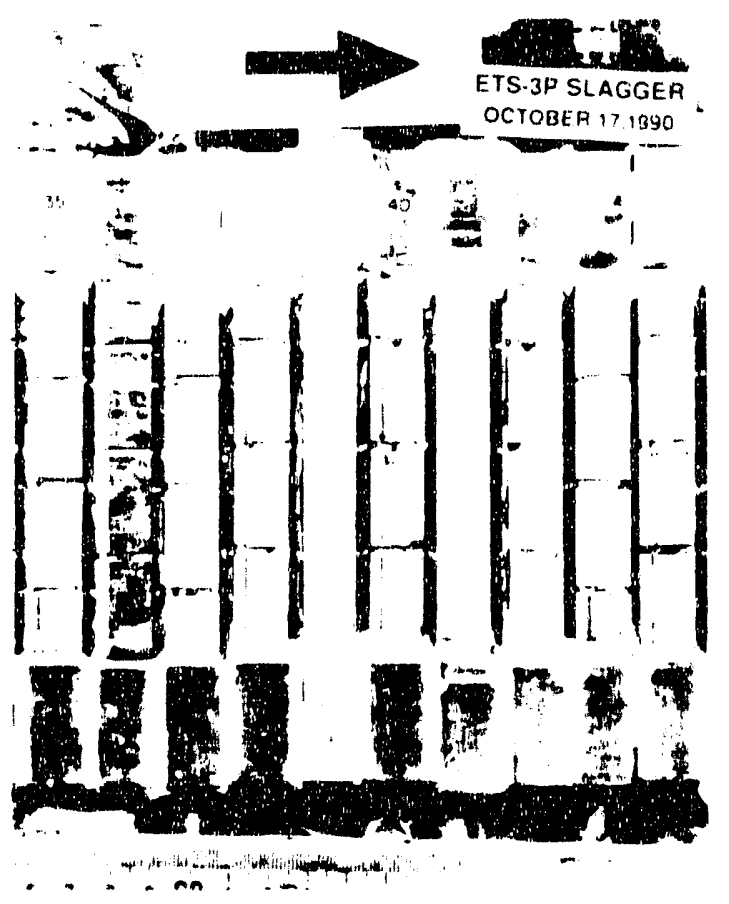

Figure 5-11. Post-Test Condition of 1A4 Slagging Anodes

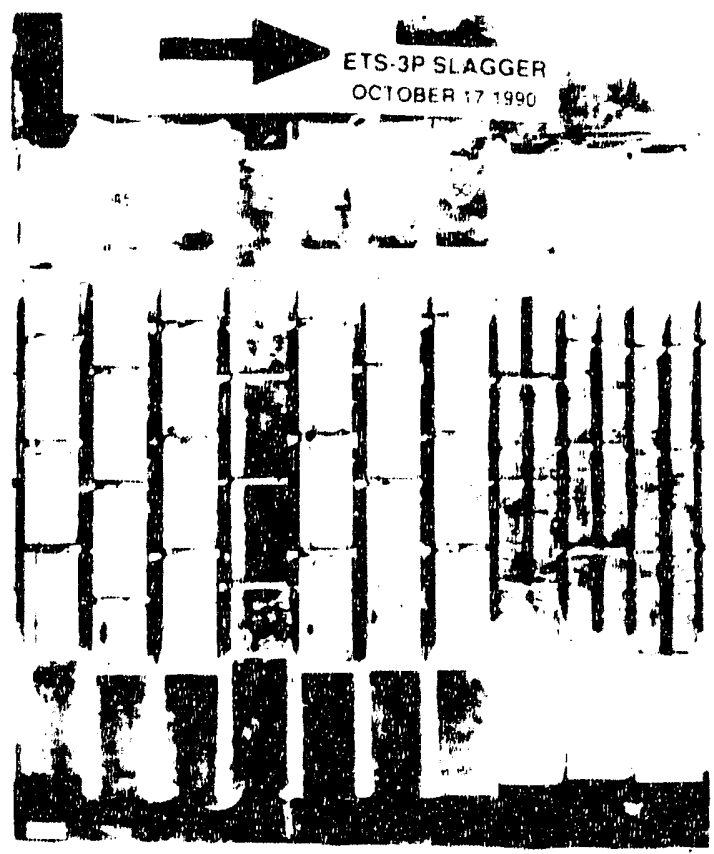

Figure 5-12. Post-Test Condition of 1A4 Slagging Anodes 
platinum temperature approximately $150^{\circ} \mathrm{F}$ over that of the platinum capped tungsten anodes or from about 400 to $550^{\circ} \mathrm{F}$. This hardly seems significant. What is much more likely, the cause is the difference in thermal properties (i.e., thermal conductivity, specific heat and melting point) between stainless steel and tungsten. The significance of thermal properties in an arcing environment is demonstrated in Table 5-1 which lists the relative resistance of metals to arc erosion for both pulsed and steady heat loads. Tungsten is one of the most resistant metals while iron is one of the least resistant.

Note that anodes 36 and 48 are different from those shown in the "before test" picture of Figure 5-2. At the last minute a quantity of $\mathrm{ZrO}_{2}$ stabilized platinum was obtained that was sufficient to install upstream corners on two of the test anodes. No platinum top foil was used on these tungsten blocks. The addition of a few hundred parts per million of $\mathrm{ZrO}_{2}$ mitigates platinum grain growth at elevated temperatures (see Figure 5-13).

In the next test the channel current density will be increased approximately $50 \%$ above prototypical conditions to see if the slagged anodes will continue to resist nlatinum grain boundary attack. Future Mark VII tests will also include the $1 \mathrm{~A} 4 \mathrm{Z}$ configuration sidewall until approximately 50 power hours have been accurnulated on it.

Conclusions drawn from the Mark VII slagging anode evaluation tests are as follows:

1. Both 1A4 slagging anode designs did appear to slag adequately in the first 18 -hour power test.

2. At prototypical (and $\mathrm{POC}$ ) current densities, no platinum grain boundary attack was observed on any of the platinum/tungsten candidate anodes.

\subsection{WATER CORROSION TEST RESULTS}

\subsubsection{Background}

In 1988 corrosion was observed (Reference 5-1) in 75 W25Cu sidewall pegs at the CDIF. A specimen was sent to Betz Entec for analysis. At the water tube end there was galvanic corrosion and some etching near the o-ring seal. Inside the waterline there was a copper rich surface, relative to the host. There was no scale buildup from the CDIF water but there was a corrosion layer of $\mathrm{W}$ and Cu oxide crystals 5 mils thick with a chemical composition consisting of $50 \% \mathrm{~W}$ and $50 \% \mathrm{Cu}$ in this area. Thus the copper was enriched in this region by a factor of two over the base metal composition. A comparison copper peg showed general corrosion due to the pH 6.8* water (Cu prefers $\mathrm{pH} 9$ ) with evidence of high velocity effects because of the patchy way the protective film came off. High velocity polishing of the copper surface, while it removes the protective oxide film, also maintains good thermal contact between metal and coolant, thus lowering the metal interface temperature. Minimum corrosion of copper occurs near $\mathrm{pH} 9$. The value 6.8 for $\mathrm{pH}$ is a result of a measurement on November 20,1990 by a Betz engineer and is not necessarily the $\mathrm{pH}$ that existed during the 1987 tests. The $\mathrm{pH}$ at the time would depend upon the operating procedures and on the state of the resin bed.

Pits were also observed in the $75 \mathrm{~W} 25 \mathrm{Cu}$ water hole inner surface. This is a common form of corrosion due to leaching of the host into deionized water. None of the observed corrosion was deemed to be life limiting with the possible exception of the pitting in the $75 \mathrm{~W} 25 \mathrm{Cu} 0$-ring seal area. However, this would not be a problem on a bar sidewall which has no o-ring seals and which, therefore, has greatly reduced electrochemical currents. Refractory metals are attacked slowly in basic solutions but are relatively stable in acidic solutions (Reference 5-2). Therefore, it was recommended that the pH be maintained at 6 or 7 , and that a corrosion inhibitor, Tolytriazole or Betz Entec CopperTrol (40 to $50 \mathrm{ppm}$ ), be added to the deionized water for the protection of the copper. In addition, high heat flux tests were deemed necessary to determine if the corrosion layer on the $75 \mathrm{~W} 25 \mathrm{Cu}$ will significantly elevate the metal temperalure since no comparable experience could be found.

*All references to $\mathrm{pH}$ are with respect to 20 degrees $\mathrm{C}$. 
TABLE 5-1. RELATIVE RESISTANCE OF METALS TO ARC EROSION

\begin{tabular}{|c|c|c|c|}
\hline \multicolumn{2}{|c|}{$\begin{array}{l}\text { IMPULSIVE HEAT LOAD } \\
\left(T_{m p}-T_{B}\right)(\lambda \rho c)^{0.5}\end{array}$} & \multicolumn{2}{|c|}{$\begin{array}{l}\text { CONTINUOUS HEAT LOAD } \\
\left(T_{m p}-T_{B}\right) \lambda\end{array}$} \\
\hline Graphite & 7200 & Tungsten & 3980 \\
\hline Tungsten & 6800 & Graphite & 3600 \\
\hline Iridium & 5550 & Copper & 3540 \\
\hline Osmium & 5400 & Molybdenum & 3530 \\
\hline Molybdenum & 5250 & Iridium & 3300 \\
\hline Rhenium & 4580 & Silver & 3180 \\
\hline Rhodiurn & 4570 & Osmium & 3120 \\
\hline Copper & 3750 & Gold & 2900 \\
\hline Chromium & 3440 & Rhodium & 2620 \\
\hline Tantalum & 3300 & Rhenium & 2150 \\
\hline Platinum & 2820 & Tantalum & 1450 \\
\hline Gold & 2800 & Platinum & 1360 \\
\hline Silver & 2770 & Aluminum & 1230 \\
\hline Beryllium & 2740 & Beryllium & 1180 \\
\hline Niobium & 2730 & Niobium & 1160 \\
\hline Nickel & 2500 & Chromium & 1160 \\
\hline Cobalt & 2480 & Nickel & 950 \\
\hline Iron & 1970 & Cobalt & 835 \\
\hline Aluminum & 1370 & Iron & 575 \\
\hline $\begin{array}{l}T_{\text {Imp }}=\text { Melting Poi } \\
T_{B}=\text { Bulk Temper } \\
\lambda=\text { Thermal Cond } \\
\rho=\text { Specific Densi } \\
c=\text { Specific Heat }\end{array}$ & & & \\
\hline
\end{tabular}




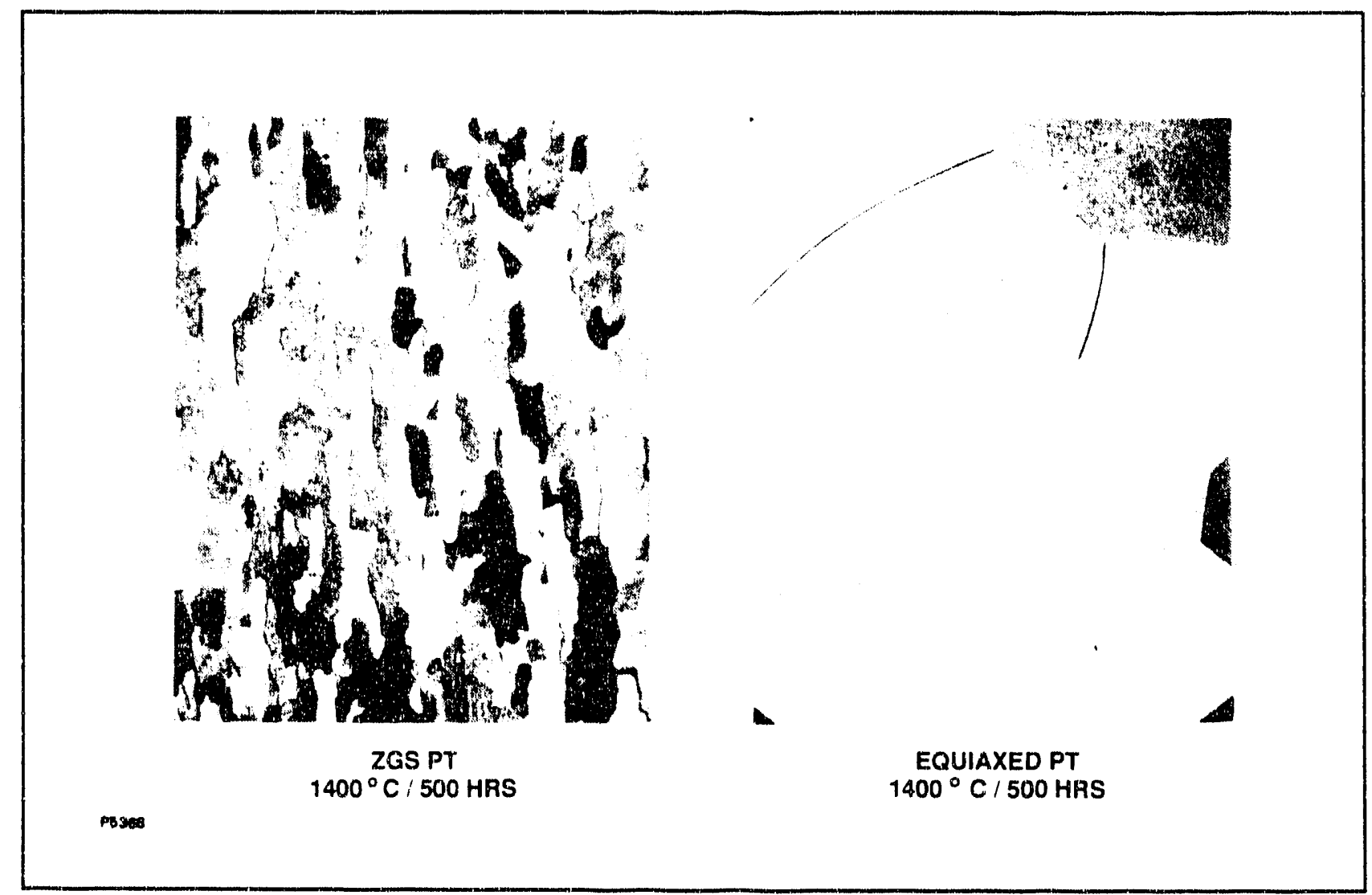

Figure 5-13. Comparison of Grain Structure: Pt vs. Zirconia Grain Stabilized Pt (each photo covers $33 \times 43$ mils, Approx. 100x)

\subsubsection{Materials}

Table 5-2 is a summary of all the materials of construction considered for wall elements in the 1A.4 channel design. Under the water-side materials category in the left-hand column are the materials which have traditionally been used and which are proven. Nevertheless, these materials were included in many of the tests described herein for comparison purposes and because some of the water conditions used represent departures from previous practice.

Two additional materials under the water-side materials category in the right hand column are molybdenum and $75 \mathrm{~W}-25 \mathrm{Cu}$, which also are two of the primary materials being considered for the sidewall gas-side surface. The advantages of utilizing the same material on the gas-side and water-side are numerous; the primary advantage is that no brazing of the elements is necessary (just one solid piece) which significantly increases the reliability of the element, as well as reducing the cost of fabrication. In addition, utilizing a water-side material which is resistant to anodic corrosion minimizes the risk of undercutting the top cap (i.e. corrosion below the level of the top cap). The wear mechanisms on the sidewalls are very similar to those observed on the cathode and, therefore, data on gas-side wear rates for cathode materials is also pertinent for determining the best materials to utilize on the sidewalls. Table 5-3 is a tabulation of pertinent gas-side wear rates for channel materials tested on the cathode wall. The anodic leading edge of a cathode is a very severe location for materials and represents the ideal location for controlled materials testing. Tests were carried out with high (120 to $160 \mathrm{~V}$ ) voltage intercathode gaps and with low voltage (0) $1060 \mathrm{~V}$ ) gaps. Some materials were tested in varying thicknesses to determine possible surface temperature effects on wear, if any. 
TABLE 5-2. MATERIALS OF CONSTRUCTION

\begin{tabular}{|l|l|l|}
\hline & Anode & Cathode and Sidewall \\
\hline \multirow{2}{*}{ Gas-Side: } & Platinum & Tungsten \\
& Tungsten & Molybdenum \\
& & $75 \mathrm{~W}-25 \mathrm{Cu}$ \\
& & $90 \mathrm{~W}-10 \mathrm{Cu}$ \\
\hline & Copper & Molybdenum \\
Water-Side: & Naval Brass & $75 \mathrm{~W}-25 \mathrm{Cu}$ \\
& $410 \mathrm{SS}$ & Copper \\
& Brazes & Naval Brass \\
& & $410 \mathrm{SS}$ \\
& & Eraze \\
\hline
\end{tabular}

TABLE 5-3. CATHODE WEAR RATES

\begin{tabular}{|c|c|c|}
\hline & Life (hrs) & Comments \\
\hline Tungsten & 3700 & high V \\
\hline Moly & 1950 & high V \\
\hline $90 \mathrm{WCu}$ & 1400 & high $\mathrm{V}$ \\
\hline $75 \mathrm{WCu}$ & 700 & high V \\
\hline
\end{tabular}

The results are presented both in terms of cross-sectional area lost and extrapolated cathode lifetime. In the presence of high voltage cathode wall nonuniformities, the ranking of materials is $\mathrm{W}, \mathrm{Mo}, 90 \mathrm{WCu}$, and $75 \mathrm{WCu}$, in that order, with $\mathrm{W}$ approximately 5 times longer lived than $75 \mathrm{WCu}$, and $\mathrm{Mo} 3$ times longer lived. Since at present there is no guarantee that iron oxide will be a viable solution over the long-term for eliminating cathode wall nonuniformities (it may lead to worse cathode wall shorting due to accumulated iron deposits), and planning for the worst, the longest lived material compatible with manufacturing and water-side corrosion constraints was chosen. Even if iron oxide works, however, the sidewall may generate moderately high voltages. In that situation, the ranking of materials remains the same.

Since tungsten cannot be fabricated with water holes, it cannot be considered as a potential water-side candidate material. This leaves Mo and W-Cu as candidate materials, and water-side corrosion testing has been carried out at Avco and other places to evaluate these materials. The most important considerations for these tests are heat flux, $\mathrm{pH}$, and dissolved oxygen. The baseline heat flux is $250 \mathrm{~W} / \mathrm{cm}^{2}$ and the recommended $\mathrm{pH}$ range is 6 to 7.

\subsubsection{Water Chemistry}

Table 5-4 shows the dissolved oxygen and pH levels accepted as standard in U.S. power plant practice. For reference, the German standar. which differs from the U.S. standard is included because of the p nce of carbon steel in the German plants. Also for comparison, the levels for dissolved oxygen and $\mathrm{p} t$ ior the CDIF and for the Avco test conditions are shown. Note that current testing is done with dissolved oxygen levels almost 3 orders of magnitude larger than called for by accepted practice. The following was observed: 
TABLE 5-4. DISSOLVED OXYGEN AND pH IN POWER PLANT PRACTICE

\begin{tabular}{|l}
\hline DISSOLVED OXYGEN: \\
U.S. POWEA PLANT PRACTICE: \\
MINIMUM $>7 \mathrm{ppb}$ \\
MAXIMUM $20 \mathrm{ppb}$ \\
LIMITS MAINTAINED USING THERMAL DEAERATION AND HYDRAZINE \\
GERMAN POWER PLANT PRACTICE: \\
100 tO 200 Ppb \\
PH IN U.S. POWER PLANTS: \\
PH $=9.0$ tO 9.6 FOR ALL FERROUS METALLURGY \\
PH $=8.8$ tO 9.3 FOR MIXED FE-CU METALLURGY \\
PH $<7.0$ CALLS FOR IMMEDIATE SHUTDOWN \\
CDIF TEST WATER: \\
DO $=3.3 \pm 0.3$ PPM \\
PH $=5.5 \pm 0.5$ (DYNAMIC), 8.0 (STAGNANT) \\
TEST WATER: \\
DO $=3.2$ pPM \\
PH $=6,7$
\end{tabular}

1. To minimize water-side corrosion, strict controls are kept on dissolved oxygen in power plants. Nevertheless, Avco has endeavored to keep within the CDIF facility limitation of testing without dissolved oxygen control. The imposition of dissolved oxygen controls at the CDIF would be beneficial to the lifetime of MHD materials and compatible with the expectations and facility operation of the ultimate customer. Certainly it would be good engineering practice.

2. The presence of copper in a system restricts the $\mathrm{pH}$ to a moderately basic region of operation, 8.8 to 9.3 (Reference 5-3). The operation of copper below pH 7 is marginal, and below pH 6 is unacceptable in standard practice. The normal operating pH at the CDIF is 6.8. Avco has tried to reach a compromise operating $\mathrm{pH}$ by testing materials in two $\mathrm{pH}$ ranges, 6 to 6.5 and 7 to 7.5 , to find a suitable operating $\mathrm{pH}$ for MHD materials.

Table 5-5 lists the standard techniques for maintaining desired oxygen and $\mathrm{pH}$ levels in a power plant system. Included in the table is a rough estimate of the amount of each additive needed to bring the two parameters to proper working levels initially. All indicated techniques are standard and the amounts of control agents are not excessive. Only the use of hydrazine to control dissolved oxygen poses potential problems in an R\&D environment and is therefore not recommended by Avco. Although it is the standard control agent in nuclear power plants, it is not recommended for MHD use because of its potential toxicity as a carcinogen and because, in an environment in which oxygen is constantly generated, too high a percentage of ammonia may develop in the water system leading to arnmonia-based corrosion problems.

\subsubsection{Electrochemistry}

Because the individual elements in an MHD channel are electrically active, voltages exist between the water-cooled elements. This leads to interelement electrochemical effects which can produce or exacerbate existing corrosion pathways, enhancing material loss and shortening element lifetime. The presence of these voltages was considered as an important element in the water-side corrosion tests. For the same 
TABLE 5-5. METHODS OF DISSOLVED OXYGEN AND PH CONTROL

\begin{tabular}{|c|c|c|}
\hline \multicolumn{3}{|c|}{ DISSOLVED OXYGEN: } \\
\hline & HYDRAZINE & $\begin{array}{l}3 \text { LB/10,000 GAL. } \\
\text { CARCINOGENIC }\end{array}$ \\
\hline & HYDROQUINONE & $20 \mathrm{LB} / 10,000 \mathrm{GAL}$ \\
\hline \multicolumn{3}{|c|}{ THERMODYNAMIC DEAERATION } \\
\hline pH: & & \\
\hline & PROPORTIONAL F & D OF $\mathrm{NaOH}$ and H2SO4 SOLUTIONS: 60 PINTS/10,000 GAL. \\
\hline
\end{tabular}

reason, in MHD systems the water conductivity is closely monitored and held to levels at which electrochemical corrosion is acceptable.

How much conductivity can be tolerated in the water line depends upon the distance between channel elements in series in the water line, the voltage between them, and the relative effects of conducting ions, the corrosion inhibiting buffers which add to the conductivity, and the current available to drive the reactions. In addition, electrochemical corrosion is dependent upon having a medium (in this case aqueous) in which the anode material will dissolve. Thus two conditions are necessary: 1) an electric potential, which can be either extemally applied or interaally generated, and 2) a medium which can chemically attack the arode. When these conditions are satisfied, the current will drive the chemical reaction. The internally generated potential difference is caused by the thermoelectric difference between dissimilar metals or between different regions of the same metal due to inhomogeneities in the metal.

Once these conditions are met and a given current is applied between anode and cathode, the current will divide itself between the various possible reactions according to the reaction rate and presence of a limiting polarization layer or development of a passivating layer. An example of a low reaction rate is a platinum anode in water. It does not erode anodically, instead the other available reaction occurs, the electrolysis of water. However if the proper concentration of the right reagent is added, the reaction can proceed with dissolution of the platinum. Passivation of stainless steel occurs because the oxide surface layer prevents chemical and electrochemical attack. But if the stainless steel is placed in an $\mathrm{HCl}$ or other chloride environment, the stainless steel is no longer passivated, the oxide film has been compromised, and the stainless steel can now be chemically and electmchemically active.

The development of a water specification for tungsten-copper with stainless water tubes follows the above logic. The issue is whether a pH can be found which produces satisfactorily low chemical attack, thus keeping the electrochemical attack low. Also, an additive which can assist in corrosion protection needs to be found along with a water conductivity compatible with the chemistry and low enough to keep reaction rates low. No difficulties are anticipated in attaining these goals on the basis of corrosion tests.

The water tubes should protect the bars from electrochemical effects (but not chemical attack) by providing partial electrical isolation of the bar from its neighbor. Electrochemical reactions will therefore take place primarily, but not exclusively, between water tubes.

As an example to clarify this, consider the path between water tubes to be $3 \mathrm{~cm}$ long, while the path between an anodic element and its neighbor's water tube as cathode will be $3 \mathrm{~cm}$ plus the water tube length for $9 \mathrm{~cm}$ total. A current of 8 microamps will be generated between the element's water tubes if there is a 100 volt drop along a $3 \mathrm{~cm}$ water path $0.55 \mathrm{~cm}$ in diameter and filled with $1 \mathrm{micromho} / \mathrm{cm}$ water. These water tubes can be chosen to be electrochemically passivated and so will not corrode away. The maximum electrochemical current between cathodic water tube and anodic element body is $1 / 3$ that possible between 
water tubes, 2.7 microamps. Note that such conditions with a pegwall could, if the copper reacts with the water, give 240 microamps over the $1 \mathrm{~mm}$ distance between pegs. 240 microamps of current move 578 micrograms of cuprous copper per hour, $57.8 \mathrm{mg}$ in 100 hours. At a density of $9 \mathrm{~g} / \mathrm{cc}$ this means $6.4 \mathrm{~mm}^{3}$ of $\mathrm{Cu}$ is lost at the water seal. This is easily enough to compromise an o-ring seal. By contrast, erosion around the surface of a water hole diameter of $5.54 \mathrm{~mm}(0.218 \mathrm{inch})$ removes only $0.0037 \mathrm{~cm}$ or 1.4 mils over $1 \mathrm{~cm}$ interior length in 100 hours. This would not compromise a water tube.

If pitting corrosion is a likely pathway, as seems possible from the pieces examined so far, then limiting the corrosion to pits can lead to effectively deeper erosion. The surface area of one $\mathrm{cm}$ of water passage is $1.74 \mathrm{~cm}^{2}$. The surface area of 10 one $\mathrm{mm}$ pits located in that length of water passage is is $0.08 \mathrm{~cm}^{2}, 1 / 22$ of the surface area of that length of passage. The erosion of 10 uniform pits would be 4.4 mils over 1000 hours if all of the erosion was localized to those pits. This is not a serious level of erosion because the electrochemical erosion rate in such low conductivity water is not serious. By contrast, pitting corrosion with a pegwall configuration is more serious because of the high currents involved and because of the fragile nature of an o-ring seal, should a pit occur there. Ten pits similar to those above would erode 308 mils over 1000 hours in a peg. The pit depth measured in the $75 \mathrm{~W} 25 \mathrm{Cu}$ CDIF peg, Test $5 \mathrm{~A}$, is 11 to 14 mils implying 40 hours of operation. Actual time was 31.5 hours electrical, 67 hours thermal and thousands of hours under stagnant conditions. It is not possible to conclude from this whether operation or stagnation caused the corrosion.

\subsubsection{Tests}

Table 5-6 is a summary of the corrosion tests performed to date at Avco and includes some additional tests and information. The first two tests, $\mathrm{pH}=6$ to 6.5 and $\mathrm{pH}=7$ to 7.5 , served to establish the $\mathrm{pH}$ levels acceptable to the materials in question. These tests were run with the materials indicated in the table and also with stainless steel and brass water tubes brazed into the test coupons. Materials not listed in the table showed little or no corrosion. In addition to $\mathrm{pH}$ control, each coupon was made $100 \mathrm{~V}$ anodic with respect to a common element. The water was polished in a resin bed and was treated with 40 to $50 \mathrm{ppm}$ CopperTrol, a benzotriazole derivative known to inhibit corrosion in $\mathrm{Cu}$ by forming an organic complex on the surface. It has no effect on water conductivity.

At the conclusion of Tests 1 and 2, two issues remained to be considered:

1. How well will Mo and $75 \mathrm{~W} 25 \mathrm{Cu}$ perform under an applied heat flux?

2. Will the corrosion layer observed in Mo cause any problems?

In an effort to answer these questions, Test 3 was performed with neutral $\mathrm{pH}$ and applied heat flux, $93 \mathrm{~W} / \mathrm{cm}^{2}$, which produced a metal temperature of $265^{\circ} \mathrm{F}$ when the film drop is considered. The result was that there was no difference in performance between this test and the first two.

Test 4 has been completed for Mo and is in progress for $75 \mathrm{~W} 25 \mathrm{Cu}$. This is the final confirmation of the results of the first 3 tests. The test duration is 100 hours each for Mo and $75 \mathrm{~W} 25 \mathrm{Cu}$ with an applied heat flux of $250 \mathrm{~W} / \mathrm{cm}^{2}$. Figure 5-14 is a schematic of the calculated temperatures in the Mo test peg operated under the conditions of Test 4, showing only selected locations for clarity. These conditions are summarized in Table 5-6. The results for Mo are no different for this test than they were for Mo in Test 1, except that the loose corrosion layer which developed on Mo in this test was only 5 microns thick as opposed to 10 microns in Test 1 . No change in the Mo water hole ID was noted. It was noted in this test that the stainless steel water tubes developed an iron oxide scale presumably from the pump and the iron pipe used in the system. Although no problems are expected in 1000 hours, the possibility of such a scale buildup can be avoided in carbon steel-containing systems if the $\mathrm{pH}$ is maintained near 7 and if dissolved oxygen controls are instituted to hold the dissolved oxygen below $200 \mathrm{ppb}$.

The tests listed in Table 5-6 as Test 5, A through E, include the 40-hour exposure of the $75 \mathrm{~W} 25 \mathrm{Cu}$ peg in the CDIF; a closed-cycle high temperature materials test at the CDIF; a Mo plate installed in the channel nozzle, a region of high heat flux; a zero dissolved oxygen test reported in the literature; and a "zero flow 


\begin{tabular}{|c|c|c|c|c|c|c|c|c|c|}
\hline $\begin{array}{l}\frac{\pi}{B} \\
0 \\
0 \\
0\end{array}$ & 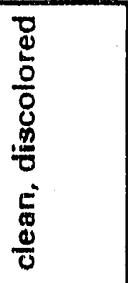 & 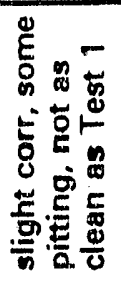 & 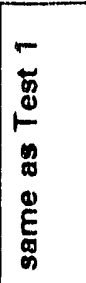 & 1 & 1 & 1 & 1 & 1 & \\
\hline 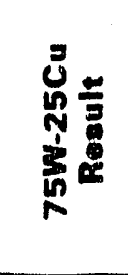 & 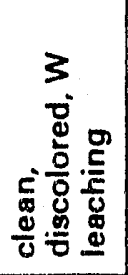 & 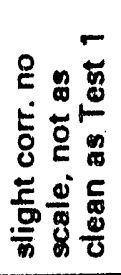 & 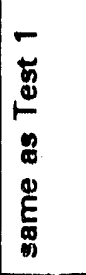 & 吕 & 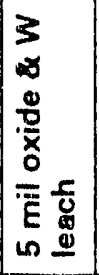 & 1 & ' & & 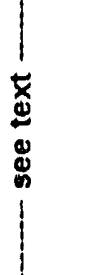 \\
\hline 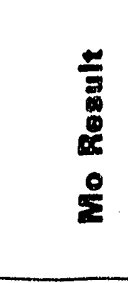 & 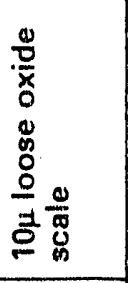 & 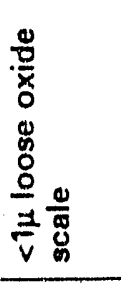 & 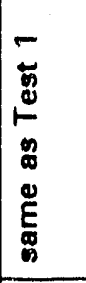 & 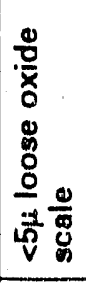 & ' & 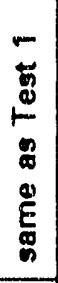 & $\begin{array}{l}0 \\
0 \\
\end{array}$ & 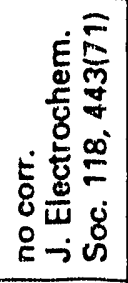 & \\
\hline 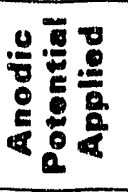 & $\stackrel{0}{0}$ & $\stackrel{\infty}{2}$ & $\stackrel{2}{2}$ & $\stackrel{0}{2}$ & $\stackrel{8}{\$}$ & $\stackrel{\circ}{\check{C}}$ & 巳 & 요 & 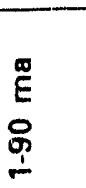 \\
\hline $\begin{array}{l}8 \\
\end{array}$ & $\mathbb{N}$ & $\simeq$ & 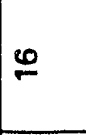 & 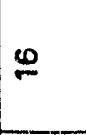 & $\stackrel{2}{N}$ & $\stackrel{\sim}{\sim}$ & $\stackrel{2}{\sim}$ & $\sim$ & 0 \\
\hline$\stackrel{3}{z}$ & 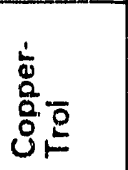 & • & - & . & \& & \& & 일 & 을 & 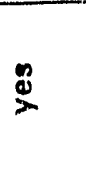 \\
\hline 送 & $\ddot{m}$ & $\stackrel{N}{m}$ & $\stackrel{n}{n}$ & $\stackrel{\sim}{m}$ & m & $\underset{m}{\tilde{m}}$ & mे & 웅 & 号 \\
\hline x & $\stackrel{\substack{n\\
}}{\pi}$ & $\begin{array}{l}n \\
0 \\
0 \\
0 \\
0\end{array}$ & ஸே & $\frac{\infty}{T}$ & $\begin{array}{l}\infty \\
0 \\
0\end{array}$ & $\begin{array}{c}\tilde{0} \\
0 \\
\omega\end{array}$ & $\begin{array}{l}\infty \\
0 \\
0\end{array}$ & 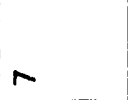 & $\frac{1}{4}$ \\
\hline 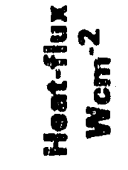 & ' & ' & 年 & 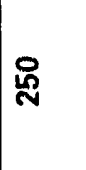 & 禺 & . & 品 & ' & . \\
\hline 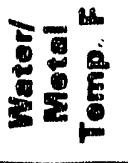 & $\frac{8}{5}$ & $\frac{8}{8}$ & 崫 & 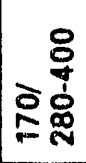 & 怘 & 吕 & 응 & $\frac{\text { n }}{\frac{N}{2}}$ & $\begin{array}{l}\text { 吕 } \\
\text { 今ั } \\
\text { 足 }\end{array}$ \\
\hline 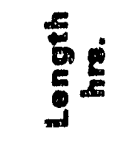 & p & E & \& & ? & 童 & 品 & 㖛 & 옹 & $\stackrel{\infty}{\circ}$ \\
\hline & 5 & 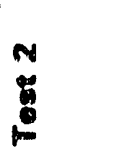 & $\begin{array}{l}m \\
0 \\
0 \\
0\end{array}$ & 8 & $\begin{array}{l}8 \\
8 \\
8\end{array}$ & $\mid \begin{array}{c}m \\
0 \\
8 \\
\end{array}$ & $\begin{array}{l}0 \\
0 \\
0 \\
0\end{array}$ & $\begin{array}{l}0 \\
8 \\
8\end{array}$ & 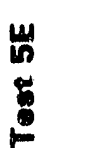 \\
\hline
\end{tabular}


rate" isothermal test carried out at Argonne. The results of the 40-hour exposure of the $75 \mathrm{~W} 25 \mathrm{Cu}$ peg at the CDIF were discussed in Section 5.2.1. The closed cycle materials water corrosion test performed at the CDIF corroborated the scale buildup on Mo, and showed the deposition of Cu on the surface of the Mo, which was dissolved by the pH 5.5 water. The Mo nozzle plate has about 55 hours on it at this point and will continue to be tested for several additional months at least. Test 5D shows that if deionized water is used with no dissolved oxygen, no corrosion of the Mo occurs. This and the results of test $5 \mathrm{E}$ are discussed in the next section.

\subsubsection{Molybdenum Corrosion}

Test 5D showed that in the absence of dissolved oxygen no corrosion of Mo takes place. This means that the reaction of Mo with water is not a simple one, like sodium and water forming the hydroxide. In fact, the reaction is electrochemical and occurs as follows:

1. Water and oxygen react at the metal-liquid interface forming a nonprotective porous corrosion film.

2. The spongy corrosion film serves as an electrolyte; oxygen and water migrate toward the bare metal and corrosion continues.

The overall reactions include the dissolution of metallic molybdenum to molybdenum ions and the reduction of oxygen to hydroxide ions:

$$
\begin{aligned}
& \text { Oxidation: } \mathrm{Mo} \rightarrow-\mathrm{Mo}^{+} \mathrm{n}+\mathrm{ne}^{-} \\
& \text {Reduction 1: } \mathrm{O}_{2}+2 \mathrm{H}_{2} \mathrm{O}+4 \mathrm{e}^{-}->4 \mathrm{OH}^{-} \\
& \text {Reduction 2: } 2 \mathrm{H}_{2} \mathrm{O}+2 \mathrm{e}^{-}->\mathrm{H}_{2}+2 \mathrm{OH}^{-} \text {(No dissolved oxygen present) }
\end{aligned}
$$

These reactions occur simultaneously by the passage of charge. They do not occur separately as charge conservation requires that the electrons which are freed by the oxidation of Mo be used in the reduction of water.

If no dissolved oxygen is present then Reduction 1 cannot proceed and Reducion 2 proceeds. Reduction 2 is a hydrogen evolution reaction, and a hydrogen evolution reaction is very slow in neutral solutions. Since the rate of oxidation depends on the rate of reduction, this reaction can be increased by dissolved oxygen. This explains why the simultaneous presence of oxygen is required to corrode molybdenum. This type of corrosion is characterized by a porous corrosion film forming and reacting continuously until the metal is completely consumed.

It would be of concem if this porous film grew large enough to prevent heat transfer to the coolant. In this case gas-side corrosion could be catastrophic. Figure 5-15 shows the porous film which developed on the waterwall surface of the Mo test coupon from Test 3. Figure 5-15A shows the typical disposition of the film in situ after drying. Note the "dry lake" or mud cracking structure to the film. In Figure 5-15B, which shows some scale deposit which was removed from the specimen, several pieces of the scale can be seen edge-on. This shows the thickness of the scale to be less than 10 microns. This scale is indistinguishable from the scale seen after Test 1 in which there was no heat flux but which lasted 4 times longer. That scale was 10 microns thick. The scale from Test 2 was less than one micron thick and indicates that a pH of 6 to 6.5 is better, though not necessary, for molybdenum.

On the basis of test results so far, the two principal test issues may be answered for molybdenum as follows:

1. Under an applied heat flux Mo develops a porous corrosion layer similar to that developed under identical water conditions but in the absence of heat flux. The limiting thickness of the corrosion scale appears to be 10 microns.

2. The loss rate of material does not appear to be close to life-limiting over a 2000-hour period. And even at a thermal conductivity of $1 \mathrm{~W} / \mathrm{mK}$, a porous, 10-micron corrosion layer would develop only $20^{\circ} \mathrm{K}$ temperature drop at $200 \mathrm{~W} / \mathrm{cm}^{2}$ heat flux. 
3. In designing the water cooling system, it must be taken into consideration that Mo will develop, in comparison to copper, an uneven skin temperature around the circumference of the water hole because of its much poorer thermal conductivity. For example, with $170^{\circ} \mathrm{F}$ water temperature and $16 \mathrm{feet} / \mathrm{sec}$ velocity at $250 \mathrm{~W} / \mathrm{cm}^{2}$ heat flux, the metal temperature is calculated to be $280^{\circ} \mathrm{F}$ (Figure 5-14) at the bottom of the water hole and $400^{\circ} \mathrm{F}$ at the top. It must be considered whether some of this interior surface will be in the boiling regime for the coolant.

\subsubsection{Analysis of Test Specimens from Tests 1 Through 3 (Reference 5-4)}

The observations and conclusions of the Betz Analytic Laboratory are reproduced here as tendered to Avco. Following that comments will be made where appropriate since some of these results must be interpreted in the light of the test goals for each set of specimens analyzed.

\subsubsection{Observations by Betz}

1. Best pH range appears to be 6.0 to 6.5 , although brief excursions in the range of 6.0 to 7.5 appear to be well tolerated.

2. Best dissolved oxygen range is estimated to be 50 to $200 \mathrm{ppb}$ (parts per billion). Additional testing may show that dissolved oxygen (DO) levels as low as 1 ppb may also be acceptable.

3. Dissolved oxygen levels should be controlled by using either hydrazine or hydroquinone. Neither adds any inorganic solids to the water and would not affect the resis'ivity (or conductance) of the water. Hydrazine has historically been the oxygen scavenger of choice in high pressure boiler applications but recent concems about safety and health in handling this material has begun a widespread switch to hydroquinone. Both are expected to perform equally well.

4. If continuous oxygen infiltration is possible, it is strongly recommended that hydroquinone be used as hydrazine generates ammonia as a decomposition by-product and ammonia in the presence of oxygen can severely attack copper components of the system.

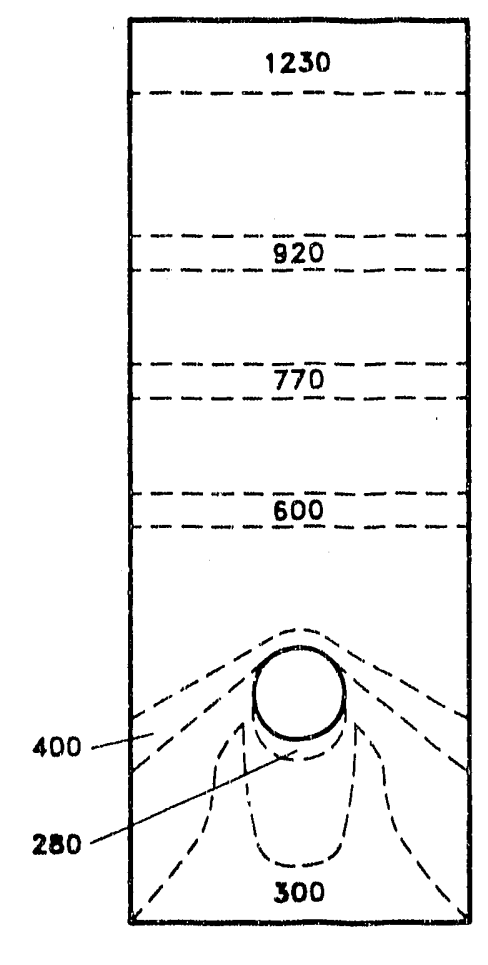

Figure 5-14. Schematic Temperature Distribution in High Heat Flux Mo Test Peg 

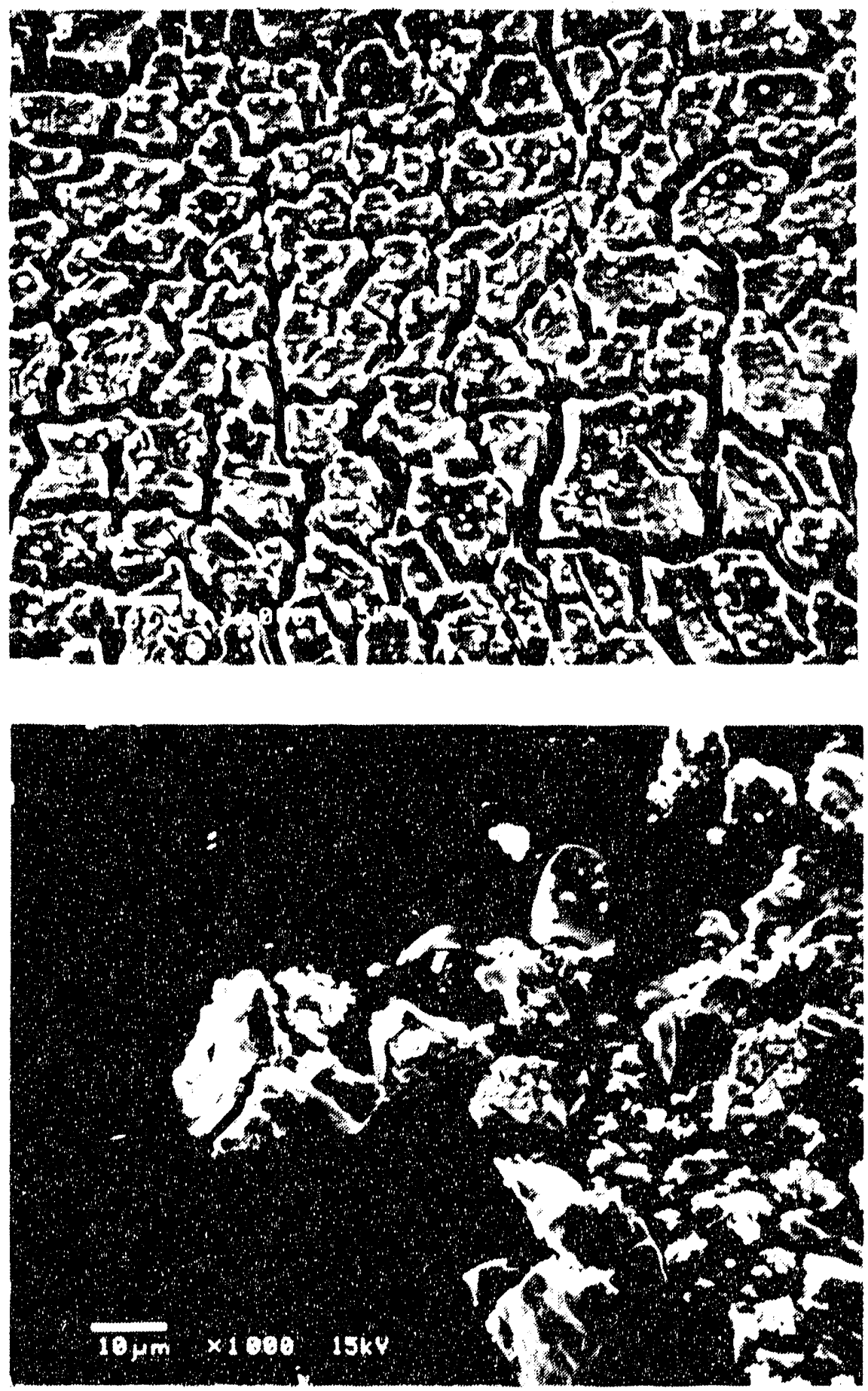

Figure 5-15. SEM Photomicrographs of Inner Surface of Water Passage in Mo Specimen from Test 3 at 1000x Magnification. Figure 5-15A shows the cracked and dessicated nature of this deposit with many rounded particles on top of the scale. Figure 5.15B shows that some of the scrapings taken from the wall and seen edge-on are not as thick as the 10-micron reference scale shown. 
5. CopperTrol should be applied in the 40 to $50 \mathrm{ppm}$ range to help minimize copper corrosion.

6. It is very doubtful that any of the passivating layers so far examined would prove detrimental to the systern even under high heat flux.

7. In low dissolved oxygen water (i.e., less than $200 \mathrm{ppb}$ ) we would expect the rate of oxide layer buildup to be severely reduced. With the use of CopperTrol we would expect essentially no oxide layer to develop beyond a 1 to 2 molecule thickness. Previous experience shows that with continued CopperTrol addition, even with dissolved oxygen excursions into the 1 to $2 \mathrm{ppm}$ (parts per million) range the oxide layer does not exceed 10 angstroms after 2000 hours operation.

8. It would be better to limit the water velocity to $12 \mathrm{ft} / \mathrm{sec}$ with $15 \mathrm{ft} / \mathrm{sec}$ as an upper limit for excursions.

9. We have not assumed metal loss to be a problem due to the thickness of the components. If design considerations change, metal loss studies might be in order.

\subsubsection{Conclusions by Betz}

1. None of the samples analyzed appeared to be experiencing extreme corrosion rates.

2. Best overall results (i.e. least corrosion and scale) appeared to have been achieved on thit $-92-90$ group.

3. Scale material consists of oxides of base metal which are corrosion by-products and are not water bome deposits.

\subsubsection{Comments on Betz Analysis}

Observation 1: This conclusion was based on the use of Mo in the system. Other than producing a high r corrosion rate, the scale buildup on Mo never exceeded 10 microns. In order to specifically test this, Test 4 was, conducted for 103 hours in the $\mathrm{pH}$ range 7.0 to 7.8. No differences were observed between these results and those of Test 1.

Observation 2: As above. all of Avco's tests were canied out with existing dissolved oxygen, 3.2 fppm. No adverse effects were observed and no life-limiting threat to the POC test exists.

Observation 6: Clearly this is an important question. Since traditional experience is generally restricted to low heat flux regimes, Avco undertook Tests 3 and 4 specifically to lay this issue to rest.

Observation 8: High water velocities are necessary in high heat flux cooling systems. There is no evidence of a life-limiting threat to velocity erosion in the MHD system for the POC test. The removal of protective films by high velocity water maintains good heat uransfer between metal and water. This issue must the addressed for 10.000 to 100,000 hour operation.

Conclusion 1: One would clearly wish to reevaluate this data for scaleup to 10,000 to 100,000 hour lifetimes. In that situation, tighter controls of $\mathrm{pH}$ must be kept along with conventional steam plant levels of DO. The question of using Mo in a system with the other materials including tungsten-copper may require separate water cooling systems.

Conclusion 2: This conclusion, essentially the same as Observation 1, bears the same comments Given the desire to use Mo and given the better performance of Mo at the lower $\mathrm{pH}$ (the 7-02-90 sample group were the rest 2 specimens. $\mathrm{pH}=6$ to 6.5 ), the fact that the other materials were still clean was the deciding factor in their decision to recommend the lower $\mathrm{pH}$. Avco's $\mathrm{pH}$ recommendations are based on the fact that the bulk of the materials in the MHD channel were not Mo and that these materials operated cleaner at the higher $\mathrm{pH}$, and the fact that specific rests of Mo at the higher $\mathrm{pH}$ stlowed no life-limiting or heat fluxlimiting changes in perfomance. These facts were overriding in the decition to recommend an operatin: ratge which included higher $\mathrm{pH}$ 


\subsubsection{Results of Test 5E (Reference 5-5)}

The materials tested include the water-side candidates of Table 5-2 plus beryllium-copper, free machining brass, $304 \mathrm{SS}$, and $90 \mathrm{~W}-10 \mathrm{Cu}$. These materials were tested in an autoclave at $250^{\circ} \mathrm{F}$ with water used in a once through system of negligible flow rate. Because of this, it is difficult to control the dissolved oxygen (effluent varied trom 3 to $7.5 \mathrm{ppm}$ ) and the $\mathrm{pH}$ (decreased from 10 to 4 throughout the test). Especially critical to any water corrosion test is the maintenance of constant $\mathrm{pH}$. The variation of $\mathrm{pH}$ from basic to acidic makes it difficult to evaluate the results for any material, especially the materials of high interest, the copper-containing and refractory metal-containing specimens. In addition, because of the physical layout of the system, applied electrical currents to provide the appropriate electrochemical pathways were not controlled to levels compatible with MHD systems (10 to 100 microamps). Current from the sample assembly was maintained at 1 amp for 50 hours. This averages 90 microamps for each of the 11 specimens, a factor of 10 to 100 too large. Clearly this would have exaggerated considerably the electrochemical corrosion effects.

The conclusions from this test are as follows:

1. All materials tested except Mo perfomed better than OFHC copper. Since OFHC copper is in no danger of life-limiting failure in the MHD system, these materials are also good choices.

2. Mo dissolved in the system 1.6 times faster by volume loss than did OFHC copper. This is still not a life threatening rate and is elevated due to the operation of the system at $\mathrm{pH}=10$. But the conciusion that in 100 hours, a Mo water hole should expand its diameter by 23 mils is not bome out in Tests 3 and 4, in which the $\mathrm{pH}$ was controlled and in which there was an applied heat flux. There the loss of material in 100 hours, with a coolant velocity of 12 or $16 \mathrm{feet} / \mathrm{sec}$, was zero in Test 4 and in Test 3 was less than 10\% of that predicted on the basis of the Argonne Test 5E. The control of dissolved oxygen would virually eliminate all molybdenum loss.

3. The corrosion of $\mathrm{Cu}$, the loss of $\mathrm{Zn}$ from the brass, and the loss of $\mathrm{Cu}$ from the tungsten-copper alloys is attributed to the acidic environment ( $\mathrm{pH}$ down to 4 ) and to the presence of sulfate ions in the water.

4. The use of sulfuric acid to control the pH during basic swings introduces the sulfate ion which was observed at several of the corrosion sites. This is not necessarily undesirable from a corrosion point of view. Acetic acid, the only viable altemative, is far less efficient as a $\mathrm{pH}$ control agent and its use would lead to high carbon buildup in a closed water system, leading to bio-organic growth. The buildup of the sulfate ion is not considered a serious source of water-side corrosion. The chloride ion would be worse, especially for high alloy steels.

\subsubsection{Conclusions}

The results of this test program determine the suitability of the various materials for water-side use in the 1A4 channel and will establish water quality criteria for the channel cooling water at the CDIF. The use of an NCR-approved corrosion inhibitor compatible with existing materials should cause no difficulty. It is anticipated that the $\mathrm{pH}$ coniml will be in a range also compatible with existing CDIF materials.

A summary of the results of the water corrosion tests is as follow's:

1. None of the materials being contemplated for use in the 1 A4 channel exhibited serious water-side corrosion.

1A. Mo is the worst performer of all materials tested but in operation it is still neither life-limited nor heat flux-limited by its corrosion.

1B. Though Mo has the highest rate of dissolution and has been known to poison small bench-scale deionization systems, there should be no impact on CDIF operation given the scale of the water system and the duration of the POC test. No change in the Mo water hole inside diameter was noted in the tests. 
2. The recommended pH range for the water is 6 to 7.5 if molybdenum is used on the sidewall, and 6.7 to 7.5 if tungsten-copper is used on the sidewall. These numbers represent shutdown alarm points, though there is some leeway in the $6.7 \mathrm{low}$ alarm for tungsteri-copper. It is noted that with ferrous-copper water systems power plant practice calls for $\mathrm{pH}$ restricted to 8.8 to 9.3.

2A. pH control should be effected through the use of $\mathrm{NaOH}_{2}$ and $\mathrm{H}_{2} \mathrm{SO}_{4}$ reagents. The low sulfate ion concentration introduced by the use of $\mathrm{H}_{2} \mathrm{SO}_{4}$ is not considered to be a problem.

2B. Since pure water should be close to neutral $\mathrm{pH}$, it is believed that the low $\mathrm{pH}$ originally reported by the CDIF was an artifact caused by the absorption of $\mathrm{CO}_{2}$ during sampling. If the low $\mathrm{pH}$ were a genuine characteristic of the water and caused by carbonation due to the design of the system, then saturating the water with nitrogen should remove the $\mathrm{CO}_{2}$, restore the $\mathrm{pH}$ balance, and reduce or eliminate the need for extemal $\mathrm{pH}$ control. In regenerating the resin bed, care must be taken with the regenerating reagents to insure that the chemical neutrality of the resin bed is maintained.

2C. The recornmended pH range in Avco tests has prevented the development of a corrosion layer in $75 \mathrm{~W} 25 \mathrm{Cu}$ such as was observed at the CDIF. Therefore, it is most likely that the corrosion layer developed under standing conditions between tests. This issue must still be investigated.

2D. If $\mathrm{pH}$ control should be necessary, a proportional integrating controller for the maintenance of $\mathrm{pH}$ levels is recommended over the simpler on-off controls in order to keep the conductivity fluctuations down to a minimum. It is likely that an on-off type of controller will cause high conductivity alarm shutdowns.

3. Though the Betz-recommended dissolved oxygen (DO) range, 50 to $200 \mathrm{ppb}$, is the most desirable, and although power plant practice is to use even lower DO levels which are also better for Mo, no serious effects were noted using the existing CDIF DO level of 3.2 to $3.4 \mathrm{ppm}$. Therefore, for the POC test Avco recommends a low DO range of 50 to $200 \mathrm{ppb}$ as being the preferred level but that acceptable operating performance is attainable with a range of dissolved oxygen up to $3.5 \mathrm{ppm}$.

3A. Should DO controls be implemented, hydroquinone is the control reagent of choice.

3B. The possibility of a scale buildup on stainless steel can be avoided in carbon steel-contairing systems if the $\mathrm{pH}$ is maintained near 7 and if dissolved oxygen contr is are instituted to hold the dissolved oxygen below $200 \mathrm{ppb}$.

4. The minimum acceptable resistivity for the deionized water is $500 \mathrm{kohm}-\mathrm{cm}$. There is no maximum acceptable water resistance.

5. The use of an NRC-approved copper corrosion inhibitor is recormmended. Two such inhibitors are CopperTrol and Tolytriazole. The recommended concentration of CopperTrol is 40 to $50 \mathrm{ppm}$.

\subsection{IA4 HARDWARE FABRICATION STATUS}

\subsubsection{Introduction}

The $1 \mathrm{~A} 4$ channel and diffuser fabrication schedule is shown in Figure 5-16. This schedule provides the duration and fa brication sequence for the diffuser, each of the channel walls, and final assembly of the channel and diffuser prior shipment to the CDIF in Butte, Montana, in March 1992. Channel fabrication activities include fabrication area setup with appropriate work stations, qualification of fabrication procedures and establishment of the quality assurance and quality control processes. A discussion and status of these activities is provided below.

\subsubsection{Fabrication Preparations}

Facilities preparation for fabrication included area layout and equipment setup. Specific work stations irclude areas and facilities for acid and caustic dips for pre-braze cleaning of tungsten and molybdenum: pre-braze giass-iead biasting ố copper, stainiess and brass pans. Speciñc iocations îor pans segregation, 


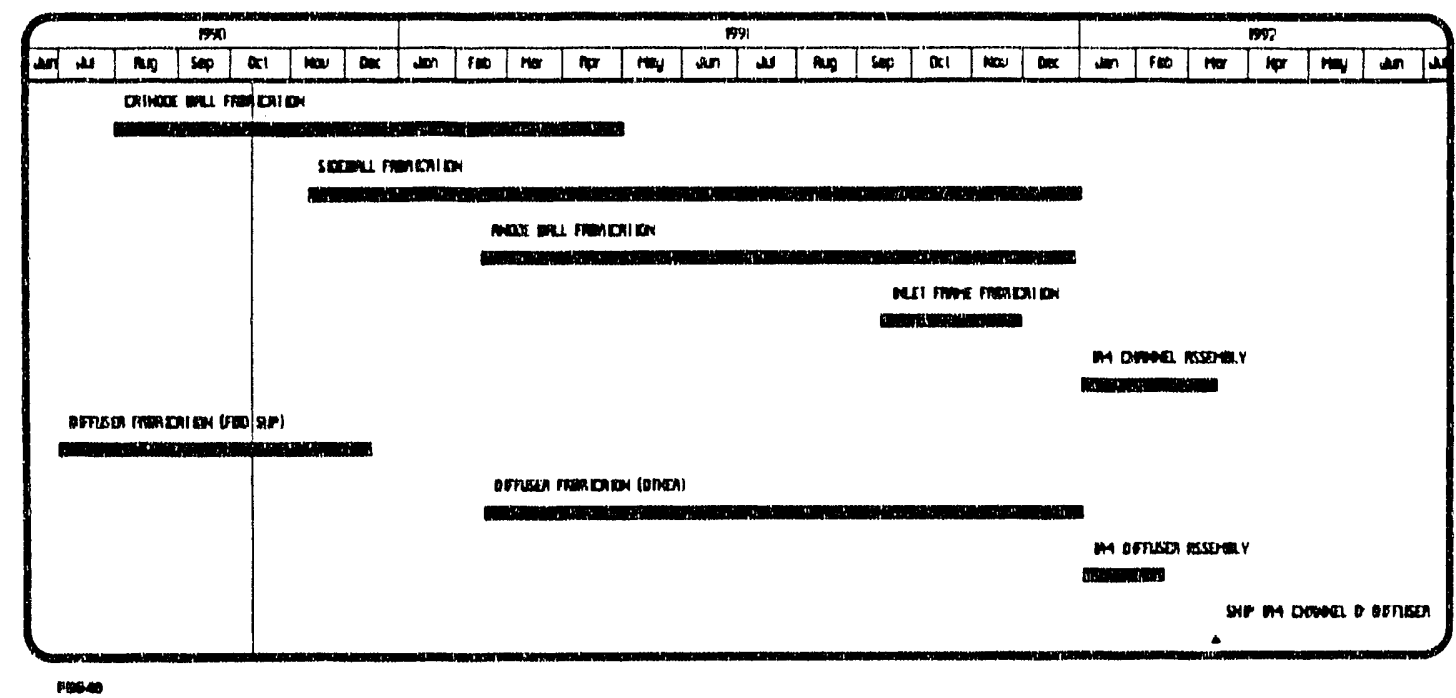

Figure 5-16. IA4 Channel and Diffuser Fabrication Schedule

parts labeling, dye penetrate testing, pre-braze fixturing and post-braze inspection were established. A system for record keeping, including fabrication checklists, was instituted.

Procedures were written to standardize:

- pre-braze cleaning

- pre-braze fixturing

- brazing - both torch and vacuum

- post-braze inspections

- post-braze flow and hydrostatic checks

- wall subassembly procedures and quality control checks

These procedures were put into practice on parts being built for the Mark VII and $1 \mathrm{~A}$ channel. In addition, several parts designed to 1 A4 channel specifications were fabricated to establish the adequacy of the procedures and techniques proposed for the $1 \mathrm{~A} 4$ channel. These exercises were used to train and qualify technicians on various aspects of channel fabrication.

Braze techniques (both vacuum and torch) and technicians were evaluated in accordance with qualification procedures written in accordance with the American Welding Society Brazing Manual guidelines. Test brazes were completed and evaluated by an American Society of Nondestructive Testing registered inspector. Results of the test brazes were filed in the Configuration Control system.

\subsubsection{Configuration Control}

in order to maintain configuration control of specifications, drawings, procedures and inspection reports, a Configuration Control system was established. A Configuration Management Plan (CMP) employed to provide configuration management and control of the $1 \mathrm{~A} 4$ hardware is described below. 


\subsubsection{Organization}

\section{Relationship to the Program Manager}

The Program Manager (PM) is responsible for configuration management and will provide final approval for determining the Class of a change. The PM will provide final approval for implementation of a change.

\section{Structure}

Implementation of the configuration management procedures is delegated to the Project Configuration Manager (PCM).

\subsubsection{Responsibilities}

The PCM is the single point of contact for all matters pertaining to configuration management and is responsible for the functions listed below:

- Prepare, implement and maintain the Configuration Management Plan.

- Assign identification numbers.

- Implement established requirements for the preparation, maintenance, and control of drawings, specifications, procedures, inspection reports and test results.

- Generate and distribute configuration identification and status reports.

- Implement preparation and submittal of Engineering Change Proposals (ECP).

\subsubsection{Configuration Identification}

\section{Configuration Identification Number (CIN)}

An identifying number will be assigned to all configuration changes. The CIN will have a prefix code of the project (S513), followed by the document or drawing number affected and a unique three digit code.

\section{Specifications and Procedures}

Specifications are assigned a drawing number. Procedures are identified as: Fabrication Procedures (FP), Inspection Procedures (IP) and Test Procedures (TP). These documents are maintained on file by the PCM.

\section{Drawings}

Each Drawing shall be identified by a single drawing number. The prefix for every drawing will be 643-. A master drawing list, including a current list of revisions will be maintained by the PCM.

\subsubsection{Configuration Control/Engineering Changes}

Proposed changes are categorized as Class I or Class II. Class I changes:

- Result in revisions to documents listed in the contract which require TRW approval.

- Affect inajor milestones or costs, or changes that may adversely affect the performance, life, reliability, interface requirements, and delivery of shipped hardware.

All other changes shall be classified as Class II.

Class I changes will be submitted on a Supplier Information Request Form (SIR) to TRW for approval, which must be granted before the change is implemented.

Class II changes made prior to the completion of the acceptance tests will not be processed through TRW. These changes will be documented, signed by the responsible engineer and verified by Quality

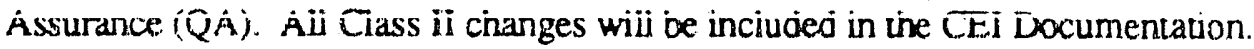




\subsubsection{Configuration Change Implementation}

All engineering changes to specifications, procedures and drawings will be processed by the PCM for distribution and storage. The PCM will obtain concurrence for the proposed change from the Design Engineer, the Fabrication Engineer and approval of the PM. The PCM will then document the approved change in accordance with the stipulations of a Class I or Class II change.

Both Class I and class II changes will be submitted to the PCM on an Engineering Change Request (ECR) form. The PCM will log the ECR and process it in accordance with the Change System Process Flow Chart shown in Figure 5-17. QA will certify that the change control process has been accomplished.

The PCM will distribute all approved changes to the initiator, the Design Engineer, the Fabrication Engineer, and drafting.

\subsubsection{Configutation Status and Accounting}

Each engineering change order will be tabulated along with the drawing numbers affected by the request and the status of each order (i.e., pending, authorized/not-authorized, complete). The approved configuration change will be distributed in accordance with Figure 5-18.

\subsubsection{Project Status}

A detailed baseline schedule for the 1A4 channel cathode wall and diffuser fabrication is shown in Figure 5-19. This schedule provides the logic and current status of each item.

As shown on the schedule, procurement of cathode tungsten caps, copper bases, brass tubes, studs and plugs was initiated. Other cathode wall activities are on schedule.

\subsubsection{Summary}

Facilities for fabrication of the 1A4 hardware are in place and are being used to build gas-side elements for the Mark VII and IA channels. Procedures necessary for the hardware fabrication have been written as have procedures for inspection and quality control. The channel and diffuser fabrication schedule shows delivery of the hardware to the CDIF in March 1992.

\section{REFERENCES FOR SECTION 5}

5-1. Glovan, Ron, MSE, private communication.

5-2. Refractory metals may be etched in basic solutions with the assistance of applied electric current. This electrochemical etching procedure is used in the industry to produce an enriched Cu surface on Tungsten Copper alloys before brazing. Similarly, because of the stability of refractory materials to strong acids, electrochemical acid etching can be used to produce a lustrous refractory-metal-rich surface by removing the copper from tungsten copper alloys.

5-3. EPRI Report CS 4629, Interim Consensus Guideline on Fossil Plant Cycle Chemistry, June 1986.

5-4. Betz Analytical Services, P.O. Box 4300, 9669 Grogan's Mill Rd., The Woodlands, TX 77380.

5-5. Natesan, K., and Soppet, W.K., "Water Corrosion Test with an Organic Additive in Support of an MHD Channel," ANL。1990. 


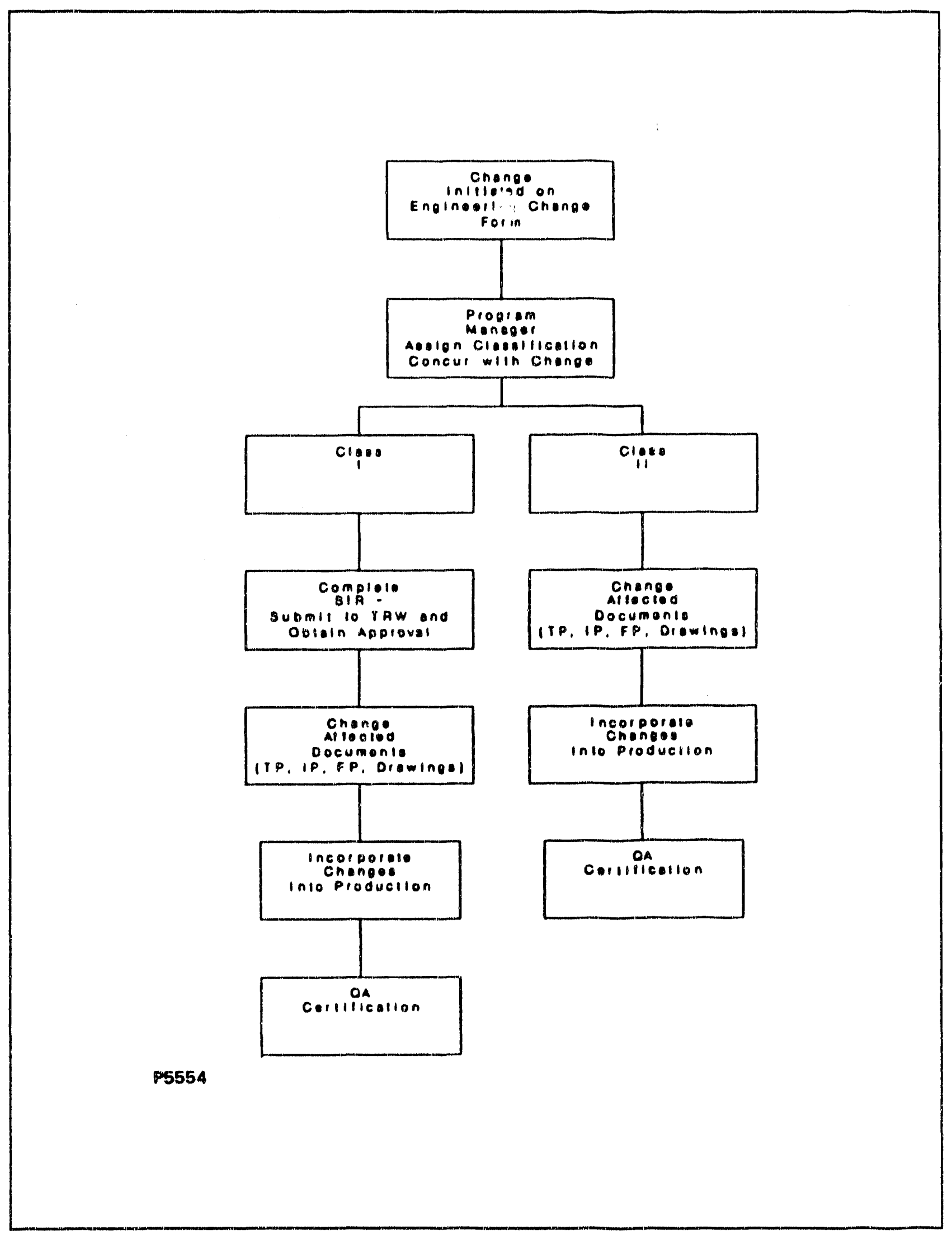

Figure 5-17. Configuration Control Flow Chart 


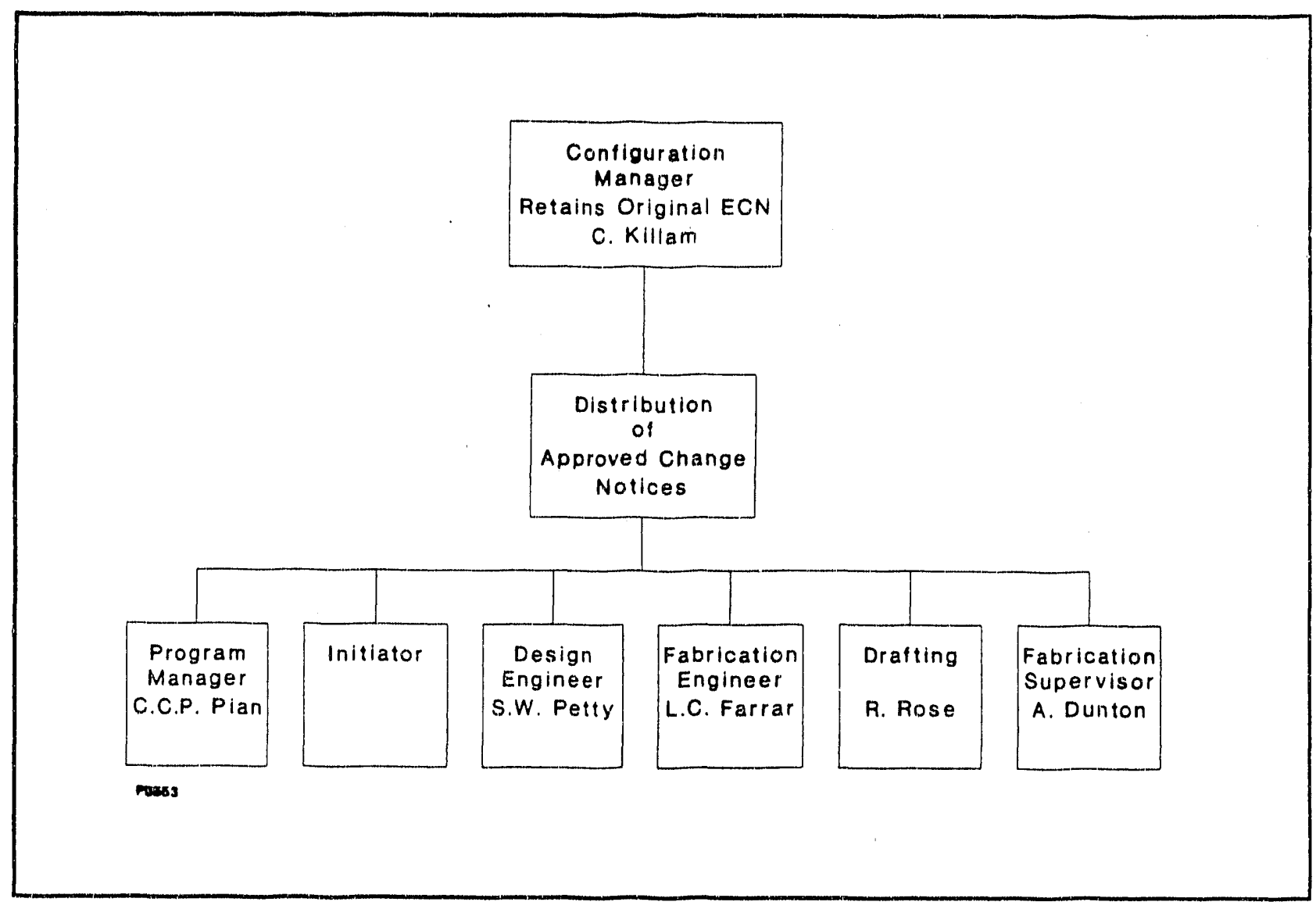

Figure 5-18. Configuration Control Change Distribution 


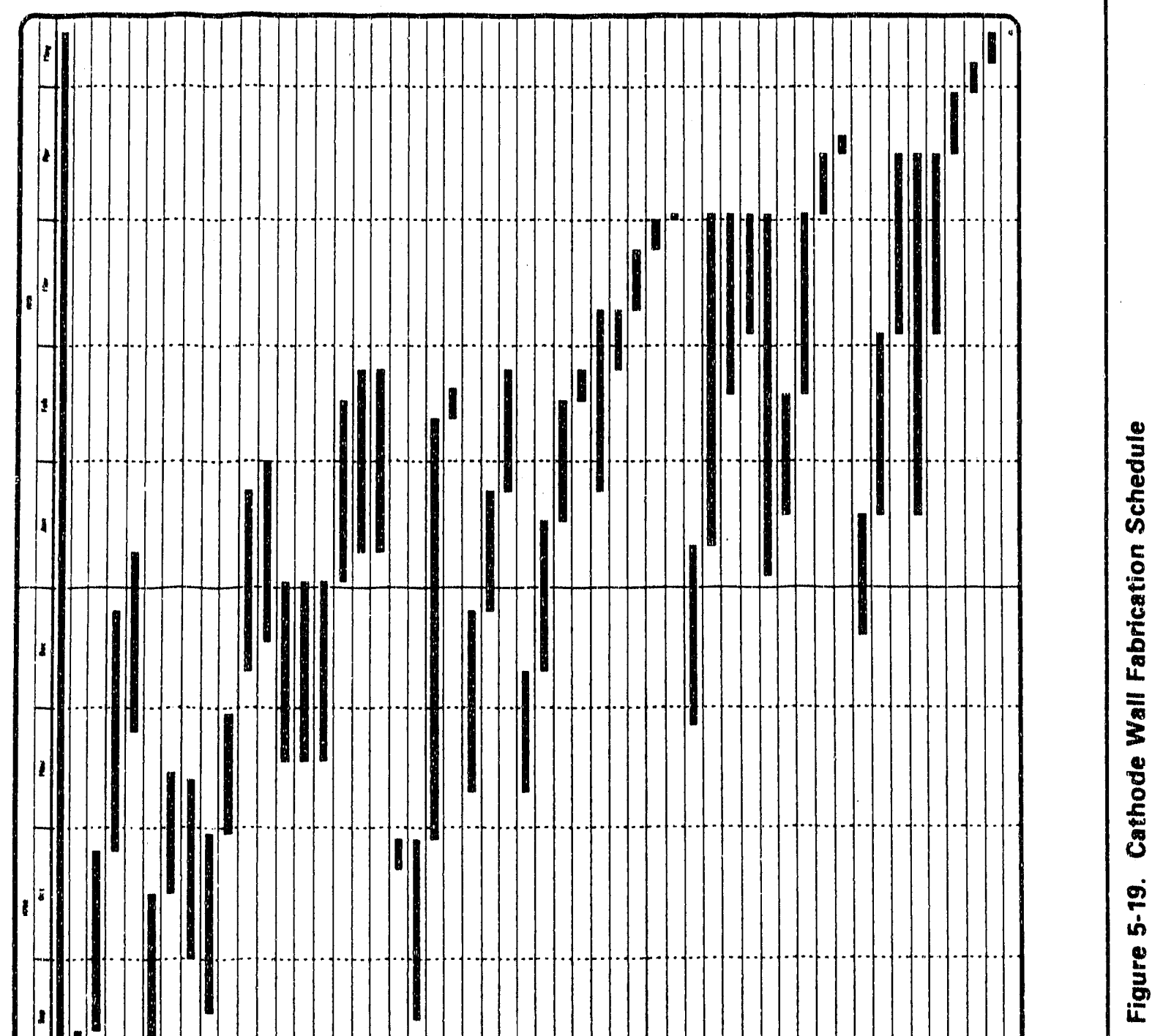
10 (1) 


\section{CURRENT CONSOLIDATION SUBSYSTEM DESIGN AND FABRICATION ('TASK 5)}

The Preliminary Design Review (PDR) for the Current Consolidation Subsystem was conducted during the last quarterly reporting period. The proposed CDIF design is a scaled version of the breadboard system tested on the Mark VII at Avco. The same two-pulse midpoint converter topology will be utilized for the current consolidators, except the component ratings are selected based on the requirements presented in Table 6-1. The design considerations in selecting the key components are presented in this section.

TABLE 6-1. CURRENT CONSOLIDATION SUBSYSTEM REQUIREMENTS

\begin{tabular}{|c|c|c|}
\hline Parameter & Requirement & Source \\
\hline $\begin{array}{l}\text { Number of Consolidators in } \\
\text { Each PTO Region }\end{array}$ & 30 & Avco \\
\hline \begin{tabular}{|l} 
Current Consolidator DC Output \\
Voltage Range \\
\end{tabular} & \pm 375 VDC & Avco/Westinghouse \\
\hline $\begin{array}{l}\text { Current Consolidator Output } \\
\text { Current Range } \\
\end{array}$ & $\begin{array}{l}\text { 0-40 Amps Max. } \\
0-30 \text { Amps Avg. }\end{array}$ & AvcoMestinghouse \\
\hline Output Ripple Current (RMS) & $5 \%$ of Maximum Load Current & Westinghouse \\
\hline Electrical Isolation & $12 \mathrm{KV}$ & TRW \\
\hline $\begin{array}{l}\text { AC Input Voltage to } \\
\text { Consolidation Converter } \\
\text { Transformers }\end{array}$ & $60 \mathrm{~Hz}, 4160 \mathrm{VAC}$ & Westinghouse \\
\hline Cooling Requirements & Forced Air & Westinghouse \\
\hline Ambient Temperature & $0-40^{\circ} \mathrm{C}$ & Westinghouse \\
\hline Design Life & $\begin{array}{l}\text { In Excess of POC Equipment }(>20,000 \\
\mathrm{Hr}, 2000 \mathrm{Start} / \mathrm{Stop})\end{array}$ & Westinghouse \\
\hline Compatibility & Operate at CDIF & sow \\
\hline Design Basis & Based on Avco Mark VII Breadboard & Westinghouse \\
\hline Scalability & $\begin{array}{l}\text { Allow an evaluation for scaling up to } \\
\text { commercial retrofit MHD power } \\
\text { plant size }\end{array}$ & SOW \\
\hline Inspection/Maintainability & $\begin{array}{l}\text { Ready access for inspection and } \\
\text { parts replacement }\end{array}$ & Westinghouse \\
\hline Personnel Safety & Standard Practices ANSI C2-1990 & Westinghouse \\
\hline Interfaces & CDIF Inverter 1A4 PTO Electrodes & sow \\
\hline Off-normal Conditions & Zone 3 seismic & Westinghouse \\
\hline EMI Effects & $\begin{array}{l}\text { All critical circuitry equipped with } \\
\text { EMI shielding }\end{array}$ & Westinghouse \\
\hline Instrumentation & $\begin{array}{l}\text { All measurements required for } \\
\text { operation self-contained }\end{array}$ & Westinghouse \\
\hline Current Consolidator & $300 \mathrm{msec}$ & Westinghouse \\
\hline AC Voltage Tolerance & $10 \%$ & Westinghouse \\
\hline
\end{tabular}


An investigation of voltage transients appearing on the DC bus of the inverter at the CDIF was carricd out. The cause of the transients was identified, and the installation of a simple RC filter from the positive bus to ground greatly reduced both the amplitude and frequency of the transient wave form. Also, it was shown that the spike does not affect any aspect of the proposed current consolidation subsystem design.

\subsection{CONSOLIDATION CONVERTER TRANSFORMER}

Derivation of the transformer secondary voltage rating needed to supply the $750 \mathrm{~V}$ electrode span voltage is presented in Figure 6-1. The resultant transformer secondary is a center tapped winding supplying a $V_{S}$ of $443 \mathrm{VAC}$ between the center tap and each end.

\subsection{GTO AND SCR VOLTAGE RATINGS}

The voltage ratings of the thyristors (SCRs) and gate turmoff thyristors (GTOs) used in the 2-pulse converters are dependent on the source voltage, protection networks, and operating conditions.

Representative 2-pulse GTO and SRC converters with associated suppression, overvoltage protection, and output filters are shown in Figure 6-2. The normal forward and reverse voltage stress that each GTO experiences is equal to twice the peak of the source voltage $V_{S}$. With a $V_{S}$ of $443 \mathrm{VAC}$, this voltage is:

$$
\mathrm{E} 1=(2.82)(443)=1253 \mathrm{~V}
$$

A more severe voltage is produced by a fault condition that would result in one of the GTOs being tumed OFF while carrying current I and not having its companion GTO being turned ON. The MOV overvoltage protector acts as an altemate path to carry current I and dissipates the energy stored in inductor L5 of the converter output filter. The resultant voltage stress produced across the GTOs can be as much as the sum of the MOV clamping voltage and the peak of the source voltage $\mathrm{V}_{\mathbf{s}}$. The forward and reverse voltage ratings, $V_{d r m}$ and $V_{\mathrm{rmm}}$, of the GTOs must be greater than this sum. A possible choice for the MOV device is a GE V480HEA50 that has a RMS voltage rating of $480 \mathrm{~V}$ and a maximum clamping voltage of $1320 \mathrm{VDC}$ (at $300 \mathrm{~A}$ ). The energy rating of this MOV is 450 Joule.

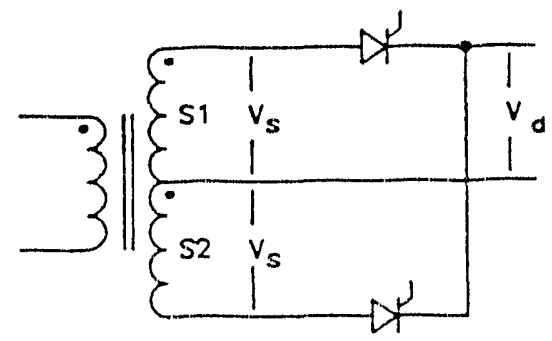

$$
\begin{aligned}
& v_{d}-.901 v_{s} \cos \alpha \\
& v_{s}-\frac{v_{d}}{.901 \cos \alpha} \\
& \alpha=\text { FIRING ANGLE }
\end{aligned}
$$

$$
\begin{aligned}
& \begin{array}{c}
\text { END } \\
\text { OF } \\
\text { SPAN } \\
\perp \\
V_{D}<0 \\
\text { INVERSION }
\end{array} \\
& \propto-160^{\circ} \\
& \text { VD }-0.5 \times \text { TOTAL SPAN VOLTAGE } \\
& \alpha=160^{\circ} \\
& V \text { SPAN }=750 \text { V. (AVCO 7/24/90) } \\
& v_{s}-\frac{.5 \times v \operatorname{SPN}}{|.901 \cos \alpha|}-\frac{.5 \times 750}{|.901 \cos 160|}-442.91 \mathrm{~V} \text {. }
\end{aligned}
$$

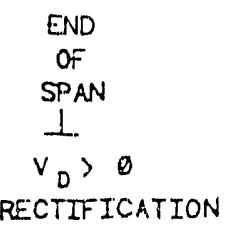

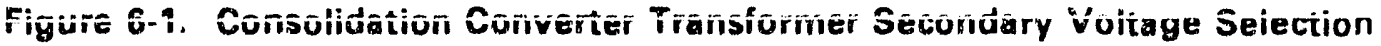




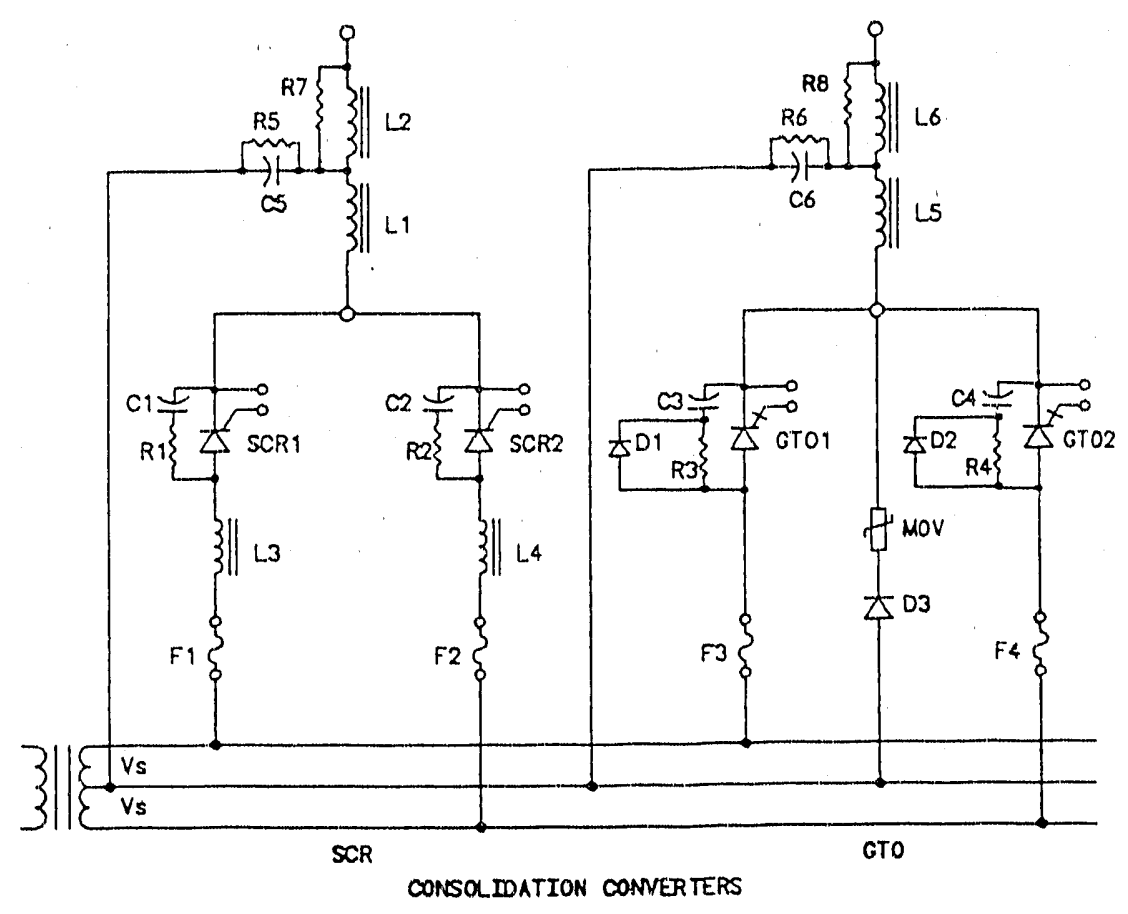

Figure 6-2. Consolidation Converter Components

$V_{d r m}>1320+(1.414)(443)=1946 \mathrm{~V}$

$\mathrm{V}_{\mathrm{rm}}>1946 \mathrm{~V}$

A POWEREX FG600C-50 with a $V_{d r m}$ and $V_{r m}$ rating of $2500 \mathrm{~V}$ is a suitable choice for the GTOs. The voltage rating $s$ of the snubber diodes and snubber capacitors in the GTO consolidation converter also should be $2500 \mathrm{~V}$.

The normal forward and reverse voltage stress encountered by SCR1 and SCR2 in the Si 'R consolidation converter is, again, twice the peak of the source voltage $V_{S}$. The commutation of current from one SCR to the other in the operation of the inverter produces a transient voltage that may exceed this level. Inductors $\mathrm{L} 3$ and $\mathrm{L} 4$ limit the rate-of-change of current, $\mathrm{di} / \mathrm{dt}$, that occurs during the hard commutation of current from one SCR path to the other. The source voltage, di/dt inductors L3 and LA, suppression network (i.e. R1 and $\mathrm{C} 1$ ), and the recovery characteristics of the SCR determine the voltage transient produced during commutation and the consequent required voltage rating of the SCR. The maximum voltage transient occurs when the effective commutation voltage is:

$\mathrm{Ec}=(2)(1.414) \mathrm{V}_{\mathrm{S}}=1253 \mathrm{~V}$

Using an inductance of 50 microhenry for each of $L 3$ and $L A$, the commutation $\mathrm{di} / \mathrm{dt}$ is:

$\mathrm{di} / \mathrm{dt}=1253 / 0.0001=12.5 \mathrm{~A}$ per microsecond

The SCR reverse recovery charge, $Q_{\pi}$, is an important devise parameter which should be minimized to reduce the commutation recovery voltage. A pessimistic value of the peak reverse recovery current, Ios, is given by:

$$
I_{o s}=\sqrt{\left(2^{*} Q_{i i}^{*} d i / d t\right)}
$$


For a $Q_{\mathrm{rr}}=150$ microcoulombs, $\mathrm{I}_{\mathrm{OS}}=61.2 \mathrm{~A}$. Computer simulation of the recovery voltage transient produced with $\mathrm{R} 1=20$ and $\mathrm{Cl}=0.5 \mu \mathrm{F}$ indicates a peak reverse voltage transient of $1600 \mathrm{~V}$.

A POWEREX T72H2430 SCR with a voltage rating of $2400 \mathrm{~V}$ and a $Q_{\pi}$ rating of $150 \mu \mathrm{c}$ is a suitable choice for the SCR consolidation converters. A $2000 \mathrm{~V}$ voltage rating for $\mathrm{C} 1$ is conservative.

\subsection{GTO AND SCR CURRENT RATINGS}

The maximum required output current of a given consolidation converter is $40 \mathrm{~A}$. The corresponding required average current rating for the individual GTOs and SCRs is $20 \mathrm{~A}$. The average current ratings of the above identified GTO and SCR are $170 \mathrm{~A}$ and $300 \mathrm{~A}$, respectively, which far exceed the required average current rating. The apparent mismatch between device current rating and required rating is a consequence of the unavailability of commercial SCRs and GTOs with lower current ratings along with appropriate voltage, $Q_{\mathrm{IT}}$, etc., characteristics.

\subsection{CONVERTER OUTPUT FILTER}

The output filter component values for each converter is similar to that used in the breadboard current consolidation subsystem supplied for the Mark VII MHD channel at Avco. Referring to Figure 6-2, the L1L2-C5-R5-R7 combination comprises the output filter. R5 is used to assure the discharge of C5 after the equipment is de-energized and is not a factor in the performance of the filter. The current and voltage ratings of the filter components will conform to the 40 A maximum current (30 amps average) and $400 \mathrm{~V}$ maximum voltage requirement of the individual consolidation converters. The various resonant frequencies of the filter are the same as those for the breadboard subsystem so that the expected response time of the converter will be similar. The expected maximum RMS output ripple current from the converter-filter combination is $5 \%$ of rated maximum output.

\subsection{CDIF CONTROL SYSTEM}

The CDIF system will use the same type of control system utilized on the breadboard system tested at Avco. Each consolidation converter will be controlled by dedicated circuitry which is fed a reference operating point from a computer which is coordinating the operation of all the consolidators in the group. This type of system was used on the breadboard subsystem that was tested on the Mark VII. The computation and administrative demands on the computers will be greater for the CDIF system due to the greater number of electrodes. Thus, computers will be selected that accommodate the faster data processing requirements for the C.DIF.

The additional electrodes also impact the current in the indirectly controlled electrode. As the number of electrodes goes up, more control tolerance errors can accumulate in this electrode. Thus, there is concern that with a large number of electrodes, this electrode current will substantially deviate from its desired profile.

Even though direct current control is not used on this electrode, in general its current is still determined by how the other electrodes are programmed. To review, the indirectly controlled electrode satisfies the following criteria:

1. Allows for passing currents due to control tolerance errors and transients on the other controllers. Since the other controllers implement PI type control which operates with zero error in steady state, a pathway for currents due to control tolerence errors must be provided.

2. Establishes the voltage of the consolidation point with respect to the channel so that the voltage excursion requined for the remaining converters is minimized. If the electrode that is at the midspan voltage of the PTO region is used, then the controllers could be designed for a voltage range that is $1 / 2$ of PTO span.

To resolve this problem, it has already been proposed that thene will be an "adjustment" algorithm implemented where this electrode current is monitored and the other references will be fine tuned to make sure this current stays within reasonable bounds. This technique was not implemented in the Mark VII tcst, 
since the number of electrodes was limited. The data collected showed that the current in this electrode was more active than the others, but still followed the basic desired profile. However, this algorithm can be added for future Mark VII tests.

Another approach is to use a proportional type control on all of the consolidators including this one. A proportional control is a non-zero error type control and would not be affected by the small control tolerance errors. The system operates with a steady state error between the feedback and the reference. This would allow a direct current control on all the converters and would minimize concems that one of the electrode currents will deviate from its desired profile. This is illustrated as "Alternative 1" in Figure 6-3.

If this type of approach is used, then some other means must be specified to reference the consolidation point to the channel. Otherwise, it will be necessary for each of the converters to have a voltage range equal to that of the PTO region. For the CDIF system, this is $750 \mathrm{~V}$. To cut this range in half as it is for the baseline approach, it would be necessary to reference the consolidation point to a sidebar on the channel that is at the midpoint voltage of the PTO span.

There are two points on this type of control:

1. In theory, the sidebar location at the mid-span PrO potential does exist, but sufficient data on sidebar characteristics are not available to make this a clear choice. Thus, further testing is required to determine the feasibility of this approach.

2. The connection to the sidebar provides a means for the tolerance error and transient currents to flow. Thus, it should be possible to operate the current consolidators as PI type control, as in the baseline approach.

Another approach is shown as "Alternate 2" in Figure 6-3. This is the same as the baseline approach, except the consolidators adjacent to the direct connection electrode are operated in the voltage mode. They would be set for a voltage output corresponding to the expected interelectrode voltage in their respective location. This allows for additional paths for the error currents to flow. The voltages can be set within some band so that the currents will remain within a certain range. Thus, some degree of current control will be possible in these electrodes.

In conclusion, the proposed control hardware configuration for the CDIF can accommodate any of the above approaches. Each current consolidator can be operated in a voltage or current mode, and the consolidation reference point connection can be made by moving cables around. Thus, the critical design process can continue without making a firm decision. However, the breadboard testing showed that the baseline approach is viable. To accommodate the CDIF system with more electrodes, this can be enhanced by additional software to fine tune the indirectly controlled electrode current.

\subsection{HIGH VOLTAGE CONSIDERATIONS}

Appropriate measures must be employed to assure proper voltage isolation for the various consolidation converters and for the different signal communications between the converters and the controls. This is particularly true for the anode electrode consolidation networks that may operate at potentials around $12 \mathrm{kV}$ with respect to system ground. Figure 6-4 shows a block diagram of the anode consolidation converters. The $4160 \mathrm{~V}: 886 \mathrm{~V}$ power transformer, $\mathrm{T}$, will provide voltage isolation between the $4160 \mathrm{~V}$ power sour:e and the anode consolidation point. The components for the different converters and filters will be mounted on intemal cabine: - - uctures that are suitably isolated from system ground. Supply transformer(s), $T_{S}$, will supply energy from the secondary of $\mathrm{T}_{\mathrm{p}}$ to the gate driver for each converter. The primary to secondary voltage insulation for these transformers will be at least $2.5 \mathrm{kV}$. The average voltage between the primary and secondary of $T_{S}$ is as much as 443 VAC and the peak transient voltage can be as high as $2 \mathrm{kV}$.

The gating pattem will be transmitted from the control to the gate driver by a fiber optic cable. This provides complete voltage isolation and excellent noise immunity. A current transducer, CTIn, is used to 


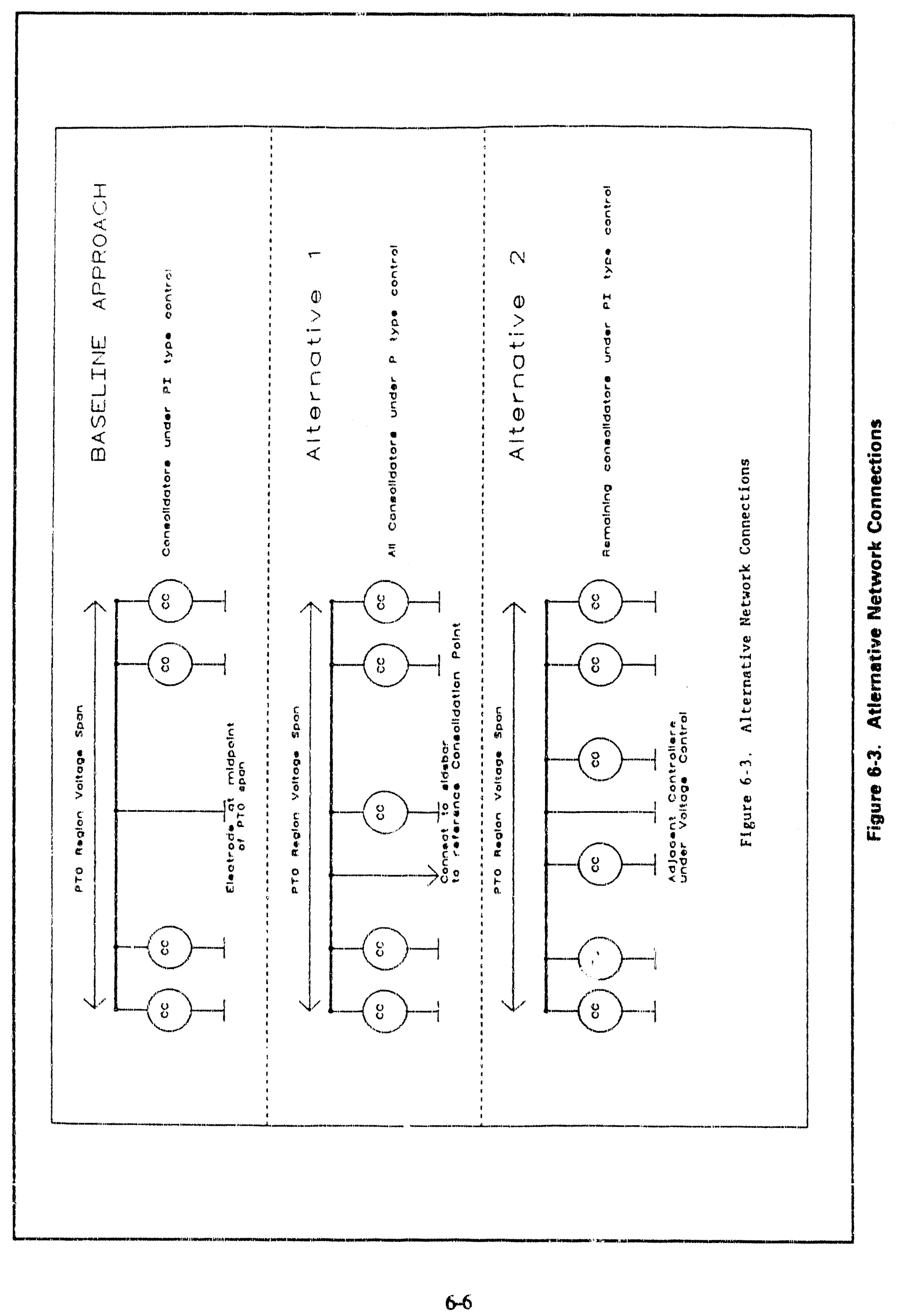




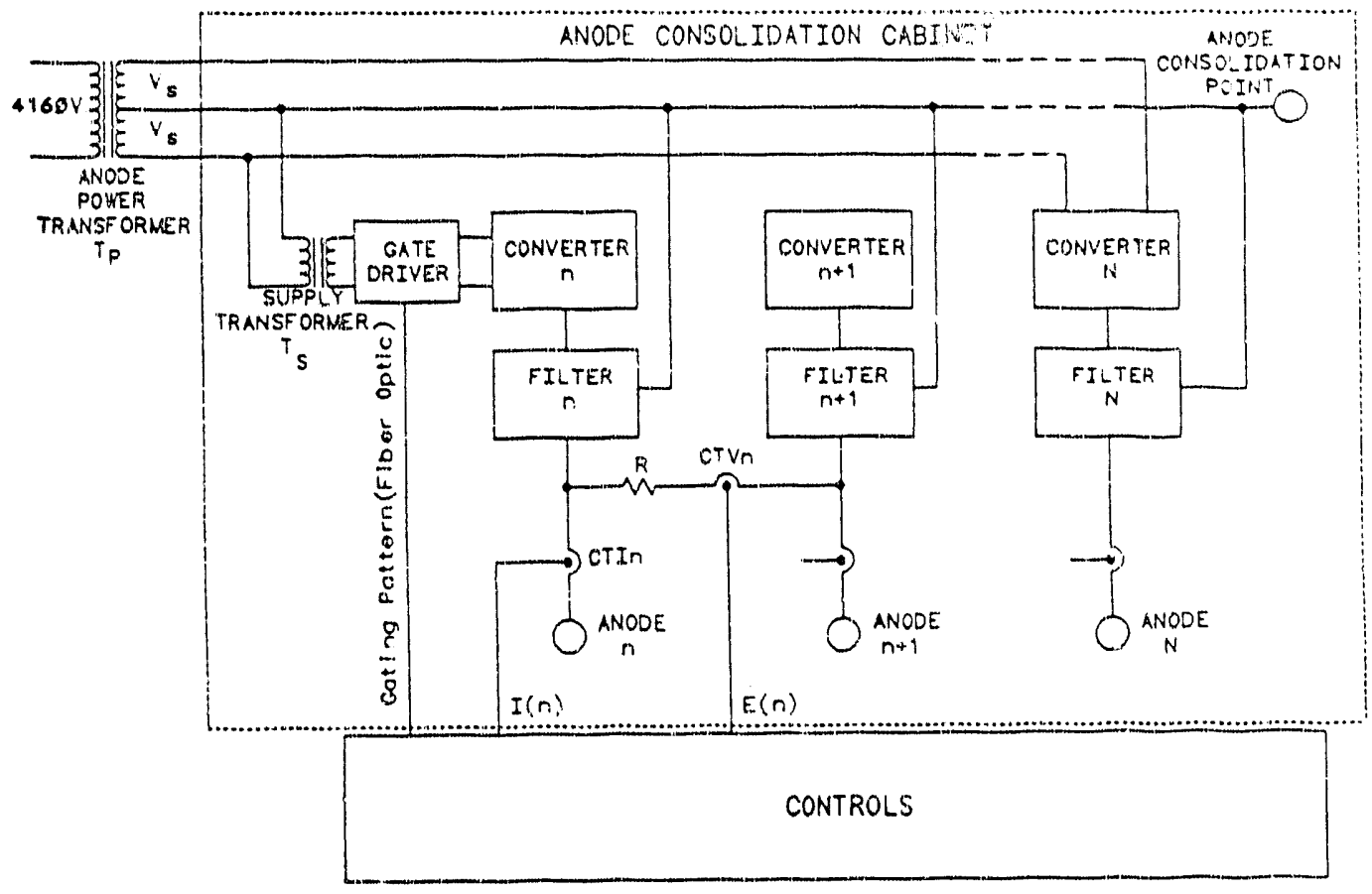

Figure 6-4. High Voltage Considerations

sense the current to anode electrode $n$. The transducer itself will be mounted at system ground potential and a cable carrying the anode electrode current will pass through the core urindow of the current transducer. The high voltage insulation properties of this cable will provide the required voltage isolation between electrode potential and the transducer output signal $l(n)$.

The interelectrode potential between anode electrode $\mathbf{n}$ and anode electrode $\mathrm{n}+1$ is sensed by producing a 0 to $5 \mathrm{~mA}$ current through a resistor $\mathrm{R}$ connecte $\mathrm{between}$ these two electrodes. This current will also excite the sense winding of current transducer CTVn. The voltage isolation rating between the sensc winding of CTVn and its output signal, $E(n)$, will be at least $20 \mathrm{kV}$. The potential between a given anode electrode and the anode consolidation bus can be derived by summing the involved interelectrode potentials.

Similar construction and voltage isolation measures will be utilized in the construction of the cathode consolidation converters where it is economically feasible. Since the cathode equipment does rot require the $12 \mathrm{kV}$ isolation levels, components with lower lewels will be used where the cost savings are significant.

Since this equipment will be operating in an electrically noisy environment, it is important that all of the electronics are properly shielded from EMI emissions. For equipment operating in this type of enviromment, it is standard practice to enclose the gate drive circuitry for the power semiconductors in metallic enclosures. Proper measures to enclose the control electronics and computers will also be required.

\subsection{BACKUP RESISTIVE CONSOLIDATION}

As a backup to the current consolidation subsystem, an autwatic switch over to a resistive consolidation system was provided. The benefits of this feature is that it eliminates the possibility of open circuiting the channel while the system is on-line. It also ninimizes the reed to shut the system down due

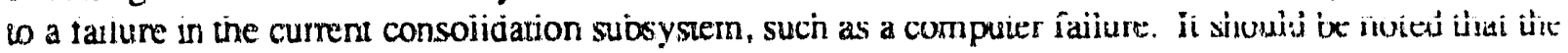
likelihood of losing, all of the current $\alpha$ olidators is extremely unlikely, given the methods for setting the 
current references. However, resistive backup is recommended because the additional circuitry required is relatively simple.

Figure 6-5 focuses on the resistive consolidation network as connected to the anode side. The overvoltage trigger fires the thyristor if excessive voltage is detected across any of the consolidation converters. An excessive voltage is one that exceeds the output range of the consolidation converters. The circuitry contained in the overvoltage trigger derives its power from the channel. Thus, this network is completely independent of the remainder of the current consolidation system.

\subsection{MECHANICAL PACKAGING/LAYOUT}

Several candidate designs are being considered for the packaging of the consolidation converter equipment and controls. One of the designs under consideration is shown in Figure 6-6 to present an estimate of the floor space required for the equipment. This design packages the power equipment for each side in two 84" $\times 72 " \times 96^{\prime \prime}(\mathrm{L} \times \mathrm{W} \times \mathrm{H})$ cabinets, with doors to access the equipment form both sides. These cabinets house the power equipment, and are electrically isolated from the controls, which are contained in separate cabinets. The input transformer for each side is also housed in a separate cabinet. With dimensions of approximately $24 \times 28$ feet, the current consolidation equipment requires 672 square feet of floor space. Figure 6-7 shows the candidate cabinet layout. Figure 6-8 show's the systern of key interlocks used to prevent accidental exposure to high voltages.

\subsection{INVERTER IMPACT ON CURRENT CONSOLIDATION EQUIPMENT}

The electrical relationship of an individual cathode consolidation converter and the CDIF inverter is illustrated in Figure 6-9. The center tap of the secondary voltage winding of transformer $T_{p}$ is the cathode consolidation point for the various cathode consolidation converters and is directly connected to the positive

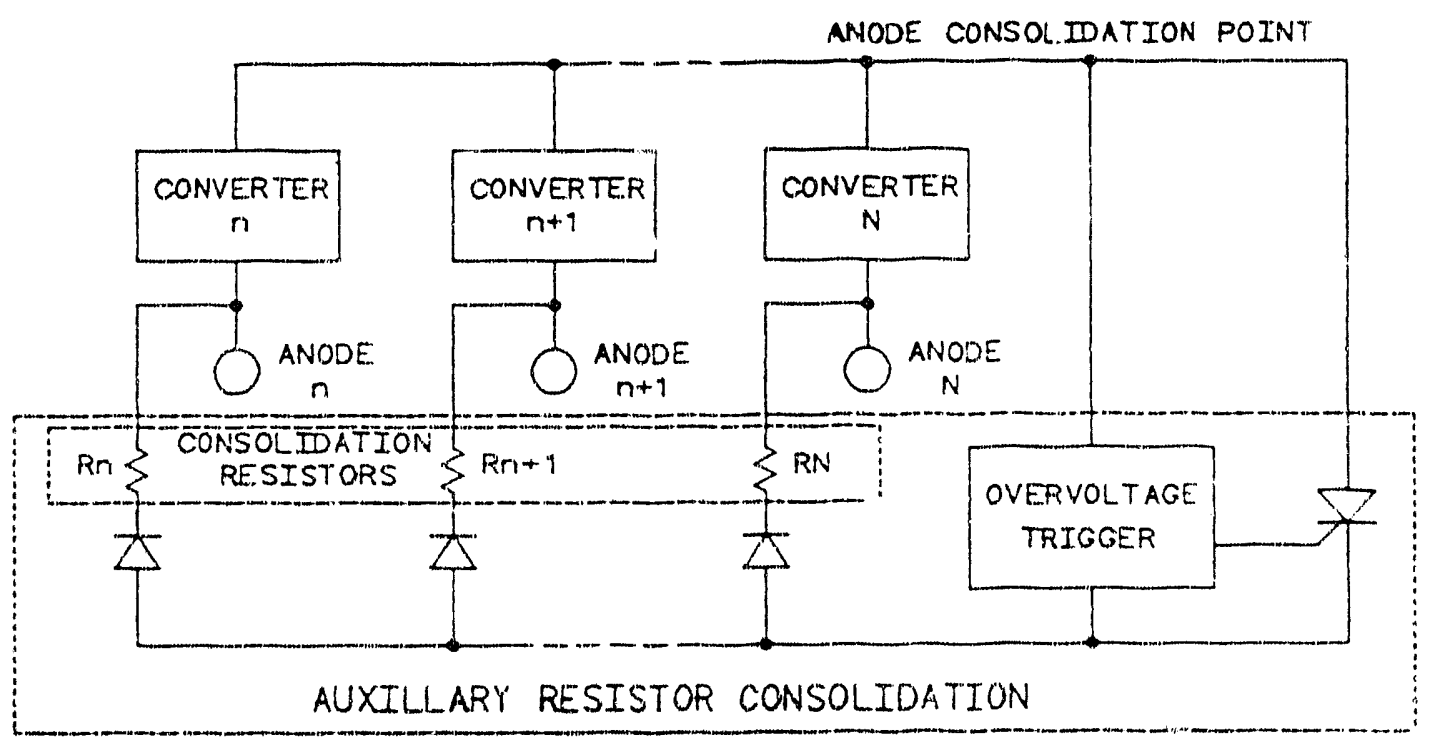

Figure 6.5. Anode Side Resistive Network Connection 


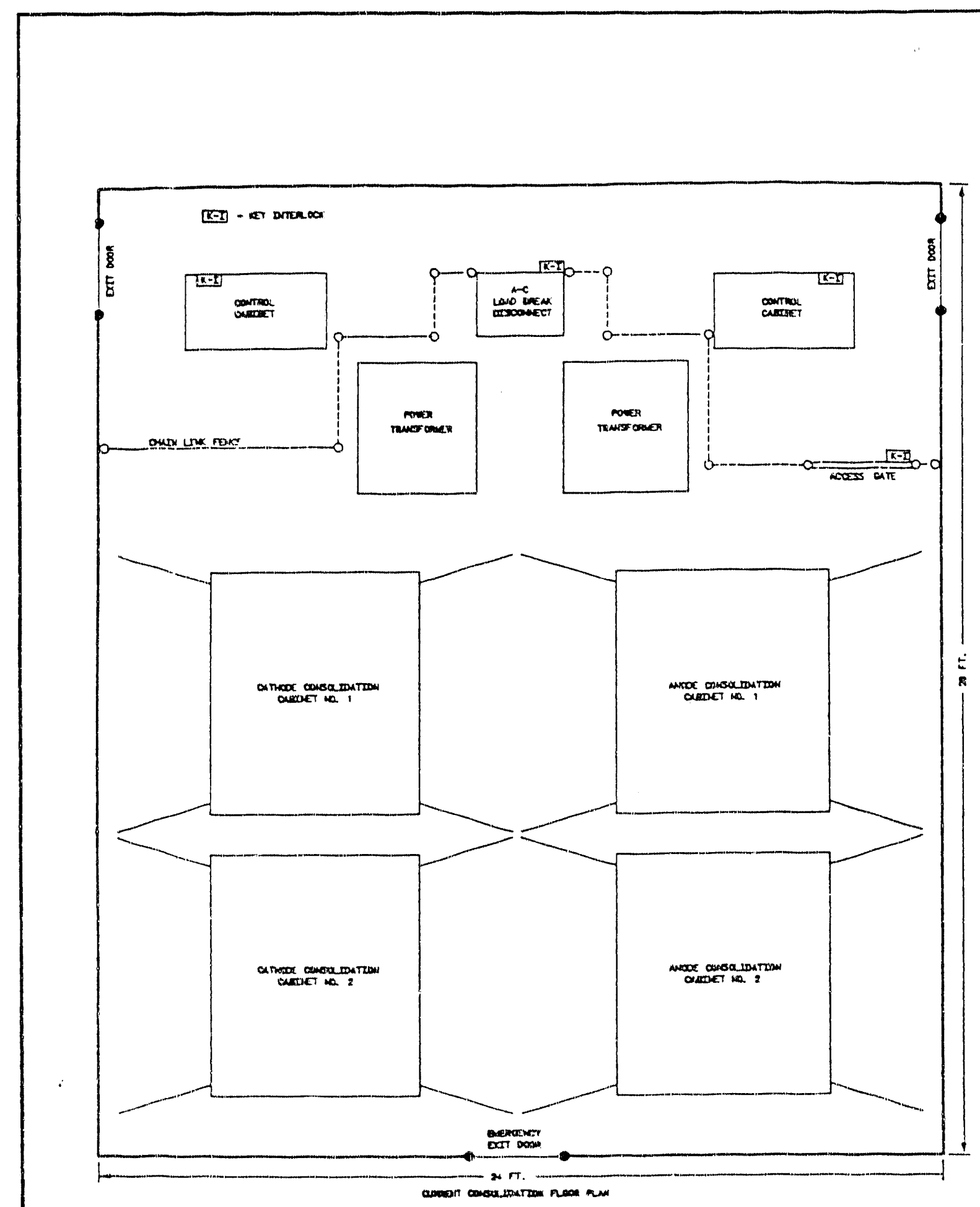

Figure 6-6. Candidate Floor Plan 

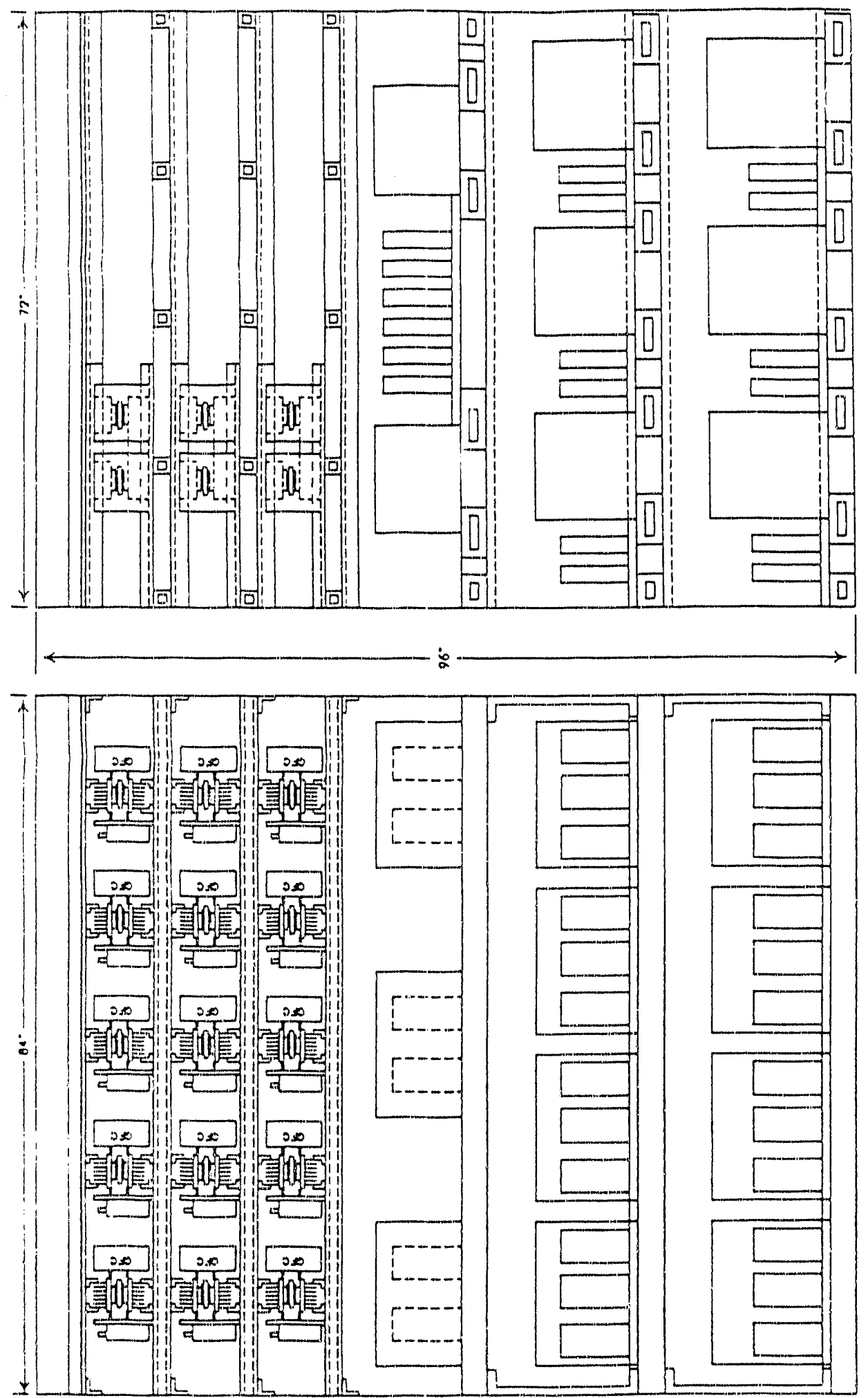


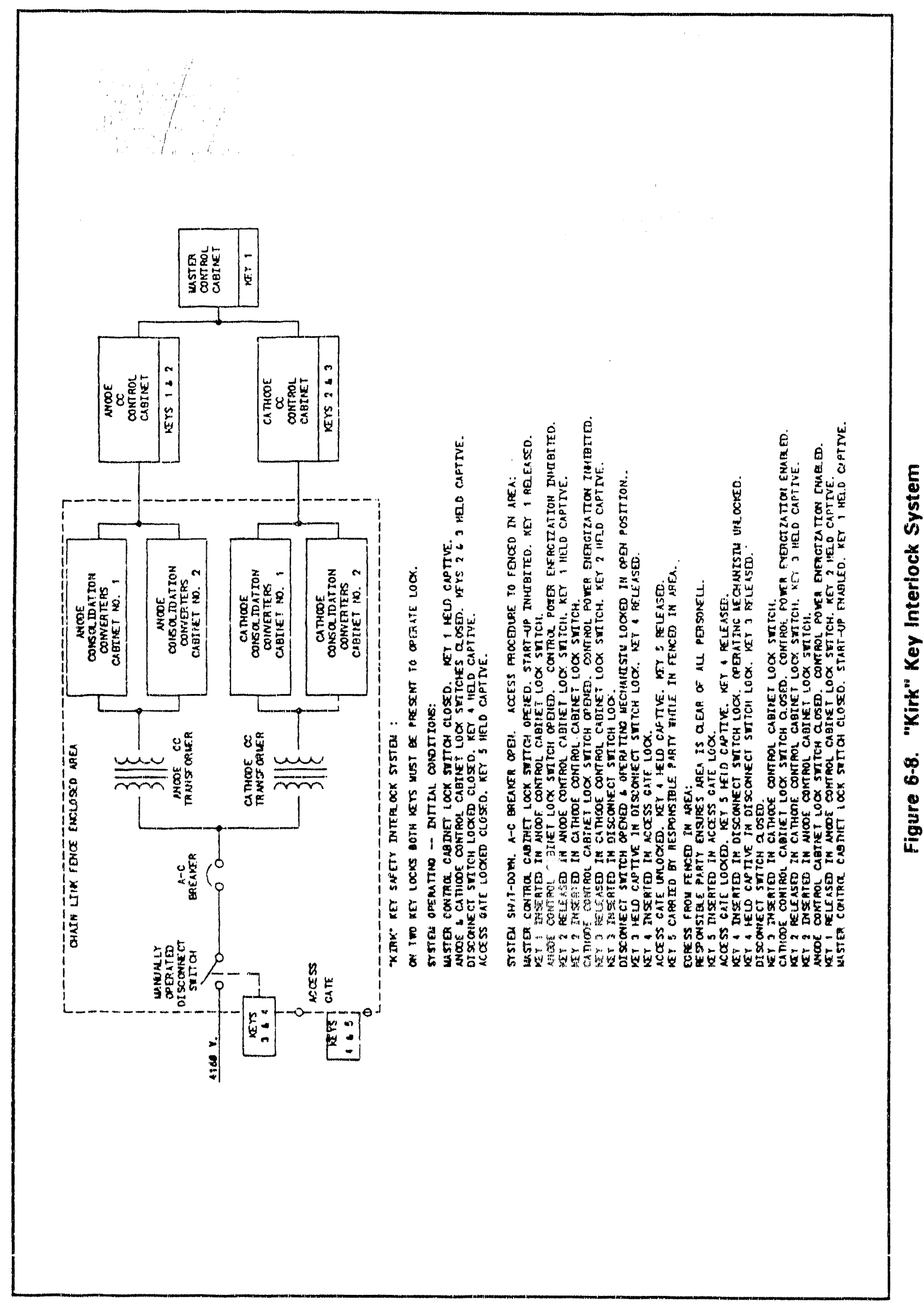




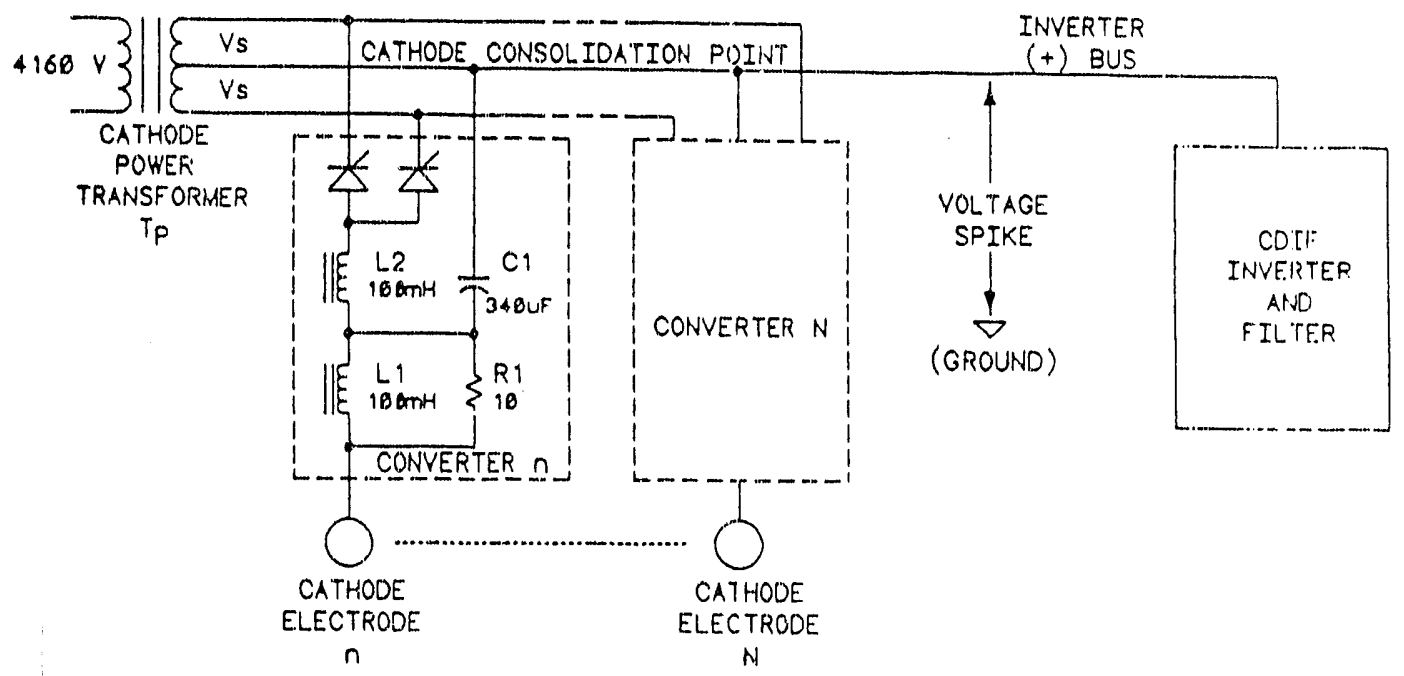

Figure 6-9. Electrical Relationship of an Individual Cathode Consolidation Converter and the CDIF Inverter

( + ) bus of the CDIF inverter. Voltage spikes (with respect to ground) existing on the inverter positive bus will also tie present at the cathode consolidation point. The voltage spikes are coupled to the different cathode ellectrodes through their associated C1-R1-L1 filter networks. The high-frequency, short duration (i.e. $10 \mathrm{kH}[\mathrm{z}, 200 \mu \mathrm{sec}$ ) content of the voltage spike does not affect the voltage on $\mathrm{Cl}$. Consequently, the solid-statt components (SCRs or GT'Os) of the different conventers are not affected by these voltage spikes. In the same manner, the anode consolidation converters are unaffected by voltage transients originating from the CDIF inverter.

Control signals between the gate drivers for the consolidation converters (not shown) and the consolidation converter controls (not shown) are also unaffected since fiber optics are used to transmit these signals. 


\section{CDIF TESTING}

Workhorse power train testing at the CDIF is divided into two phases: 1) design verification testing (DVT) of the coal-fired precombustor (CFPC) and 2) the Confirmation Test Series. During previous reporting periods, the precombustor DVT program was completed and the confirmation testing was initiated. The Confirmation Test Series is focused on confirming the design of the prototypical power train components prior to fabrication of the actual prototypical hardware.

\subsection{BACKGROUND}

Confirmation testing continued duriag the thirteenth quarter and consisted of a continuation of two of the test series which had been initiated during last quarter: the 90-CC-Series which focused on the checkout and design verification testing of the current control subsystem and the 90-MATL-Series which focused on testing of the Avco prototypical channel coupons. Concurrent with these test series, there were several attempts at long duration (24-hour) continuous thermal/electrical operation in order to evaluate: 1) the long term effects of iron oxide injection on the cathode wall voltage nonuniformities, and 2) the impact of long duration thermal operation on the accumulation of slag (fouling) within the coal-fired precombustor components.

Six tests were conducted during this quarter, accumulating 46.6 thermal hours and 15.7 power hours. A long duration thermal test of 21 hours, 15 minutes was completed which marked a new milestone in CDIF test history.

The power train configuration for this series of tests is described in the following sections.

\subsubsection{Combustor}

The combustion subsystem configuration was identical to that utilized for testing during the previous reporting period. The second stage oxygen was configured with an effective $L / W$ of 2.7 and 12-port horizontal injection.

For this series of tests, the existing workhorse "filler" section was replaced with a new component which simulates the gas-side metal temperatures which will exist during prototypical operation with higher cooling water temperatures. The filler is the component which transitions from the coal-fired precombustor to the first stage. The new filler is ide utical in terns of method of construction to the existing workhorse filler, however: 1) the gas-side metal thickness was increased in order to attain the higher metal surface temperatures that will exist with the prototypical hardware, and 2) the materials of construction have been changed to match the materials selected for the prototypicai hardware. The purpose of the new filler section is to evaluate the effect of metal surface ternperature and metal composition on the propensity for slag accumulation within this region of the combustor.

\subsubsection{Channel}

The $|A|$ channel is currently configured with prototypical anode elements at electrode positions 40 through 45 and at 108 through 110 . Elements in the first group have a 0.6-inch pitch and elements in the second group have a 0.7 -inch pitch. Cathodes with prototypical cross-sections are located at electrode positions 69 through 76 (0.6-inch pitch) and 98 through 103 (0.7-inch pitch). A group of sidewall elements composed of: 1) molybdenum caps on copper bases, 2) 75\% tungsten-25\% copper solid element, 3 ) tungsten caps on copper bases, and 4) tungsten elements on $75 \%$ tungsten-25\% copper bases are also installed.

Prior to the start of this test series, the workhorse elernents on the anode wall were replaced. The new elements were modified by filling the existing slag retention groove with a stainless steel rod and, hence, providing a "non-slagging" anode wall design. 


\subsubsection{Current Controls and Consolidation}

The current control and consolidation configurations were identical to that utilized for testing during the previous reporting period. Four cabinets of 64 circuits each, for a total of 256 circuits, have been installed in the Trans-Rex room and were wired to control currents in all of the diagonal connections with an $N+15$ overlap. The forward and aft channel power take-off regions were resistively consolidated. Special instrumentation was installed on the current controls and inverter for diagnostic measurements.

\subsection{WORKHORSE POWER TRAIN TESTING (SUBTASK 6.3)}

\section{0-CHEK-02 - Facility Checkout Test (08/10/90)}

The primary objective of this test was to confirm overall system readiness for a long duration ( 24-hour) test attempt. With the exceptions of the seed system and the fuel oil injection system, most systems operated well. The seed system was unable to attain the requisite flow rate due to large aggregates of seed material plugging the mix tee and feed lines. The problem appears to be the result of moisture contamination of the seed system during down times and will require a system and/or operational modification in order to mitigate the problem.

The fuel oil system, which feeds the oil-fired vitiator, was also unable to attain the requisite flow rate. Problems with the fuel oil system were two-fold: 1) the facility divert valve was leaking which allowed a portion of the oil flow to leak into the recirculation : ne and, hence, less flow was directed to the bumer assembly, and 2 ) the orifices in the burner assembly were partially plugged. The oil bumer assembly will be redesigned, prior to the duration test, in order to minimize oil coking on the internal oil injection ports which eventually results in plugging of the injection orifices.

After the conclusion of the test, the seed system was cleaned, the oil bumer assembly was cleaned, and a manual shut-off valve was added to the fuel oil recirculation loop in order to prepare for the long duration test attempt.

\section{0-MATL-05 - Long Duration Test Attempt (08/14/90-08/15/90)}

The objective of this test was to provide long duration, continuous thermal/electrical operation in order to evaluate: 1) the long term effects of iron oxide injection on cathode wall voltage nonuniformities, and 2) the impact of long duration thermal operation on the accumulation of slag (fouling) within the coal-fired precombustor components (Table 7-1). Power generation was terminated during the early portion of the test due to observations of irregularities in the interanode voltage distribution and was not reinstated for the duration of the test. The interanode voltage nonuniformities had been observed during earlier tests, and the results of an investigation into the cause of the irregularities is discussed in Section 8 of this report.

The thermal portion of the test was 21 hours, 15 minutes and provided the longest continuous thermal run duration in CDIF history. The facility was able to provide continuous operation of all consumable systems. However, the N/O ratio and equivalence ratio varied during the test due to fluctuations in coal and oxygen flow rate $(\mathrm{N} / \mathrm{O}=0.68$ to $0.72, \phi 1=0.53$ to $0.57, \phi 2=0.88$ to 0.92$)$. The test was terminated when the oxygen supply was depleted. It should be noted that the batch slag tank system is run time limited and, hence, at approximately 14 hours into the test, the slag tap was closed off and $100 \%$ of the slag was carried over into the channel.

Post-test observations identified that there was not any accumulation of slag (fouling) within the combustion can of the coal-fired precornbustor or the transition to the first stage assembly (called the "filler" section). However, there was a bridge of slag which formed extending from the base of the combustion can to the inlet of the filler section. This slag formation appeared to be self-limiting. However, additional long duration, continuous operation is required in order to confirm this observation. It should be noted that the filler assembly installed for this test incorporated an increased intemal metal thickness such that the metal surface temperature was the same as that predicted during operation of the prototypical combustor with higher cooling water temperatures. A post-test leak check identified that there was a minor leak in one of 
TABLE 7-1. LONG DURATION THERMAL/ELECTRICAL OPERATION

THERMAL TIME $=21.25$ HOURS POWER TIME $=0.5 \mathrm{HOURS}$

\begin{tabular}{|c|c|c|c|c|c|c|c|c|c|}
\hline $\begin{array}{l}\text { SECO } \\
\text { CONF }\end{array}$ & $\begin{array}{l}\text { STAAGE } \\
\text { URATIO }\end{array}$ & & TESTINC & OBJECI & VES & & TEST & ESULTS & \\
\hline $\begin{array}{l}L W=2.7 \\
0.363 \text { - inct }\end{array}$ & $\begin{array}{l}\text {-port horiz } \\
\text { injectors }\end{array}$ & & $\begin{array}{l}\text { - Long terr } \\
\text { oxide inj } \\
\text { - Impact of } \\
\text { operatior } \\
\text { of slag ff }\end{array}$ & $\begin{array}{l}\text { ffects } 0 \\
\text { ion } \\
\text { ng dure } \\
\text { n accur } \\
\text { ing) }\end{array}$ & $\begin{array}{l}\text { ron } \\
\text { on } \\
\text { lation }\end{array}$ & $\begin{array}{l}-\mathrm{N} \\
\mathrm{ca} \\
\mathrm{CO}\end{array}$ & $\begin{array}{l}\text { fouling of } \\
\text { ? after a } 21 \\
\text { htinuous th }\end{array}$ & $\begin{array}{l}\text { ler or co } \\
\text { our } 15-m \\
\text { mal run }\end{array}$ & $\begin{array}{l}\text { ustion } \\
\text { ute }\end{array}$ \\
\hline TEST DESIG & IATION & & $A C T$ & L TES & SOND & TION & & & \\
\hline TEST & DATE & N/O & PREHEAT & PHII & PHIL & $y_{0} \mathrm{~K}$ & $\begin{array}{c}\text { S.S. } \\
\text { POWER }\end{array}$ & $\begin{array}{l}\text { SLAG } \\
\text { - REC. }\end{array}$ & $\begin{array}{l}\text { CFC } \\
\text { H.L. }\end{array}$ \\
\hline 90-MATL-05 & $08 / 94 / 90$ & 0.70 & $1200 / 2900$ & 0.55 & 0.90 & 1.7 & N/A & $-28 \%$ & $\approx 7 \%$ \\
\hline
\end{tabular}

* Note: Slag recovery assumed to be $28 \%$ based on an estimate of 14 hours as the time that the slag tank was full of slag.

the second stage oxygen injection frames (located at $L / W=0.8$ ). A decision was made not to replace the injection frame until the next time the channel is removed.

90-CC-03 and 90-CC-04 - 1A4 Current Control Design Verification Test Series (08/28/90-08/30/90)

The objective of this test series was a continuation of the $1 \mathrm{~A} 4$ current control design verification testing initiated during the previous reporting period. During the previous reporting period, it was determined that the $1 \mathrm{~A} 4$ current control units, as installed at the CDIF, were not performing as designed. The initial design verification tests, 90-CC-01 and 90-CC-02, confirmed that the currents within several control groups were not being properly controlled and the number and location of the uncontrolled regions varied randomly with time and test conditions.

A number of clock and driver boards were removed from the CDIF cabinets and returned to Avco for a series of bench top and Mark VII channel tests. These tests identified that the boards were functioning properly and, therefore, it was concluded that the problems experienced at the CDIF were unique to the environments and installation at the CDIF.

These results and observations were reviewed by the recently formed Power Management Working Group and a diagnostic test series was formulated in understand and resolve the operational prob ems. Possible causes of the operational problems included:

- the inverter voltage transient which appears on the positive $D C$ bus,

- noise frorn the magnet power supply (RF and EMI), or

- noise on the line voltage supply.

To identify the specific cause(s) of the problem, the facility system was configured as described in Section 7.1.3. In addition, however, one bay of the current controls (Cabinet 2, Bay 3) consisting of a masier and 15 slaves was fully instrumented for high speed voltage and current across the diagonal links. A patch boand network was also installed which allowed simultaneous monitoring of the voltages and currents, the clock board gate pulse characteristics, and the $480 \mathrm{VAC}$ supply voltage. 
The initial test conducted during the test series on $08 / 28 / 90$ (90-CC- 03$)$ was structured primarily to determine if the inverter voltage transients were interfering with the operation of the current controls (Table 7-2). The test was performed with the inverter on, under open/short circuit conditions, and therefore functionally disconnected from the power train. During the test, it was observed that the current control operation was, as with the previous tests, erratic. As the magnetic field strength was increased, by increasing the current on the magnet power supply, the number of current control circuits and the control deadband increased. Since the test was performed without the inverter functionally on-line, the inverter voltage transients were essentially eliminated as the root cause of the current control problem.

Additional testing was conducted both on and off-line in an attempt to isolate the operational problems. These included:

- Shielding the current control enclosures

- Operation with selected plant systems tumed on and off

- Clean, regulated DC power provided to power the current control units

These diagnostic tests eventually established that the cause of the current control operational problems was a combination of voltage sag and line supply noise. It was observed that the supply voltage was noisy when the magnet power supply was activated and was "pulled down" by as much as 20 to 25 percent when all plant systerns were in operation. This reduction in supply voltage resulted in insufficient regulated DC power to the clock boards which resulted in constant gate pulses to the GTOs and eventually intermittent loss of control over the entire group of circuits (master and 15 slaves).

In preparation for 90-CC-04, MSE provided temporary power to the current control circuits that was decoupled from the remaining plant systems. It provided a clean constant AC supply voltage between 440 to 460 VAC. (depending on the phase) during the test. Several different test conditions were performed during the test, including a short circuit and open circuit test and power tests over a range of voltages and currents with the inverter connected. The current control units performed as designed during the entire test series and maintained current balances within design specifications at all conditions. A typical streamwisc distribution of the electrode current is shown in Figure 7-1. To ensure that the inverter voltage transient

TAELE 7-2. CDIF CURRENT CONTROL DIAGNOSTIC TESTING

$$
\text { Thermal Time }=6-1 / 4 \text { hours } \quad \text { Power Time }=3-1 / 3 \text { hours }
$$

\begin{tabular}{|c|c|c|c|c|c|c|c|c|c|}
\hline \multicolumn{3}{|c|}{$\begin{array}{l}\text { SECOND STAGE } \\
\text { CONFIGURATION }\end{array}$} & \multicolumn{3}{|c|}{ TESTING DBJECTIVES } & \multicolumn{4}{|c|}{ TEST RESULTS } \\
\hline \multicolumn{3}{|c|}{$\begin{array}{l}\text { - } L W=2.7,12 \text { EACH } 0.363^{\circ} \\
\text { horizontal injection }\end{array}$} & \multicolumn{3}{|c|}{$\begin{array}{l}\text { To determine cause of } \\
\text { current controls not } \\
\text { performing } \\
\text { To implement fix to current } \\
\text { controls }\end{array}$} & \multicolumn{4}{|c|}{$\begin{array}{l}\text { Power source to cabinets was } \\
\text { cause of nonperformance of } \\
\text { current controls } \\
\text { - Modification to driver boards or } \\
\text { new power source required at the } \\
\text { CDIF }\end{array}$} \\
\hline \multicolumn{3}{|c|}{ TEST DESIGNATION } & \multicolumn{5}{|c|}{ ACTUAL TEST CONDITIONS } & & \\
\hline TEST & DATE & No & PREHEAT & PHII & PHiz & $\psi_{0} \mathrm{~K}$ & $\begin{array}{l}\text { S.S. } \\
\text { POWER }\end{array}$ & $\begin{array}{l}\text { SLAG } \\
\text { REC. }\end{array}$ & $\begin{array}{l}\text { CFC } \\
\text { H.L. }\end{array}$ \\
\hline $90-C C-03$ & $08 / 28 / 90$ & 0.70 & $1200 / 2900$ & 0.55 & 0.90 & 1.7 & N/A & $28 \%$ & 0.70 \\
\hline $90 . \mathrm{CC}-04$ & $08 / 29 / 90$ & 0.70 & $1200 / 2900$ & 0.55 & 0.80 & 1.7 & N/A & $?$ & 0.70 \\
\hline
\end{tabular}




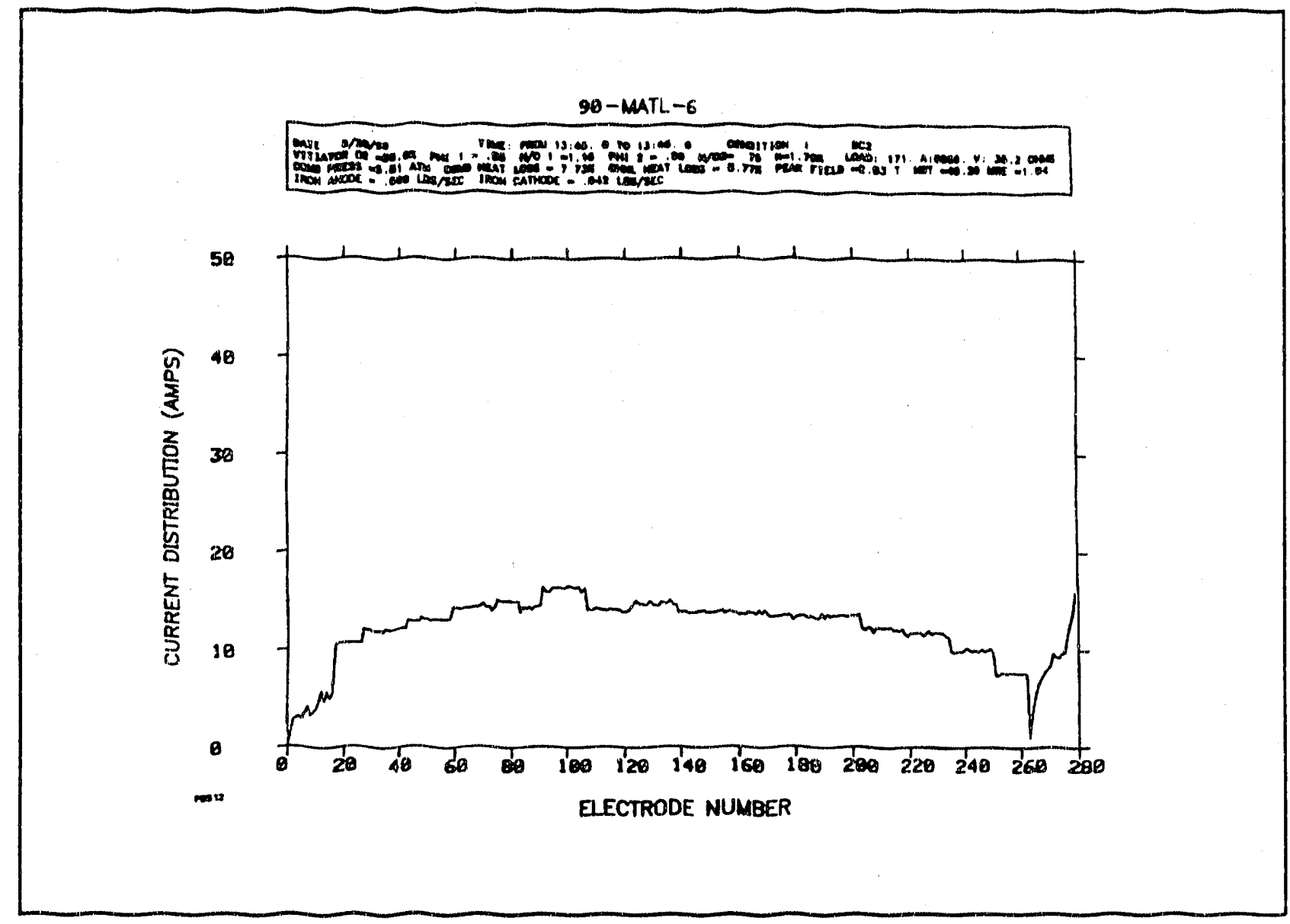

Figure 7.1. Typical Streamwise Current Distribution with Current Controls

does not affect the operation of the current controls, a power test was conducted both with and without the R-C filter iristalled on the positive DC bus. The inverter filter consisted of an equivalent $1 \Omega-3.6 \mu \mathrm{F} \mathrm{R}-\mathrm{C}$ circuit, which has been effective in reducing the measured voltage transient by one half. The current controls operated effectively in either mode. However, the current mes sured across the diagonal links detected a current spike with the inverter in operation and the R-C filter removed. The frequency of the observed spike coincided with the measured frequency of the inverter voltage transient $(\sim 180 \mathrm{~Hz})$. The current spike was not detectable by the instrumentation with the $\mathrm{R}-\mathrm{C}$ filter installed. This suggests that the inverter voltage transient enters the channel in the PTO region and propagates down the channel through the diagonal connections. This demonstrates the importance of attenuating the inverter voltage transient, and further attenuation may be desirable.

In summary, the design verification testing of the current control units has been completed. The current controls are capable of predictable performance over a wide range of operating conditions, provided an acceptable/compatible supply voltage is available. The Power Management Working Group is investigating possible corrective actions in supply voltage compatibility including current control design modifications, filtering of the existing supply voltage, and/or separate supply power.

90-MATL-06 (09/20/90) and 90-MATL-07 (09/27/90) - Electrical Duration Tests with Current Controls in Operation

The primary objectives of this series of tests were to (Table 7-3):

1) Accumulate 50 electrical hours on the prototypical channel elements (coupon) installed in the 1990 1A. channel. (This channel was fully described in the eleventh quarterly report.) 
TABLE 7-3. CDIF LONG DURATION CONTINUOUS ELECTRICAL TESTING

Max. Achievable Power Time $=7.8$ hours

\begin{tabular}{|c|c|c|c|c|c|c|c|c|c|}
\hline \multicolumn{3}{|c|}{$\begin{array}{l}\text { SECOND STAGE } \\
\text { CONFIGURATION }\end{array}$} & \multicolumn{3}{|c|}{ TESTING OBJECTHVS } & \multicolumn{4}{|c|}{ TEST RESULTS } \\
\hline \multicolumn{3}{|c|}{$\begin{array}{l}\text { L } W=2.7,12 \text { port horiz. } 0.363^{\circ} \\
\text { injectors }\end{array}$} & \multicolumn{3}{|c|}{$\begin{array}{l}\text { 22-hour continuous } \\
\text { olectrical test }\end{array}$} & \multicolumn{4}{|c|}{ - Unachievable to date } \\
\hline \multicolumn{3}{|c|}{ TEST DESIGNATION } & \multicolumn{6}{|c|}{ ACTUAL TEST CONDITIONS } & \\
\hline TEST & DATE & No & PREHEAT & PHII & PHI2 & $\% \mathrm{~K}$ & $\begin{array}{l}\text { S.S. } \\
\text { POWER }\end{array}$ & $\begin{array}{l}\text { SLAG } \\
\text { REC. }\end{array}$ & $\begin{array}{l}\text { CFC } \\
\text { H.L. }\end{array}$ \\
\hline 90-MATL-06 & $09 / 20 / 90$ & $0.75,0.80$ & 2900 & 0.55 & 0.90 & 1.7 & 1.0 & $44 \%$ & $7.5 \%$ \\
\hline 90-MATL-07 & $09 / 27 / 90$ & 0.77 & 2900 & 0.55 & 0.90 & 1.7 & .85 & $44.9 \%$ & $7.5 \%$ \\
\hline
\end{tabular}

2) Provide lnng duration, continuous electrical operation in order to evaluate the impact of long term iron oxide injection on cathode wall voltage nonuniformities.

3) Provide long duration, continuous thermal operation in order to evaluate the impact of long term operation on slag accumulation within the precombustor components.

These tests were conducted at new operating conditions $(N / O=0.78$ versus $N / O=0.70$ during previous test) in order to more closely approximate the electrical stress levels predicted for the POC and retrofit power train operation. A detailed discussion of how these new operating conditions were developed was presented in Section 3.1.3 of this report.

90-MATL-06 was comprised of two tests which accumulated a total of 8.8 thermal hours and 7.8 power hours. The first test was terninated due to arcing to ground on a thermocouple connection which came in contact with the test stand. The second test was terminated due to the formation of a plug in the vent line on the coal system which resulted in the inability to continue to process coal. Modifications to the coal feed system are planned in order to mitigate this problem and provide reliable coal feed for long duration operation. Post-test inspection identified a minor water leak in the channel forward workhorse bar sidewall and in one of the combustor second stage frames. These were not repaired prior to 90-MATL-07.

90-MATL-07 was comprised of two tests which accumulated a total of 3.2 thermal and 1.9 power hours. The first test was terminated due to a leak in the quench water system. The second test was terminated due to indications of rising CO levels within the magnet bore, indicative of a gas leak. Post-test it was determined that the high $\mathrm{CO}$ levels were probably due to a gas leak at the channeliciffuser interface which occurred as a result of warpage of the diffuser plate. A post-test decision was made to remove the channel and repair the sidewall leak and to remove the second stage and replace the frame which was leaking

\subsection{OTHER CDIF ACTIVITIES}

Other activities at the CDIF mainly involving test train repair are described in the following sections.

\subsubsection{Combustor Hardware Activities}

The primary combustion subsystem hardware related activities performed during this reporting period were:

1. the replacement of one of the second stage oxygen injector frames,

2. the installation of a new second stage frame which allows retorquing of the second stage assembly while it is installed, and 
3. the installation of a modified precombustor combustion can which simulates the prototypical hardware surface conditions (material type and grooves).

The second stage oxygen injector frame was replaced due to a cooling water leak along the bottom surface. The leak occurred in an area where gun-drilling of a coolant passage in the copper results in a reduced copper thickness ( $<0.040$ inch) between the copper and stainless steel cladding surface. This is the second failure of this type. The previous failure also occurred on an oxygen injection frame (identical design) located in the same position ( $\mathrm{L} / \mathrm{W}=0.9)$ within the second stage assembly. In both cases, the oxygen injector frame was not being utilized to inject oxygen (oxygen was injected upstream of this frame, at $\mathrm{L} / \mathrm{W}=2.7$, and the oxygen ports on this frame were plugged). The exact cause of these failures is being investigated. Preliminary indications are that the brazing procedure (segmentation of stainless steel caps, length of time at braze temperature) results in increased porosity of the copper which makes it susceptible to stress-corrosion cracking during operation and/or downtimes when acids condense on the surface. A new brazing procedure is being developed and the failure analysis on the existing frames is continuing.

A new second stage frame was installed and the assembly was modified in order to allow a retorque of the assembly tie rods, if required, without removal of the second stage and channel assemblies from the CDIF test stand. A tie rod preload is necessary to create gas pressure 0-ring sealing between the individual second stage frames. The tie rod preload has been observed to relax following extended operation. The new second stage frame was essentially a modification of an existing frame which consisted of removing material along the frame edges to allow assess to the tie rods. Second stage design parameters such as mixing length $(\mathrm{L} / \mathrm{W})$, cooling water passage layout, and tie rod/o-ring requirements for the assembly were preserved for this retorque assembly. This assembly is currently being confirmed at the CDIF for the prototypical hardware design.

The workhorse precombustor combustion chamber was modified in order to confirm that the prototypical hardware surface conditions, in particular the material type and surface grooves, would not result in increased slag accumulation during long duration operation. The prototypical design requires axial grooves along the inner surface in order to reduce thermal stresses during operation with high temperature cooling water. The combustion chamber inner surface was plasma-sprayed with Inconel ó 25 coating (65\% nickel, $21 \%$ chromium) to a thickness of 0.025 inches. After polishing to a 125\# finish, round-bottomed grooves were then machined 0.015 inches into the surface, along the axial direction of the chamber. This component is currently being tested at the CDIF without changes to the chamber $\mathrm{L} / \mathrm{D}$, instrumentation or cooling water requirements.

\subsubsection{Channel Hardware Activities}

The channel was removed and disassembled following 90-MATL-07. Inspection of the individual walls revealed that:

1. The workhorse elements on the left forward bar sidewall had only a limited remaining lifetime and required replacement. (It should be noted that the right forward sidewall is a pegwall design.)

2. Some of the workhorse elements on the anode wall had severely worn leading edges and/or loss of the material which had been used to fill the slagging groove. In both cases, copper was exposed on the gas-side surface. The elements required replacement.

3. Several of the diffuser plates had received less coolant flow than required (due to unbalanced parallel flow paths) which had resulted in $\mathrm{CaCO}_{3}$ precipitation on the inner coolant passages and loss of heat transfer capability. The plates were warped and required cleaning of the passageways, straightening of the walls and installation of stiffener plates on the sidewall.

The prototypical coupons on the anode wall and sidewall were removed and sent to Avco for evaluation. The results of this evaluation will be reported a subsequent quarterly report. 
In order to minimize the downime (non-test) period, the decision was made to only implement the repairs/replacements identified in items 2 and 3 above and to replace the left forward bar sidewall with an existing new pegwall. Because of this decision, the prototypical sidewall coupons could not be reinstalled: however, the prototypical anode coupons were reinstalled in the refurbished anode wall. The channel was reassembled and readied for installation at the end of this reporting period.

Concurrent with this activity, a new anode wall and two fonward bar sidewalls (one new, one refurbished) are being prepared in order to incorporate new prototypical channel elements. These new elements are described in the following sections.

\subsubsection{Sidewall}

Two sets of 1 A4 style sidewall bars are being fabricated. These elements incorporate the Z-bar geometry of the $1 A 4$ channel design. Elements for installation in both the right and left forward sidewalls are being fabricated. There will be twelve rows of elements in each group. Each now will be comprised of five bars, two end bars and three intermediate bars. These sidewall elements are designed with a 0.7 -inch pitch. Figure 7-2 shows a layout of the bars, including element cross sections. Two base materials will be incorporated. Molybdenum is the primary choice and $75 \%$ tungsten $25 \%$ copper press-sintered alloy is used as a backup. The final design choice will be contingent upon water-side corrosion and gas-side erosion studies currently underway at Avco. Tungsten caps are used on rows adjacent to the cathode wall in areas of high electrical stress.

The 1 A4 sidewall is designed with four intermediate bars, i.e., rows are comprised of six total elements. However, geometric considerations reduced the number of sidewall segments in the $1 \mathrm{~A}$ channel. This adjustment and the fact that the 1A channel sidewall bar height is 1.00 inch, while the 1 A.4 uses 1.25 inch high elements, is not expected to significantly influence the test results.

\subsubsection{Anode}

Several $1 \mathrm{~A} 4$ style anode elernents are being readied for installation in the 1A channel. Both slagging and "nonslagging" elements will be installed. A map for the element installation and their respective cross sections are shown in Figure 7-3.

\subsubsection{Cathode}

A group of $1 \mathrm{~A} 4$ style cathodes are also being installed in the channel. As shown in Figure 7-4, these wungsten-capped elements have the exact cross section of the 1A4 elements and will be installed at positions 91097.

\subsubsection{Inlet Frame}

Work continued on fabrication of the second stage test frame that is being constructed similar to the $1 \mathrm{~A} 4$ channel inlet frame. The frame is depicted in Figure 7-5.

\subsubsection{Current Controls}

The design verificastion test of the current control units was completed during this reporting period. As described in Section 7.2, the units performed well over a wide range of conditions as long as a clean (minimal voltage sag, low noise) 480 VAC supply voltage was provided. A temporary "clean" 480 VAC line has been provided by MSE as an interim solution. However, a more permanent fix must be implemented. During this downtime, Avco replaced the step-down transformers powering the clock boards in arder to increase the voltage on the secondary side. This modification should prevent the clock boards from dropping out even if the supply voltage sags or has a significant noise level. Operation of the current controls with the new transformers and the "old" (not "clean") 480 VAC supply line will be checked out during the next reporting period. 

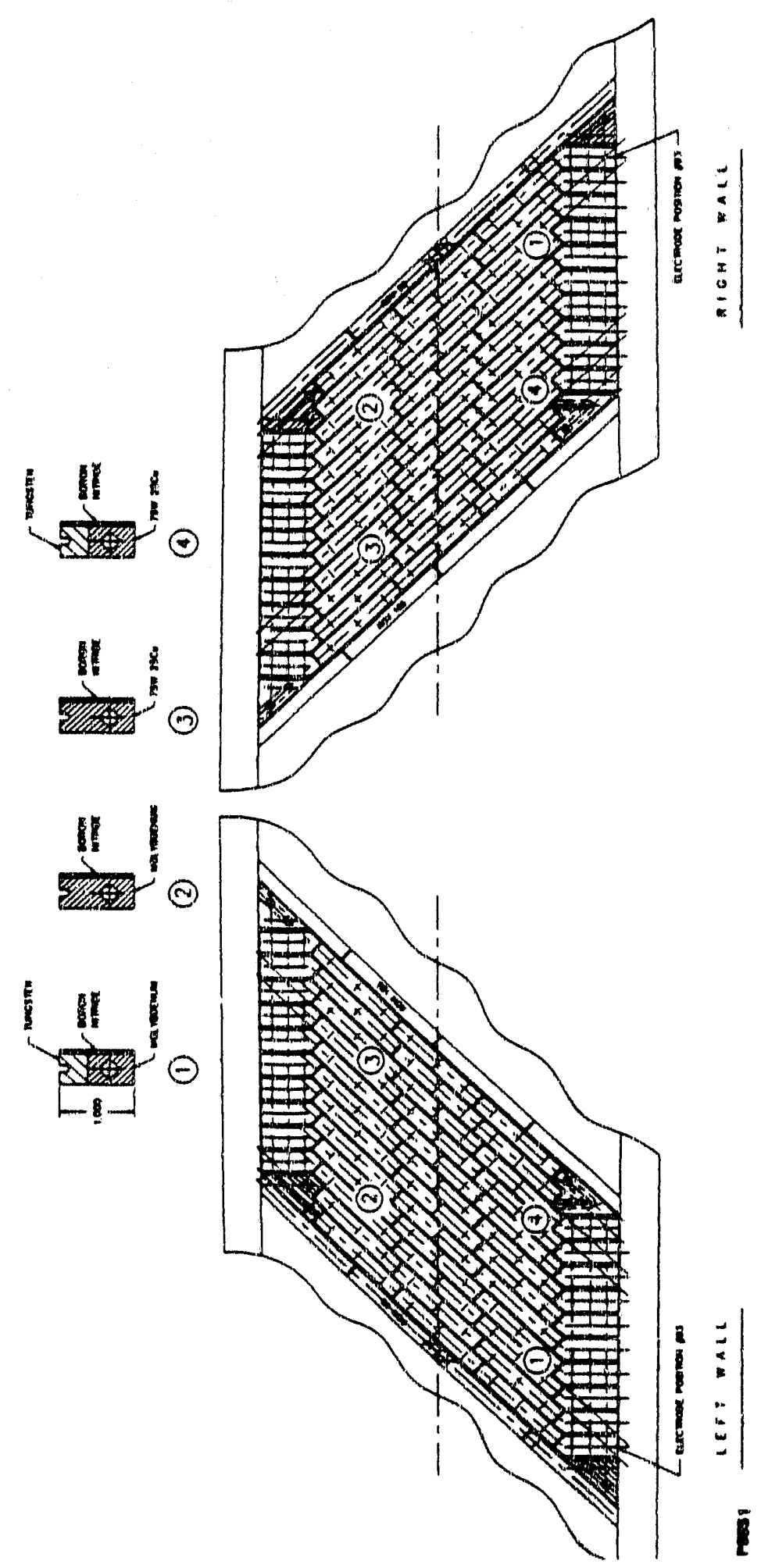


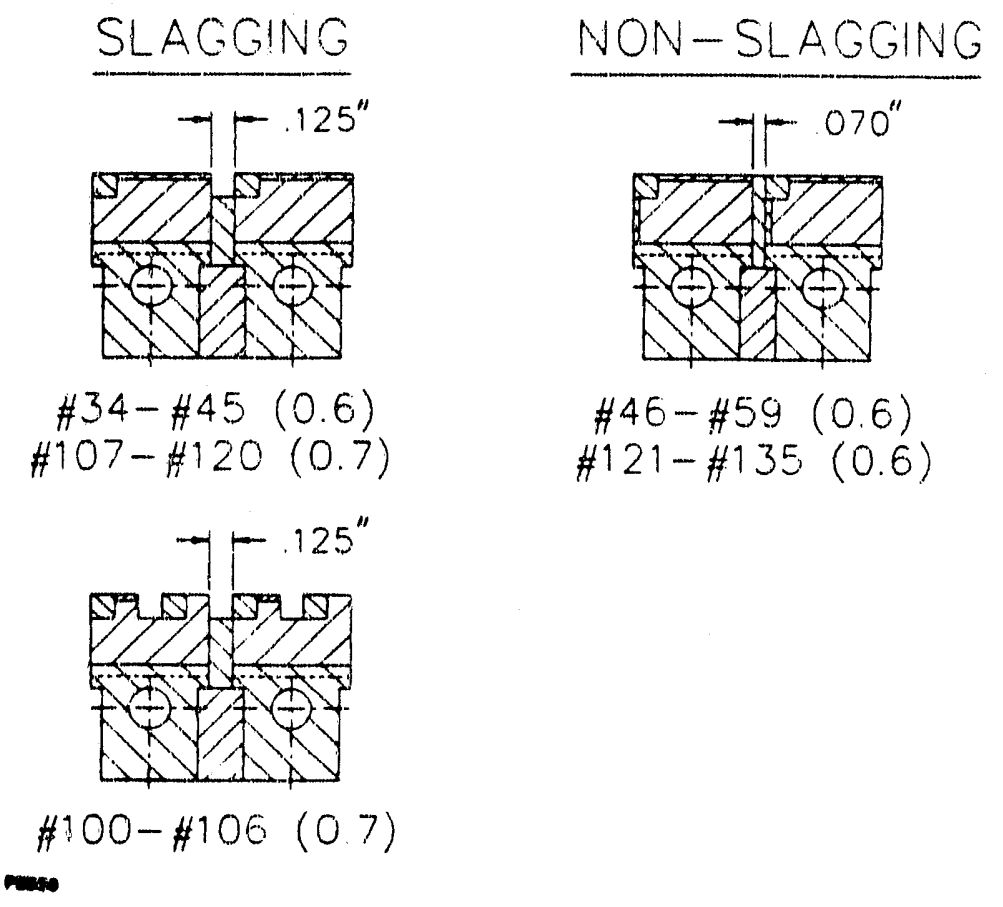

Figure 7.3. Sehematic of IAM Style Anode Woll Test Coupons

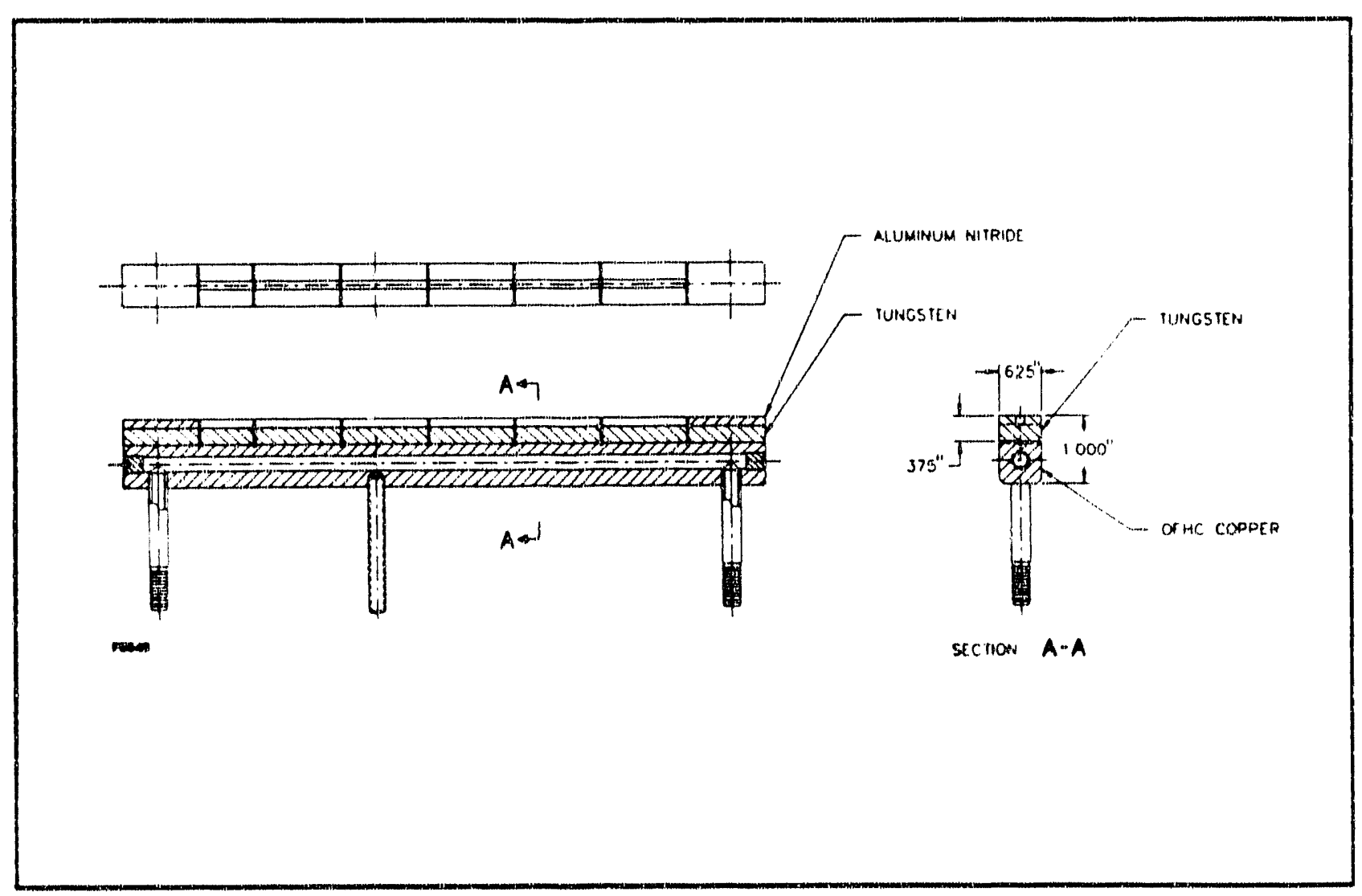

Figure 7-4. Schomatic of 1A4 Style Cathode Wall Test Coupons 

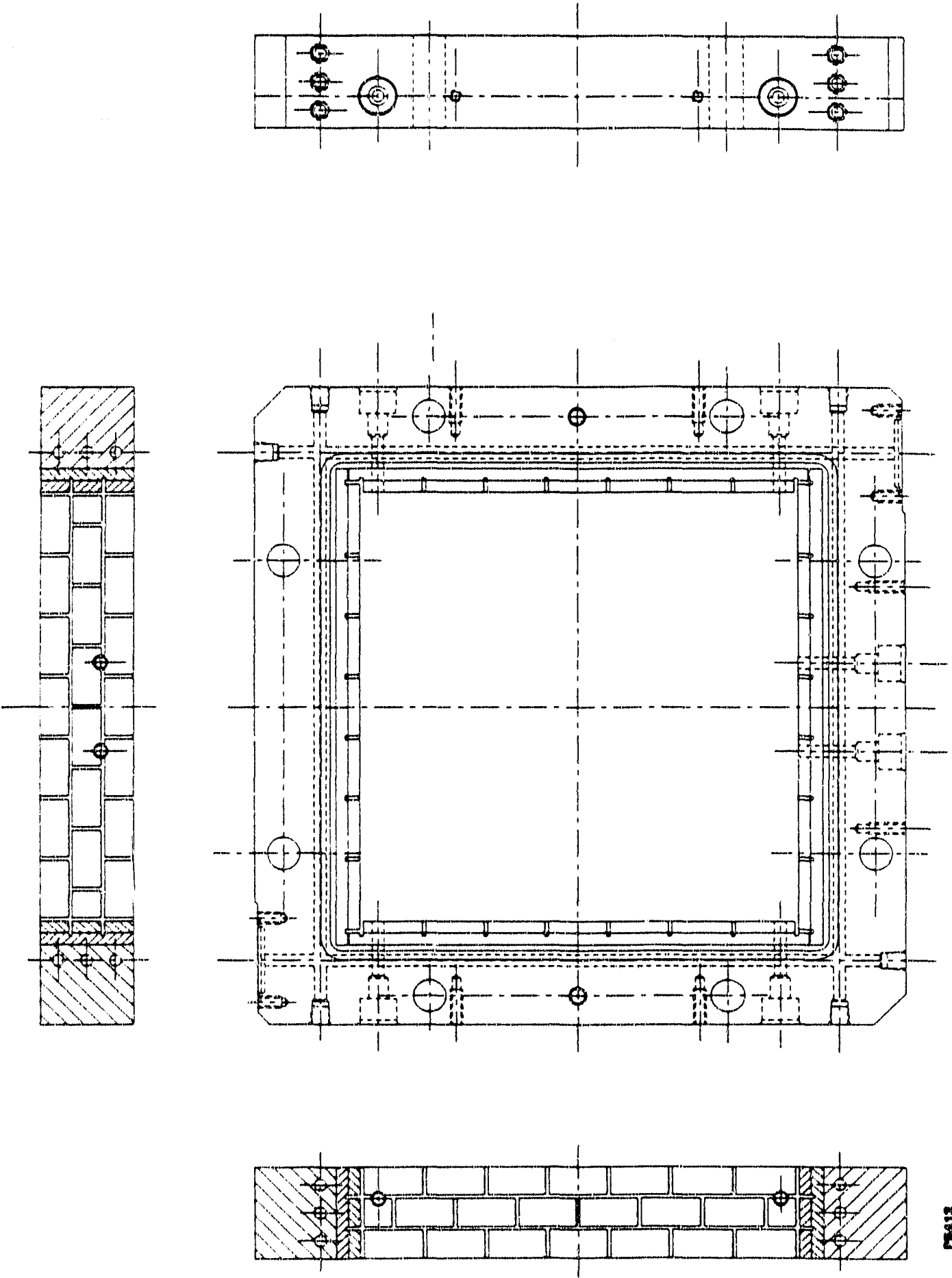

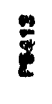




\subsubsection{Current Consolidation}

As directed by an action item from the Channel Subsystem CDR with DOE, Avco is following a plan to test the current controls as backup consolidators to the Westinghouse circuits. A schematic of the proposed test sequence is shown in Figure 7-6. In general, the two current control cabin sts presently installed in the high voltage room (Cabinets 7 and 8 ) will be used to investigate consolidation first in the forward power take-off (PTO) region, then in the rear. In the meantime, MSE will install the two stored cabinets (Cabinets 5 and 6) in the Trans-Rex mom. When this has been completed, all four of the original current control cabinets will be used to simultaneously consolidate the front and rear PTO regions.

During this downtime, current control Cabinets 7 and 8 were installed as current consolidators for the forward PTO region. Operation of these units will be checked out during the next reporting period.

\subsubsection{Slag Rejection System Activities}

Phase 1 of the slag rejection system installation was initiated and completed during this reporting period. Phase 1 entailed removal of the existing slag tank extension and installation of the continuous slag rejector components (denseveyor, valves and collection tank). The instrumentation and controls for this system will not be installed until Phase 2 and, hence, the system will still be operated as a batch holding system ( 10 hours capacity) until Ptiase 2 equipment is installed.

\subsection{TEST PLANS}

The testing required for the workhorse hardware is shown in Table 7.4. With the repaired channel the test objectives for next quarter include:

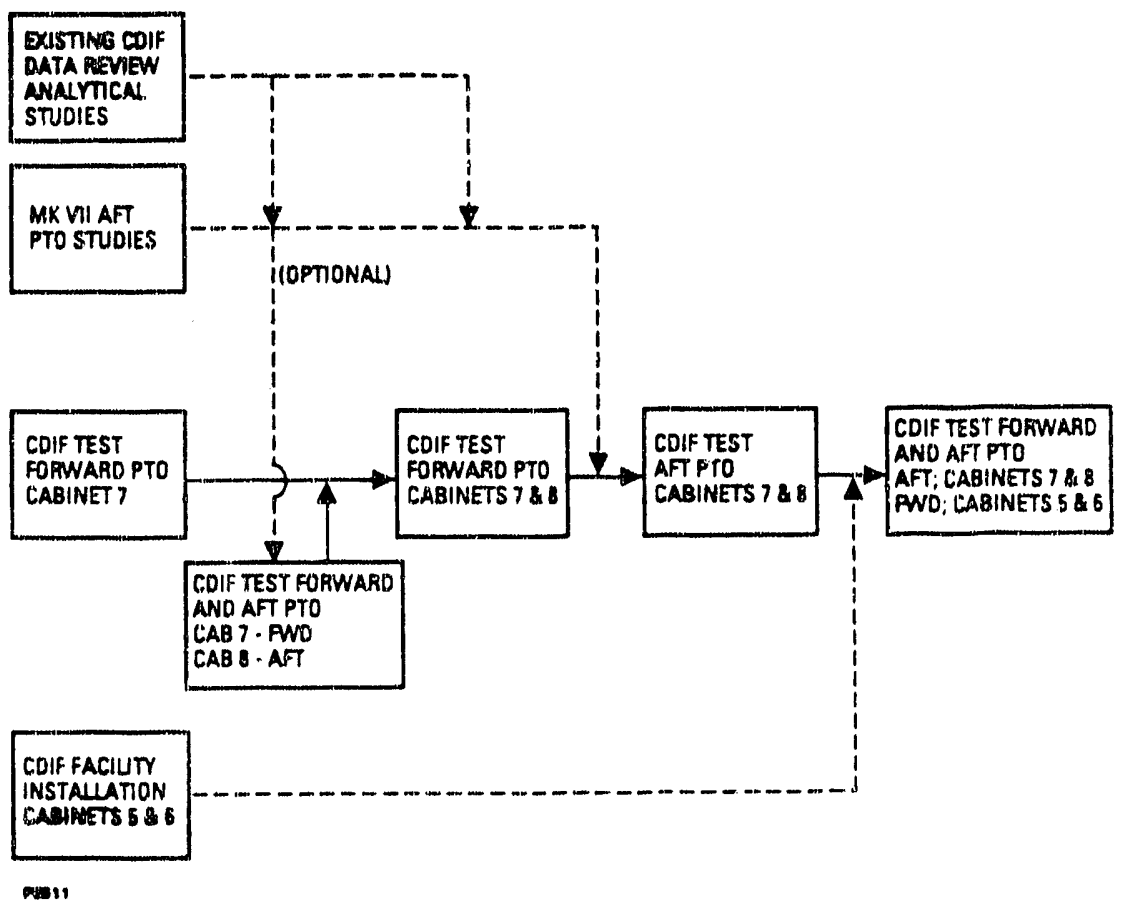

Figure 7-6. Current Consolidation Test and Installstion Logic 
- Testing the current controls as current consolidators

- A long duration (22-hour electrical) test completion

The Z-wall sections (test coupon sections) will be installed on the forward sidewalls. Additional coupons will be installed on the anode and cathode wall (0.7-inch pitch). This channel (1991 coupon channel) will attempt to have 50 electrical hours completed prior to February 15, 1991. 


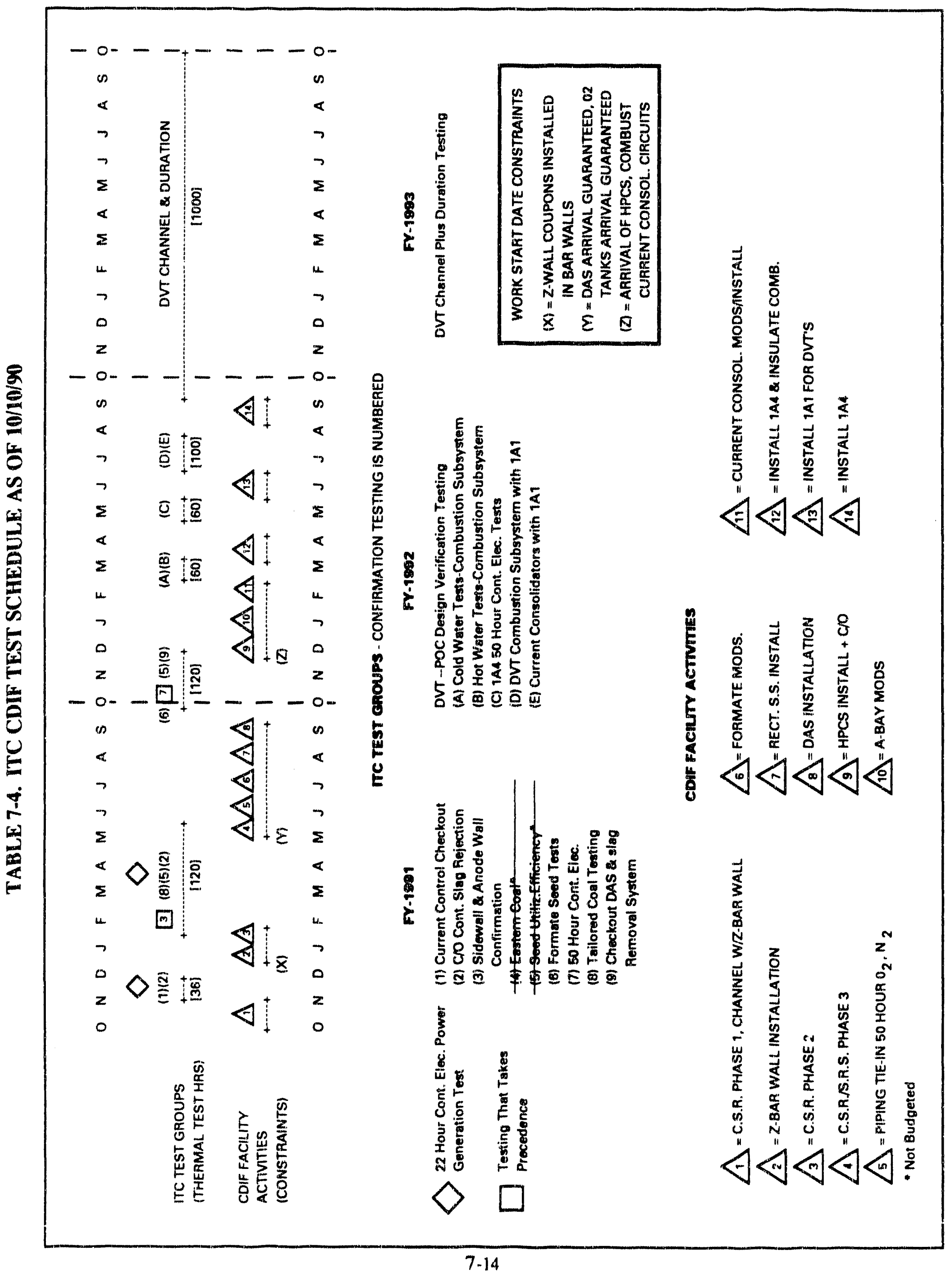




\section{MODELING AND PERFORMANCE ANALYSIS ACTIVITIES (SUBTASK 1.3)}

Subtask 1.3 of the ITC program, Power Train Performance Analysis, encompasses a broad range of activities aimed at: 1) understanding the fundamental chemical, electrical, and flow phenomena which occur in an MHD topping cycle power train, and 2) analyzing and interpreting the results of the many ongoing test programs to determine hardware performance. By thoroughly understanding the basic processes and knowing how the components and subsystems perform, information is obtained on ways to design better equipment and assess the risks of scaling up to the next level of development.

Modeling and performance analysis are ongoing parts of the ITC program. Two major efforts which are part of this subtask and which will continue throughout the contract are cold flow modeling of the combustion subsystem components and analysis of power train performance data obtained during resting at the CDIF. From time to time, other modeling and analysis activities arise from or ane performed to support these major modeling and performance analysis efforts.

During the last quarter, a variety of performance analysis and modeling tasks were performed. In Section 8.1, an evaluation of precombustor heat flux oscillations is described. The evaluation was performed in order to determine the origin and the general nature of the oscillations. In Section 8.2, an investigation of CDIF interanode voltage irregularities is presented.

\subsection{ANALYSIS OF PRECOMBUSTOR HEAT FLUX OSCILLATIONS}

An analysis of precombustor component heat flux variations or "events" was performed in order to determine the origin and to evaluate the general nature of the variations. The characteristic heat flux oscillations are most prevalent in the transition section (located between the combustion can and the air inlet), although oscillations have also been observed in the CFPC combustion can and filler section.

An example of the heat flux events which occur in the transition section is shown in Figure 8-1. The thermal spike is unique in that it increases abruptly and then decreases slowly until the occurrence of the next abrupt spike. The abrupt increase in heat loss is thought to be due to the loss of a slag layer along the transition walls which had grown too large and was sheared off. This is supported by the fact that the maximum heat loss is equal to that value observed at the beginning of the test, when the transition walls were free from slag. The slow decrease in heat loss is thought to be due to the accumulation of slag which spills over from the precombustor can. Post-test, both the precombustor can and transition section have been observed periodically to possess a small amount of slag.

Table 8-1 shows the precombustor can and transition heat loss data for tests ranging from 89-CFC-14 to 90-MATL-7. This range of precombustor tests covers a little over one years worth of testing. Two precombustor can heat loss values are documented for each test. The first is the maximum heat loss value, which is the maximum steady state heat loss value excluding startup spikes. Second, a minimurn precombustor can heat loss is documented since, in many cases, the precombustor can steady state heat loss is observed to decrease during the test, possibly due to slagging. Also shown in Table 8-1 ane the number of transition heat loss spikes (characteristic spikes) observed for each test. The characteristic spikes in the transition section have been observed since early in the precombustor testing. The amplitudes of the spikes during a test tend to vary and thus both total spikes and also "major" spikes (maximum amplitude spikes) are counted for each test. General order of magnitude spike durations are also given in Table 8-1. Furthermone, upper, lower, and average transition heat loss values are given for each test.

Figure 8-2 shows a plot of the effect of test duration on the nurnber of characteristic thermal spikes observed in the transition section. As observed from the plot, thermal spiking does not increase with longer test periods.

Figure 8-3 shows the effect of test duration on major thermal spike amplitudes in the transition section. The thermal spike amplitudes are observed to be larger for tests with longer duration. The increase in spike amplitude is observed to be due to a lower minimum transition heat loss value, with the upper transition heat 


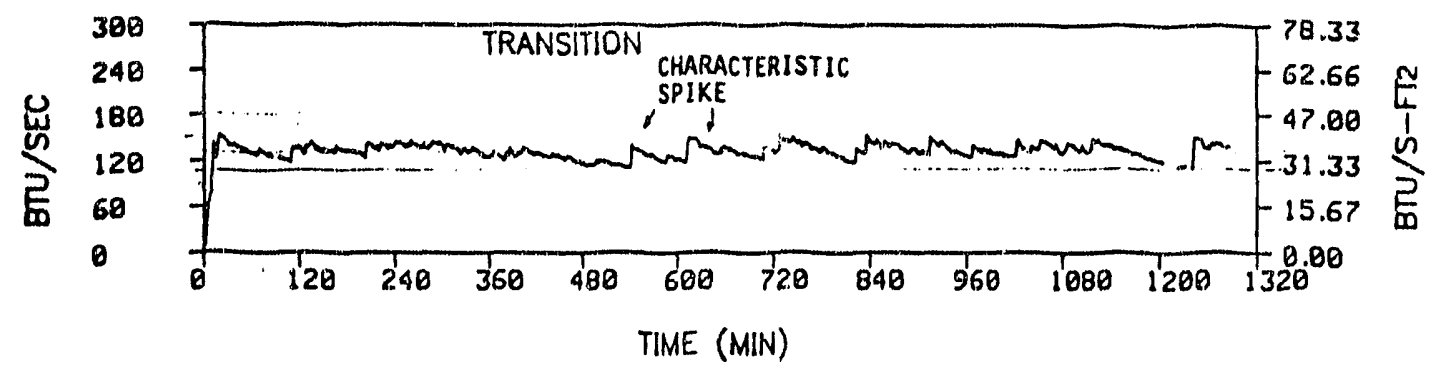

Figure 8-1. Precombustor Trensition Thermal Spiking - (90-MATL-5)

loss value steady and unchanged. This is shown in Figure 8-4 by a linear plot of spike amplitude versus the transition lower heat loss value.

Figure 8-5 shows the effect of test duration on precombustor can heat loss. The maximum precombustor can heat loss is observed to be very steady and reproducible for all tests. On the other hand, the minimum precombustor can heat loss (toward end of test) is observed to be lower for tests with longer test periods. This could be due to increased slag accumulation on the precombustor can walls for the longer tests. Also, increased slag accumulation in the precombustor can translates to more slag overflow to the transition section, consistent with the larger spike amplitudes observed in Figure 8-3.

Conclusions to be drawn from this heat flux variation study are as follows:

- Characteristic spiking in the transition section has been observed since early in the precombustor testing.

- The number of thermal spikes in the transition section was observed to be independent of test duration.

- For all tests to date, the apparent buildup of slag in the combustion can and transition section has had little or no impact on combustor pressure drop or general performance and appears to be selflimiting. However, the situation will continue to be monitored in upcoming long-duration tests.

\subsection{JVESTIGATION OF CDIF INTERANODE VOLTAGE IRREGULARITIES}

\subsubsection{Summary}

Stusies were performed to investigate the cause of observed irregularities in interanode voltage distribution on the 1A1 workhorse channel between 90-DIAG-13 and 90-MATL-4 tests. Possible causes of interanode irregularities include details of wall(s) construction, moisture condensation on the anode wall, a 


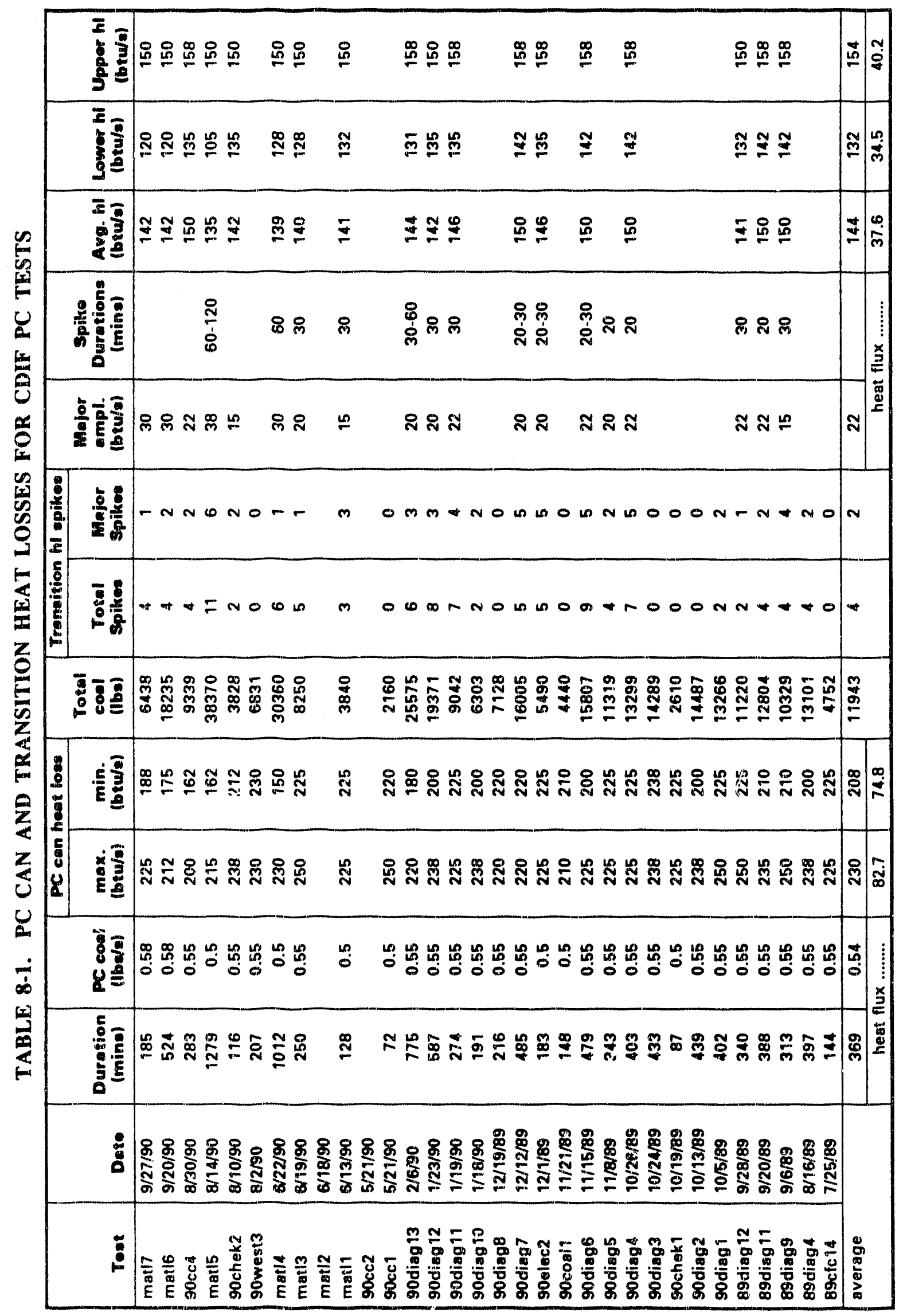




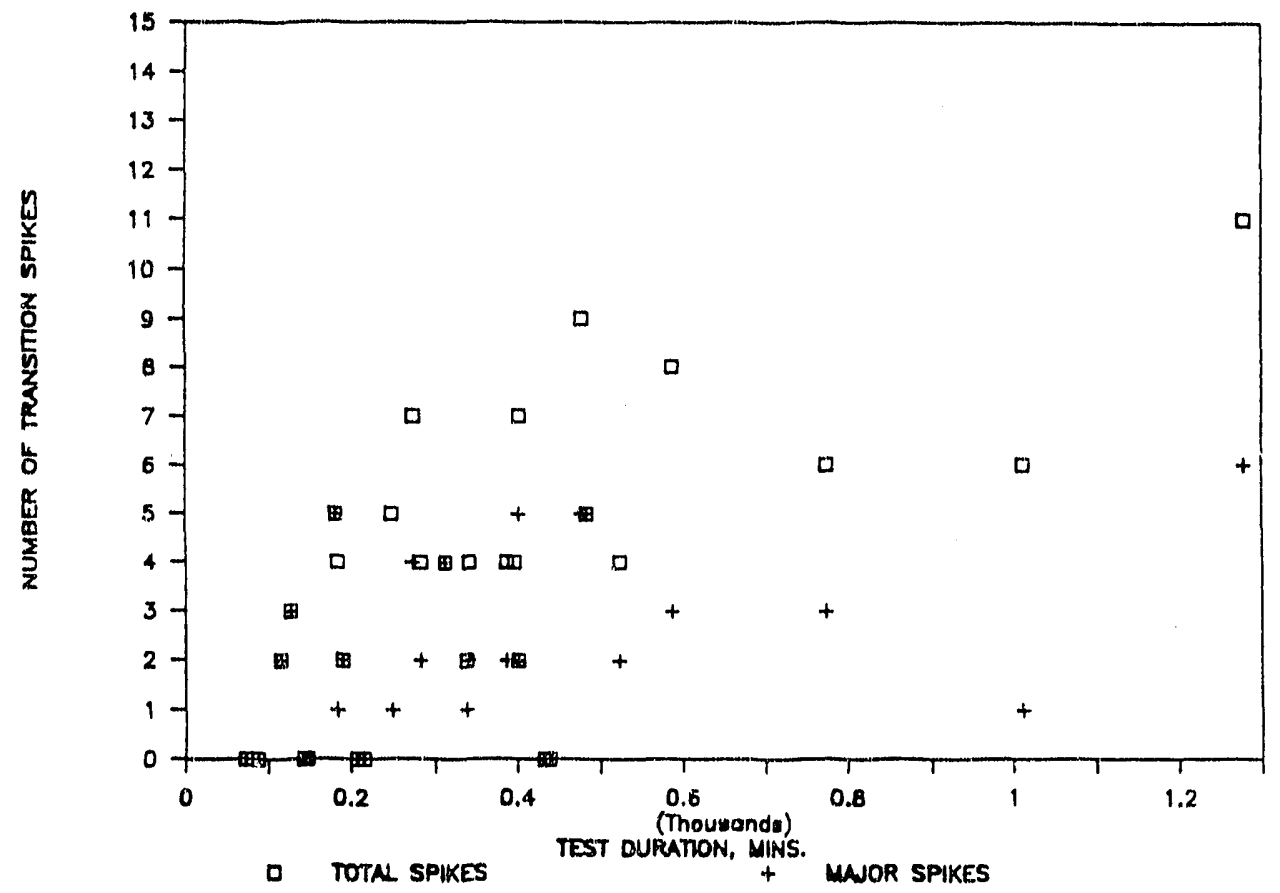

Figure 8-2. Effect of Test Duration on the Numbers of Thermal Spikes in the Transition Section

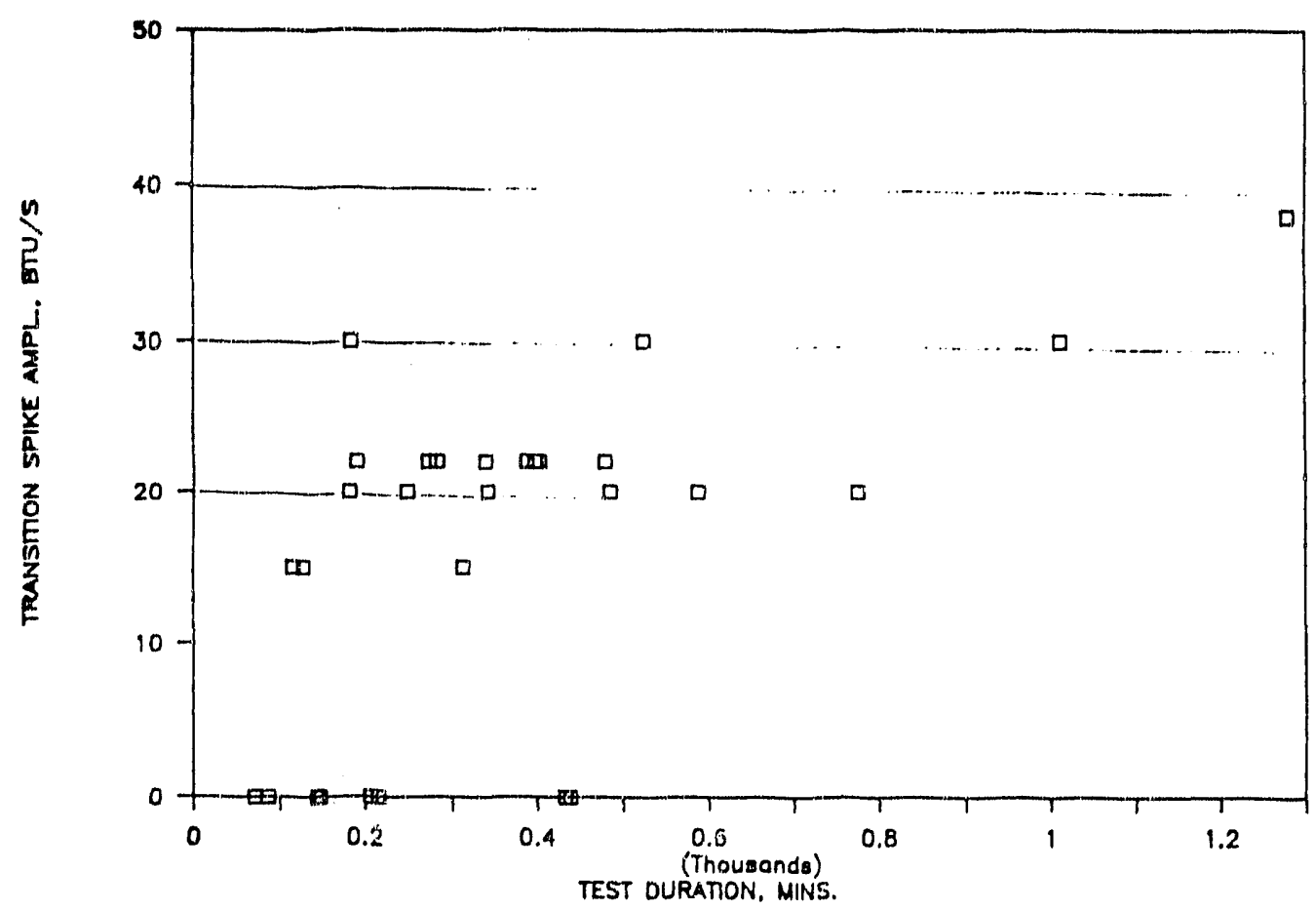

Figure 8-3. Effect of Test Duration on Major Thermal Spike Amplitudes 


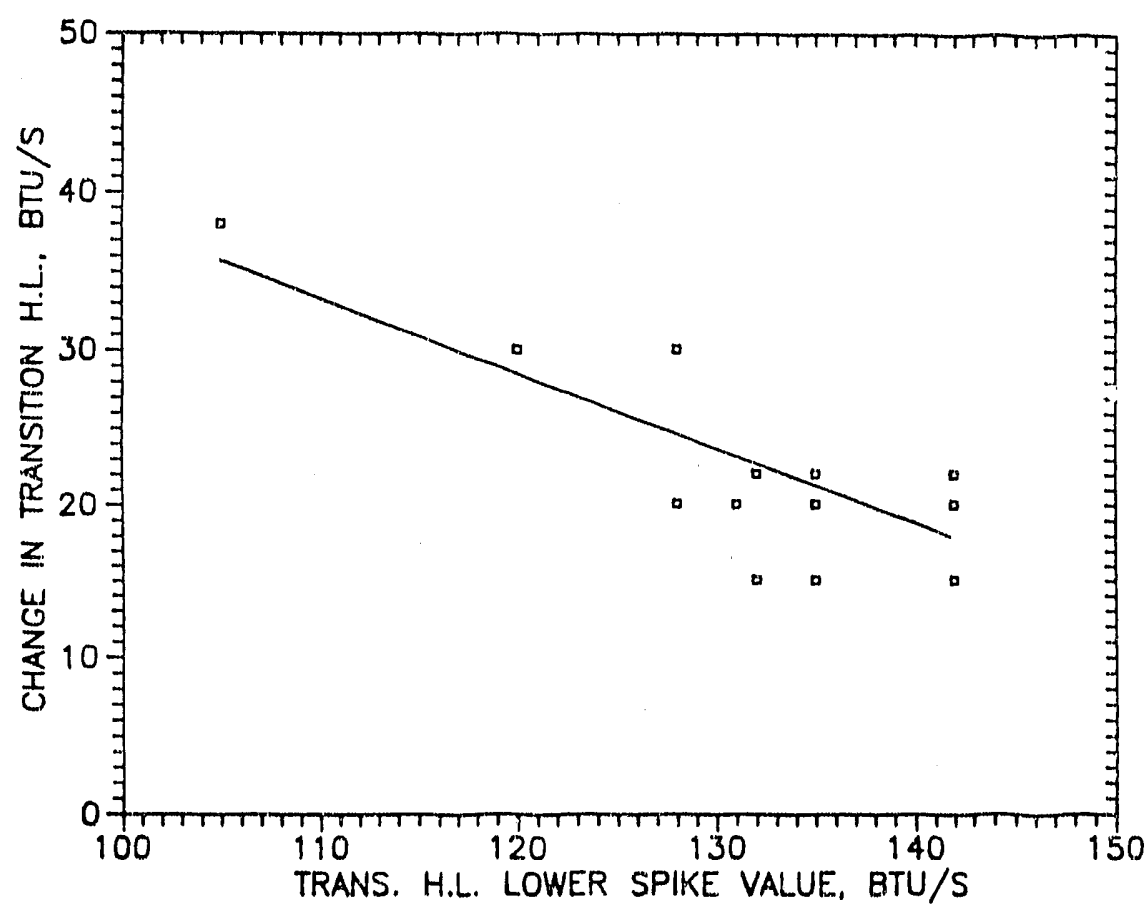

Figure 8-4. Effect of Lower Transition Heat Effect of Loss Value on Spike Amplitudes

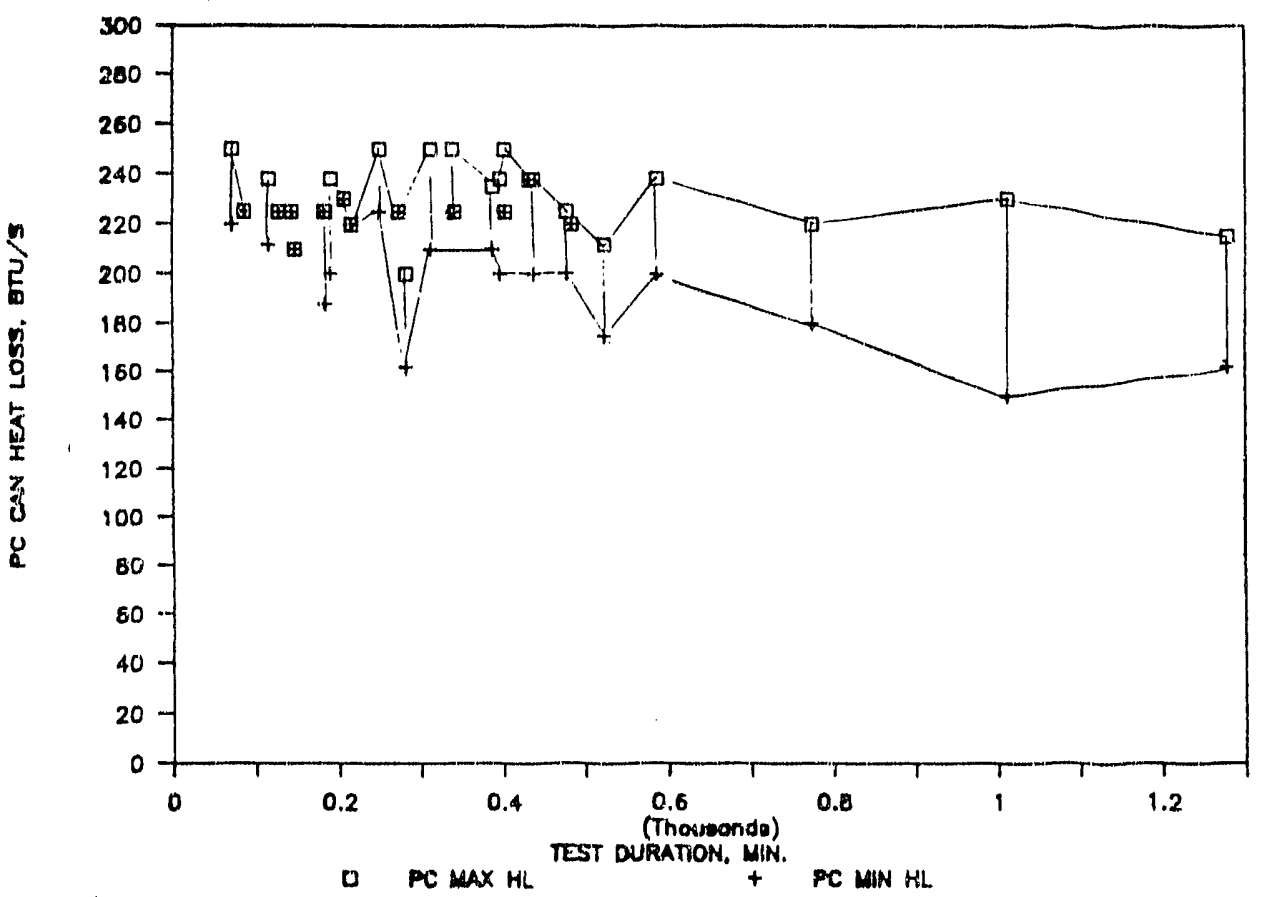

Figure 8-5. Effect of Test Duration on Precombustor Can Heat Loss 
reflection of cathode wall shorting onto the anode wall, and too much iron oxide addition. Only the last two proposals have been ruled out.

The largest contribution to anode irregularities was due to high voltages established at the bar sidewall/anode junction. The bar sidewall results in unfavorable voltage gradients which lead to breakdown and degradation of the comer joint seal. This deficierncy is mitigated on the 1 A 4 by the use of a Z-bar sidewall design and an improved corner joint insulator. Tests are ongoing in the Mark VII to quantify these improvements and the results will be reported in a future quarterly.

\subsubsection{Introduction}

Ragged interanode voltage distributions have been observed during several recent test series (between 90-DIAG-13 and 90-MATL -4 tests). It has ben suggested that moisture condensation may be a cause of anode short $s$ and accompanying interanode shortings. This ard other possibilities are discussed below. A list of observations is presented firt. This is follswed by possible causes of the interinode irregularities and finally the rnost probable cause is discussed.

\subsubsection{Observations}

Observations were made for three separate channel builds. The first channel build is that used for 90 DIAG-I through 90-DIAG-13 and is referred to as the "80-hour channel." The second channel build is that used for the initial portion of the coupon test series (90-MATL-1 th cough 90-MATL-4) and is designated as the "20-hour channel." The final build described is that used for the next segment of testing (90-WEST-1, 2, 3,90-CK-2,90-MATL-5, 90-CC-3 and 4,90-MATL-6 and 7) and is referred to as the "16-hour channel."

The 80-hour channel experitnced heavy wear on the anode gas-side surfaces Some of this wear is believed to be caused by slagging groove depth exceeding the height of the stainless steel cap and led to undercutuing. Evidence of arc attacks was present on the snode wall adjacent to the left and right aft sidewalls (both forward sidewalls were pegwalls).

Test data for the 80-hour channel indicated an interanode voltage discontinuity at the mid-channel tlange. The number of interanode shorts and irregularities grew as the 80-hour test progresset. Figure 8-6 is an interanode voltage distribution from the end of the 80-hour test.

The 20-hour channel experienced the same kind of wear seen in the 80-hour channel but in a lesser degree. With time, the gas-side surface of the 20-hour channel would probably look like that of the 80-hour channel. This channel had only one forward peg wall (the right). In the anodes adjacent to the barwall, arc damage like that observed in the 80-hour channel was present. 1A4-type anode test coupons were installed for this build. The comer joint for this build was notably thinner than is usual (scen by examining the glass/RTV seal).

Test data for the 20-hour channel indicated an interanode voltage discontinuity at the mid-channel flange. Also, much irregularity in the interanode volkage distributions was present. Unlike the 80-hour build, interanode irreguiarities appeared early in this test series. Certain electrode gaps (besides the midjoint flange) were consistently inegular. Figure 8-7 shows an interanode voltage distribution toward the end of the 20-hour chanmel build.

The 16-hour channel build was still installed at the time this investigation was made. As a result, decailed hardware inspections like those made af the conclusion of tests with the other two builds was not possible. There is a difference, however, between the 20 -hour build and the 16-hour build. The latter uses a boron nitride strip (approximately 75 mils thick) instead of the fiberglass/RTV joint (nominally 30 mils thick) in the two previous builds. The sidewalls in the 16-hour build ane the same ones used in the 20-hour build.

Preliminary test data from 90-MATL $-5,90-\mathrm{CC}-3$ and $90-\mathrm{CC}-4$ show litule shorting thus far. There were insufficient electrical hours on this channel build to dissem whether the boron nitride conter joint will 

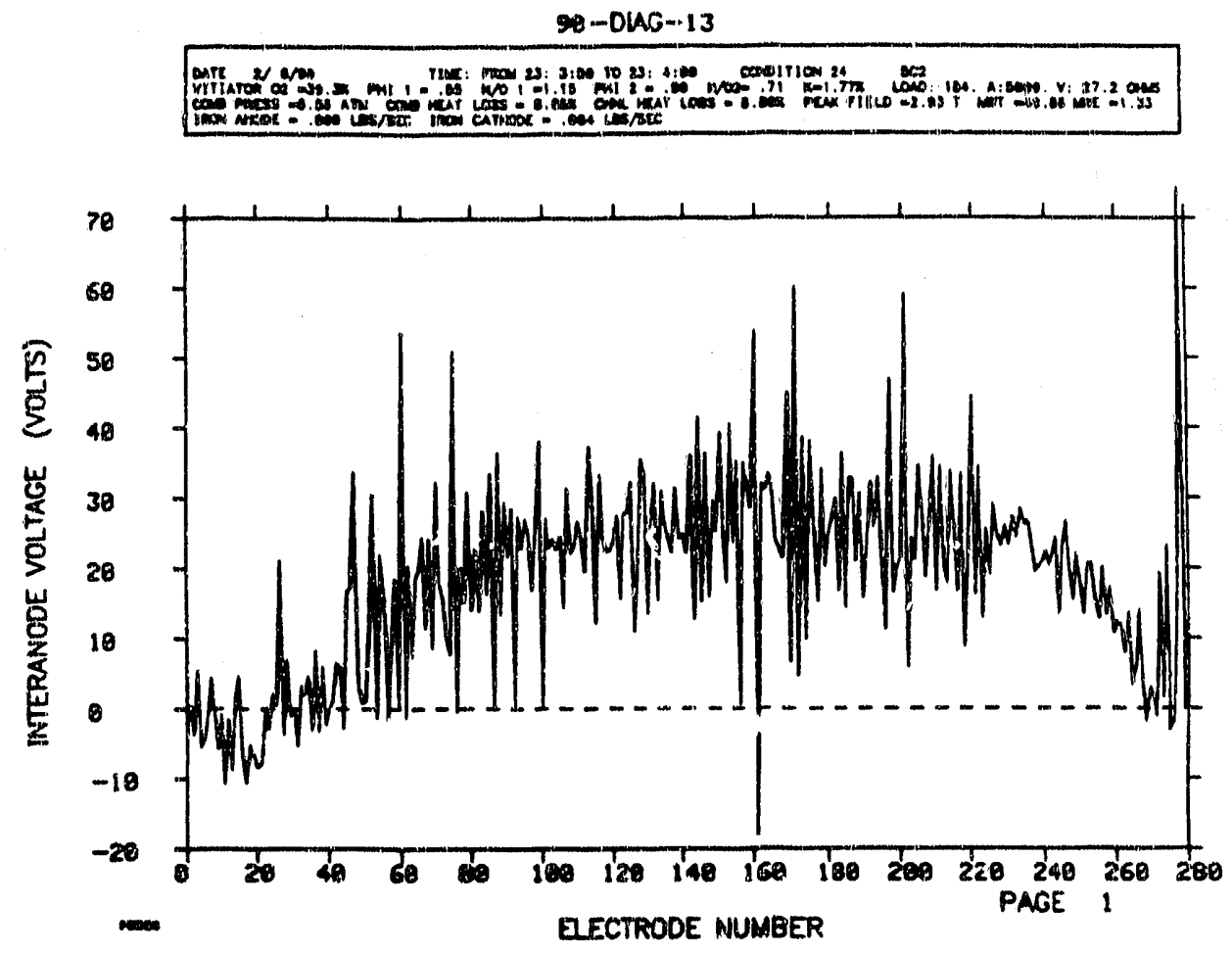

Figure 8-6. Interenode Voltage Distribution at the End of the 80-Hour Build Test Series

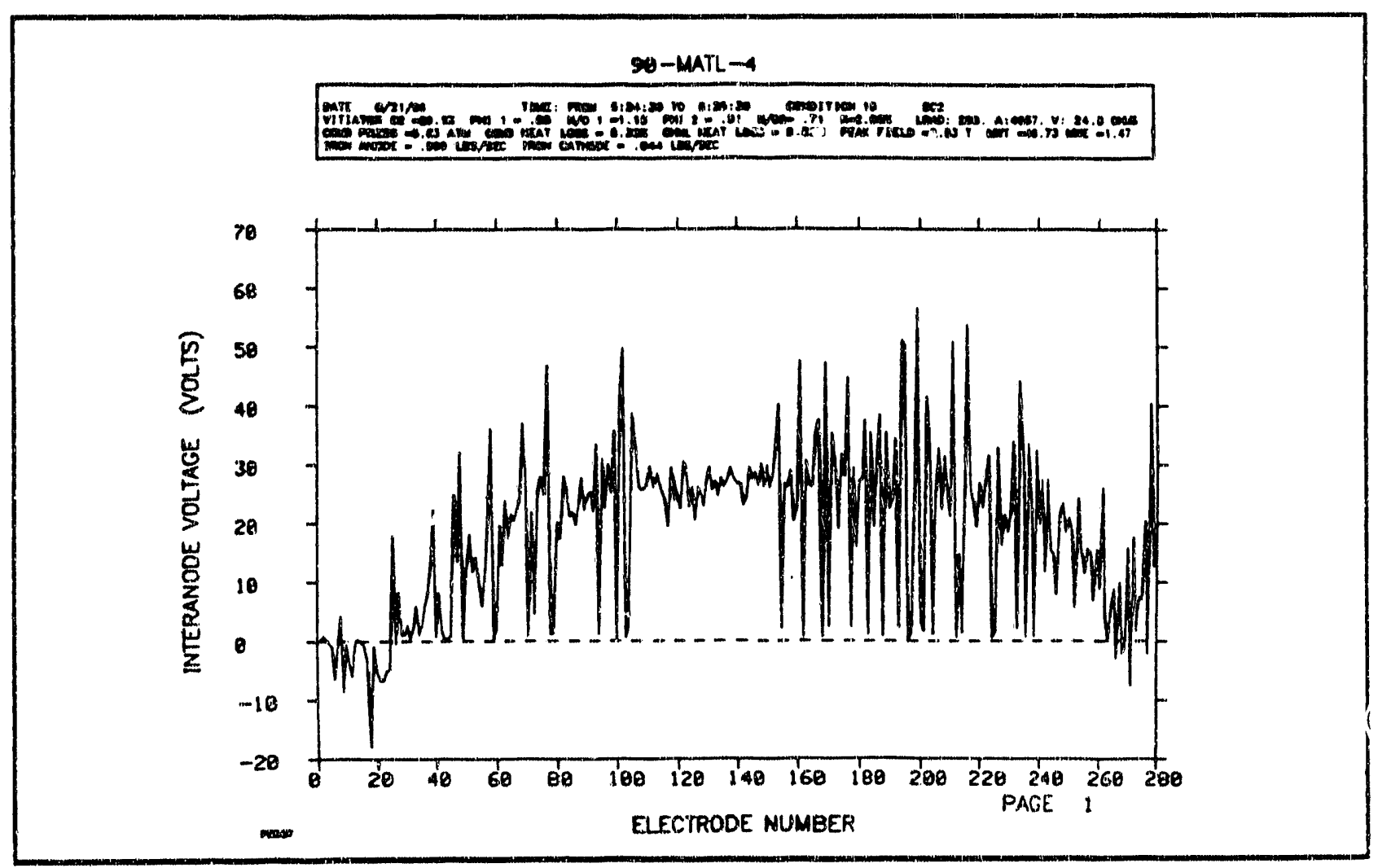

Figure 8-7. Interenode Voltage Distribution at the End of the 20-Hour Build Test Series 
prevent arc damage with continued service. Future work in the baiance of this test series could examine the wear. The 16-hour build has a voltage discontinuity at the mid-channel joint, as seen in Figure 8-8.

\subsubsection{Possible Causes and Discussion}

There are six possible causes of the irregularities observed in rece't interanode distributions. These are:

- Anode/sidewall comer joint deficiencies,

- Anode wall deficiencies,

- Anode wall test coupons,

- Moisture condensation on the anode wall,

- Reflection of cathode wall shorting, and

- Shorting as a result of too much iron oxide addition

Each of these will be discussed in tum.

\subsubsection{Corner Joint Deficiencies}

The evidence presented above suggests that the comer joint was deficient in some recent test series. The most likely cause of this damage is arcing on the sidebars or simply the large potential difference between IAI barwall elements and anode elements. If this were the case, thrn the JxB force would force these arcs into the comer joint causing damage. There is evidence that maily anodes are shorted together as a result of arcing activity. Post-test inspections revealed pieces of metal embedded in the interanode insulator as a result of arcing. The channel builds for the 80-hour test series and the 20-hour test series (90MATL-1 through 90-MATL-4) both experienced severe wear in the comer regions adjacent to sidebars. The 16-hour build (90-MATL-5, 90-CC-3 and 90-CC-4) had boron nitride strips placed between the sidebar and the anode wall which might alleviate arcing.

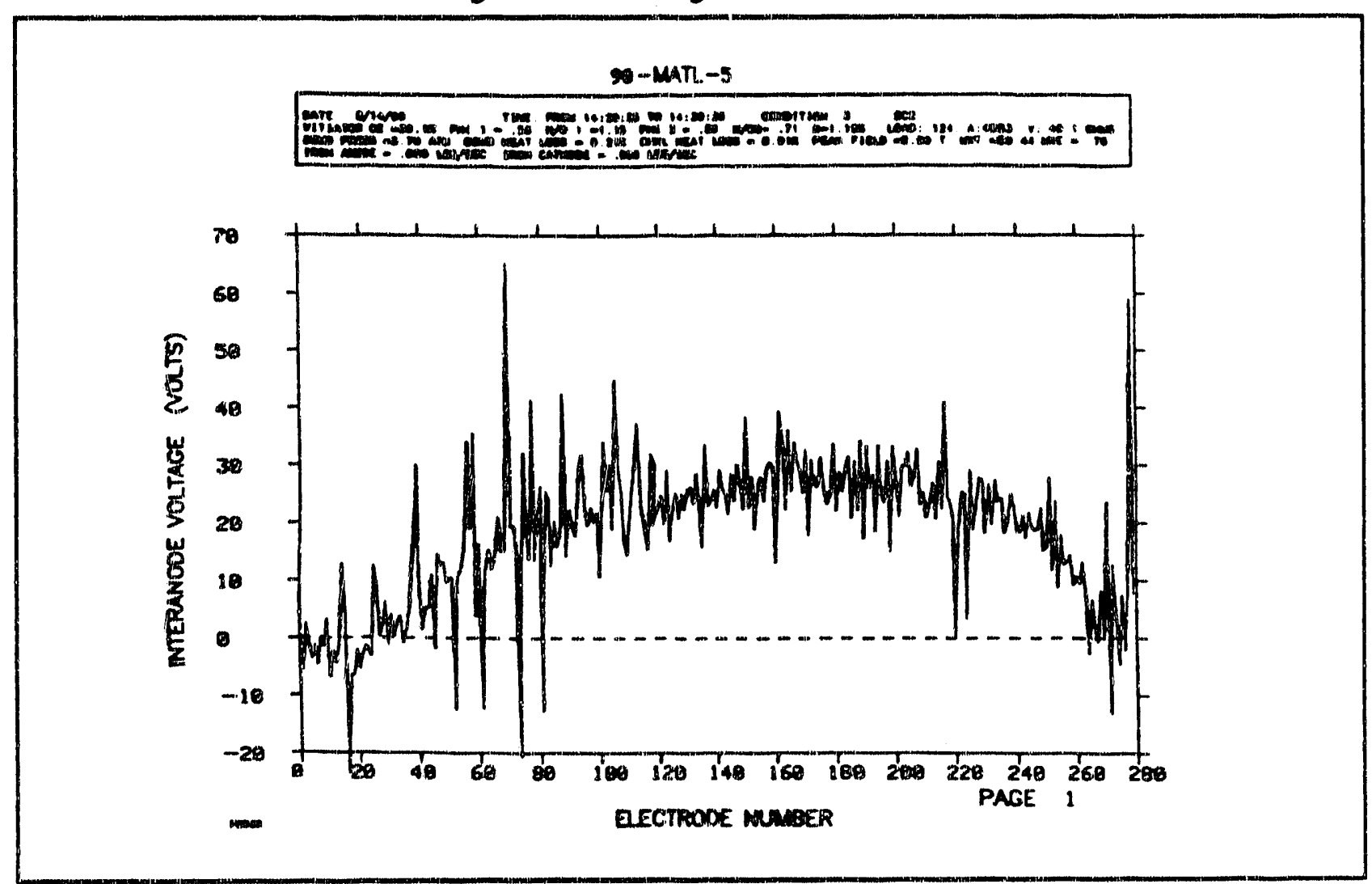

Figure 8-8. Interanode Voltage Dixtribution in the 16-Hour Build Test Series 
It is likely that the deterioration in the quality of interanode voltages during the 80-hour test was simply the result of large bar-to-anode potentials or large interbar voltages over a long period. This could have lead to the eventual failure of the comer joint and subsequent interanode shorts.

Interanode shorting in the 20-hnur channel build are most likely the result of a poorly made comer joint. The comer joint in this build was quite thin and might have allowed rapid arc damage that lead to interanode shorting.

The 1A4 Z-bar sidewall should more closely match the gas equipotential in both the core and boundary layer regions. This may eliminate or mitigate a source of arcing and reduce the possibility of this type of damage in the $1 \mathrm{~A} 4$ channel.

\subsubsection{Anode Wall Deficiencies}

The 20-hour channel build exhibited interanode shorting during its initial power operation. Since (noncoupon related) voltages were similar in the 16-hour build and the 80-hour build, it is unlikely that shorting originated on the anode wall. The voltage discontinuity at anode 160 , however, is attributed to the midchannel joint.

\subsubsection{Anode Wall Test Coupons}

A portion of the irregularities in the 20-hour build and the 16-hour build can be attributed to anode wall test coupons. For example, both the 20-hour build and the 16-hour build experienced interanode voltage irregularities at gaps 81 and 224. These gaps are the ends of two types of 0.6-inch anode coupons. Figures 8-9 and 8-10 show the location of forwand and aft anode coupons, respectively. Dissimilar materials in adjacent anodes can cause variations in the boundary layer voltage drop which will result in abnormal interanode voltage distributions. None of the irregularities in the 80 -hour build can be attributed to test coupons since none were included in that build.

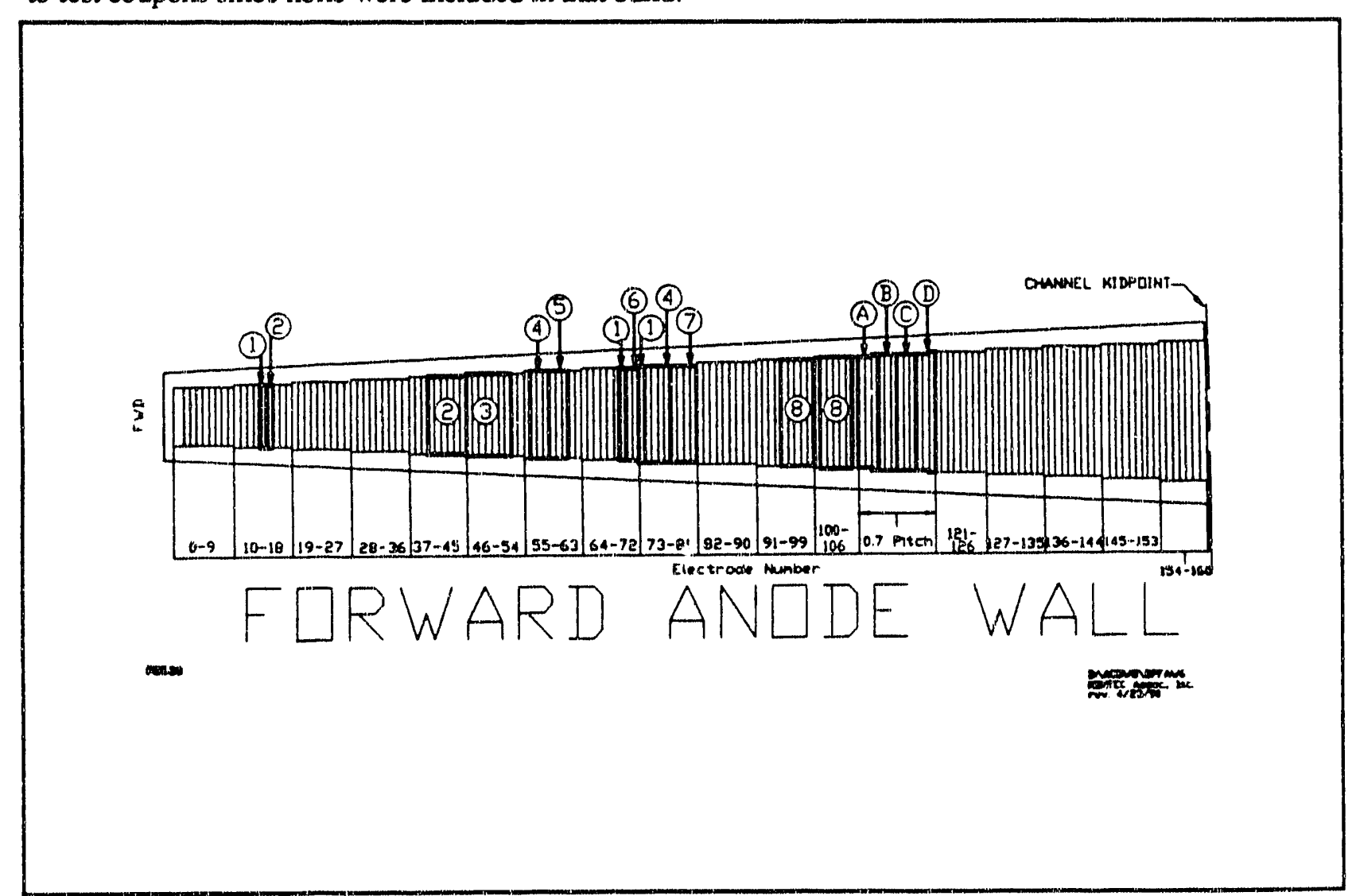

Figure 8-9. Map of the 1A4 Type Test Coupon Location in the IA1 Channel: Forward Region 


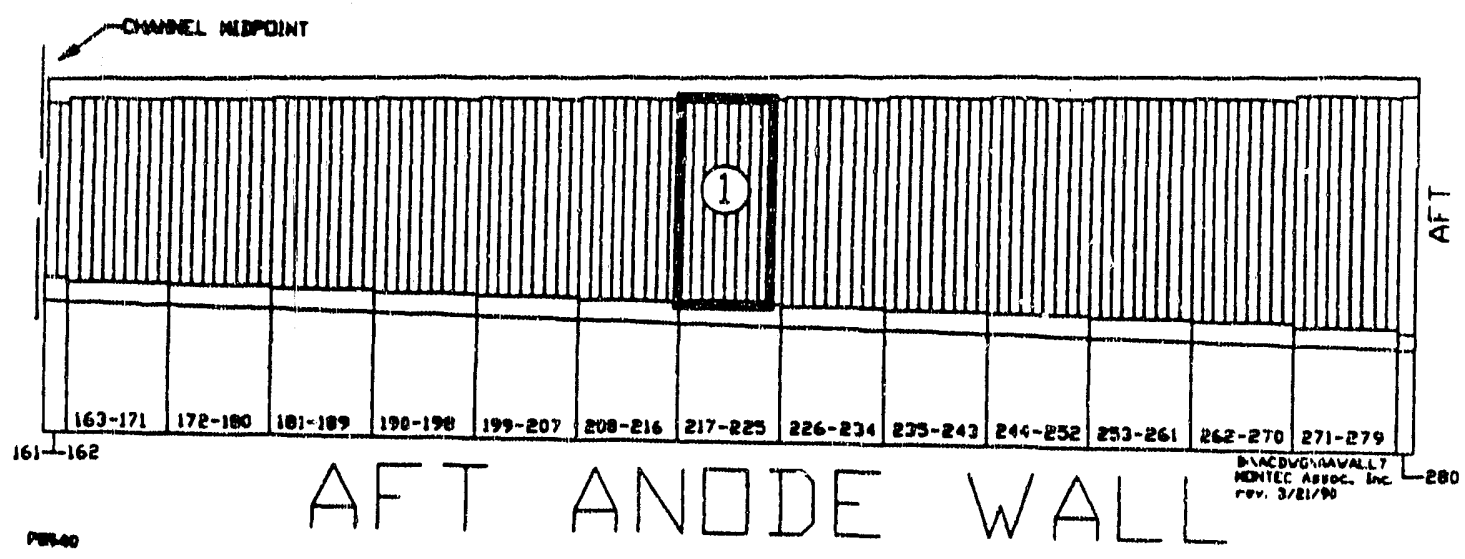

Figure 8-10. Map of the 1A4 Type Test Coupon Location in the MA1 Channel: Aft Region

\subsubsection{Moisture Condensation on the Anode Wall}

Although condensation was originally suggested as the cause of interanode voltage irregularities, this theory was not supported by post-test observations. Neither the channel build used in the 80-hour test series nor that used in the 20-hour build exhibited pitting on the backside of anodes that might be expected to accompany moisture condensation. Calculations were carried out to investigate whether a change in the equivalence ratio or an intemal water leak would rnake the channel more susceptible to moisture condensation. These calculations indicate that the dew point does not change considerably (no more than 6 degrees Fahrenheit) with variations in equivalence ratio, or even if an intemal water leak doubled the amount of water in the channel. Figure 8-11 shows the location of cooling water passes on the anode wall. There is no consistent pattem between the location of the cooling pass boundaries and interanode irregularities.

\subsubsection{Reflection of Intercathode Voltage Irregularities}

Anode wall shorting could be a result of the reflection of cathode wall shorting resulting from slag polarization. This was quickly ruled out by examining associated anode and cathode wall interelement voltage distributions. After accounting for the overlap (typically 11 electrodes), there is no correlation between the anode and cathode shorts. In addition anode shorts often occurred when the cathode was unpolarized.

\subsubsection{Excess Iron Oxide Addition}

It has been demonstrated that an excess of iron oxide will fail to reduce shorting and can actually induce shorting (Reference 8-1). While iron oxide was sometimes employed on the anode wall during the 80-hour test series, it was never used during the 20-hour channel test series. From this, it was concluded that iron oxide was not the cause of irregularities on the anode wall. 


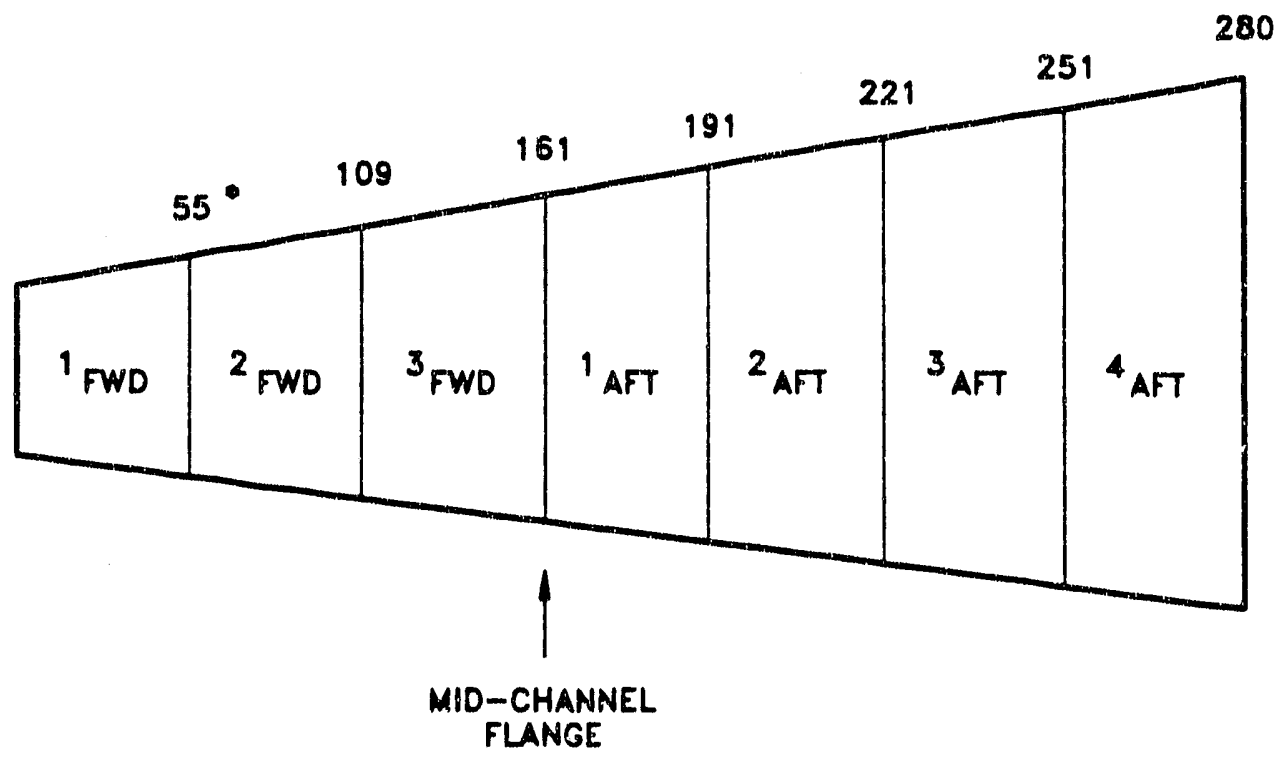

P2235

- coumdary is betweEn imoicated anode and ITS upstream meIghgor

Figure 8-19. IA1 Anode Wall Plumbing: Forward and Aft Cooling Passes

\subsubsection{Conclusions}

After a review of hardware and test results from three channel builds, no definitive conclusions can be made as to the cause of the interanode imegularities. However, it is likely that the irregularities are from several sources:

1) A combination of large interbar or sidebar-anode voltages and weak comer joints may be a source of arcing and subsequent anode shorts. The use of " $Z$ " barwalls and stronger comer joints on the 1 A4 will reduce sidebar-anode voltages (by matching the gas equipotential in the core and in the boundary layer regions) and reduce the possibility of comer damage, respectively.

2) As (non-coupon related) voltages were similar in the 16 -hour build and the 80 -hour build, it is unlikely that shorting originated on the anode wall.

3) The interanode discontinuity associated with the mid-channel flange will be eliminated with the $1 \mathrm{~A} 4$ design.

4) Some of the irregularities from the last two builds are a result of dissimilar materials in adjacent electrodes. This type of irregularity will be eliminated with the 1A4 design.

5) Moisture condensation on the anode wall does not appear to be the source of anode irregularities.

6) The origin of the anode irregularities is not assaciated with cathode wall shorting.

7) An excess of iron oxide on the anode wall is not the cause of anode wall shorting. 


\section{REFERENCE FOR SECTION 8}

8-1. TRW, MHD Integrated Topping Cycle, Eleventh Quarerly Technical Progress Repon, February 1990 through April 1990, MHD-ITC-90-312, U.S. Department of Energy Contract No. DE-AC2287PC90274, Section 8.4. 


\section{TTIRC AND POC INTEGRATION TASK FORCE ACTIVITIES (TASK 8)}

The Task 8 activities of the ITC program relate to the operation of the MHD Technology Transfer, Integration and Review Committee (TTIRC) and TRW's role in ensuring the integration of the three POC program: Integrated Topping Cycle, Integrated Bottoming Cycle and Seed Regeneration Process. The integration function is the responsibility of the POC Integration Task Force.

In the previous reporting period, the POC Integration Task Force completed its evaluation of the three POC programs. The recommendations for additions and/or amendments to the program which would be beneficial to meet the requirements of the Retrofit Reference Design Basis (RRDB) were reviewed and approved.

The Task Force recommendations were ranked in order of importance by a cross-section of TTIRC and POC program participants to be demonstrated as part of the POC testing and/or prior to proceeding to the repowering of a coal-fired power station. These prioritized recommendations, summarized in tabular form in Table 9-1, were passed on to the DOE early in the reporting period.

Final distribution of the fourth semi-annual status report of the MHD TTIRC was completed during the reporting period.

A draft copy of the fifth semi-annual status report MHD TTIRC was prepared and distributed to the DOE and TTIRC Executive Committee for review. Final distribution of the report will be completed after review and discussion at the winter Executive Committee meeting. 


\section{TABLE 9-1. RECOMMENDATIONS FOR POC PROGRAM INTEGRATION}

\section{$\mathrm{K}_{2} / \mathrm{s}$ Ratio}

It is recommended that the following activities be addressed:

- Document and investigate, enalytically and experimentally, the sulfur level and $K_{2} / S$ ratio corrosion relationship for the components exposed to sulfur containing gases.

- Technical and economic analysis of seed regeneration operation for low sulfur Western coal incorporating $\mathrm{K}_{2} \mathrm{CO}_{3}-\mathrm{K}_{2} \mathrm{SO}_{4}$ separation prior to regeneration or seed bypass at conditions which still fulfill the requirements for projected NSPS sulfur removal.

- Continue to study the effects of $K_{2} / S$ ratio on HRSR, ESP and baghouse performance and costs.

\section{ESP/Baghouse Operation}

It is recommended that ESP and baghouse performance continue to be investigated over the range of gas temperatures $\left(250-750^{\circ} \mathrm{F}\right.$ ) and $\mathrm{K}_{2} / \mathrm{S}$ ratios (1-3).

Other relevant industrial and DOE experience should be investigated.

Seed Reganeration Integration and Slag Rejection

It is recommended that the seed regeneration process be integrated intu both of the retrofit conceptual designs.

The feeding of molten salt or an aqueous salt solution (transport and in ection methods) should be investigated within the POC program.

It is recommended that seed recovery efficiency and economics be evaluated to establish a lower limit for slag rejection.

\section{Overhall MHD Combustor Stiochiometry}

It is recommended that testing be performed at the lowest stoichiometries possible, and still moet performance and reliability requirements, sufficient to develop performance maps within the 0.80 to 0.95 range.

\section{Additives}

It is recommended that the impact and econornics of iron oxide addition on the HRSR and sead regeneration process be assessed if iron oxide is selected for MHD channel operation. Other methods for alleviating cathode wall shorting should continue to be investigated.

\section{Singla Load Vorsus Multiple Load Oparation}

It is recommended that multiple losd operation be investigated as part of the POC program because it is necessary for efficient retrofit operation.

Performance and Reliability

It is recommended that the POC program build a reliability data base by operating the power train at projected retrofit channel stresses.

RAM (Reliability, Availability, Maintainability) analysis should be incorporated into the test programs.

\section{Part Load Operation}

It is recommended that analytical design efforts be performed to establish part load operating conditions, integrated control strategies and information on test requirements.

Socond Stage Oxidant

It is recommended that testing of low pressure second stage preheated oxidant injection be performed. 


\section{TABLE 9-1. RECOMMENDATIONS FOR POC PROGRAM INTEGRATION}

(CONTINUED)

\section{Scalability}

It is recommended that the basic design selected for testing of critical components and equipment should be capable of scaleup and applied to early commercial systems.

Discrepancies between the POC programs, the projected retrofit components and early commercial systems should be investigated and resolved.

Integrated Plant Control Strategy

It is recommended that integrated plant control strategies be studied in the POC programs. Studies should include plant control, fault analysis, dynamic modeling, part load, startup/shutdown.

\section{Soed Impurities}

Once the levels of impurities are known, after POC seed regeneration plant demonstration, the effects on various components should be evaluated in conjunction with methods for controlling buildup to acceptable levels.

\section{Superconducting Magnets}

It is recommended that previous experiences with SCM's from both MHD technology and other technologies be catalogued and specific design parameters compared with SCM requirements for a retrufit facility and early commercial plant.

\section{Second Stage Cooling}

It is recommended that the impact of second stage cooling on an early commercial facility be assessed. 


\section{PLANNED ACTIVITIES}

\section{Task 1}

- Continue the bench scale testing of the electrical isolator PEEK material to get 50 hours of operation at $400^{\circ} \mathrm{F}, 1000 \mathrm{psi}$.

- Continue the interface definition for the current consolidation subsystem.

- Prepare for the manufacturing readiness review.

- Maintain the detailed integrated schedule for the manufacturing phase of the program.

Task 2

- Complete sign-off of the Combustion Subsystem drawings.

- Resolve remaining manufacturing issues.

- Complete vendors selection process.

- Assess impact of operating Combustion Subsystem with low pressure water and make recommendation regarding the CDIF cooling water system.

\section{Tasks 3 and 4}

- Complete Mark VII evaluation of slagging anode and Z-bar sidewall designs.

- Complete fabrication of new prototypical channel element coupons for installation and evaluation in $1 \mathrm{~A} 1$.

- Complete high heat flux $\left(250 \mathrm{~W} / \mathrm{cm}^{2}\right)$ water-side corrosion tests.

- Continue fabrication of 1A4 channel and diffuser elements.

Task 5

- Finish full-scale Current Consolidation Subsystem design.

- Hold Current Consolidation Subsystem CDR with TRW.

\section{Task 6}

- Checkout testing of Phase 1 of the slag rejection system.

- Begin checkout testing of the curreni controls as current consolidators.

- Install and test new prototypical channel element coupons including Z-bar sidewall sections and slagging anode designs.

- Continue long duration, continuous electrical operation of the power train.

\section{Task 8}

- Schedule TTIRC Executive Committee meeting for early February, 1991 in conjunction with DOE Contractor's Review meeting in Pittsburgh, PA.

- Prepare final copy of fifth semi-annual status report for distribution. 


\section{SUMMARY}

Critical Design Reviews (CDRs) were held with DOE for the Combustion, High Pressure Cooling and Channel Subsysterns. A Preliminary Design Review (PDR) was held for the Current Consolidation Subsystem. The Combustion Subsystem design was approved for fabrication at the conclusion of the design review. Some open channel design issues were identified at the CDR which will require additional test data to resolve, therefore, a "close-out" CDR will be held in February 1991 in order to complete the design review process.

A number of key activities were performed during this reporting period as part of the Combustion Subsystem manufacturing activities. The detailed drawings of all of the components have been completed and the process of checking and approving the drawings (sign-off) is $80 \%$ complete. A long duration (250)hour) hot-fire test of the prototypical panel design was successfully performed at UTSI. This test essentially confirmed not only the design but also the manufacturing and assembly process. In addition, test of a prototypical high pressure/temperature electrical isolator for the HPCS continued during this reporting period.

Mark VII and bench scale testing was performed at Avco to support the prototypical chanriel vesign and manufacturing development. The Mark VII tests focused on compariscin of slagging and non-slagging anode designs as well as Z-bar sidewall confirmation tests. Bench scale tests were performed in order to establish the optimum water conditions for the proof-of-concept tests and to quantify, where possible, tr: corrosion rates expected for the water-side materials used. None of the materials being contemplated for use in the $1 \mathrm{~A} 4$ channel exhibited serious water-side corrosion. The recominended pH range for the water is 6 to 7.5 if molybdenum is used as the wate'-side material and 6.7 to 7.5 if tungsten-copper is used. The use of an NCR-approved corrosion inhibitor such as CopperTrol or Tolytrianzole is recommended. The existing CDIF dissolved oxygen level of 3.2 to $3.4 \mathrm{ppm}$ is acceptable, although a lower range (50 to 200 $\mathrm{ppb}$ ) is recommended as being the preferred level. The minimum acceptable resistivity is $500 \mathrm{kohm}-\mathrm{cm}$.

Facilities for fabrication of the 1A4 hardware are in place and are being used to build gas-side elements for the Mark VII and 1A channels. Procedures necessary for the hardware fabrication have been written as have procedures for inspection and quality control. The channel and diffuser fabrication schedule shows delivery of the hardware to the CDIF in March 1992. The design of the diffuser is complete and assembly is in progress.

Confirmation testing continued at the CDIF and consisted of three test series as follows: 1) facility checkout to confirm overall system readiness for a long duration test, 2) long duration thermal/electrical operation, and 3) current control design verification testing. There were a total of 46.6 thermal test hours which resulted in 15.7 power hours.

The results of a diagnostic test series established that the cause of the current control operational problems was a combination of voltage sag and line supply noise. Possible corrective actions being investigated include current control design modifications, filtering of the existing supply voltage, and/or separate supply power. MSE is providing a temporary "clean" supply voltage as an interim solution. 


\section{QUARTERLY REPORT DISTRIBUTION LIST}

Required U.S. Department of Energy Distribution

Dr. Harold Chambers

Technical Project Office

PM-40, MS 922-206

U.S. Department of Energy

Pitusburgh Energy Technology Center

P.O. Box 10940

Pittsburgh, PA 15236

Ms. Debra Ball

Contracting Officer

AD-22, MS 921-165

U.S. Department of Energ

Pittsburgh Energy Technology Center

P. O. Box 10940

Pittsburgh, PA 15236

Dr. Victor Der

U. S. Department of Energy

Office of Fossil Energy

FE-32

Washington, DC 20545

General Counsel for Patents

U.S. Department of Energy

Chicago Operations Office

9800 South Cass Avenue

Argonne, IL 60439

U.S. Department of Energy *

Office of Technology Transfer

P. O. Box 10940, MS 922

Pittsburgh, PA 15236

* First obtain clearance from Office of Patent Counsel, Chicago, then mail copies to OTT with statement, "Patents Cleared by Chicago Office of Patent Counsel on (Insert Date) 


\section{Additional Distribution}

Dr. William Swift

Argonne National Laboratory

9700 South Cass Avenue

Argonne, IL 60439

Dr. R. Kessler

Avco Research Laboratory

2385 Revere Beach Parkway

Evereth. MA 02149

Mr. S. Petty

Avco Research Laboratory

2385 Revere Beach Parkway

Everett, MA 02149

Mr. John Rackley

Babcock \& Wilcox

1562 Beeson Street

Alliance, $\mathrm{OH} 44601$

Dr. J. L. Bates

Battelle Pacific Nonthwest Labs

PSL Building 3000 Area

Box 999

Richland, WA 99352

Dr. Bert Zauderer

Coal Tech Corporation

P. O. Box 154

Merion Station, PA 19066-0154

Mr. R. King

U.S. Department of Energy

Butte Project Office

P.O. Box 3462

Butte, MT 59702

Mr. G. Staats

U.S. Department of Energy

Pittsburgh Energy Technology Center

P.O. Box 10940, PM-20/MS 922-208

Pittsburgh, PA 15236

Dr. R. Rosa

Montana State University

Department of Mechanical Engineering

Bozeman, MT 59715

Mr. L. Farrar

Montec Associates

P.O. Box 4182

Butte, MT 59702
Mr. Norm Swift

U.S. Department of Energy

Chicago Operations Office

9800 South Cass Avenue

Argonne, IL 60439

Dr. R. A. Carabetta

U.S. Department of Energy

Pittsburgh Energy Technology Center

P.O. Box 10940

Pittsburgh, PA 15236

Mir. Leo Makovsky

U.S. Department of Energy

Pittsburgh Energy Technology Center

P. O. Box 10940, MS 922-206

Pittsburgh, PA 15236

Dr. A. Cohn

Electric Power Research Institute

P.O. Box 10412

3412 Hillview Avenue

Palo Alto, CA 94303

Mr. A. C. Dolbec

Electric Power Research Institute

P. O. Box 10412

3412 Hillview Avenue

Falo Alto, CA 94303

Dr. William Owens

Gilbert/Commonwealth, Inc.

19664 Club House Roaci, Suite 820

Gaithersburgh, MD 20879

Dr. Peter Marston

MIT/Plasma Fusion Center

175 Albany Street

NW17-207

Cambridge, MA 02139

Dr. W. S. Shepard

Mississippi State University

D.I.A.L.

P.O. Drawer MM

Mississippi State, MS 39762

Dr. C. Kruger

Stanford University

Terman Mech. Eng., Roorn 214

Stanford, CA 94305

Mr. S. Demetriades

STD Corporation

P.O. Box "C"

Arcadia, CA 91006 
Mr. Jeff Richards

TRW

P.O. Box 3767

Industrial Pirk

Butte, MT 59702

Mr. G. Funk

MSE, Inc.

P.O. Box 3767

Industrial Park

Butte, MT 59702

Mr. J. Sherick

MSE, Inc.

P.O. Box 3767

Industrial Park

Butte, MT 59702

MSE, Inc.

P.O. Box 3767

Industrial Park

Butte, MT 59702

Aan: Librarian

Dr. W. Thielbahr

U.S. Deparment of Energy

Idaho Operations Office

78.5 Dor Place

ldaho Falls, ID 83402

Mr. L. Kovalsky

Westinghouse Electric Corp.

Research and Development Center 1310 Beulah Road

Pittsburgh, PA 15235

Mr. M. Tuck.

MSE, Inc.

P.O. Box 3767

Industriai Park

Butte, MT 59702

Dr. Bob Wright

U. S. Department of Energy

Office of Fossil Energy

FE-32

W'ashingron, DC 20545
Mi. C. Maxwell

STD Corporation

P.O. Box "C"

Ancadia. CA 91006

Mr. N. Johanson

University of Tennessee Space

Institute

'Tullahoma, TN 37388

Dr. Susan Wu

Engineering Research and

Consulting, Inc.

P. O. Box 417

Tullahoma, TN 37388

Mr. L. Van Bibber

Westinghouse Electric Corporation

Advanced Energy Systems Division

P.O. Box 10864

Pittsburgh, PA 15236

Mr. W. Irving

WMI, Inc.

236 N. Falmouth Highway

North Falmouth, MA 02556

Dr. Carl C. P. Pian

Avco Research Laboratory

2385 Revere Bezch Parkway

Evereth, MA 02149

Mr. J. M. Bauer

TRW Space and Technology Group

One Space Fark, O1/1160

Redondo Beach, CA 90278

Dr. Joel Muehihauser

Univ. of Tennessee

Space Institute

Tullahoma, TN 37388 


\section{APPENDIX A. NOMENCLATURE}

\section{Abbreviations}

1. AIC - Ash Injected Combustor

2. CDIF - Component Development and Integration Facility

3. CDR - Critical Design Review

4. CFC - Coal-Fired Combustor

5. CFPC - Coal-Fired Precombustor

6. CTS - Capistrano Test Site (TRW)

7. DCT - Design Confirmation Test

8. DOE - Department of Energy

9. DVT - Design Verification Test

10. FETS - Fossil Energy Test Site (TRW)

11. GOX - Gaseous oxygen

12. ITC - Integrated Topping Cycle

13. MEF - Material Evaluation Fixture

14. OFV - Oil-Fired Vitiator

15. PDR - Preliminary Design Review

16. POC - Proof-of-Concept

17. PRD - Project Requirements Document

18. PEM - Performance Evaluation Module

19. TTIRC - Technology Transfer, Integration and Review Committee

\section{Symbols}

20. B - Beta - Hall parameter

21. $\delta$ - Boundary layer thickness (Metirs)

22. $\sigma$ - Plasma Conductivity (Mhos/m) - There are several definitions for plasma conductivity, as follows:

1. Mid-channel conductivity - the conductivity at the channel mid-point determined experimentally from a plot of conductivity vs. channel axial length. This is the conductivity most often used in presenting test results. Unless otherwise specified, $\sigma$ rofers to this conductivity.

2. Inlet conductivity - the conductivity at the channel inlet. This parameter can be determined experimentally by extrapolating the conductivity vs. channel length curve to zero.

3. Bulk conductivity - the conductivity determined in the $1 \mathrm{Al}$ channel at CDIF by taking the voltage drop divided by the current. This parameter is available on-line and is used to spot conductivity changes during testing.

4. PEM conductivity - the conductivity measured at the Performance Evaluation Module at CTS at subsonic (stagnation) conditions.

23. $\$ 01$ - Precombustor Equivalence Ratio - Ratio of oxygen input to the coal-fired precombustor combustion chamber to stiochiometric oxygen required for complete combustion of fuels. 
24. $\phi_{1}$ - First Stage Equivalence Ratio - Ratio of oxygen input to the first stage to stiochiometric oxygen required for complete combustion of fuels.

25. \$2 - Overall Equivalence Ratio - Ratio of total oxygen inputs to stiochiometric oxygen required for complete combustion of fuels.

26. AR - Aspect Ratio - The height $\mathrm{H}$ (anode to cathode distance) divided by the width $\mathrm{D}$ (sidewall to sidewall distance) of the channel

27. B - Magnetic field (Tesla)

28. $E_{\mathrm{X}}$ - Axial electric field (volts/m)

29. Le-Electric current (amps)

30. IsC - Short circuit current (amps)

31. Ix - Axial current (amps)

32. I leak - Constant current leakage that is proportional to the Hall voltage (relating to cathode wall nonuniformities, plasma nonuniformities, and/or voltage drops) (amps).

33. $\mathrm{J}_{\mathrm{y}}$ - Faraday current density (amps/ $\mathrm{cm}^{2}$ )

34. \%oK - Amount of potassium injected as a percent of total mass flow through power train.

35. L/D - Length -to-hydraulic diameter ratio (second stage)

36. $M W_{e}-$ Electric megawatts (power output)

37. MWt - Thermal megawatts (heat input rate)

38. N/O - Molar ratio of nitrogen to oxygen inputs (all input streams).

39. Novlp - Number of overlapped electrodes in channel.

40. $\quad \mathrm{P}$ - electrode pitch $(\mathrm{m})$

41. $\mathrm{Pb}$ - bumer pressure (atm)

42. $P_{\text {diss }}$ - Power dissipated in ballast resistors (watts)

43. R-Resistance between shorted cathode gaps Johms/gap)

44. Rleak - An end-to-end resistance that is independent of Hall voltage (i.e., current transpon through the liquid slag layer) (ohms/gap).

45. Rlink - Resistance value of link resistor (ohms)

46. T250 - Temperature at which slag viscosity equals 250 poise

47. $V_{\propto c}$ - Open-circuit voltage (volts)

48. $\Delta \mathrm{V}$ - Transverse voltage drop (e.g., $\Delta \mathrm{V}_{\mathrm{bl}}$ - across boundary layer) (volts)

\section{Definitions}

49. Heat Flux - Heat loss per unit area (watts/ $\mathrm{cm}^{2}$ ).

50. Heat Loss - Sensible heat loss to cooling circuits, usually stated as a percent of total thermal input to the combustor.

51. Slag Recovery - Weight of dry slag collected in slag tank as a percentage of dry, $\mathrm{SO}_{3}$-free ash fed to the combustor ( $\mathrm{SO}_{3}$ is volatile and is not found in the slag).

52. Weight Percent Oxygen in First Stage (wt. \% $\mathrm{O}_{2}$ ) - Weight percent of oxygen in vitiated gases entering combustor first stage. 

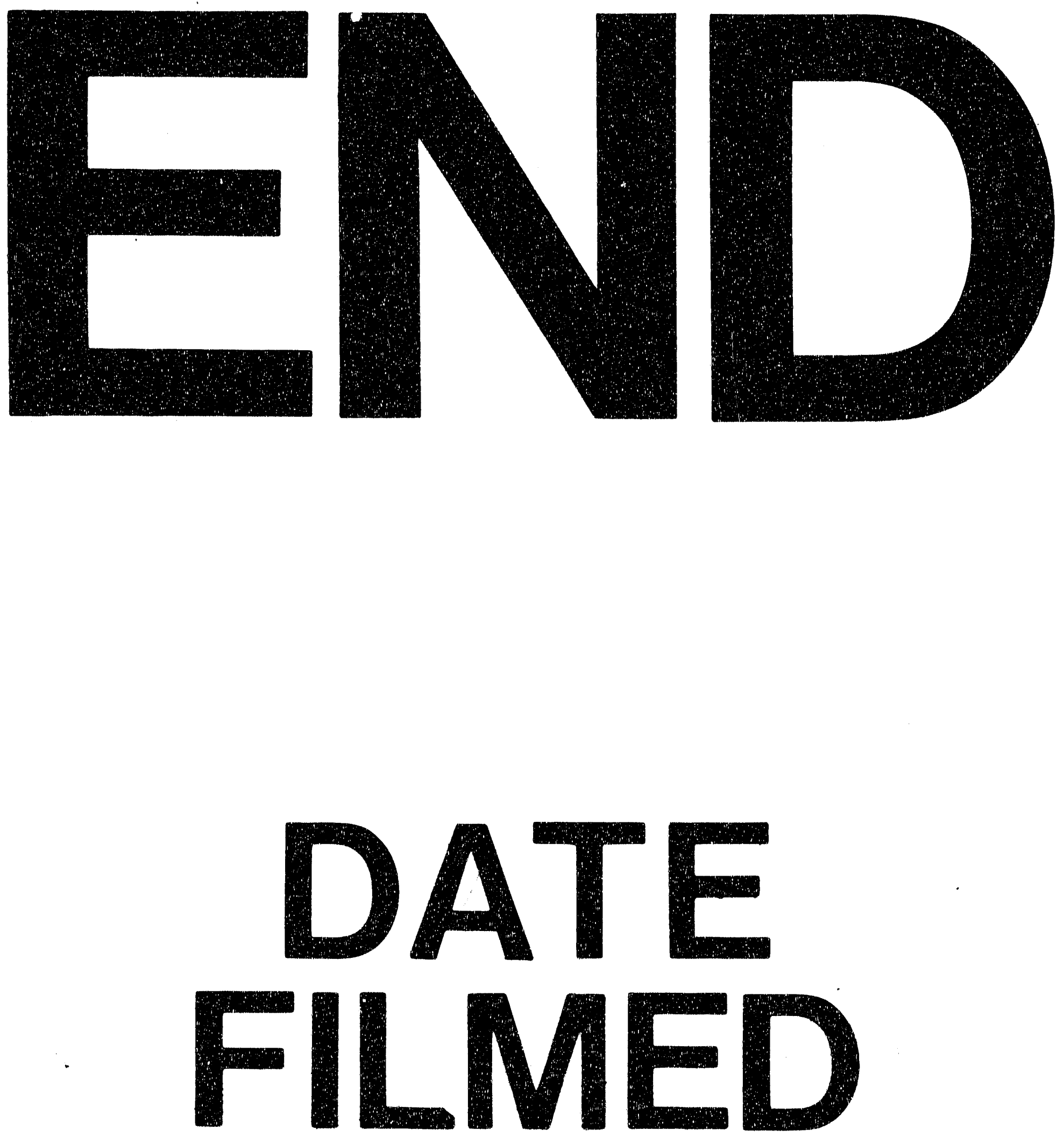

㲤

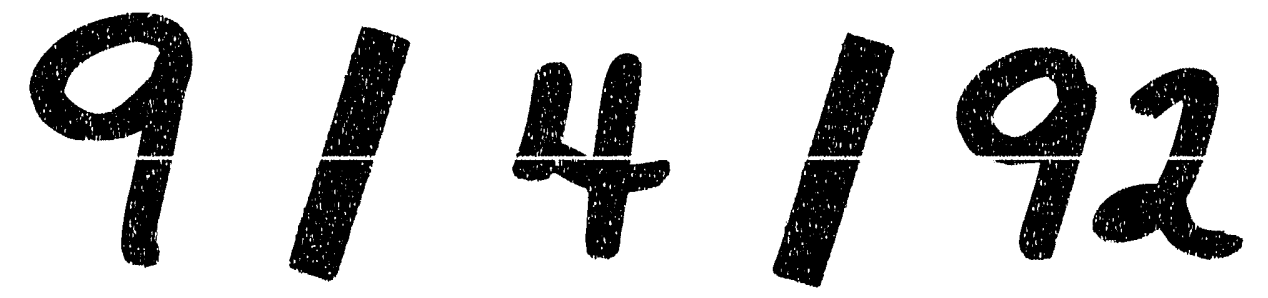




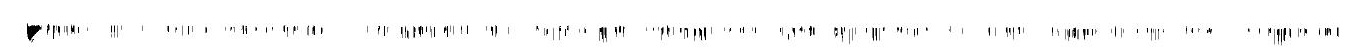

